\title{
STUDIES IN SIMULTANEOUS GENERATION OF CENTRAL AND AXIAL CHIRALITY VIA THE BUCHWALD-HARTWIG REACTION
}

\author{
by \\ Robert Anthony Denning \\ Bachelor of Science, Chemistry \\ Ryerson University
}

August 2014

\begin{abstract}
A thesis presented to Ryerson University
in partial fulfillment of the

requirements for the degree of

Master of Science

in the Program of Molecular Science
\end{abstract}

\author{
Toronto, Ontario, Canada, 2014 \\ (C) Robert Anthony Denning, 2014
}




\section{Author's Declaration \\ AUTHOR'S DECLARATION FOR ELECTRONIC SUBMISSION OF A THESIS}

I hereby declare that I am the sole author of this thesis. This is a true copy of the thesis, including any required final revisions, as accepted by my examiners.

I authorize Ryerson University to lend this thesis to other institutions or individuals for the purpose of scholarly research

I further authorize Ryerson University to reproduce this thesis by photocopying or by other means, in total or in part, at the request of other institutions or individuals for the purpose of scholarly research.

I understand that my thesis may be made electronically available to the public. 


\section{Abstract \\ STUDIES IN SIMULTANEOUS GENERATION OF CENTRAL AND AXIAL CHIRALITY VIA THE BUCHWALD-HARTWIG REACTION}

by Robert Anthony Denning

Master of Science, Molecular Science, Ryerson University, 2014

The Buchwald-Hartwig reaction has been investigated previously by the Viirre group to show that intramolecular cyclization using palladium and (R)-(+)-2-(diphenylphosphino)-2'-methoxy1,1'-binaphthyl, can instill enantioselectivity. This system was continued to show that steric bulk on the 2' position on the phenyl ring attached to the nitrogen malonamide can lock the rotation ending in a chiral axis. The diastereomers resulting from this chiral axis can be selectively formed when the substrate is 2-(2-bromobenzyl)-N1,N3-bis(2-(tert-butyl)phenyl)-2methylmalonamide and using a similar ligand $(R)$-dicyclohexyl(2'-methoxy-[1,1'-binaphthalen]2-yl)phosphane with enantio- and diastereoselectivities of $88 \%$ and $99 \%$ respectively. The work presented in this thesis continues on this class of substrates to include $N, 1-\operatorname{Di}([1,1$ '-biphenyl]-2yl)-3-methyl-2-oxo-1,2,3,4-tetrahydroquinoline-3-carboxamide, as well as a newer class of monoamide substrates. The monoamide substrates allowed the interpretation of events occurring in the Buchwald-Hartwig reaction, ultimately showing that the chiral center on the substrate has some control as to the outcome of the chiral axis. Lastly, a timed sampling kinetics experiment was done to investigate if the enantiomers of the starting material were being consumed at different rates or if one diastereomeric product was being produced favourably. The kinetics experiment shows that the system does not have a preference as to the starting material or product being produced. 


\section{Acknowledgements}

This thesis would not have been possible without the help of several people I would like to thank. My supervisor, Dr. Russell Viirre, has guided me along through both my undergraduate and graduate research career. He has been extremely understanding and patient when I have had to go through some tough times outside of school. He is very knowledgeable and always allows his students to drop into his office to discuss anything. Without him, I wouldn't be where I am today.

I would also like to thank my supervisory committee, Dr. Bryan Koivisto and Dr. Rob Gossage, along with Dr. Viirre. They have given me guidance through my thesis and have helped to overcome some problems experienced over the course of the three years I've taken to do my masters.

My time at Ryerson wouldn't have been complete without the friendships I've made. Working closely with past and present lab members has always made me enjoy my time in the lab and brought a smile to my face. We've enjoyed a lot of good laughs and music as we complete out flash columns. The people that I've gotten closest to are; Chris Bentley, Bashar Alkhouri, Augusto Matarrazo, Billy Kanellis, Nande Wright, Salma Elmallah, Devin Machin, Shane Harrypersad and Krimo Toutah, also everyone in lab KHE 209 and KHE 202. I would like to give a special thank you to Salma Alkarmi for training me when I first came into research.

Lastly, I would like to thank my family. My parents have always given me time to vent any frustrations and allowed me to flourish. They have always been there when needed, and are very understanding. They are easy going and supportive and those qualities are what has had made my life through school a smooth process. I'll always be indebted to them for their support. 
The other side of the family coin is my beautiful fiancée, Sarah Caine. Everything I do to progress myself to academically, financially, emotionally is for her. I strive to be a better person because she allows me to advance. The unconditional love and support she has given me, even when she has fallen on hard times, is a true testament of her character. I'm so glad to have the chance of marrying her, and yes I'm finally done my almost decade of school. 


\section{Table of Contents}

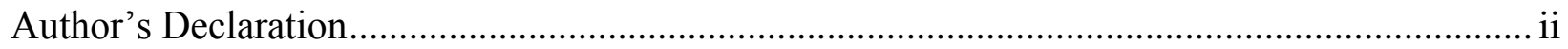

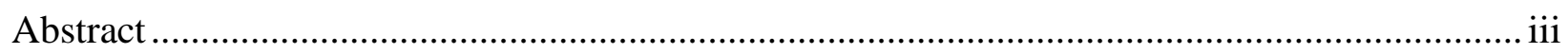

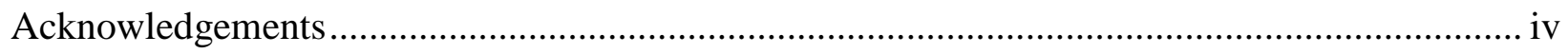

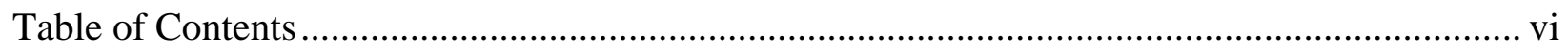

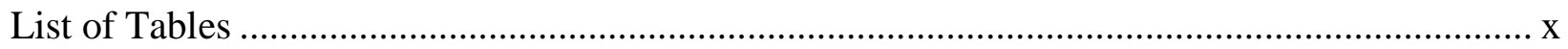

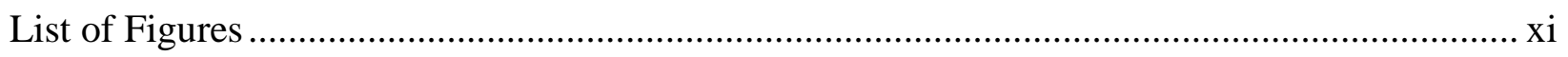

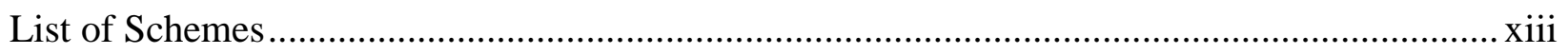

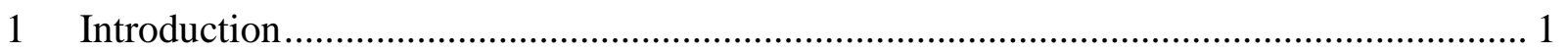

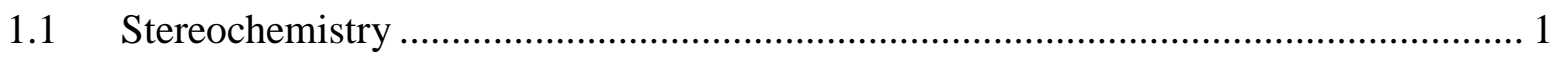

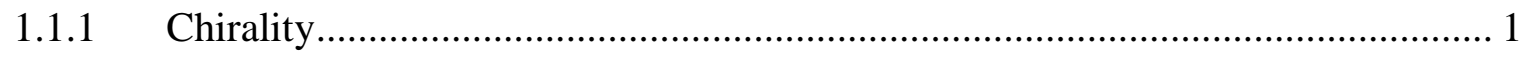

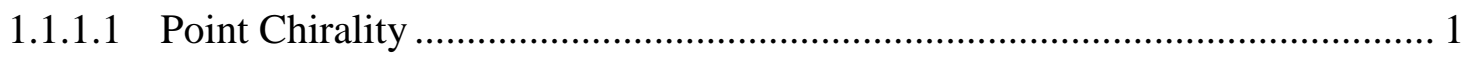

1.1.1.2 Axial Chirality .............................................................................. 1

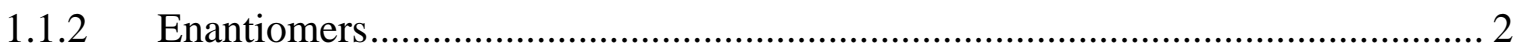

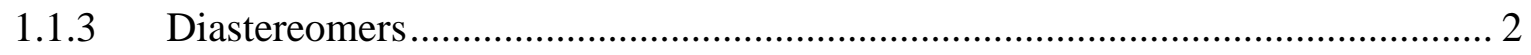

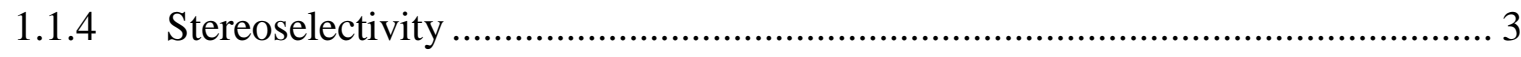

1.2 Buchwald - Hartwig Cross-coupling Reactions................................................... 4

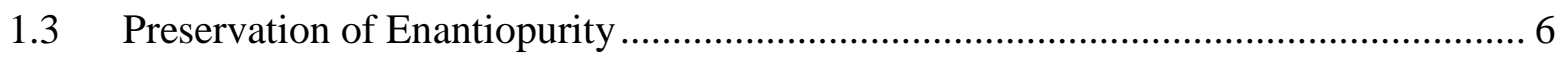

1.4 Regioselective Buchwald-Hartwig Amination .................................................. 7

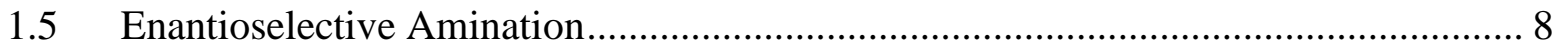




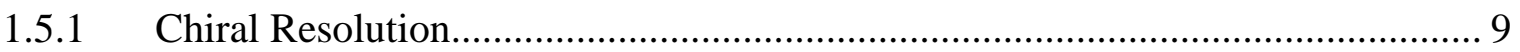

1.5.2 Asymmetric Amination .......................................................................... 9

1.5.3 Enantioselective Formation of a Chiral Axis ................................................ 11

1.6 Biphenyl Based Ligands .............................................................................. 12

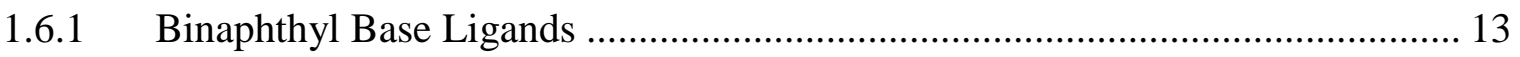

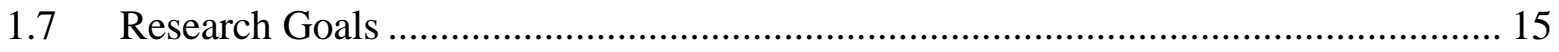

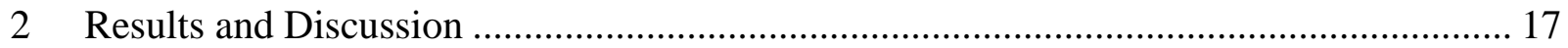

2.1 Synthesis Towards Substituted Malonamides ..................................................... 17

2.2 Cyclization of Substituted Malonamides......................................................... 21

2.2.1 Analyzing Enantioselectivity and Diastereoselectivity of Cyclized Substituted

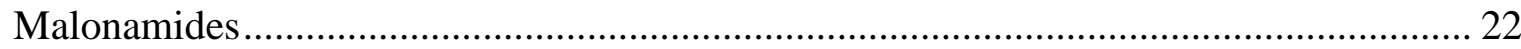

2.3 Synthesis Towards Monoamide Compounds ..................................................... 32

2.4 Cyclization of Substituted Mono Amide Compounds.......................................... 36

2.4.1 Analyzing Enantioselectivity and Diastereoselectivity of Cyclized Monoamide

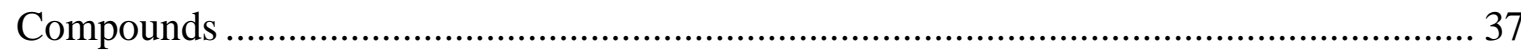

2.4.2 Kinetics Experiment of the Cyclization Reaction of 11 with $(R)-\mathrm{Cy}_{2} \mathrm{MOP}$ and

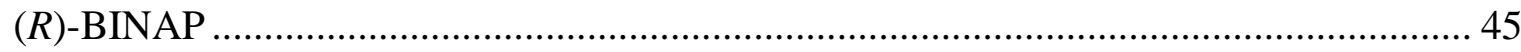

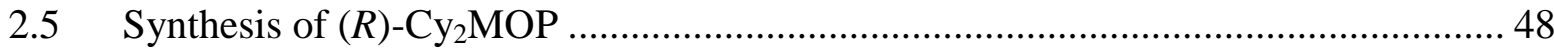

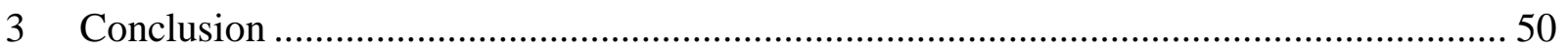

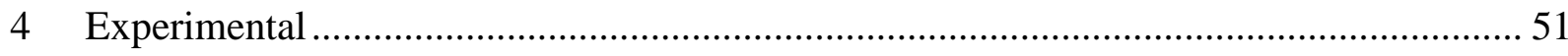


4.1 Synthesis Towards Substituted Malonamides

4.1.1 Diethyl 2-(2-bromobenzyl)malonate (2) …………..................................... 51

4.1.2 Diethyl 2-(2-bromobenzyl)-2-methylmalonate (3) ………………………..... 52

4.1.3 Diethyl 2-(2-bromobenzyl)-2-methylmalonate (3) ………………………....... 52

4.1.4 2-(2-Bromobenzyl)-2-methylmalonic acid (5) …………................................ 53

4.1.5 2-(2-Bromobenzyl)-N1,N3-bis(2-(tert-butyl)phenyl)-2-methylmalonamide (6) 54

4.1.6 N1,N3-Di([1,1'-biphenyl]-2-yl)-2-(2-bromobenzyl)-2-methylmalonamide (7) .. 55

4.1.7 N,1-Bis(2-(tert-butyl)phenyl)-3-methyl-2-oxo-1,2,3,4-tetrahydroquinoline-3-

carboxamide (8) 56

4.1.8 N,1-Di([1,1'-biphenyl]-2-yl)-3-methyl-2-oxo-1,2,3,4-tetrahydroquinoline-3carboxamide (9) 57

4.2 Synthesis Towards Monoamide Compounds ………………………........................ 58

4.2.1 2-(2-Bromobenzyl)-3-ethoxy-2-methyl-3-oxopropanoic acid (10) .................... 58

4.2.2 Ethyl 2-(2-bromobenzyl)-3-((2-(tert-butyl)phenyl)amino)-2-methyl-3-

oxopropanoate (11)

4.2.3 Ethyl 3-([1,1'-biphenyl]-2-ylamino)-2-(2-bromobenzyl)-2-methyl-3-

oxopropanoate (12) 60

4.2.4 Ethyl 2-(2-bromobenzyl)-2-methyl-3-oxo-3-(phenylamino)propanoate (13)..... 61

4.2.5 Ethyl 1-(2-(tert-butyl)phenyl)-3-methyl-2-oxo-1,2,3,4-tetrahydroquinoline-3carboxylate (14) 62 
4.2.6 Ethyl 1-([1,1'-biphenyl]-2-yl)-3-methyl-2-oxo-1,2,3,4-tetrahydroquinoline-3carboxylate (15) 63

4.2.7 Ethyl 3-methyl-2-oxo-1-phenyl-1,2,3,4-tetrahydroquinoline-3-carboxylate (16) 64

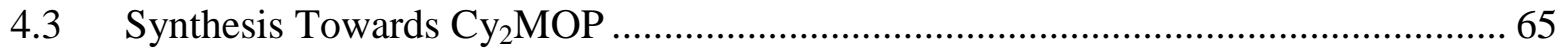

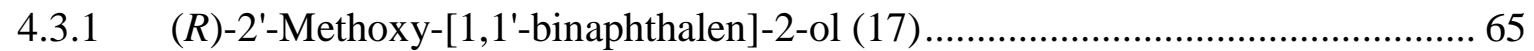

4.3.2 (R)-2'-Methoxy-[1,1'-binaphthalen]-2-yl trifluoromethanesulfonate (18) ......... 66

4.3.3 (R)-Dicyclohexyl(2'-methoxy-[1,1'-binaphthalen]-2-yl)phosphane (19) ........... 67

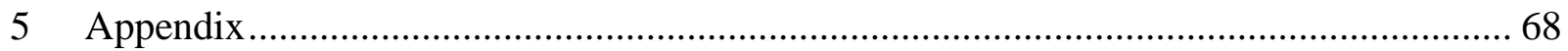

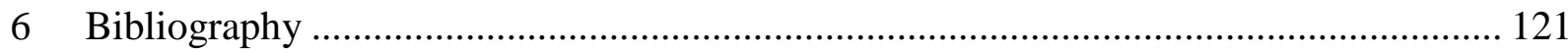


List of Tables

Table 1 - Enatioselectivity and Diastereoselectivity of the Cyclization of 6 and 7 by SPHOS

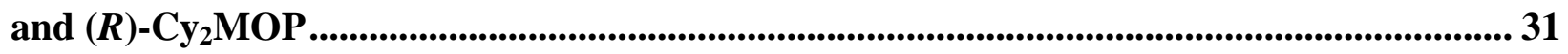

Table 2 - Enatioselectivity and Diastereoselectivity of the Cyclization of 14, 15 and 16 by

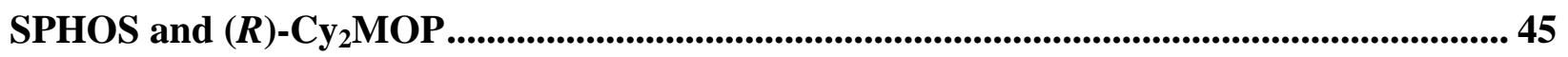

Table 3 - Reaction Kinetics of the Cyclization of 14 with $(R)-\mathrm{Cy}_{2} \mathrm{MOP}$............................... 47 


\section{List of Figures}

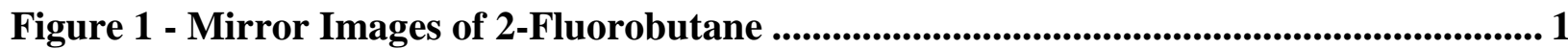

Figure 2 - Axial Chirality Due to Restricted Rotation Both Sterically and by $\pi$ Bonds........ 2

Figure 3 - The Four Configurations in Molecules with Two Chiral Centers .......................... 3

Figure 4 - Enantioselective Palladium Catalyzed Arylation ................................................... 3

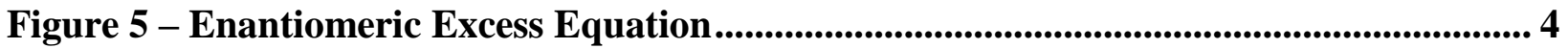

Figure 6 - General Buchwald-Hartwig Reaction .................................................................. 4

Figure 7 - Preservation of Optical Purity after Amination .......................................................... 7

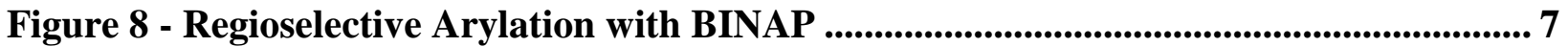

Figure 9 - Regioselective Amination by Aryl Halide Selectivity ............................................... 8

Figure 10 - Kinetic Resolution Via Buchwald-Hartwig Amination ......................................... 9

Figure 11 - Desymmetrization of Malonamides with $(R)$-MOP.......................................... 10

Figure 12 - Double N-Arylation of Malonamide Substrate with Pd/(S)-BINAP................... 10

Figure 13 - Generation of a Chiral Axis by Arylation .............................................................. 11

Figure 14 - Intramolecular Amidation Forming a Chiral Axis .......................................... 12

Figure 15 - Several Achiral Ligands for Buchwald-Hartwig Amination................................ 13

Figure 16 - Common Binapthyl Phosphine Ligands............................................................. 14

Figure 17 - $(S)$-BINAPO Complex with Palladium.............................................................. 14

Figure 18 - Selective Monoamination with MOP-type Ligand ..................................................... 15

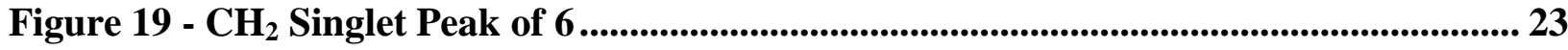

Figure 20 - Diastereotopic Protons of 9 via Pd/SPHOS....................................................... 24

Figure 21 - Diastereotopic Protons of 9 via Pd/(R)-Cy $\mathrm{Cy}_{2} \mathrm{MOP}$.......................................... 25

Figure 22 - Single Diastereomer of 8 via Pd/SPHOS ...................................................... 25 
Figure 23 - Single Diastereomer of 8 via $\mathrm{Pd} /(\mathrm{R})-\mathrm{Cy}_{2} \mathrm{MOP}$.......................................................... 26

Figure 24 - HPLC Chromatogram of 9 via Pd/SPHOS................................................................... 27

Figure 25 - HPLC Chromatogram of 9 via Pd/(R)-Cy $\mathrm{Cy}_{2} \mathrm{MOP}$...................................................... 28

Figure 26 - Product 8 via Pd/SPHOS .................................................................................. 29

Figure 27 - HPLC Chromatogram of 8 via Pd/(R)-Cy2MOP.................................................... 30

Figure 28 - Monoamide Compounds Used to Understand Enantio- and Diastereoselectivity within the Buchwald-Hartwig Reaction............................................................................................... 32

Figure 29 - Diastereotopic Protons of 14 via Pd/SPHOS........................................................... 38

Figure 30 - Diastereotopic Protons for 14 via Pd/(R)-Cy ${ }_{2} \mathrm{MOP}$................................................... 39

Figure 31 - Diastereotopic Protons for 15 via Pd/SPHOS................................................................. 40

Figure 32 - Similar Diastereoselectivity Seen Producing 15 via Pd/(R)-Cy $\mathbf{y}_{2} \mathrm{MOP}$................. 41

Figure 33 - Cyclization Forming 16 Only Produces Enantiomers ............................................... 41

Figure 34 - HPLC Chromatogram of 14 via Pd/SPHOS................................................................ 42

Figure 35 - HPLC Chromatogram forming Product 14 via Pd/(R)-Cy $\mathrm{C}_{2} \mathrm{MOP}$......................... 43

Figure 36 - Unresolved Chromatogram of 15 via Pd/SPHOS........................................................ 44

Figure 37 - Optimized HPLC Conditions to Identify 11 and 14................................................. 46 


\section{List of Schemes}

Scheme 1 - Original Mechanism Of the Buchwald-Hartwig Using Tin Amides...................... 5

Scheme 2 - Buchwald-Hartwig Cross-Coupling Mechanism .................................................... 6

Scheme 3 - Previous Work Published by the Viirre Group ................................................ 16

Scheme 4 - Synthesis of Diethyl 2-(2-Bromobenzyl)malonate from Diethyl Malonate ........ 17

Scheme 5 - Synthesis of Diethyl 2-(2-Bromobenzyl)-2-methylmalonate from Diethyl 2-

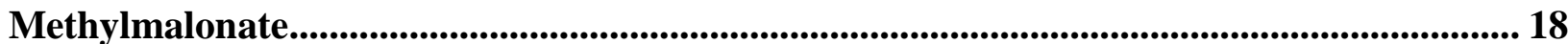

Scheme 6 - Hydrolysis of Diethyl 2-(2-bromobenzyl)-2-methylmalonate ................................ 19

Scheme 7 - Malonamide Formation from Malonic Acid ...................................................... 20

Scheme 8 - General Reaction for the Cyclization of Malonamides ....................................... 22

Scheme 9 - Transesterification of Diethyl Malonate to Dimethyl Malonate ........................... 33

Scheme 10 - Monomethylation Attempts on Substituted Malonic Acid ............................... 33

Scheme 11 - Monohydrolysis of Substituted Dimethyl Malonate............................................... 34

Scheme 12 - Monohydrolysis of Diethyl 2-(2-bromobenzyl)-2-methylmalonate..................... 35

Scheme 13 - Conversion of Mono Acid to Mono Amide...................................................... 35

Scheme 14 - Cyclization of Monoamide Compounds ............................................................. 37

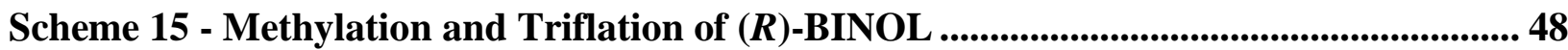

Scheme 16 - Synthesis of $(R)-\mathrm{Cy}_{2} \mathrm{MOP}$ from $(R)$-Me-BINOL-Otf...................................... 49 


\section{Introduction}

\subsection{Stereochemistry}

Stereochemistry is an area of chemistry devoted to understanding the differences between molecules which have the same atoms and bonds but differ in their three-dimensional structures. Isomers that differ in this way are known as stereoisomers. ${ }^{1}$ This thesis deals with issues of stereochemistry and will therefore begin with a brief introduction into the matter.

\subsubsection{Chirality}

Chirality is a property of certain organic molecules that arises from not being superimposable on their mirror image, as seen in Figure 1.

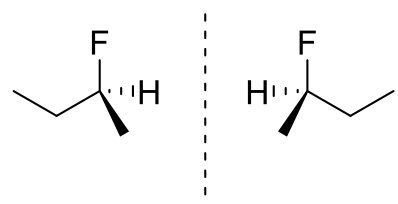

\section{Figure 1 - Mirror Images of 2-Fluorobutane}

\subsubsection{Point Chirality}

Point chirality exists when having four different groups bonded to a central tetrahedral carbon atom. ${ }^{1}$ As in Figure 1, the carbon atom bonded to F, H, ethyl and methyl is at the center of the chirality. This is known as the chiral center. ${ }^{1}$

\subsubsection{Axial Chirality}

When the chiral element is not on a single atom, but along a bond between two atoms, this is known as axial chirality. ${ }^{2}$ Generally, bonds are allowed to rotate freely, but when this 
rotation is restricted by steric hindrance or $\pi$ bonds, this creates an element of chirality, as in Figure 2.
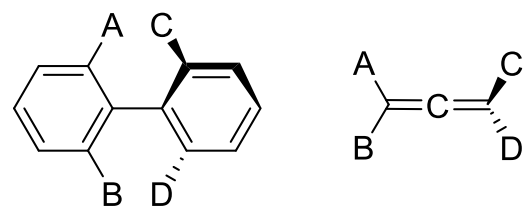

\section{Figure 2 - Axial Chirality Due to Restricted Rotation Both Sterically and by $\pi$ Bonds}

\subsubsection{Enantiomers}

Refering back to Figure 1, the two molecules differ only in the arrangement of the substituents bonded on the chiral center. These give rise to the nonsuperimposable mirror images as seen. The pair that is represented in this figure are known as enantiomers. ${ }^{1}$ Enantiomers have identical physical and chemical properties in achiral environments. Enantiomers behave differently in chiral environments, i.e. chiral reactions and biological activities, and can be separated by chiral means, i.e. chiral salts, chiral HPLC, etc.

\subsubsection{Diastereomers}

Molecules that have $n$ chiral centers or elements typically have $2^{\mathrm{n}}$ different stereoisomers. For instance, the four possible arrangements in a molecule that has two chiral centers or elements are, $R R, S S, S R, R S$. When both chiral elements are switched to the opposite configuration, those molecules are enantiomers. This means, $R R$ is the enantiomer of $S S$, and $S R$ is the enantiomer of $R S$. A diastereomer is when at least one chiral element is different, while at least one is the same. ${ }^{1}$ For instance, in this case $S R$ and $R S$ are diastereomers of $R R$ and $S S$. This is depicted by the stereoisomers of ephedrine and pseudoephedrine in Figure 3. 


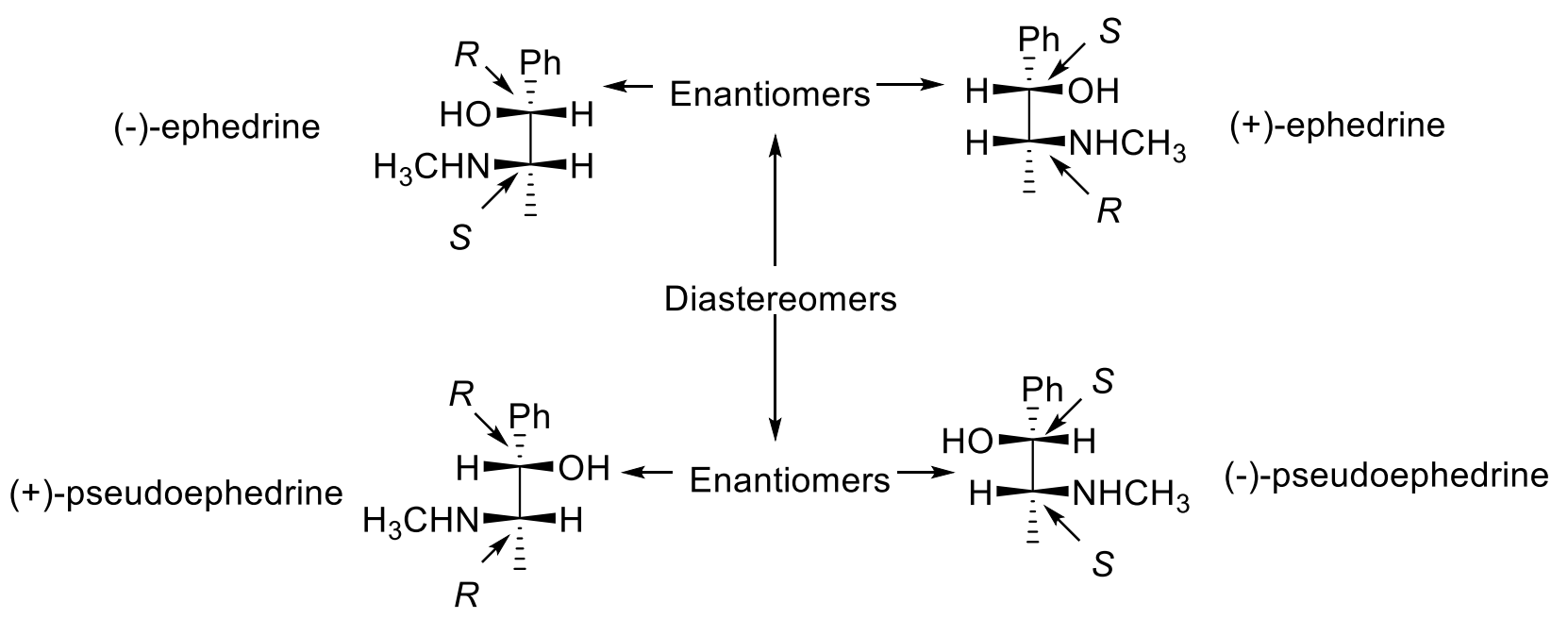

Figure 3 - The Four Configurations in Molecules with Two Chiral Centers

\subsubsection{Stereoselectivity}

Reactions that have achiral reagents and produce a chiral product always produce equal

amounts of $R$ and $S$. This is known as a racemic mixture. When one or more reagents or catalyst, used in a reaction is chiral, then there can be a preference for one enantiomer over another, as depicted in the reaction given in Figure $4 .^{3}$<smiles>CC1=CC(=O)CCC1</smiles>

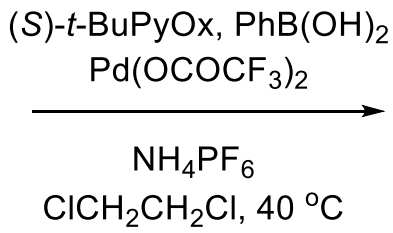

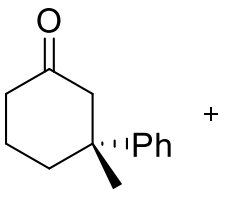

$95 \%$

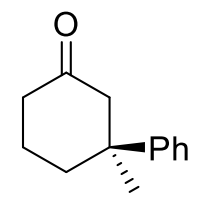

$5 \%$

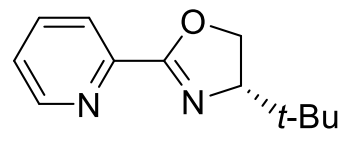

(S)-t-BuPyOx

Figure 4 - Enantioselective Palladium Catalyzed Arylation 
Stereoselectivity is measured in enantiomeric excess or \%ee. The enantiomeric excess is calculated by the difference of the enantiomers divided by the sum of the enantiomers. The ee for the reaction in Figure 4 is 90\% ee.

$$
\frac{|R-S|}{|R+S|} \times 100=\frac{|95-5|}{|95+5|} \times 100=90 \% \text { ee }
$$

\section{Figure 5 - Enantiomeric Excess Equation}

An enantiomeric excess of $100 \%$ would mean only one of the enantiomers was produced, or enantiopure. An enantiomeric excess of $0 \%$ would be equal parts of each enantiomer, or racemic.

\subsection{Buchwald - Hartwig Cross-coupling Reactions}

In the early 1990's, Buchwald ${ }^{4}$ and Hartwig ${ }^{5,6}$ started working on palladium catalyzed nitrogen arylation. The overall reaction is seen in Figure 6.

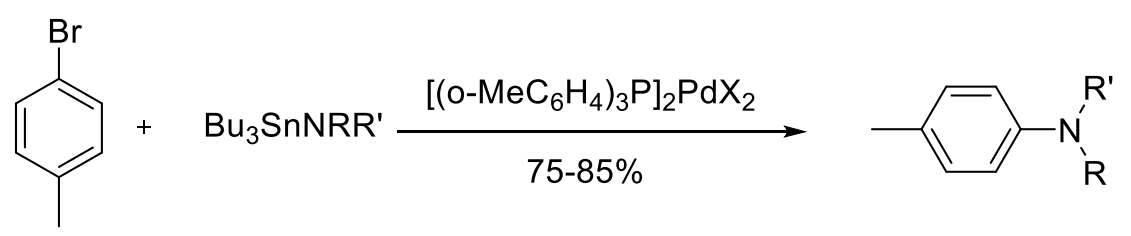

\section{Figure 6 - General Buchwald-Hartwig Reaction}

The mechanism originally proposed by both Buchwald and Hartwig had a step to make tin amides which would enter into the catalytic cycle, but this was found to be unnecessary as the palladium is able to coordinate the secondary amine without the tin treatment. However, it was found that certain cases might require tin amide formation to increase yields (as seen in Scheme 1.)^{6}$ 


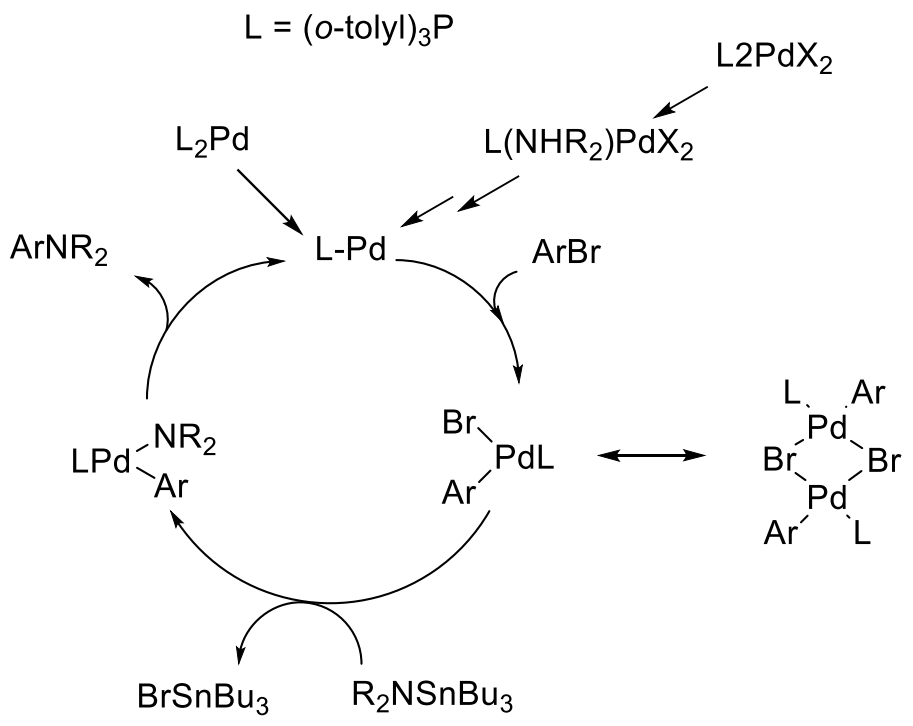

\section{Scheme 1 - Original Mechanism Of the Buchwald-Hartwig Using Tin Amides}

The reaction mechanism, as seen in Scheme 2, works with either monodentate or bidentate ligands forming 3- or 4-coordinate palladium complexes, respectively. If the palladium source used is $\mathrm{Pd}(\mathrm{II})$ it then must be reduced to a $\mathrm{Pd}(0)$ complex before it can enter into the catalytic cycle. There are several ways in which it can be reduced within the reaction mixture. The first example of reduction is beta-hydride elimination of the amine species present. ${ }^{7}$ The palladium species can also be reduced by the phosphine ligand, in which case the phosphine is oxidized to a phosphine oxide, with the assistance of water. ${ }^{8}$ The next step in the cycle is the oxidative addition of the aryl halide to the palladium forming a 3 or 4 coordinate complex. Then the amine coordinates to the palladium, followed by deprotonation of the amine and release of the palladium bound halide as a salt. ${ }^{6}$ The final step is the reductive elimination of the substrate forming the $\mathrm{C}-\mathrm{N}$ bond and regeneration of the $\operatorname{Pd}(0)$ catalyst. There is also a potential side 
reaction that can happen at this stage where reductive elimination does not occur but betahydride elimination occurs, forming the debrominated arene product, and an imine.

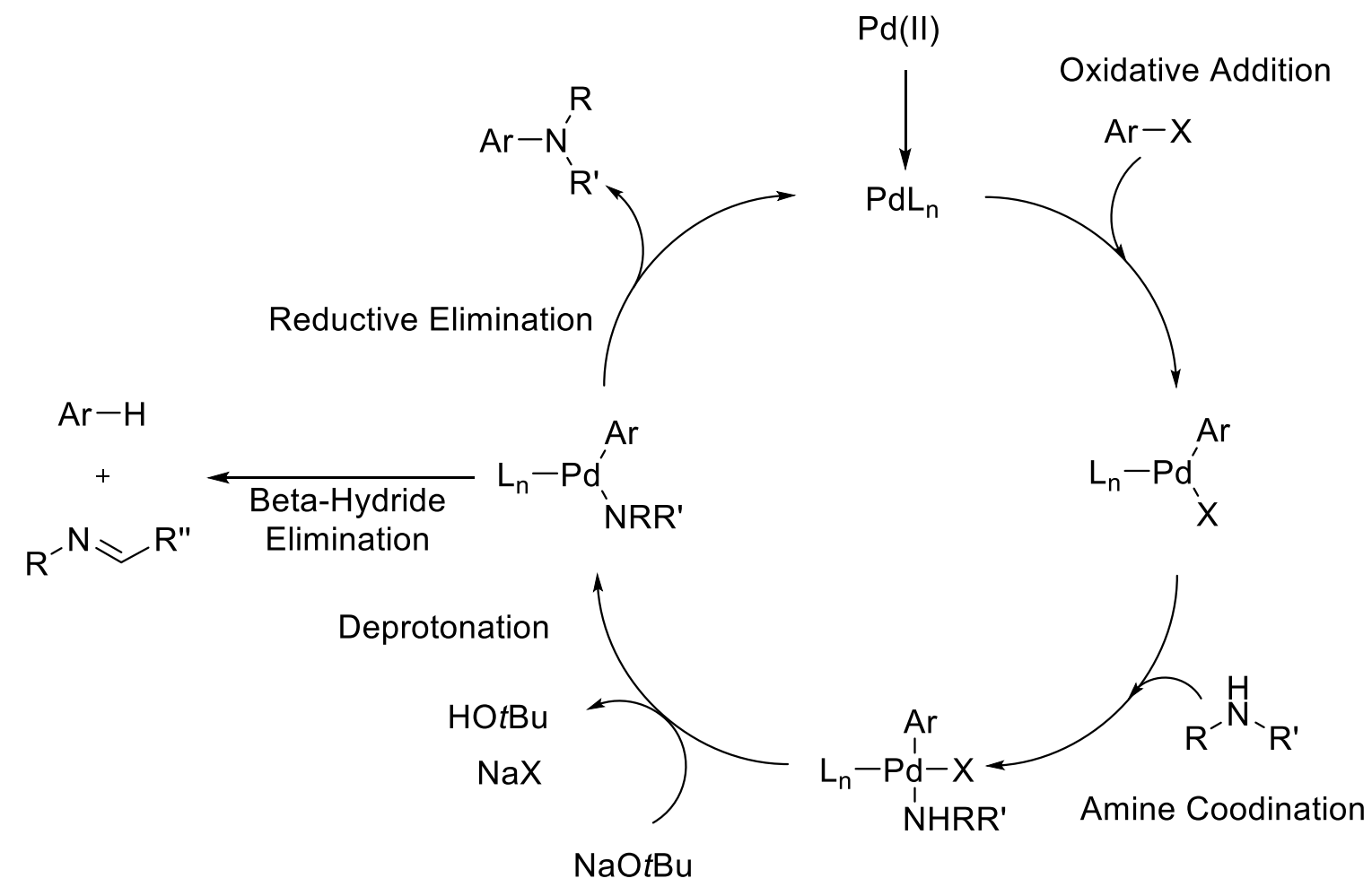

\section{Scheme 2 - Buchwald-Hartwig Cross-Coupling Mechanism}

\subsection{Preservation of Enantiopurity}

In 1997, Wagaw et al. had shown that coupling an optically active amine with an aryl halide can be done without the racemization of the product (Figure 7.) ${ }^{9}$ This discovery is critical to the pharmaceutical industry, as optically pure drugs have proven to be generally more active than their racemic counterparts. ${ }^{10}$ 


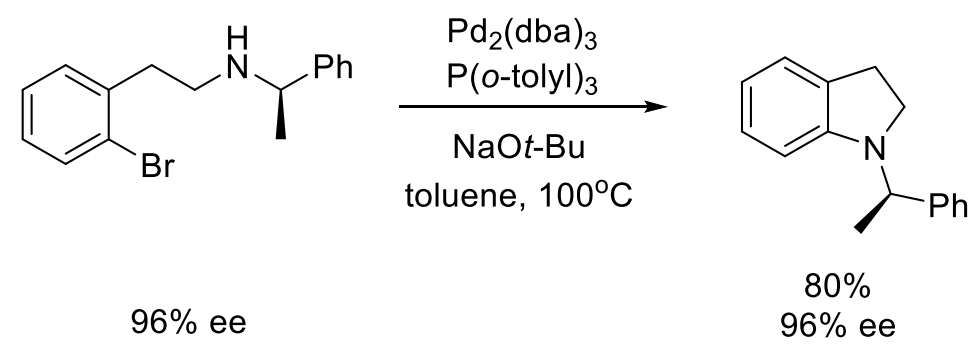

Figure 7 - Preservation of Optical Purity after Amination

\subsection{Regioselective Buchwald-Hartwig Amination}

Differentiation of similar amine groups with the use of the Buchwald-Hartwig amination reaction can be done with (i) the use of a chiral ligand, or (ii) by taking advantage of halide reactivity in the reaction.

Uzarewicz-Baig et al. demonstrated that camphor diamines can be selectively arylated at the primary amine attached to a $2^{\circ}$ carbon as opposed to primary amine attached to a $3^{\circ}$ carbon in the presence of $\mathrm{Pd}_{2}(\mathrm{dba})_{3}$ and racemic BINAP, as seen in Figure 8. Yields range from moderate to excellent and can tolerate many different types of arenes. ${ }^{11}$ This is selective due to the ligand in the catalyst, $( \pm)$ BINAP. The steric bulk of the ligand selectively arylated the less bulky nitrogen.

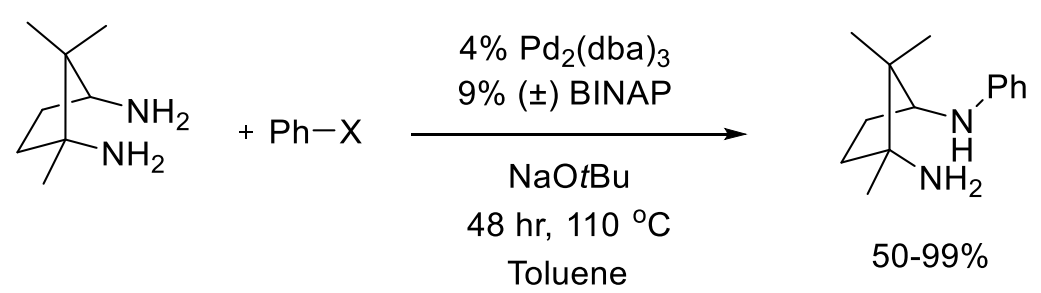<smiles>CC(C)(C)c1ccc2c(-c3c(-c4ccccc4)ccc4ccccc34)c(-c3ccccc3)ccc2c1</smiles>

Figure 8 - Regioselective Arylation with BINAP 
Another example of regioselective Buchwald-Hartwig reaction involves differentiation at the oxidative addition step. It was observed that, given a choice for the palladium to react with either a napthyl bromide or a napthyl iodide, the iodide was chosen with good to excellent yields (70-95\%). The ligand used is the achiral Xantphos with palladium acetate and cesium carbonate, as seen in Figure $9 .^{12}$

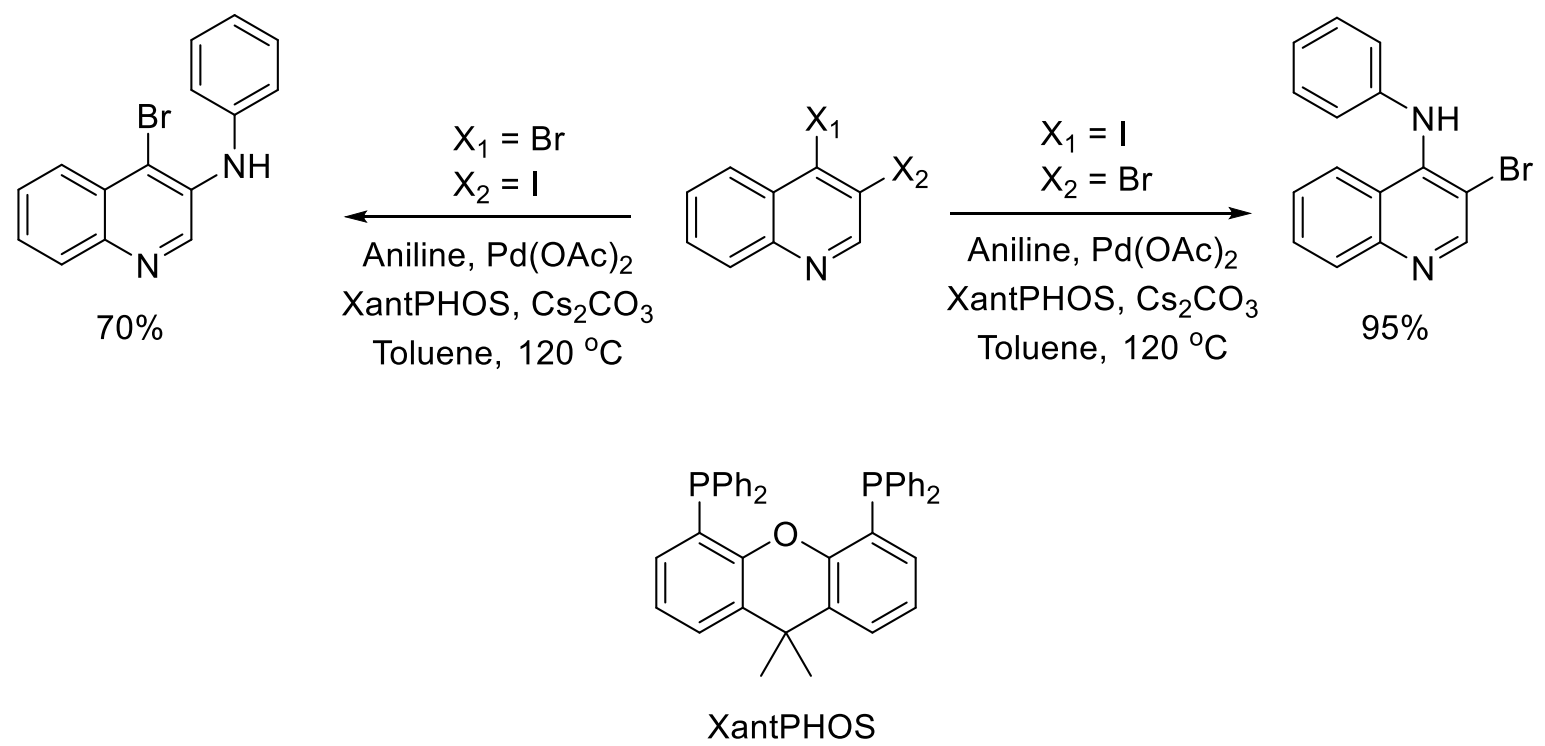

Figure 9 - Regioselective Amination by Aryl Halide Selectivity

\subsection{Enantioselective Amination}

Since the Buchwald-Hartwig amination is the formation or an aryl-nitrogen bond, it is generally not thought to be able to have enantioselective properties. The only cases to date have been either when the amination is selecting a single enantiomer to react with, thus derivatizing only one enantiomer and thus making them separable, or when the substrate has a plane of symmetry that is being broken by the amination usually through regioselection. 


\subsubsection{Chiral Resolution}

Researchers at Merck were able to selectively resolve 4,12-dibromo-[2.2]paracyclophane with the use of $\operatorname{Pd}_{2}(\mathrm{dba})_{3}$ and $(S)$-PHANEPHOS, Figure 10. The reaction takes place more favourably (about 3 to 4 times more) on the $\mathrm{S}$ enantiomer of the substrate. The reaction produces a complex mixture of compounds but leaves the $\mathrm{R}$ enantiomer of the starting material in a $93 \%$ ee. It is interesting to point out that this resolution discriminates at the aryl halide oxidative addition stage of the mechanism.

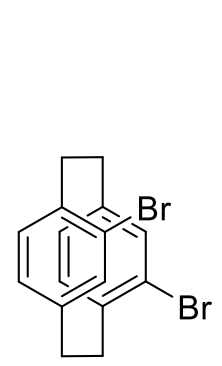

(R)

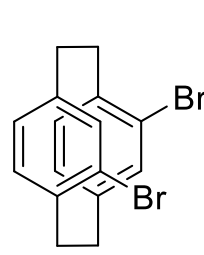

(S)

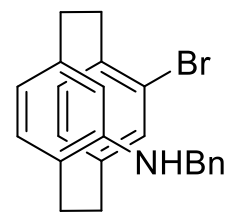

(S)-PHANEPHOS

$\mathrm{BnNH}_{2}$

$\mathrm{Pd}_{2}(\mathrm{dba})_{3}$

$\underset{\text { Toluene, } 50^{\circ} \mathrm{C}}{\stackrel{\mathrm{NaOtBu}}{\stackrel{(S)}{\longrightarrow}}}$
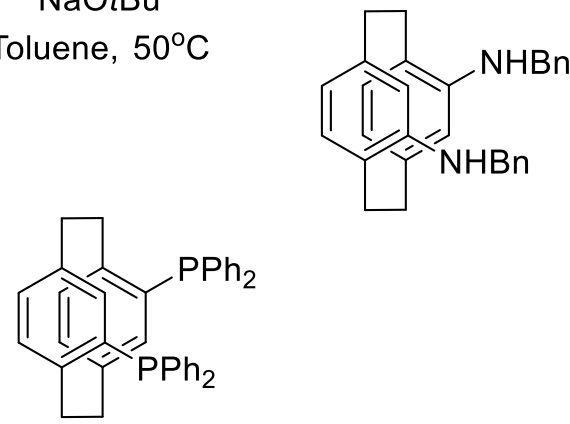
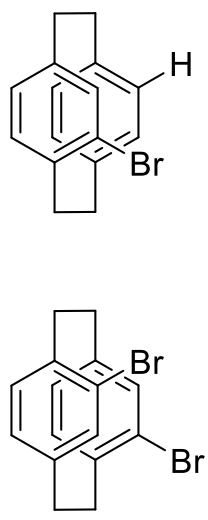

$46 \%$ recovered $93 \%$ ee

(S)-PHANEPHOS

Figure 10 - Kinetic Resolution Via Buchwald-Hartwig Amination

\subsubsection{Asymmetric Amination}

In the case of desymmetrization of a molecule by amination, the selectivity is given preference to a single enantiomer, also with the use of chiral ligands. Porosa and Viirre, had shown in 2009 , that with a substituted malonamide substrate, they were able to produce optically active quinolinone moieties in excellent yields and good enantiomeric selectivities, Figure $11 .^{13}$ 
<smiles>[R]NC(=O)C(C)(Cc1ccccc1Br)C(=O)N[R]</smiles>

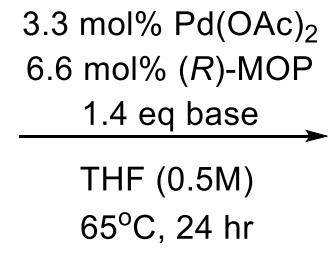<smiles>COc1ccc2ccccc2c1-c1c(P)ccc2ccccc12</smiles><smiles>[R]NC(=O)C(C)(C)C(=O)N([R])c1ccccc1C</smiles><smiles>[R]NC(=O)[C@]1(C)Cc2ccccc2N([R])C1=O</smiles>

$90-99 \%$ yield, $30-70 \%$ ee

$(R)-M O P$

\section{Figure 11 - Desymmetrization of Malonamides with $(R)$-MOP}

Following on this asymmetric amination, Sasai et al. have designed a similar malonamide substrate, but in this case they have made the central prochiral carbon doubly substituted with bromobenzyl groups in which case both amides was arylated (Figure 12). ${ }^{13,14}$ They use the same catalyst loading but with $(S)$-BINAP which is similar to $(R)$-MOP in structure. They also achieve similar yields and enantioselectivites as Porosa and Viirre.
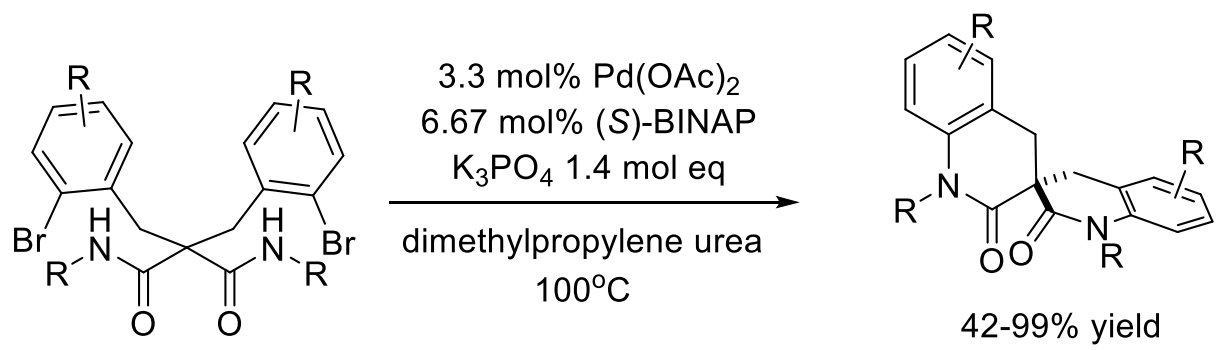

$42-99 \%$ yield $38-70 \%$ ee

Figure 12 - Double N-Arylation of Malonamide Substrate with Pd/(S)-BINAP 


\subsubsection{Enantioselective Formation of a Chiral Axis}

Another form of enantioselectivity that can be brought on by the Buchwald-Hartwig amidation is with the formation of a chiral axis. Generally C-N single bonds can freely rotate and it is rare that there is a chiral axis formed by this reaction due to nitrogen's ability to invert. Taguchi et al. in 2005 presented a reaction in which the amine was attached to a 2-( $t$ butyl)phenyl group, thus post arylation the $t$-butyl group sterically locked free rotation forming a chiral axis as shown in Figure 13. ${ }^{15}$

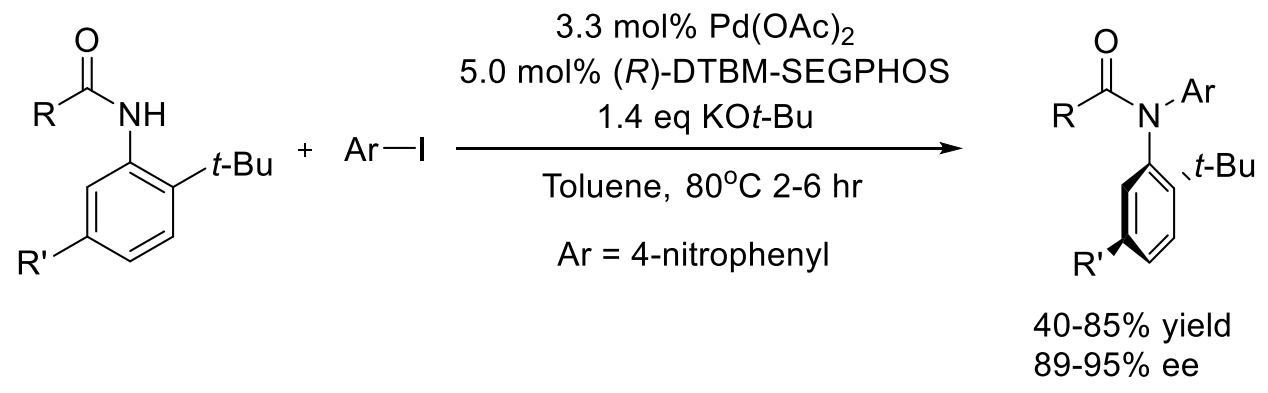

Figure 13 - Generation of a Chiral Axis by Arylation

The group extended this concept to intramolecular reactions (Figure 14) and were able to drive the reaction to excellent yields and enantioselectivities, $95 \%$ and $96 \%$, respectively. In this case they have switched to using $(S)$-BINAP and a weak base $\mathrm{Cs}_{2} \mathrm{CO}_{3}$. The reaction also takes a considerable amount of time longer than previous trials. 
<smiles>[R]c1ccc(C(C)(C)C)c(NC(=O)CCc2ccccc2I)c1</smiles>

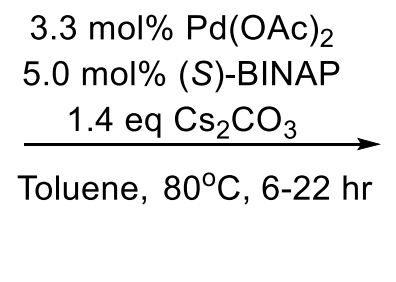<smiles>[R]c1ccc(N2C(=O)CCc3ccccc32)c(C([R])(C)C)c1</smiles>

Yield up to $95 \%$ ee up to $96 \%$

\section{Figure 14 - Intramolecular Amidation Forming a Chiral Axis}

\subsection{Biphenyl Based Ligands}

Over the years since the Buchwald-Hartwig amination was first reported, there have been efforts devoted to making better more robust or selective ligands. Modifications have shown drastic changes to the scope of the reaction. Originally the ligands were simple monophosphine biphenyl compounds with bulky alkyl groups on the phosphine, DavePhos and JohnPhos, depicted in Figure 15. Larger, bulky groups were attached onto this scaffold to create greater reactivity and diversity among the Buchwald-Hartwig reactions. The robustness of these catalyst systems are have improved as well, catalyst loadings are seen as low as $0.05 \mathrm{~mol} \%$ and are still able to drive reactions to near completion. A select few examples of the ligands employed are depicted in Figure 15. All of these ligands pictured are achiral. ${ }^{16}$ 


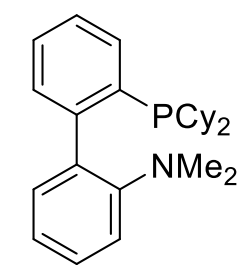

DavePhos<smiles>CCCCCCCCCCCCCCC</smiles>

JohnPhos<smiles>COc1cccc(OC)c1-c1ccccc1P(C)(=O)c1ccccc1</smiles>

SPhos

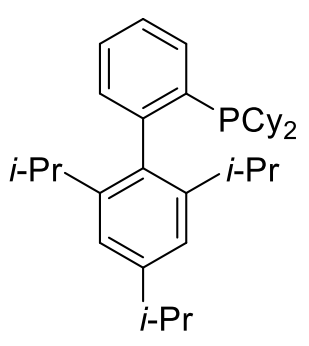

XPhos

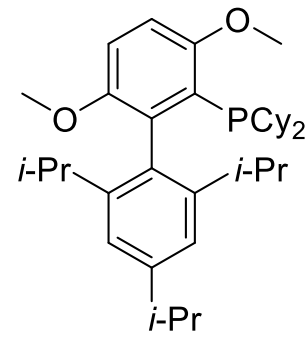

RuPhos<smiles>CCCOc1cccc(OCC)c1-c1ccccc1OCC</smiles>

BrettPhos

\section{Figure 15 - Several Achiral Ligands for Buchwald-Hartwig Amination}

\subsubsection{Binaphthyl Base Ligands}

The binaphthyl ring system unlike the biaryl ring system, has an extra benefit of being chiral. The phosphine is still bound to the bulky dialkyl/biaryl groups as this aspect aids in both the oxidative addition and the reductive elimination steps. ${ }^{16}$ Generally without substituents the rings can freely rotate about the $\mathrm{C}-\mathrm{C}$ bridge, but when a substituted phosphorus, nitrogen or oxygen is attached at the 2 and 2' position, that rotation is locked, forming a chiral axis. ${ }^{17,18}$ The most notable binaphthyl phosphine ligands are $(R)$-BINAP and $(R)-\mathrm{MOP} .^{19}$ 
<smiles>COc1ccc2ccccc2c1-c1c(P)ccc2ccccc12</smiles>

$(R)-\mathrm{MOP}$<smiles></smiles>

$(R)$-BINAP<smiles>Pc1ccc2c(c1-c1ccccc1-c1ccccc1)OCO2</smiles>

$(R)$-SEGPHOS

Figure 16 - Common Binapthyl Phosphine Ligands

Oxidation of the phosphorus has been thought to deactivate the ligand rendering it incapable of coordinating to the palladium. In cases like BINAP where there are two phosphorus atoms, if one atom is oxidized to $\mathrm{P}=\mathrm{O}$ the oxygen has been shown to coordinate the palladium along with the pre-existing P(III) atom, as seen in Figure $17 .^{20}$

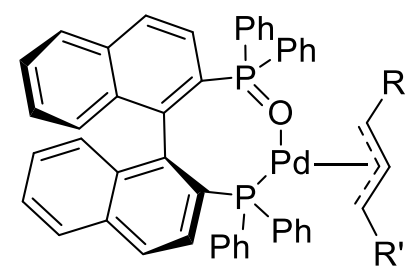

\section{Figure 17 - (S)-BINAPO Complex with Palladium}

Most modifications to the MOP-type ligands have been at the 2,2' position on the binaphthyl scaffold, since the commercially available BINOL has two alcohol groups for facile derivatization. Generally the modifications are other bulky alkyl groups to increase the selectivity. Zhang et al. created several ligands, through an 8 step synthesis, containing bulky alkyl group such as; $\mathrm{Cy}, t$ - $\mathrm{Bu}, \mathrm{Me}, i \mathrm{Pr}$ and $\mathrm{Bn}$, to investigate simple amination. Interestingly, they found one of their ligands was particularly effective for monoarytlation of primary amines as depicted in Figure $18 .^{21}$ 


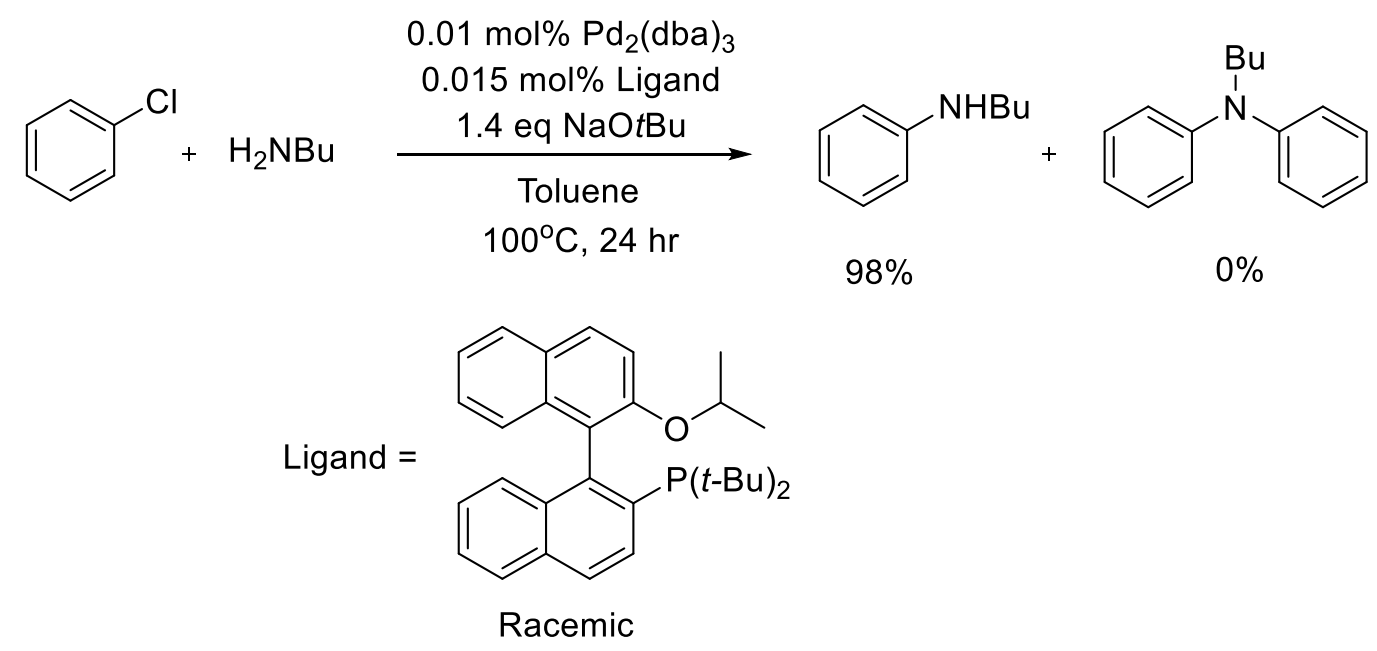

Figure 18 - Selective Monoamination with MOP-type Ligand

\subsection{Research Goals}

The objective of this thesis is to extend the previous work of desymmetrization of malonamides reported by the Viirre group to include bulky otho-substituted phenyl substituents on the malonamide nitrogen atoms. This class of substrates possess both a prochiral centre and axis, with the possibility of setting both selectively in a single Buchwald-Hartwig event, as seen in Scheme 3. ${ }^{13}$ 


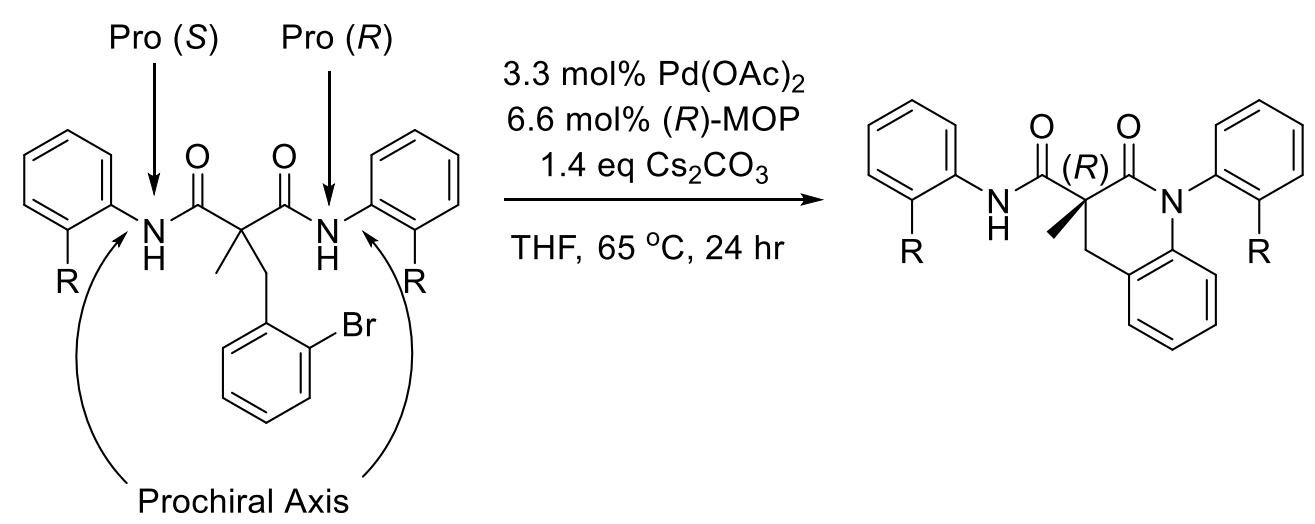

\section{Scheme 3 - Previous Work Published by the Viirre Group}

Previous work in the Viirre group completed by Augusto Matarazzo, preliminarily reported that $(R)$-dicyclohexyl(2'-methoxy-[1,1'-binaphthalen]-2-yl)phosphane, which will henceforth be referred to as $(R)-\mathrm{Cy}_{2} \mathrm{MOP}$, was more effective ligand for this transformation then phenyl substituted MOP used in earlier desymmetrizations. Matarazzo had completed the cyclization of the 2-t-butylphenyl malonamide compound, the sample that was sent for crystallographic data was not enantiopure, meaning the absolute configuration observed cannot be linked to the major peak in the HPLC as there is a chance that it was compound producing the minor peak in the HPLC. ${ }^{22}$ This is where the thesis will begin. Also, as the ligand is not commercially available, a secondary goal of the project was to develop a practical method for the synthesis of $(R)$ $\mathrm{Cy}_{2} \mathrm{MOP}$. 


\section{Results and Discussion}

\subsection{Synthesis Towards Substituted Malonamides}

To determine the absolute configuration of the cyclized product $\mathbf{8}$ that was previously carried out by Matarazzo, ${ }^{22}$ the substrate 6 needed to be prepared. Although the original synthesis was carried out using diethyl methylmalonate, starting with diethyl malonate would allow for further customizability of the alkyl group at the alpha carbon.

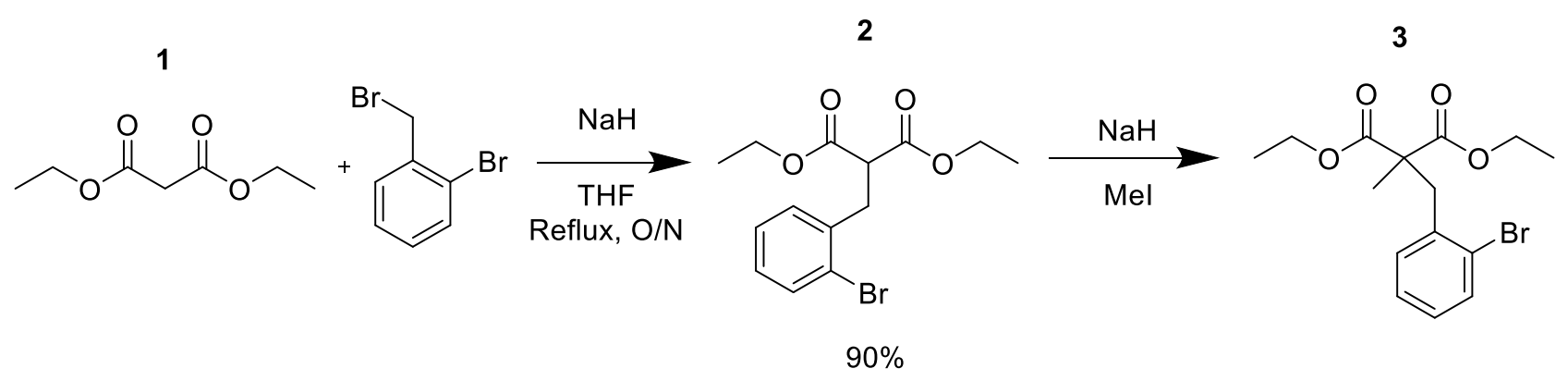

\section{Scheme 4 - Synthesis of Diethyl 2-(2-Bromobenzyl)malonate from Diethyl Malonate}

The first step from $\mathbf{1}$ to $\mathbf{2}$ is a substitution step in which a 2-bromobenzyl group is added to diethyl malonate. Sodium hydride was used since it deprotonates the central carbon irreversibly. The reaction proceeded smoothly and the resulting diethyl 2-bromobenzylmalonate was obtained in a good yield. The following methylation step converting $\mathbf{2}$ into $\mathbf{3}$ proved to be challenging. The reaction did not go to completion and would require column chromatography to separate the starting material from the product. The problem was that under the solvent systems; hexanes/EtOAc, hexanes/Et $2 \mathrm{O}, \mathrm{EtOAc} / \mathrm{Et}_{2} \mathrm{O}$, neat DCM, DCM/hexanes, and $\mathrm{CHCl}_{3}$, a good enough separation was not attainable for chromatography. The difference in polarity imparted by the addition of only a methyl group on this already non-polar compound was not large enough to separate 2 from 3 . Other forms of separation were not options either. For instance, the starting 
material and the product are both oils at room temperature and thus cannot be purified by crystallization. The next reaction is a hydrolysis reaction and the reactivity of the esters on the starting material and the product are comparable, leading to a more complex mixture of compounds. Thus, starting material of this reaction could not have been carried over and then separated at a later step. After several attempts at trying to purify this compound or drive the reaction to completion, was prepared using the original synthesis as reported by Matarazzo.

The synthesis that was carried out previously uses diethyl methylmalonate $\mathbf{4}$ as a starting material in order to obtain compound $\mathbf{3}$, as seen in Scheme 5.<smiles>CCOC(=O)C(C)C(=O)OCC</smiles><smiles>BrCc1ccccc1Br</smiles>
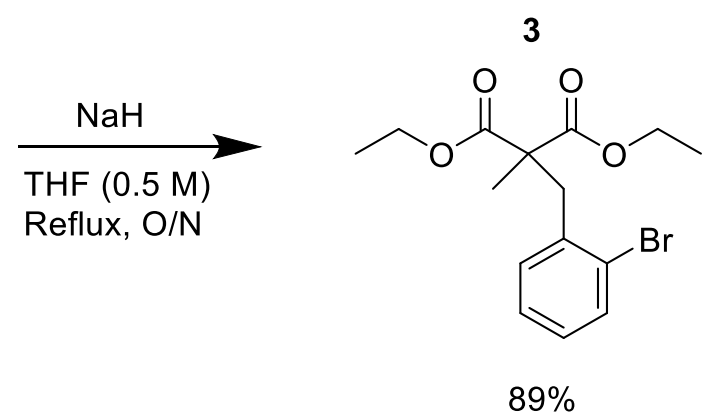

\section{Scheme 5 - Synthesis of Diethyl 2-(2-Bromobenzyl)-2-methylmalonate from Diethyl 2- Methylmalonate}

Scheme 4 would have allowed for customizability of the alkyl position at the alpha carbon. This could have led to the investigation of the electronic and steric properties that position has on the cyclization of the malonamide end product. Unfortunately due to the separation issues, the starting material was switched to 4 for the ease of synthesis as seen in Scheme 5. The substitution reaction in Scheme 5 to produce 3 in $89 \%$ yield uses $\mathrm{NaH}$ in THF.

The next reaction in the synthesis of $\mathbf{8}$ was the saponification of $\mathbf{3}$ affording the substituted malonic acid $\mathbf{5}$, as seen in Scheme 6. 

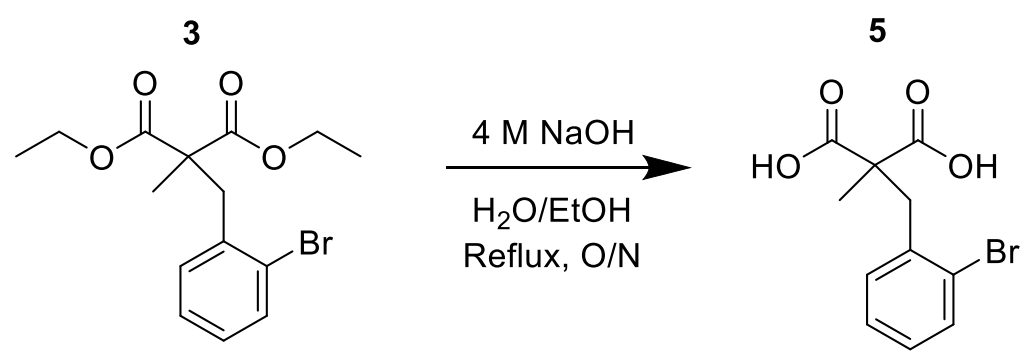

$10-100 \%$

\section{Scheme 6 - Hydrolysis of Diethyl 2-(2-bromobenzyl)-2-methylmalonate}

Both reaction and workup conditions needed to be carefully controlled in order to obtain good yield. During early attempts, the reaction was heated to reflux overnight in accordance to similar syntheses, but this high temperature and caustic conditions led to decarboxylation of the product.

The workup includes an initial extraction with $\mathrm{Et}_{2} \mathrm{O}$ while the aqueous phase remains basic to recover any starting material that had not reacted. This is followed by protonation of the carboxylic acid groups with $1 \mathrm{M} \mathrm{HCl}$, which produces $\mathbf{5}$ and is no longer soluble in the water/EtOH mixture. The product 5 was believed to be soluble in $\mathrm{DCM} / \mathrm{CHCl}_{3}$, and so this was chosen as an extraction solvent. Visibly the precipitate had disappeared. Upon concentration under vacuum, there was nothing left in the flask. Since after concentrating the $\mathrm{Et}_{2} \mathrm{O}$ phase only produced trace amounts of unreacted $\mathbf{3}$, the original thought was that compound $\mathbf{5}$ was undergoing decarboxylation during the concentration step of the workup, but there was no evidence of by product. Replicating this reaction, proved to yield the same result, of an absence of anything in any flask.

The successful attempt at the isolation of $\mathbf{5}$ was due to filtering out the precipitate after acidification and realizing the compound is not soluble in DCM but EtOAc instead. Switching 
the extraction solvents was able to isolate 5 in a $91.5 \%$ yield. This reaction is $100 \%$ based on recovered starting material.

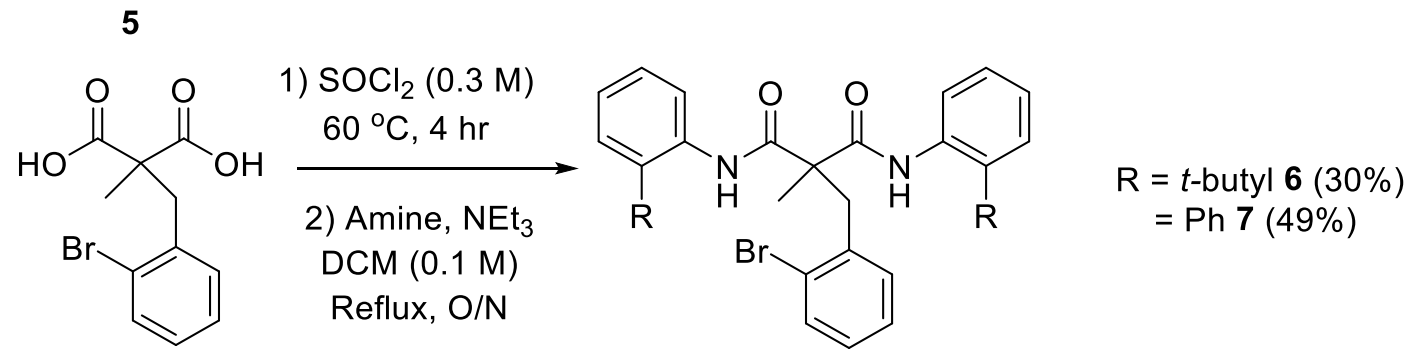

\section{Scheme 7 - Malonamide Formation from Malonic Acid}

The formations of different malonamides were done under identical reaction conditions, as shown in Scheme 7. The malonic acid was taken up in thionyl chloride and heated to $60{ }^{\circ} \mathrm{C}$ for four hours to convert to the acid chloride. It is difficult to monitor this reaction by TLC because the thionyl chloride creates large dark spots on the silica plate. The acid chloride was not isolated because it can decompose easily back to the starting material $\mathbf{5}$, after prolonged exposure to moisture. After the four hours at elevated temperature, the product was worked up and carried through. The reaction was evaporated under vacuum to remove extra thionyl chloride, redissolved in chloroform and further concentrated several times to remove any traces of thionyl chloride. After this brief work up there was still a slight thionyl chloride smell that was apparent but further evaporation did not dissipate the smell. The acid chloride was dissolved in DCM (0.1 M), and the desired amine (2-t-butyl aniline or 2-biphenylamine) was added slowly over ice. The reaction was warmed to room temperature and allowed to stir for an hour before being cooled again and having the base added. The reaction was heated to reflux overnight and the work up consisted of an acid extraction to remove extra amine and base. The yields are generally poor to moderate for this reaction with the best yields being $30 \%$ and $49 \%$ for the bis( $t$-butylphenyl) 
malonamide and bis(biphenyl) malonamide, respectively. The poor yields could be due to the low nucleophilicity of anilines. Also the amines that are used are sterically hindered by the bulky ortho substituents. With the difficulty these bulky amines have forming the amide, it is statistically challenging to form an acid chloride and subsequent nucleophilic displacement twice on the same molecule. For example, if the amide formation proceeds with a moderate yield of $65 \%$, then having this happen twice on the same molecule the yields are multiplicative resulting in an overall yield of $42 \%$.

\subsection{Cyclization of Substituted Malonamides}

As in the amide formation, each malonamide was cyclized via the Buchwald-Hartwig C-N cross-coupling using SPHOS (achiral) or $\mathrm{Cy}_{2} \mathrm{MOP}$ (chiral) as the ligand. The general procedure for the reaction, as seen in Scheme 8, was adding the malonamide, palladium source and ligand to a Schlenk flask while evacuating and back filling with nitrogen in between each addition. Ensuring the nitrogen backfilling in between each addition seemed to be the best route to exclude oxygen from the reaction mixture. Previous work in the lab had added all the solids and then evacuated and backfilled three times in a row lead to irreproducible results. Better reproducibility was found when all solids excluding the base were dissolved in anhydrous toluene $(0.1 \mathrm{M})$ and heated to $100{ }^{\circ} \mathrm{C}$ to obtain a clear solution. This generally happened within $20-30$ seconds but the reaction was given three minutes to ensure complete solvation. Upon cooling to room temperature, the base was added and the reaction was sealed for 48 hours at $100{ }^{\circ} \mathrm{C}$, under $\mathrm{N}_{2}$. During the 48 hours, some of the reactions turned black and some did not. This black precipitate is the palladium catalyst becoming inactive and precipitating. This was not an indication of completion as some reactions would have the reaction go to completion before the catalyst decomposed and some would not. Moderate to great yields were observed, with the better yields 
stemming from the $t$-butyl substituted compounds. This could be due to the inherent steric bulk causing issues in allowing the coupling of the palladium to the nitrogen and aromatic group at the same time while still being bound to the bulky ligand. The difference in yields among the substrates could be due to differences in which each bulky substituent interacts with the catalyst, electronic differences of the two amides (i.e. pKa or nucleophilicity) or by agostic interactions that result from the $t$-butyl C-H bond interacting with the palladium atom's empty d orbital, assisting in the coordination of the amine. The $\mathrm{sp}^{2}$ nature of the $\mathrm{C}-\mathrm{H}$ bond present in the biphenylamine is less nucleophilic and thus has a lower yield. Further study into the interaction of these types of substrates with the catalyst is underway in the Viirre group.

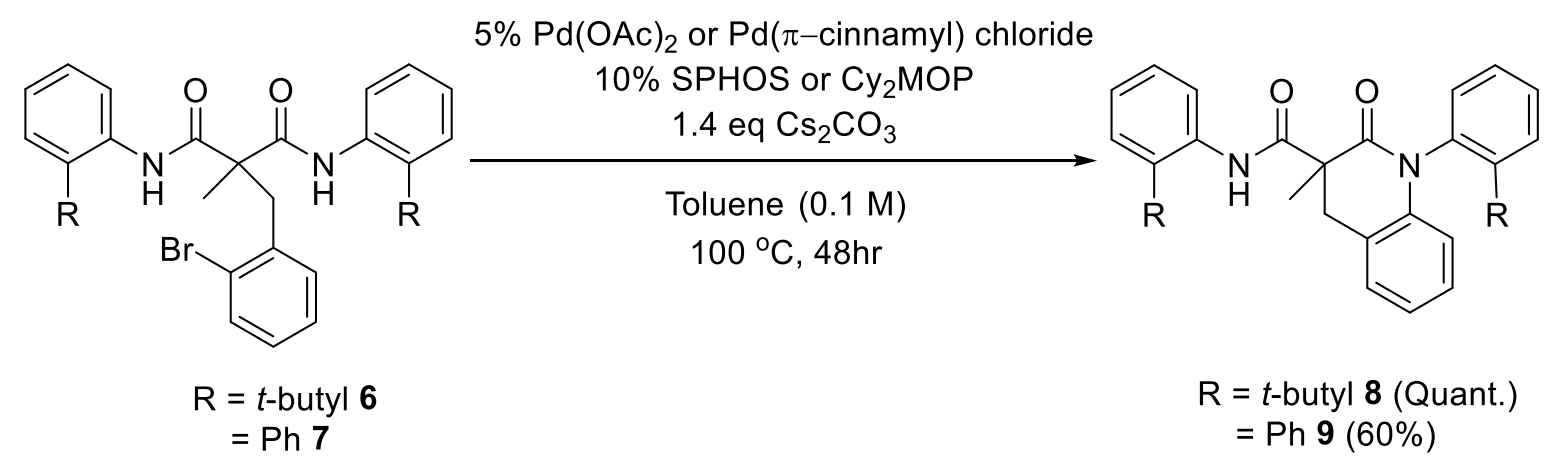

\section{Scheme 8 - General Reaction for the Cyclization of Malonamides}

\subsubsection{Analyzing Enantioselectivity and Diastereoselectivity of Cyclized Substituted}

\section{Malonamides}

There are two ways in which diastereoselectivity is calculated, by NMR and HPLC. Enantioselectivity can only be analyzed by HPLC, since enantiomers are magnetically equivalent. The way that the diastereomeric ratio is calculated by ${ }^{1} \mathrm{H}$ NMR is observing the ratio 
and splitting pattern of the benzylic $\mathrm{CH}_{2}$ peaks. In the starting materials 6 and 7 the protons are equivalent and produce a singlet for two protons, as seen in Figure 19.

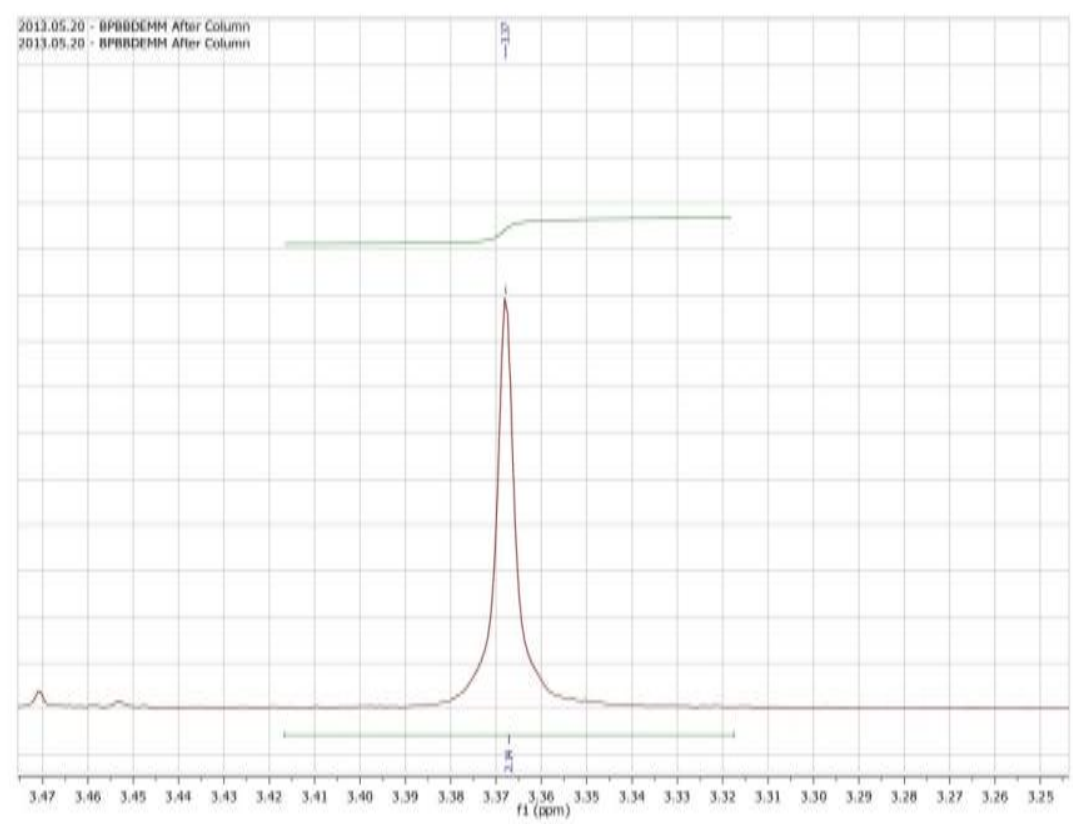

Figure 19 - $\mathrm{CH}_{2}$ Singlet Peak of 6

When the cyclization reaction forming the chiral products $\mathbf{8}$ and $\mathbf{9}$, the two protons are no longer magnetically equivalent, they are diastereotopic. The two protons couple to each other, forming two doublets leaning towards each other, and integrate for one proton each. Since diastereomers are not magnetically equivalent, each set of diastereomers give rise to a pair of leaning doublets that are well resolved in the ${ }^{1} \mathrm{H}$ NMR spectrum. The diastereomeric ratio is calculated by dividing the integration of one pair of doublets by the integration of the combined 4 doublets. The four doublets can be observed easily in the ${ }^{1} \mathrm{H}$ NMR spectrum of 9 when cyclized with the Pd/SPHOS catalyst system, Figure 20. 


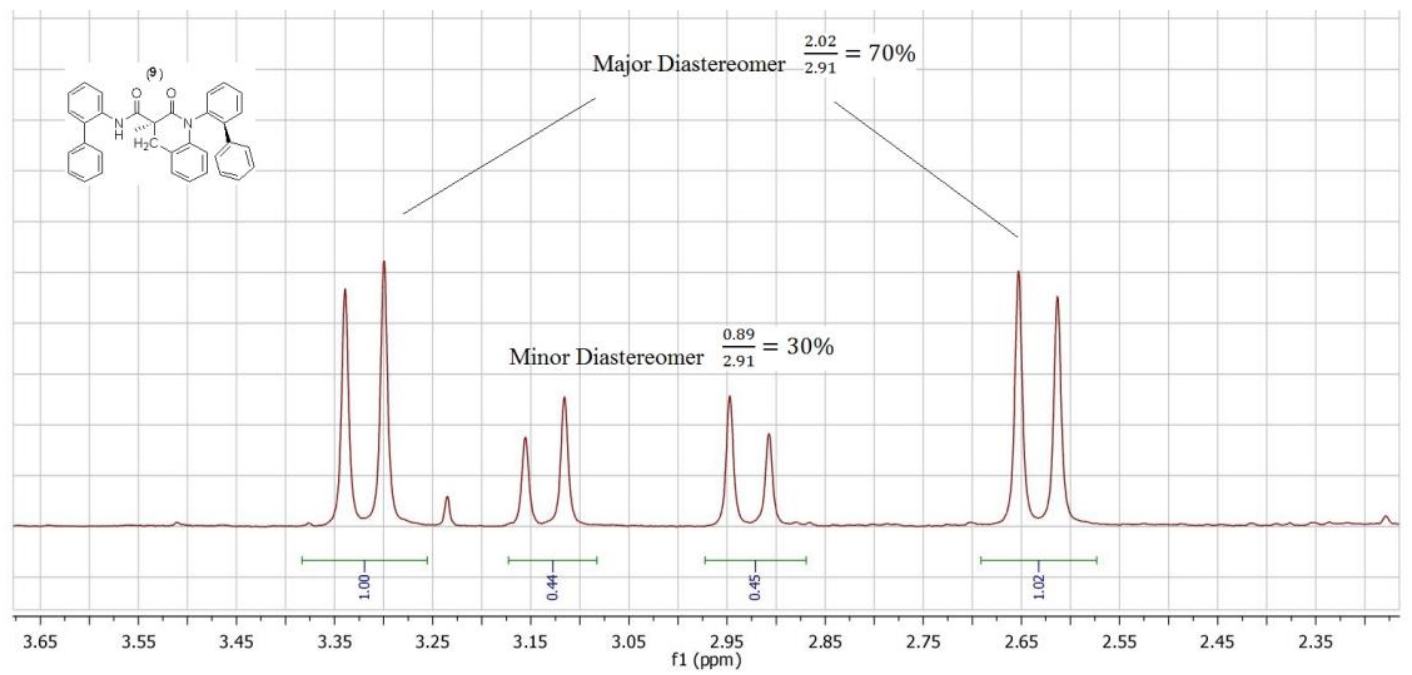

Figure 20 - Diastereotopic Protons of 9 via Pd/SPHOS

Using the protons in Figure 20 as an example, the integration all of the doublets total 2.91. It is clear which protons are on the same diastereomer as the doublets are paired in integration and amount of leaning towards one another. Totaling the integration of the two major diastereomeric protons is 2.02 , and dividing by the total integration yields a diastereomeric ratio of $70 \%$. The diastereoselectivity of $\mathbf{9}$ when cyclized with Pd/SPHOS can be compared to the cyclization of 9 when cyclized with $\mathrm{Pd} /(R)-\mathrm{Cy}_{2} \mathrm{MOP}$ as in Figure 21 . 


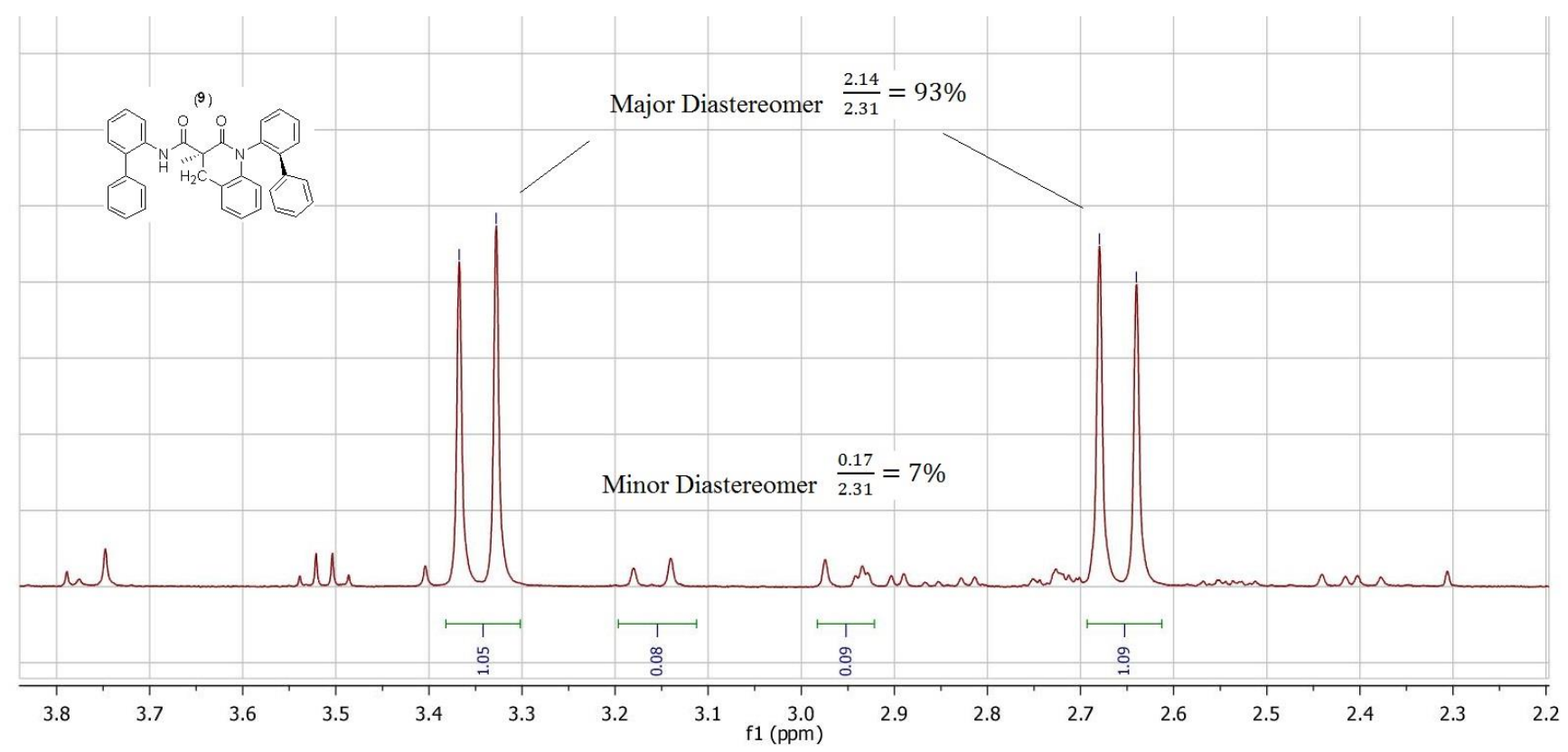

Figure 21 - Diastereotopic Protons of 9 via $\mathrm{Pd} /(R)-\mathrm{Cy}_{2} \mathrm{MOP}$

The ${ }^{1} \mathrm{H}$ NMR spectra of $\mathbf{8}$ when cyclized with Pd/SPHOS (Figure 22) and Pd/(R)$\mathrm{Cy}_{2} \mathrm{MOP}$ (Figure 23) show only one set of doublets meaning that there is only one diastereomer formed in the reaction. This was later confirmed by HPLC.

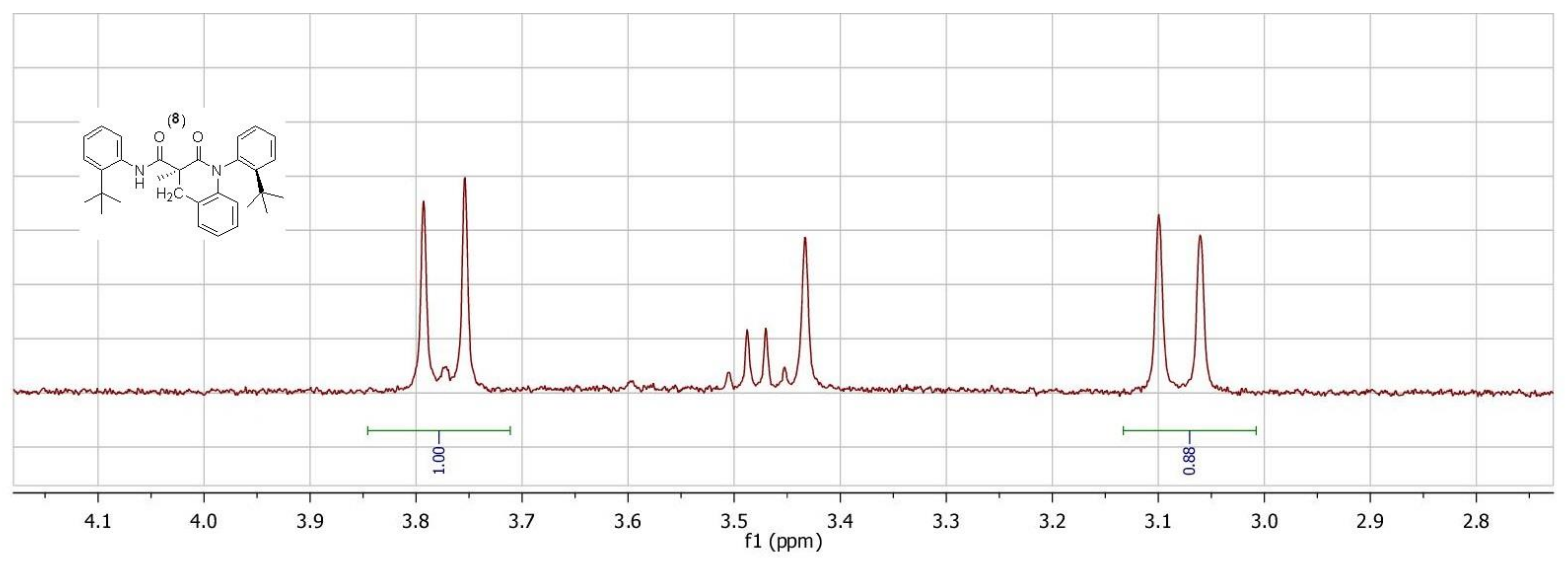

Figure 22 - Single Diastereomer of 8 via Pd/SPHOS 
There is an impurity peak seen at 3.48, but it is quite evident that there is only one set of doublets meaning that there is only one diastereomer produced in this reaction. A comparable spectrum is seen in Figure 23, when the $\mathrm{Pd} /(R)-\mathrm{Cy}_{2} \mathrm{MOP}$ catalyst system was used.

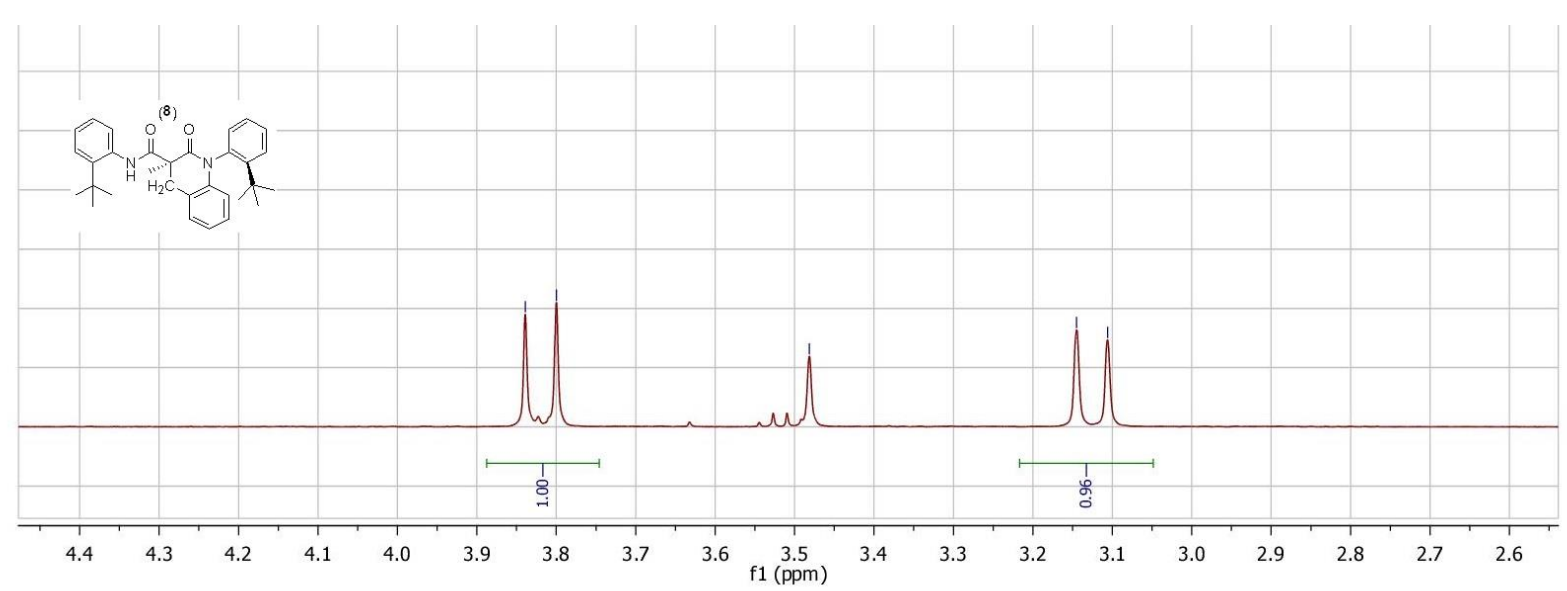

Figure 23 - Single Diastereomer of 8 via $\mathrm{Pd} /(R)-\mathrm{Cy}_{2} \mathrm{MOP}$

The diastereomeric ratio and enantiomeric excess of the compounds $\mathbf{8}$ and $\mathbf{9}$ can be calculated by HPLC. Using a Chiralpak OD-H column, each of the four diastereomers are separated and integrated based on the area of each peak. To understand which two peaks correlate to a set of diastereomers, the product formed from the Pd/SPHOS reaction analyzed by HPLC first. Since the SPHOS is achiral, there cannot be any enantioselectivity, resulting in two pairs of peaks that can be seen to have the same areas, as seen in Figure 24. 


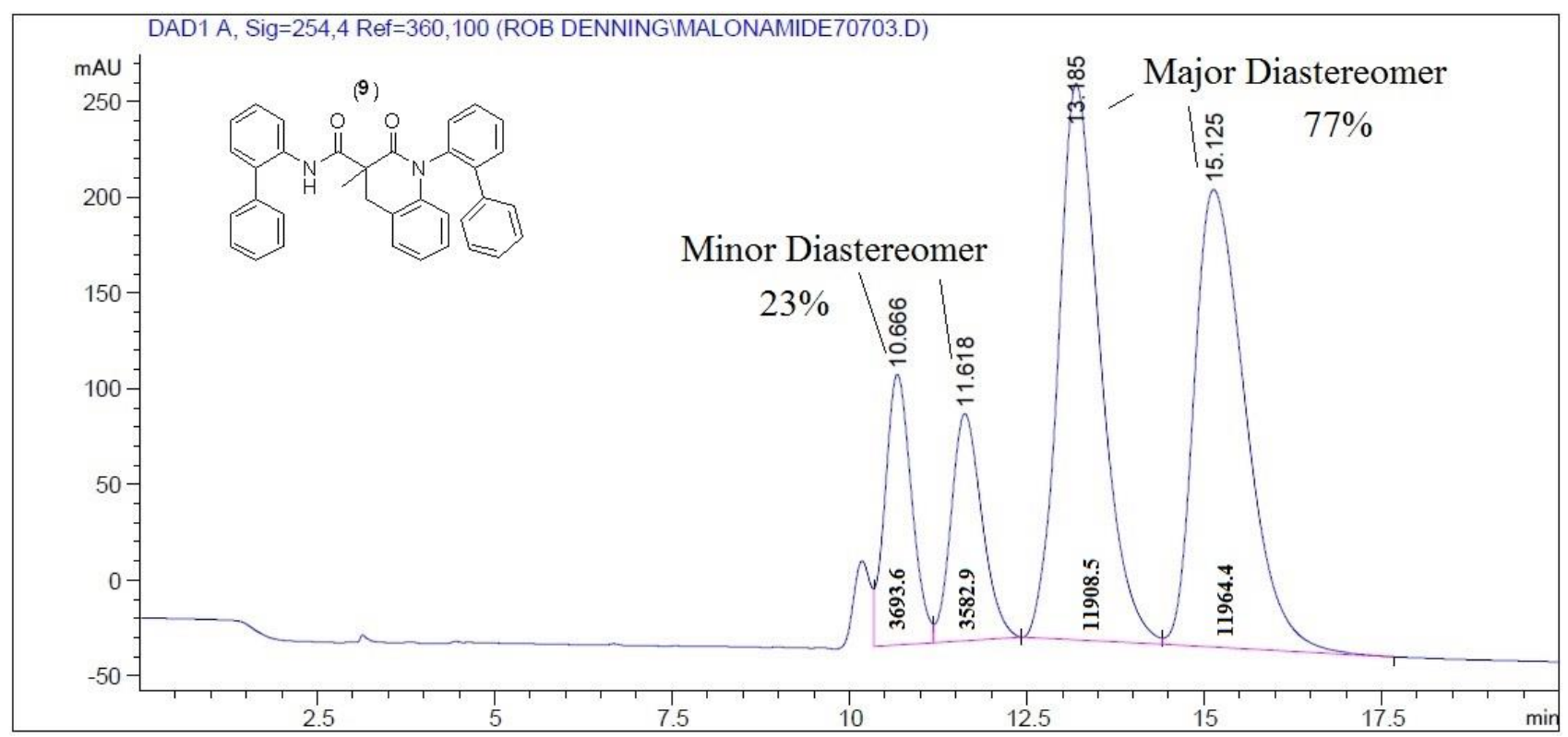

Figure 24 - HPLC Chromatogram of 9 via Pd/SPHOS

With the identification of the diastereomers as seen in the Figure 24, analysis of the HPLC chromatogram of 9 as cyclized by $\mathrm{Pd} /(R)-\mathrm{Cy}_{2} \mathrm{MOP}$ shows enantioselectivity. In Figure 25, the peak area in increasing order is $2072.2,6148.2,14744.9,6627.4$, which totaled is 29592.7 The diastereomeric ratio as per the HPLC is $72 \%$ which differs from the results seen in the ${ }^{1} \mathrm{H}$ NMR spectra. The enantiomeric excess is $38 \%$ and $49.5 \%$ for the major and minor diastereomers, respectively. 


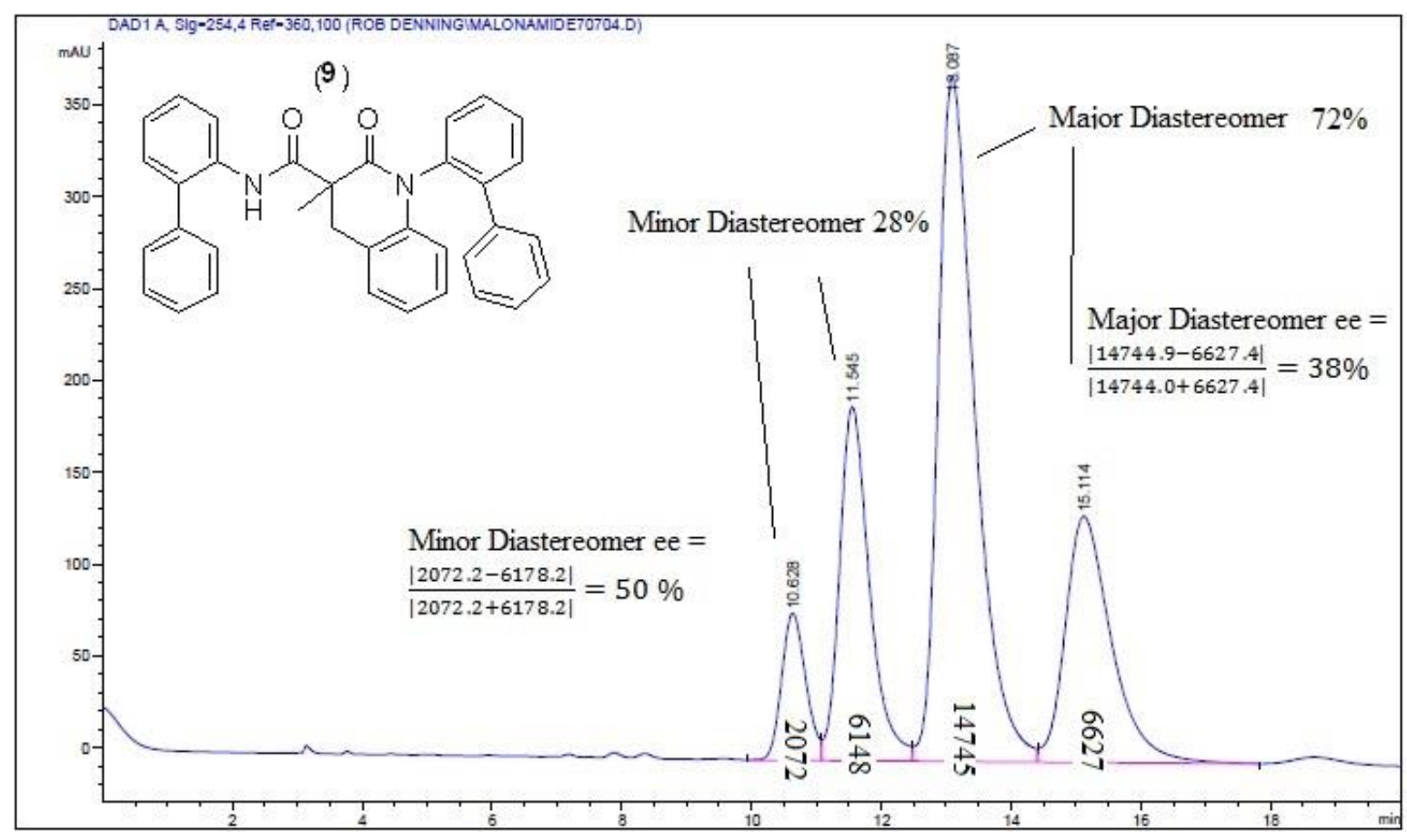

Figure 25 - HPLC Chromatogram of 9 via $\mathrm{Pd} /(\mathrm{R})-\mathrm{Cy}_{2} \mathrm{MOP}$

The HPLC chromatograms of $\mathbf{8}$ are not as well resolved but there is only one diastereomer that is seen. There is a contaminant of starting material seen but it does not interfere with the analysis, the Pd/SPHOS reaction forming 8 is shown in Figure 26. 


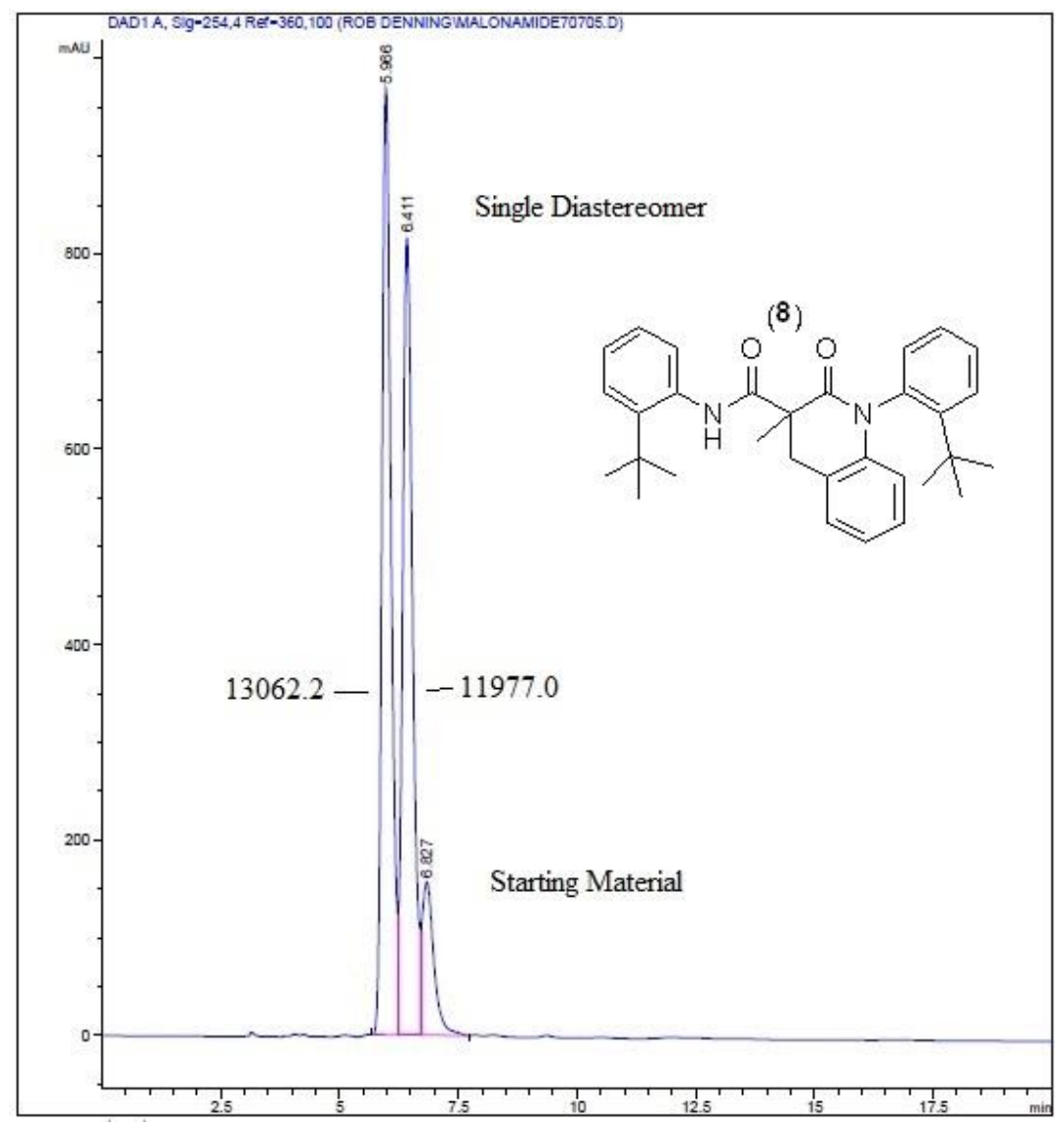

Figure 26 - Product 8 via Pd/SPHOS

Once again, with the identification of the enantiomeric peaks established, the chromatogram of the reaction forming product 8 with $\mathrm{Pd} /(R)-\mathrm{Cy}_{2} \mathrm{MOP}$ can be done, shown in Figure 27 . With the NMR and HPLC data, the reaction forming product 8 with $\mathrm{Pd} /(R)-\mathrm{Cy}_{2} \mathrm{MOP}$, is $100 \%$ diastereoselective and $90 \%$ enantioselective. This means that out of four possible conformations, one is being highly selected for. 


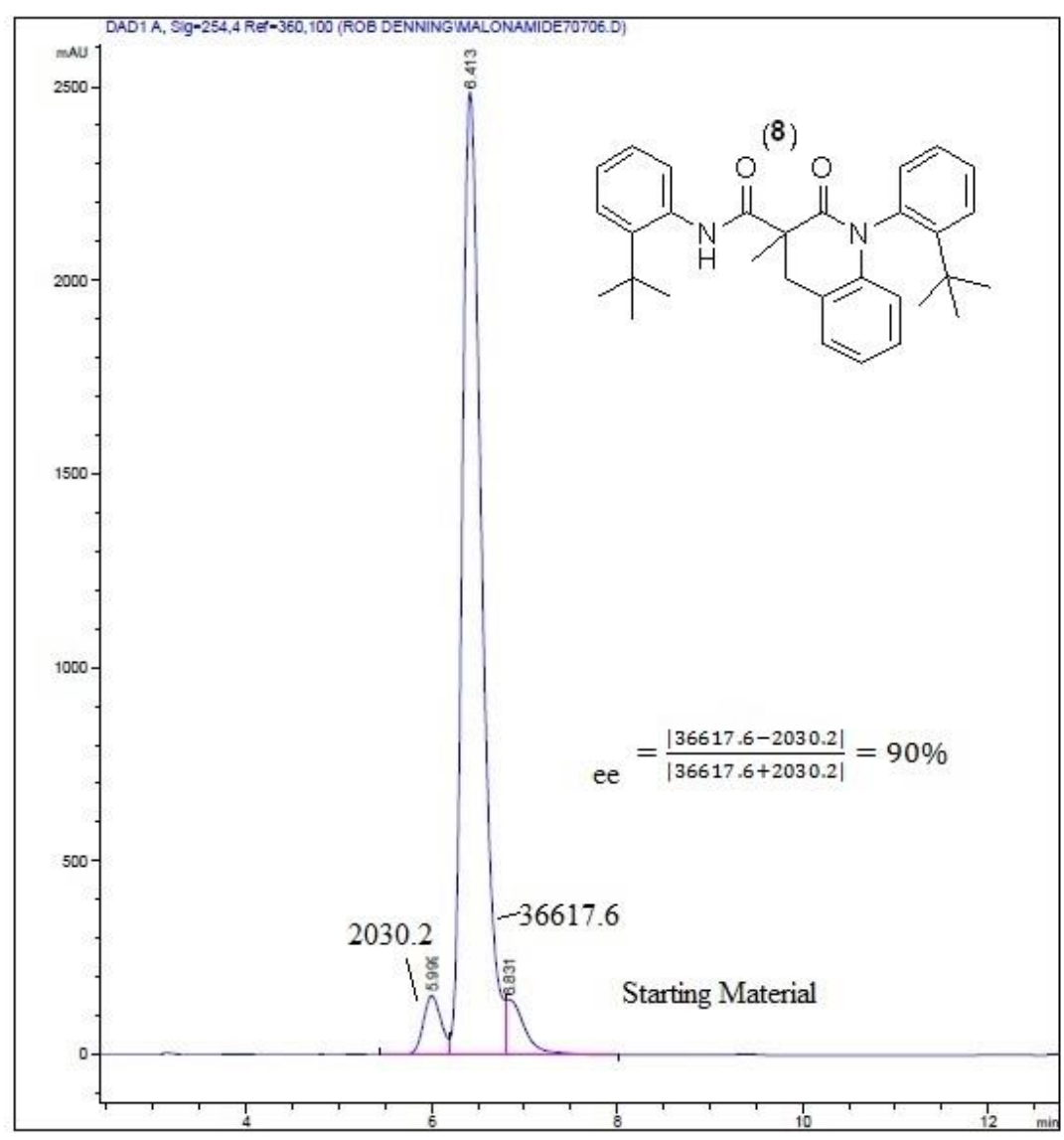

Figure 27 - HPLC Chromatogram of 8 via Pd/(R)-Cy2MOP

The two compounds 8 and 9 were cyclized with SPHOS and $(R)-\mathrm{Cy}_{2} \mathrm{MOP}$ as the ligand. Since SPHOS is achiral the reaction won't exhibit enantioselectivity but the reaction is able to show diastereoselectivity. The results for the four reactions are summarized in Table 1. 


\begin{tabular}{|l|c|c|c|c|}
\hline & NMR dr & HPLC dr & Major Diastereomer ee & Minor Diastereomer ee \\
\hline Cyclized 8 by SPHOS & $100 \%$ & $100 \%$ & $4 \%$ & NA \\
\hline Cyclized 8 by $(R)-$ & $100 \%$ & $100 \%$ & $90 \%$ & NA \\
Cy 2 MOP & & & & NA \\
\hline Cyclized 9 by SPHOS & $70 \%$ & $77 \%$ & & \\
\hline $\begin{array}{l}\text { Cyclized } 9 \text { by }(R)- \\
\text { Cy }\end{array}$ & $93 \%$ MOP & $72 \%$ & $38 \%$ & $50 \%$ \\
\hline
\end{tabular}

Table 1 - Enatioselectivity and Diastereoselectivity of the Cyclization of 6 and 7 by SPHOS and $(R)-\mathrm{Cy}_{2} \mathrm{MOP}$

From Table 1, it is clear to see that the enantioselectivity and diastereoselectivity are favoured in the cyclization reaction that forms $\mathbf{8}$. Although there is a slight enantioselectivity seen in the SPHOS reaction forming $\mathbf{8}$, this is within the margin of error for the instrument; as only the chiral ligand, $(R)-\mathrm{Cy}_{2} \mathrm{MOP}$, can result in enantioselectivity. In both reactions forming 8 involving SPHOS and $(R)-\mathrm{Cy}_{2} \mathrm{MOP}$, the diastereoselectivity is preserved, which is reflected in the NMR and HPLC results. The diastereoselectivity then could be caused by either the ligand, in the catalyst system or it can be potentially directed by the substrate.

The overall cyclization reaction to form 9 shows poorer enantio- and diastereoselectivity when using $\mathrm{Pd} / \mathrm{SPHOS}$ and $\mathrm{Pd} /(R)-\mathrm{Cy}_{2} \mathrm{MOP}$. The reaction using $(R)-\mathrm{Cy}_{2} \mathrm{MOP}$ does show greater diastereoselectivity, as by NMR (Figure 21) but when viewing the HPLC chromatogram (Figure 25) there seems to be the same amount of selectivity for one diastereomer as seen with the 
$\mathrm{Pd} / \mathrm{SPHOS}$ system. Also there is only moderate selectivity seen in the $(R)-\mathrm{Cy}_{2} \mathrm{MOP}$ reaction at $36 \%$ and $50 \%$ ee for the major and minor diastereomers respectively.

The different bulky R substituent, phenyl (9) as opposed to $t$-butyl (8), is impacting the cyclization negatively. For reasons stated earlier, the nature of the biphenyl substrate produces poorer reactivities and selectivities.

\subsection{Synthesis Towards Monoamide Compounds}

Further investigation into the mechanics of this cycle needed to be done, thus the next system looked at were the monoamide compounds 11-13, as seen in Figure 28.

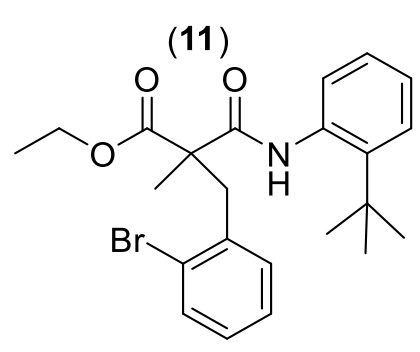

(12)<smiles>CCOC(=O)C(C)(Cc1ccccc1Br)C(=O)Nc1ccccc1-c1ccccc1</smiles>

(13)<smiles>CCOC(=O)C(C)(Cc1ccccc1Br)C(=O)Nc1ccccc1</smiles>

\section{Figure 28 - Monoamide Compounds Used to Understand Enantio- and Diastereoselectivity within the Buchwald-Hartwig Reaction}

Since these compounds only have one potentially reactive amide functional group and begin the reaction mixture as a racemic mixture, they offer the possibility of determining whether it is the substrate or the catalyst that influences axial chirality. Starting from $\mathbf{3}$ the first step was a monohydrolysis of the malonate, Scheme 12 . This proved to be very difficult since both esters have the same reactivity and reaction temperatures required for the hydrolysis to occur were high, which would encourage both esters to hydrolyze. Failed attempts include; room temperature for seven days, $0.5 \mathrm{M} \mathrm{NaOH}$ and $0.25 \mathrm{M} \mathrm{KOH}$, slight heating at $40{ }^{\circ} \mathrm{C}$, different 
solvent systems (THF, EtOH, EtOH/water, $\mathrm{MeOH} /$ water), phase transfer catalysts

(tetrabutylamonimum hydroxide), which all either resulted in no reaction or dihydrolysis. Once $\mathrm{MeOH}$ was used instead of $\mathrm{EtOH}$, but this only resulted in transesterification and the dimethyl malonate 20, was recovered in $62 \%$ yield, Scheme 9 .

3
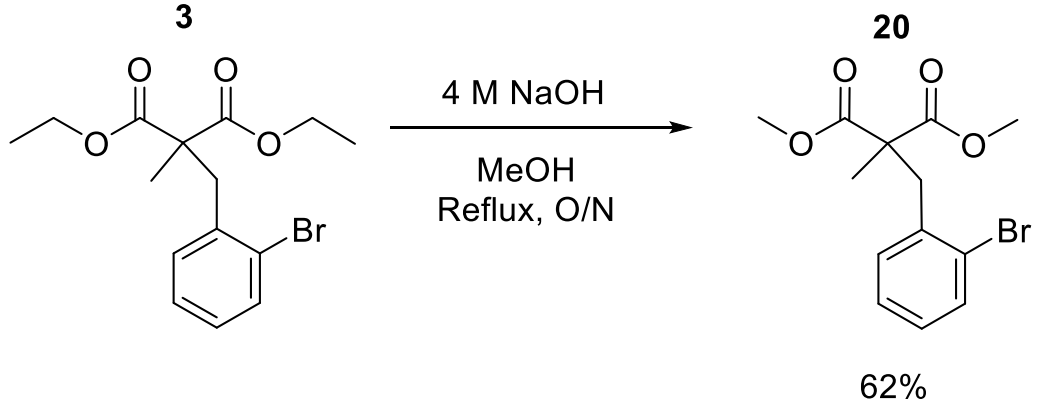

\section{Scheme 9 - Transesterification of Diethyl Malonate to Dimethyl Malonate}

Mono methylation of the diacid $\mathbf{5}$ was also attempted with methyl iodide or dimethyl sulphate in a phosphate buffer but the reactions either did not work or formed the dimethyl ester 20, Scheme 10.
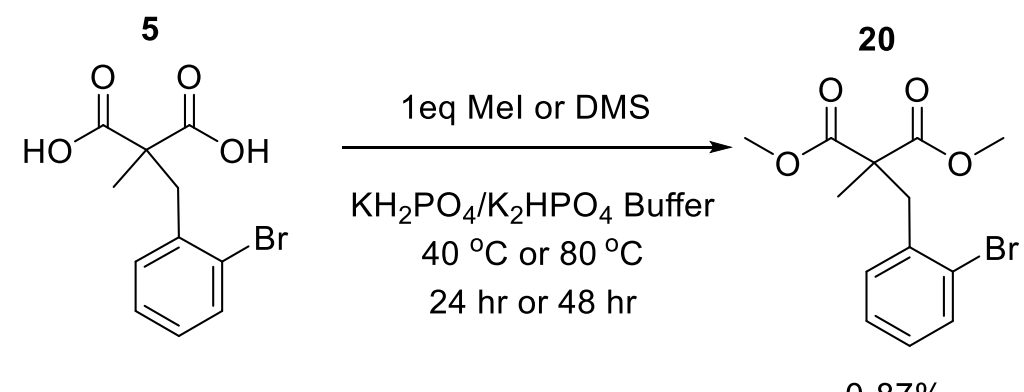

Scheme 10 - Monomethylation Attempts on Substituted Malonic Acid 
With a sizable amount of the dimethyl malonate $\mathbf{2 0}$, it was considered for future derivatization. Monohydrolysis reactions were attempted and proved to be successful by solubilizing the base as well as the substrate separately, followed by a slow addition of the base solution to the substrate solution over ice. A quick one hour reflux with a subsequent acid workup afforded the monoacid compound $\mathbf{2 1}$ in $32 \%$ yield, Scheme 11 . Compound 21 was carried through to both the 2-(t-butyl)phenylamide and 2-biphenylamide. The issue with this route was that there was not enough material to continue through, considering diethyl 2methylmalonate was the original starting material. Also it was different from our other models, so this route was not pursued further.

20

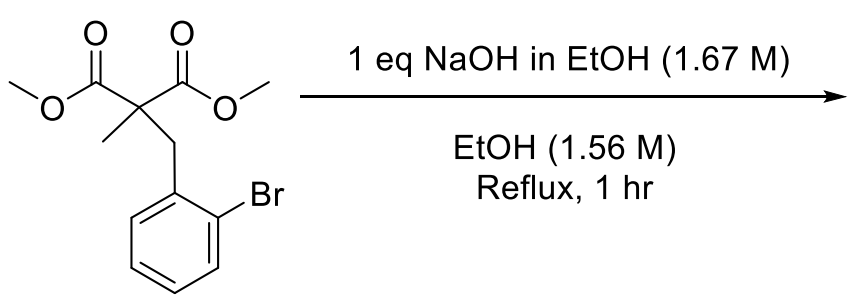

21<smiles>COC(=O)C(C)(Cc1ccccc1Br)C(=O)O</smiles>

$32 \%$

\section{Scheme 11 - Monohydrolysis of Substituted Dimethyl Malonate}


The reaction conditions that were used for the monohydrolysis of the derivatized dimethyl malonate, were used to achieve a monohydrolysis of the diethyl malonate, as seen in Scheme 12.

3<smiles>CCOC(=O)C(C)(Cc1ccccc1Br)C(=O)OCC</smiles>

1) 1 eq $\mathrm{NaOH}$ in $\mathrm{EtOH}(1.67 \mathrm{M})$ EtOH (1.56 M)

Reflux, $1 \mathrm{hr}$

10<smiles>CCOC(=O)C(C)(Cc1ccccc1Br)C(=O)O</smiles>

$33-81 \%$

\section{Scheme 12 - Monohydrolysis of Diethyl 2-(2-bromobenzyl)-2-methylmalonate}

The large fluctuation in yield for the reaction is likely due to greater difficulty in achieving very slow addition of the $\mathrm{NaOH}$ on smaller scales, thus smaller attempts ended up in poorer yields. Mechanical addition with a motorized syringe would make this addition simpler in the future.

With a reliable method to produce the monohydrolyzed product on hand, the next step was to make the 2-(t-butyl)phenylamide and 2-biphenylamide analogs. The same conditions that were used for the conversion of the malonic acids, $\mathbf{6}$ and 7, to the malonamides, $\mathbf{8}$ and $\mathbf{9}$, were used for the mono acid mono ester conversion, as seen in Scheme 13.<smiles>CCOC(=O)C(C)(Cc1ccccc1Br)C(=O)O</smiles>

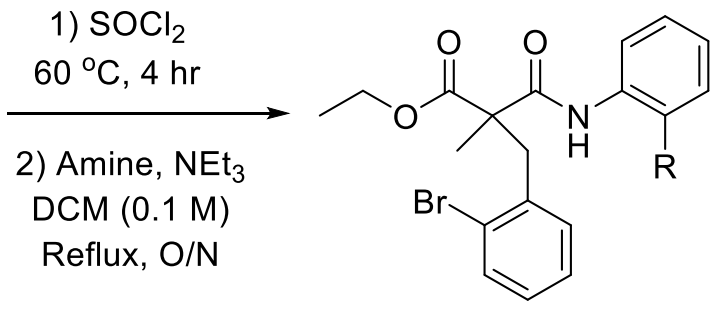

$=\mathrm{H} 13(62 \%)$ 
The reactions forming monoamides, $\mathbf{1 1 - 1 3}$, were still plagued by the problems that occurred in the formation of compounds $\mathbf{8}$ and $\mathbf{9}$. There is still the use of aniline compounds which have lower nucleophilicity and the formation of the acid chloride is difficult to monitor by TLC. The yields of the reactions forming 11-13, are higher than reactions that form $\mathbf{8}$ and $\mathbf{9}$, could be attributed to the fact that only one acid chloride and subsequent nucleophilic attack needs to occur and thus poor yields are not amplified. Also in the reaction to form the malonamide compounds, $\mathbf{8}$ and $\mathbf{9}$, the second amine attack might be impeded sterically after the first amide is formed.

\subsection{Cyclization of Substituted Mono Amide Compounds}

The final step would be to cyclize compounds, 11-13, with catalyst systems including SPHOS and $(R)-\mathrm{Cy}_{2} \mathrm{MOP}$. The cyclization reactions were conducted in the same manner as the

malonamide compounds. Each reaction was run for 48 hours, except compound 13. Since 13 has no bulky substituent on the ortho position of the phenyl ring, a chiral axis is not possible and thus the reaction can only lead to two enantiomeric products. The idea was that if the reaction was stopped early enough, prior to completion there may be some selectivity either for one enantiomer. The general reaction is represented in Scheme 14. 


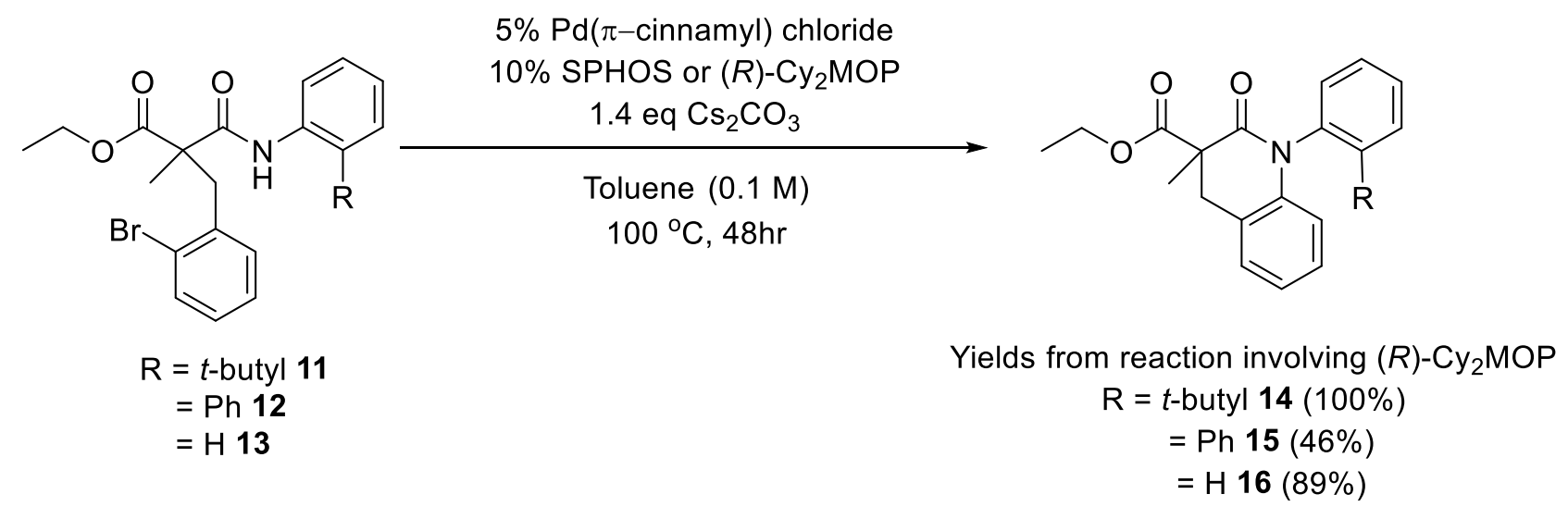

Scheme 14 - Cyclization of Monoamide Compounds

The reaction forming 15 produced the lowest yield of all monoamide compounds 14-16 which was analogous to cyclized malonamide reactions forming $\mathbf{9}$. Both products 9 and $\mathbf{1 5}$ have the 2biphenylamide substituent which again is poorer in reactivity and selectivity for reasons stated earlier. The compound $\mathbf{1 6}$ does not have a comparable malonamide to be measured against but it is interesting to note that without any bulky ortho substituent, the reaction does not go to completion whereas the reaction to form $\mathbf{1 4}$ does. Similar to compound $\mathbf{8}$, the 2-tbutylphenylamide substituted $\mathbf{1 4}$ goes to completion showing that the catalyst system is complimented very well by the ortho $t$-butyl group.

\subsubsection{Analyzing Enantioselectivity and Diastereoselectivity of Cyclized Monoamide Compounds}

The enantio- and diastereoselectivity of the cyclized monoamide compounds 14-16 were analyzed in the same manner as the malonamide compounds 8 and 9 . The ${ }^{1} \mathrm{H}$ NMR of compound 11 when cyclized with the Pd/SPHOS catalyst system shows poor diastereoselective control compared to previous malonamide reactions, as seen in Figure 29. 


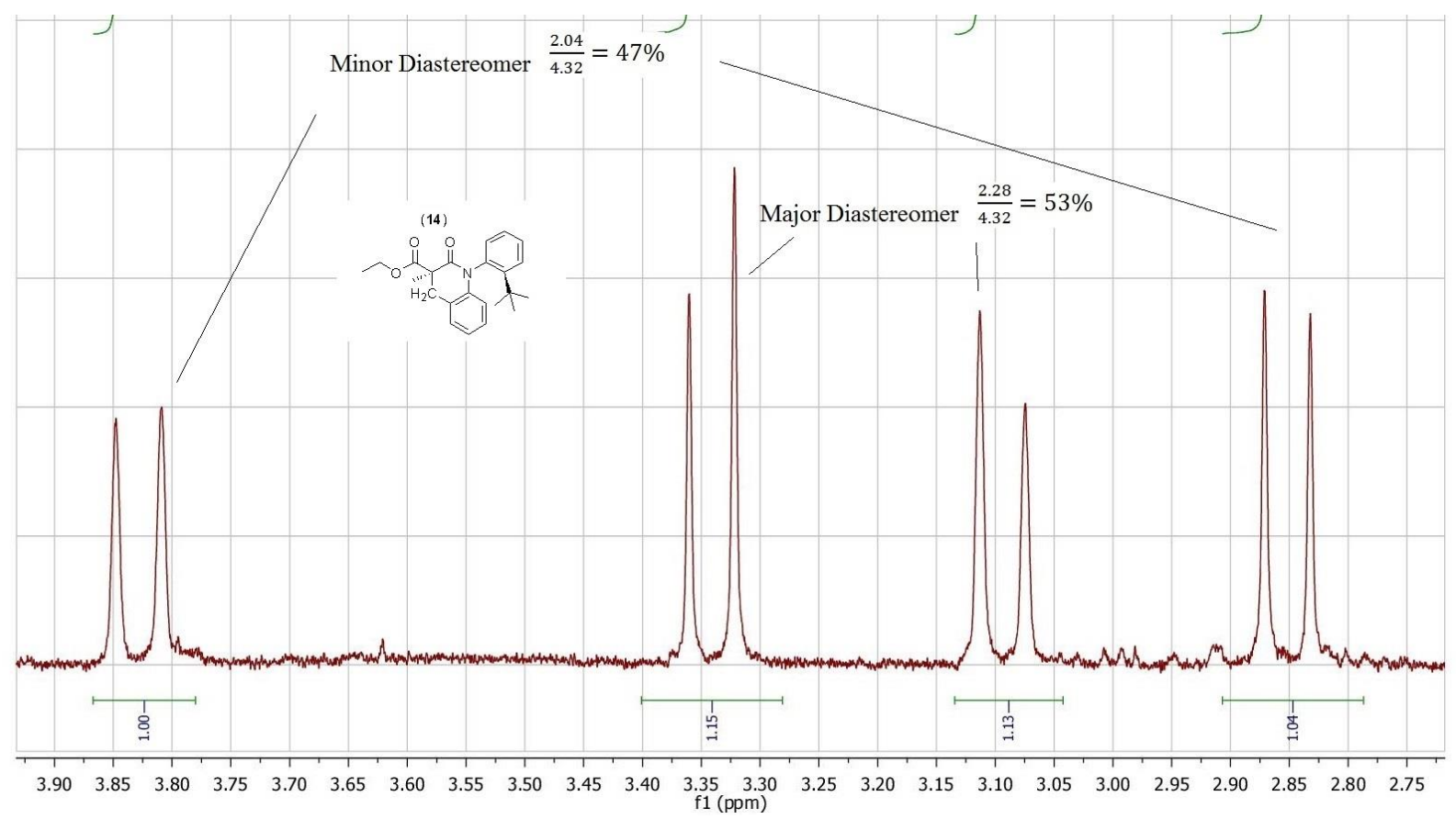

Figure 29 - Diastereotopic Protons of 14 via Pd/SPHOS

The same reaction forming product 14 with the $\mathrm{Pd} /(R)-\mathrm{Cy}_{2} \mathrm{MOP}$ catalyst produced just as good of diastereomer control as the Pd/SPHOS containing reaction, as seen in Figure 30. Throughout this project the diastereomeric ratio is the same for the reactions involving the same substrate but differ in catalyst makeup. This means that the diastereomeric ratio is more dependent on the substrate than on the catalyst. 


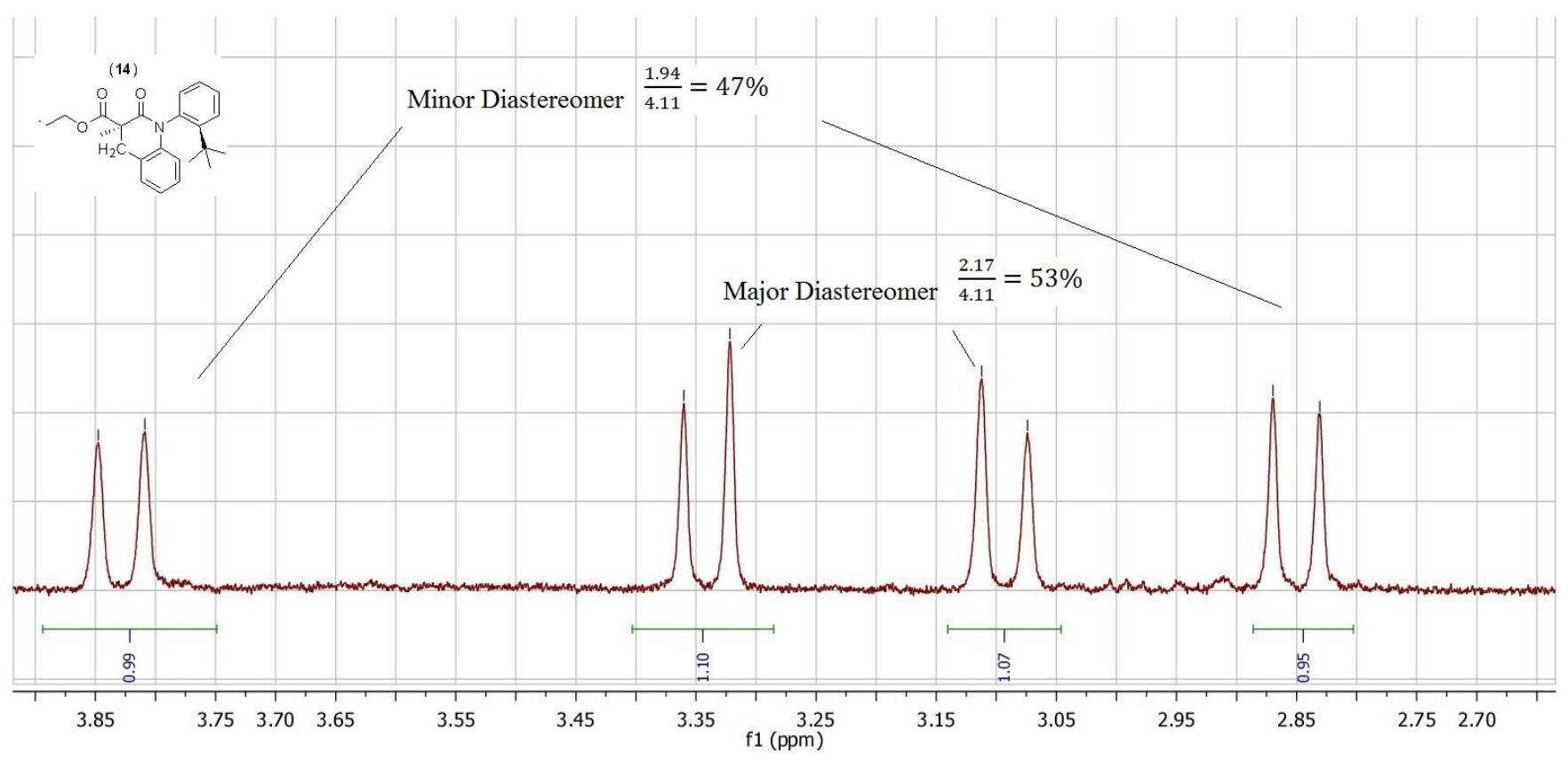

Figure 30 - Diastereotopic Protons for 14 via Pd/(R)-Cy $2 \mathrm{MOP}$

There is an improvement when comparing the diastereomeric ratio of product $\mathbf{1 4}$ to that of product 15. The diastereomeric ratio is 75:25 for $\mathbf{1 2}$ when cyclized with either Pd/SPHOS, as seen in Figure 31. Once again, it might be due to the substrate and how it interacts with the catalysts to produce the diastereomer. Future research into precatalyst systems could shed light on the interactions of the catalyst and the substrate. 


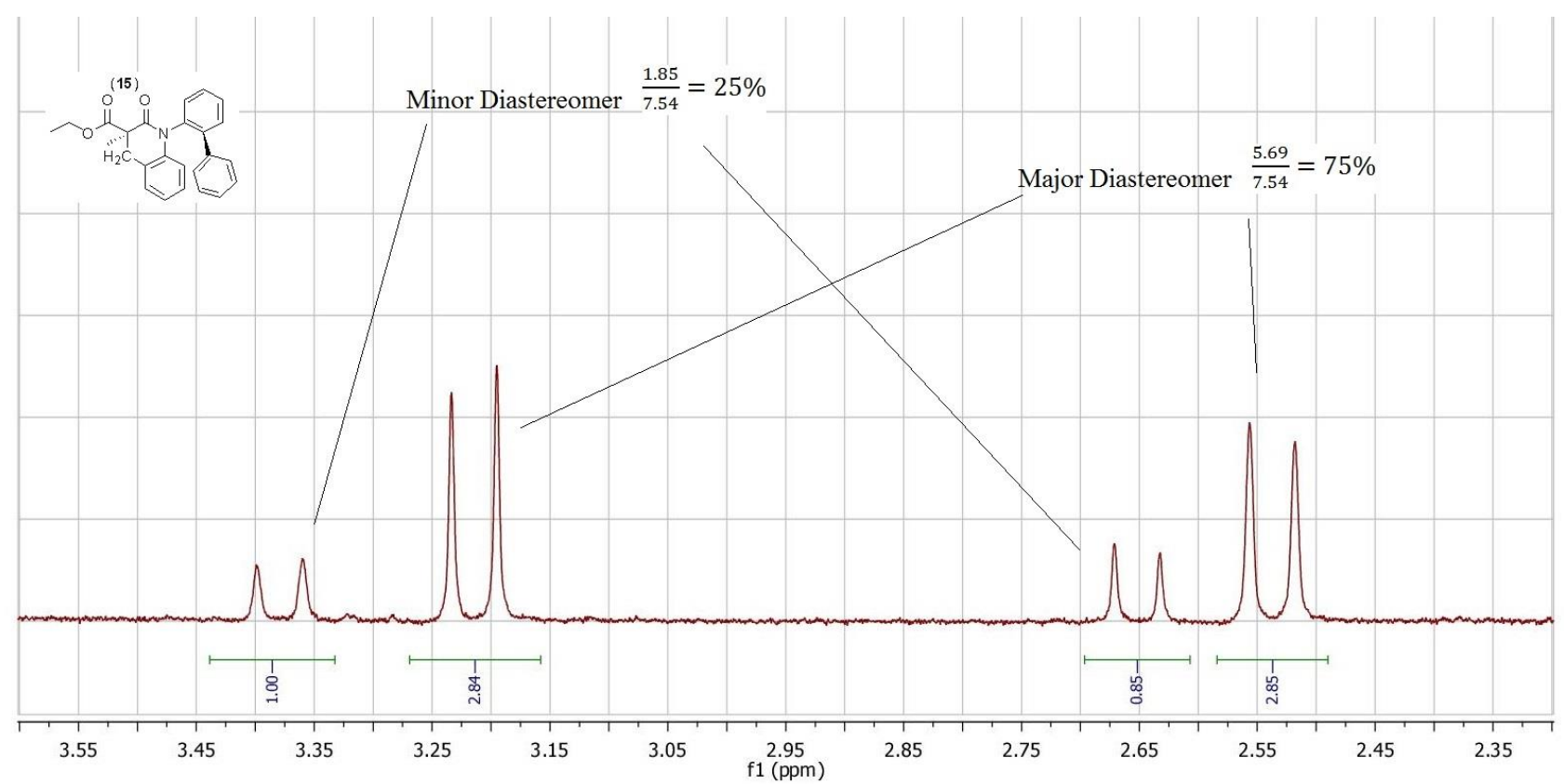

Figure 31 - Diastereotopic Protons for 15 via Pd/SPHOS

Diastereomeric enrichment seen in Figure 31, is reproduced when compound $\mathbf{1 5}$ is synthesized by the $\mathrm{Pd} /(R)-\mathrm{Cy}_{2} \mathrm{MOP}$ catalyst, as in Figure 13. 


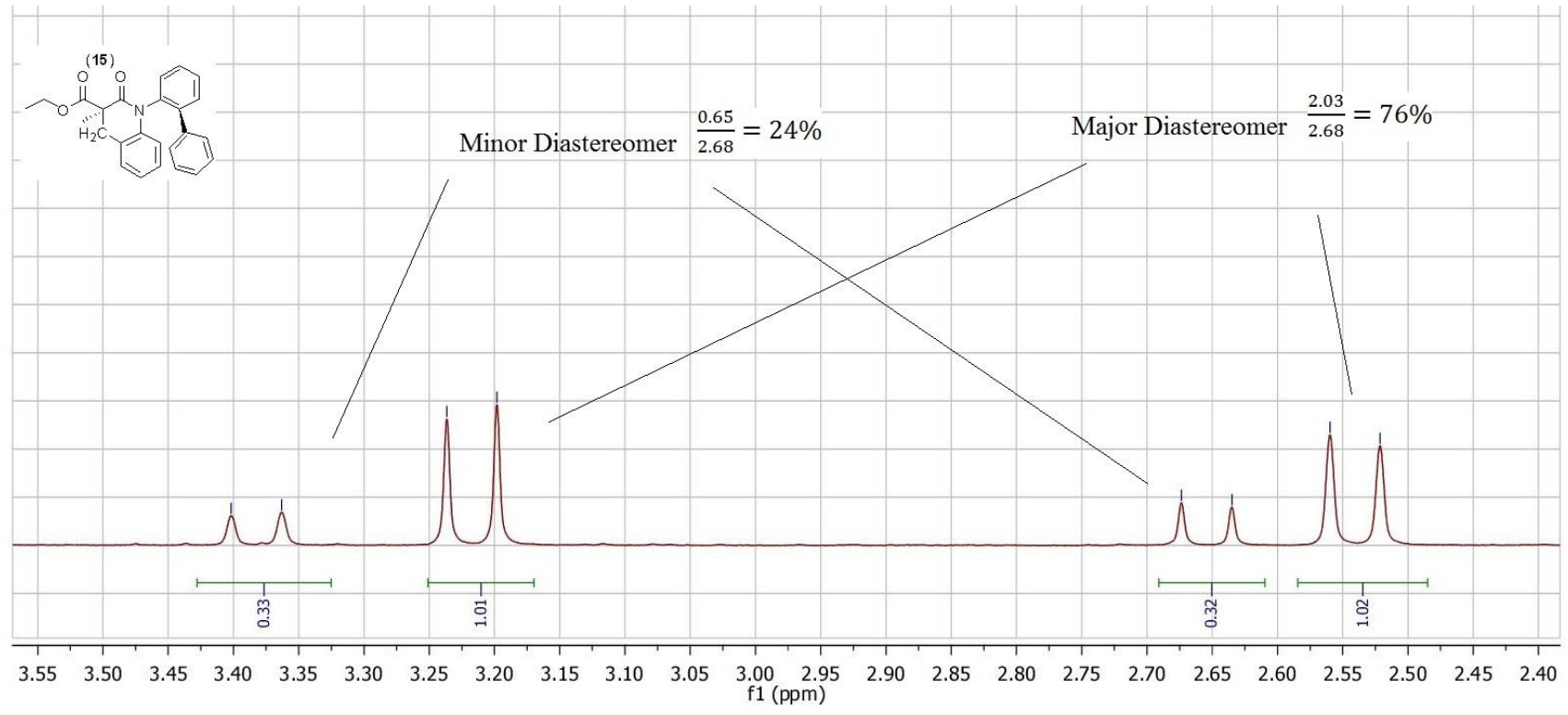

\section{Figure 32 - Similar Diastereoselectivity Seen Producing 15 via Pd/(R)-Cy $2 \mathrm{MOP}$}

Since the substrate $\mathbf{1 3}$ does not have the potential to form and not a chiral axis, there are no diastereomers that are present and thus only a single set of doublets are produced in the ${ }^{1} \mathrm{H}$ NMR of both the $\mathrm{Pd} / \mathrm{SPHOS}$ and $\mathrm{Pd} /(R)-\mathrm{Cy}_{2} \mathrm{MOP}$ reactions, as seen in Figure 33.

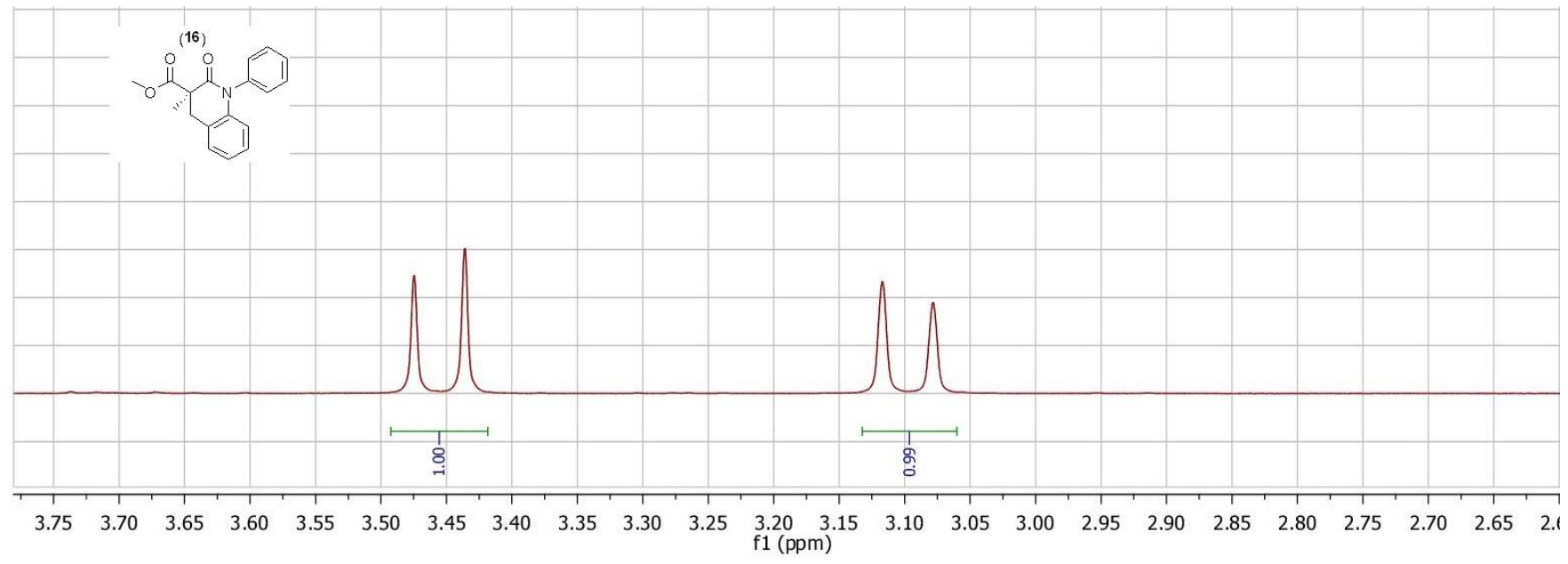

Figure 33 - Cyclization Forming 16 Only Produces Enantiomers 
Analysis of the cyclized monoamide compounds 14-16 with HPLC has proven to be difficult. HPLC conditions in order to separate all four diastereomers of $\mathbf{1 4}$ have been found. But conditions to successfully separate all four diastereomers of $\mathbf{1 5}$ and enantiomers of $\mathbf{1 6}$ have not yet been discovered. Once again, the product 14 cyclized by Pd/SPHOS allows the identification of the diastereomeric peaks in the chromatogram, as seen in Figure 34.

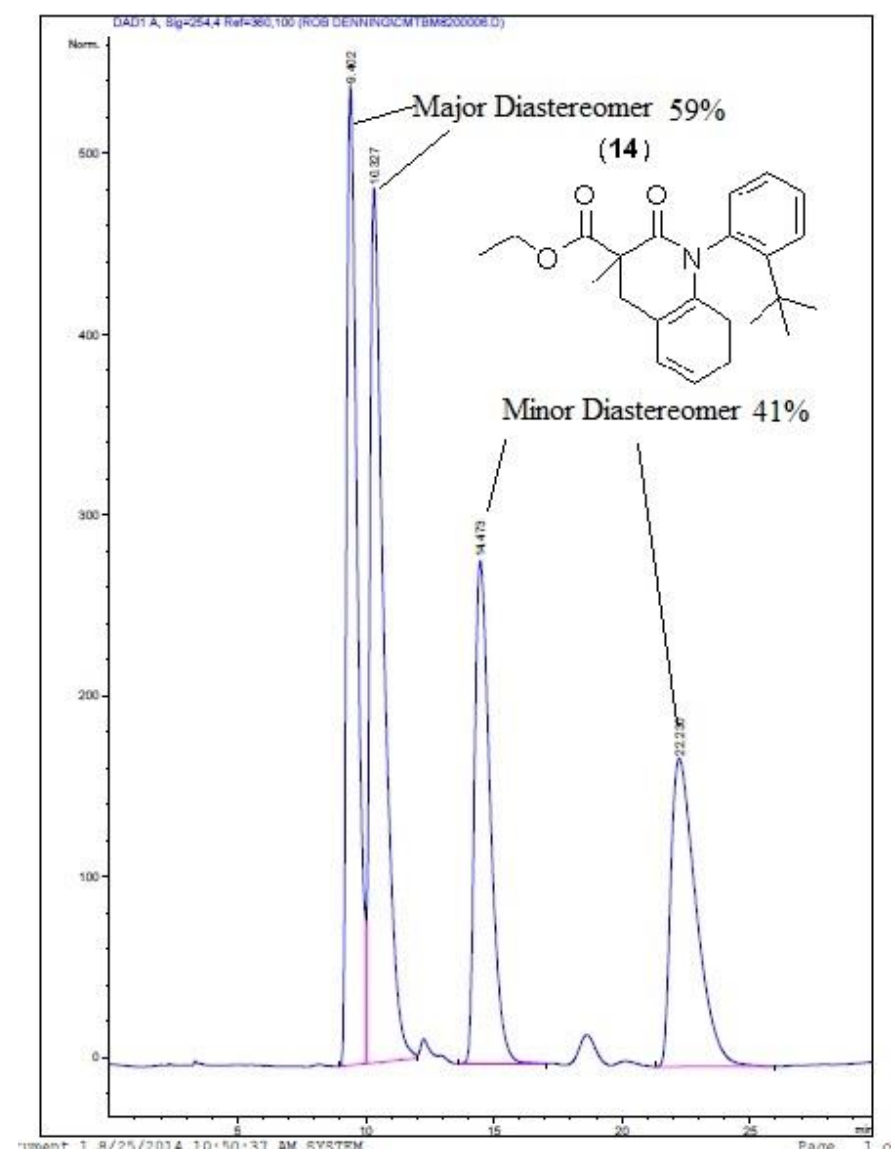

\section{Figure 34 - HPLC Chromatogram of 14 via Pd/SPHOS}

It is evident that the first two peaks represent the major diastereomer and the last two peaks represent the minor diastereomer. Using this information the analysis of the reaction forming $\mathbf{1 5}$ 
with $\mathrm{Pd} /(R)-\mathrm{Cy}_{2} \mathrm{MOP}$ can be done to calculate both the diastereomeric ratio and enantiomeric excess, the HPLC chromatogram is seen in Figure 35.

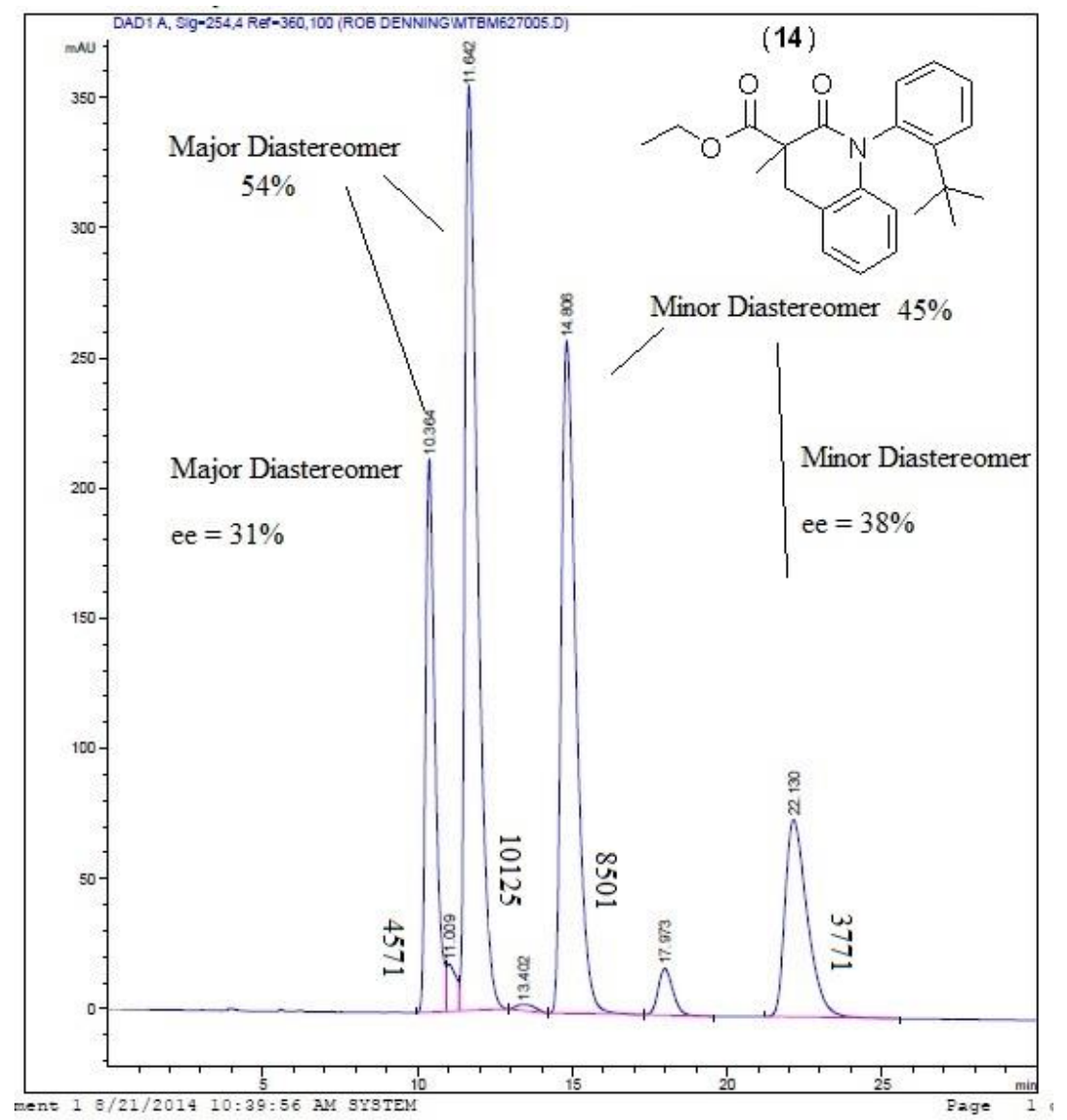

Figure 35 - HPLC Chromatogram forming Product 14 via Pd/(R)-Cy ${ }_{2} \mathrm{MOP}$

As stated earlier, the HPLC conditions to fully resolve the four diastereomers of $\mathbf{1 5}$ could not be found. However, the diastereomeric ratio can be calculated since the diastereomers are separated, shown in Figure 36. 


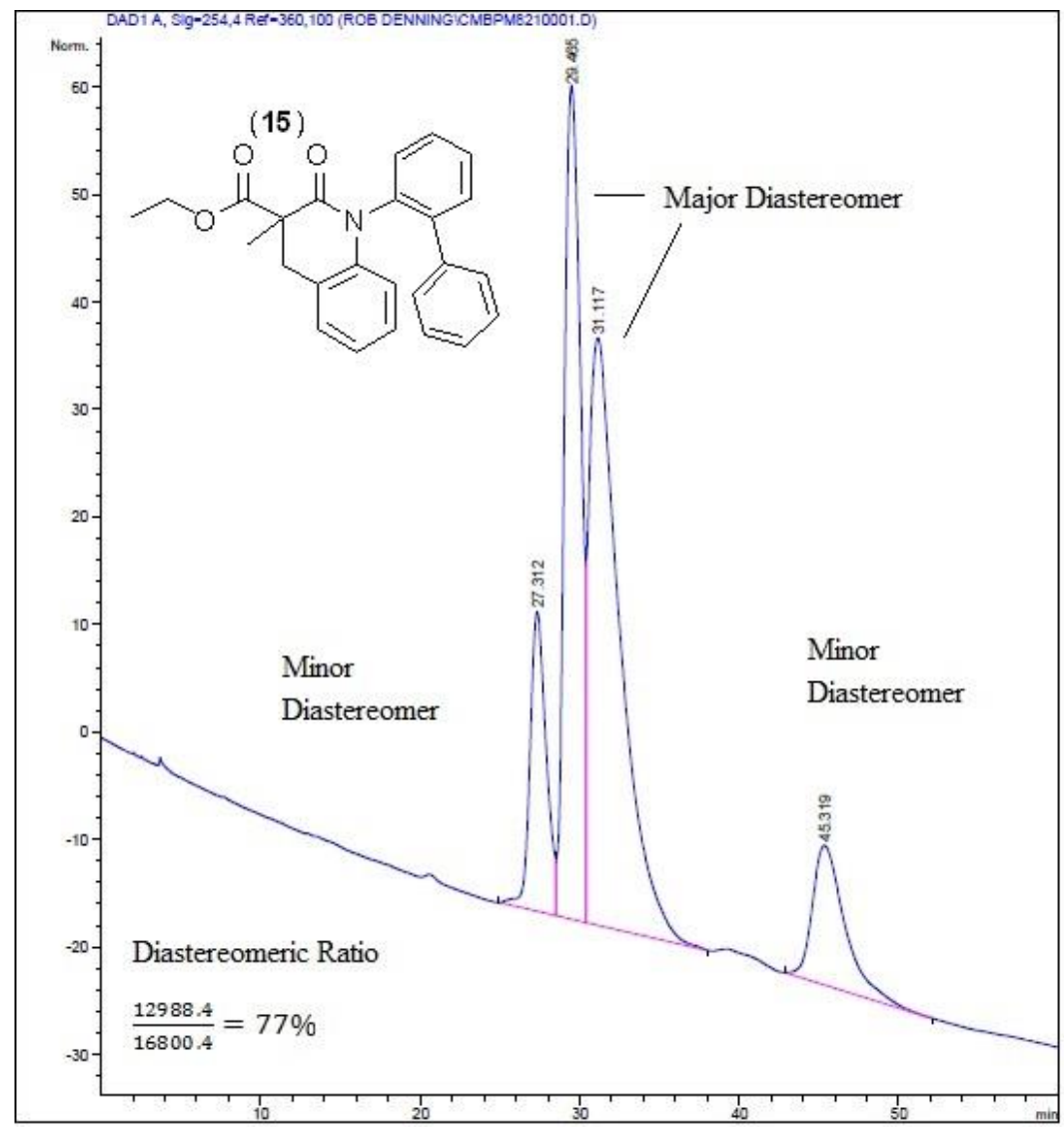

Figure 36 - Unresolved Chromatogram of 15 via Pd/SPHOS

This monoamide reaction scheme was pursued to show the potential substrate directing effects on the overall diastereomeric and enantiomeric selectivity of the reaction. Unfortunately, to date, HPLC conditions to resolve enantiomers of $\mathbf{1 6}$ have not been found. Also there seems to be some inconsistent results creating non-comparable chromatograms for compound $\mathbf{1 5}$ cyclized by $\mathrm{Pd} /(R)-\mathrm{Cy}_{2} \mathrm{MOP}$. The results for the $\mathrm{dr}$ (by NMR and HPLC) and er (by HPLC) are shown in Table 2. 


\begin{tabular}{|l|c|c|c|c|}
\hline Product & NMR dr & HPLC dr & Major Diastereomer ee & Minor Diastereomer ee \\
\hline $\mathbf{1 4}$ via SPHOS & $53 \%$ & $59 \%$ & NA & NA \\
\hline $\mathbf{1 4}$ via (R)-Cy ${ }_{2} \mathrm{MOP}$ & $53 \%$ & $54 \%$ & $31 \%$ & $38 \%$ \\
\hline $\mathbf{1 5}$ via SPHOS & $75 \%$ & $77 \%$ & NA & NA \\
\hline $\mathbf{1 5}$ via (R)-C $y_{2} \mathrm{MOP}$ & $75 \%$ & & & NA \\
\hline $\mathbf{1 6}$ via SPHOS & NA & NA & NA & \\
\hline $\mathbf{1 6}$ via (R)-C $y_{2} \mathrm{MOP}$ & NA & NA & & \\
\hline
\end{tabular}

\section{Table 2 - Enatioselectivity and Diastereoselectivity of the Cyclization of 14, 15 and 16 by SPHOS and $(R)-\mathrm{Cy}_{2} \mathrm{MOP}$}

Comparing Table 2 with Table 1 with respect to the $\mathrm{dr}$ of the compounds, previously it was the compound with the $t$-butyl substituent $\mathbf{8}$ that had complete diastereoselectivity, but in the case with mono amide compounds the diastereoselectivity for the biphenyl compound $\mathbf{1 5}$ has held constant but is now much higher than the $t$-butyl compound 14. It is also evident by the HPLC that there is degradation in the enantioselectivity of the compounds as well. This would give the impression that either the steric nature of the distant amide is directing the enantioselectivity or impacting the catalyst in a way that helps it form one enantiomer.

\subsubsection{Kinetics Experiment of the Cyclization Reaction of 11 with $(R)-\mathrm{Cy}_{2} \mathrm{MOP}$ and $(R)$ - BINAP}

The kinetics of the cyclization reaction of $\mathbf{1 1}$ was studied to investigate if there was a preference towards consuming a single enantiomer of $\mathbf{1 1}$ or producing a single diastereomer/enantiomer of $\mathbf{1 4}$. HPLC conditions were optimized so the peaks for the starting material did not overlap with the peaks for the product. Figure 37 shows an example chromatogram a mixture of $\mathbf{1 1}$ and $\mathbf{1 4 .}$ 


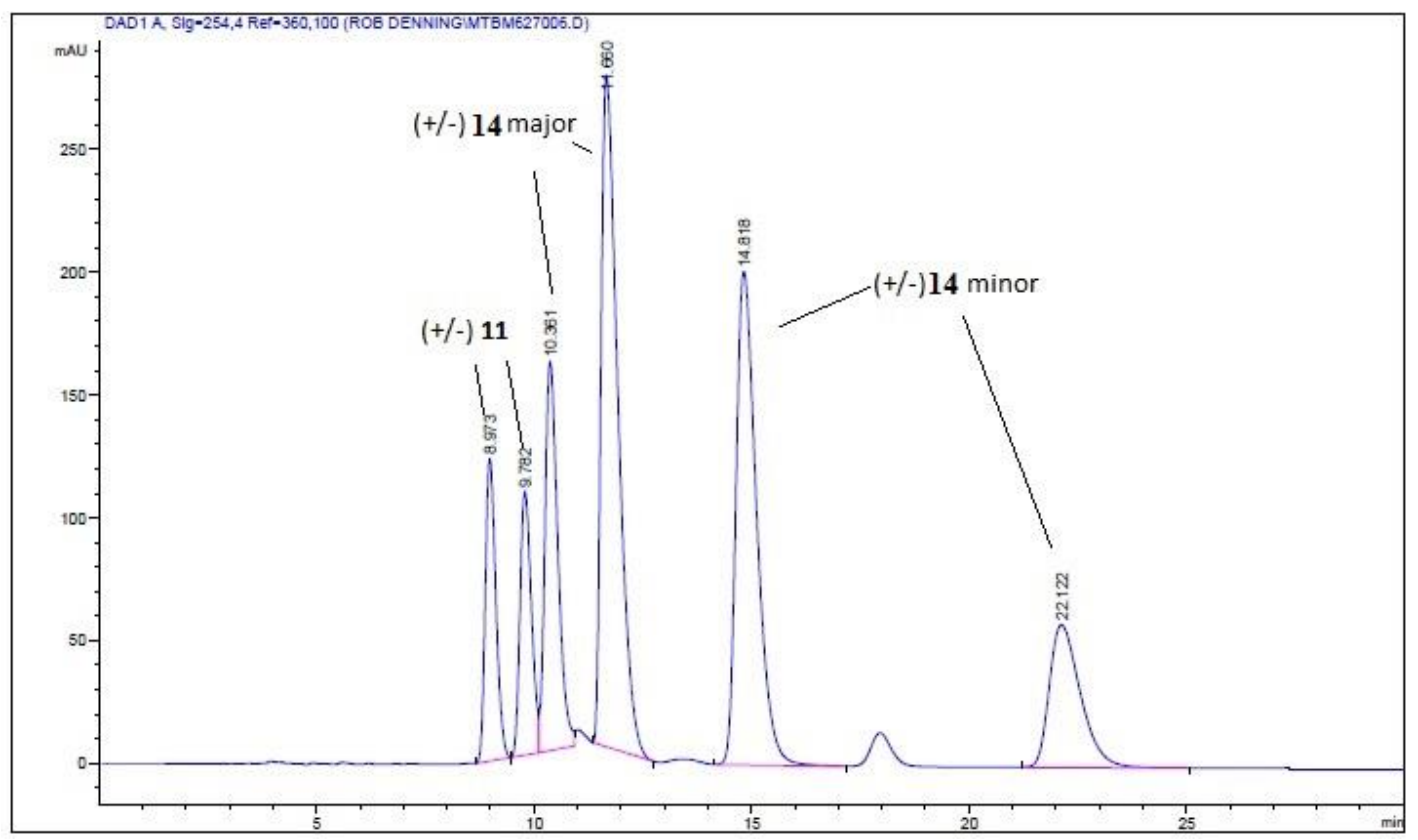

Figure 37 - Optimized HPLC Conditions to Identify 11 and 14

The reaction was done according to the condition in Scheme 14, with samples of the reaction being taken at time intervals; $15 \mathrm{~min}, 30 \mathrm{~min}, 45 \mathrm{~min}, 1 \mathrm{hr}, 2 \mathrm{hr}, 4 \mathrm{hr}, 6 \mathrm{hr}, 24 \mathrm{hr}$, and 48 hr. The drops were then diluted in $1 \mathrm{~mL}$ of $10 \%$ IPA/Hexanes and analyzed by HPLC. At the time of the experiments the absorption coefficients of all compounds in the reaction were not known. Thus quantification of the drop was not done, which could have led to the determination of the amounts of each compound present. Since the drop was not quantified, percent areas are shown in Table 3 to understand the amount of consumption/production as the reaction progresses. This reaction was not monitored by NMR since the enantiomers of the starting material, 11, and the two sets of enantiomers of the product, 14, cannot be seen since they are magnetically equivalent. 
<smiles>CCOC(=O)C(C)(Cc1ccccc1Br)C(=O)Nc1ccccc1C(C)(C)C</smiles>

11 two enantiomers

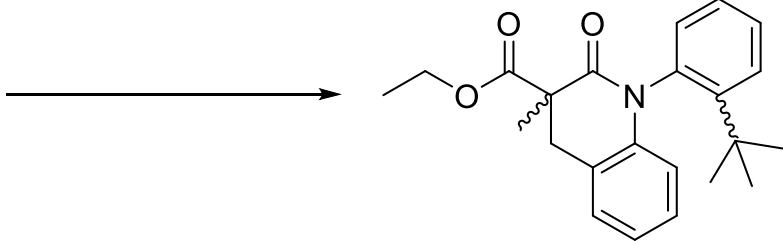

14

four diastereomers

Relative Peak Area (\%)

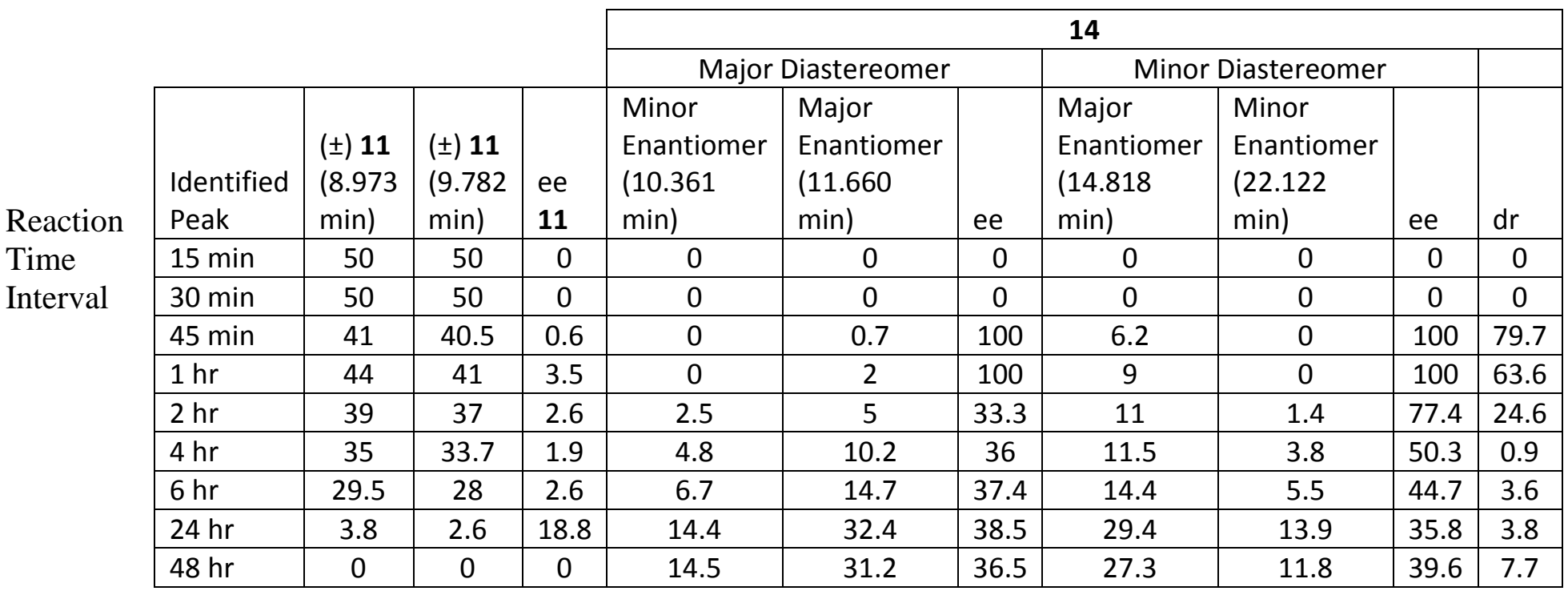

Table 3 - Reaction Kinetics of the Cyclization of 14 with $(R)-\mathrm{Cy}_{2} \mathrm{MOP}$

The first two peaks mentioned $(8.973 \mathrm{~min}$ and $9.782 \mathrm{~min})$ are the enantiomers of the starting material 11, where the last 4 peaks $(10.361,11.660,14.818$ and $22.122 \mathrm{~min})$ are the four diastereomers of the product. Over the course of 48 hours each enantiomer of $\mathbf{1 1}$ is consumed at roughly the same rate. Looking at the ( \pm ) $\mathbf{1 4}$ major diastereomer peaks, there is an initial selectivity seen at the 45 min mark, but there is only a small amount of major enantiomer present. The major enantiomer has an overall percentage of 31.2 percent at 48 hours, giving a 36.5\% ee. With the $( \pm) \mathbf{1 4}$ minor peaks, the last peak takes a while before it is seen in the HPLC, 
two hours after the reaction has started. The ee for the ( \pm ) $\mathbf{1 4}$ minor peaks, which is $39.6 \%$ ee, is similar to the $( \pm) \mathbf{1 4}$ major peaks.

The kinetics experiment was also repeated with $(R)$-BINAP and $(R)$-DTBM-SEGPHOS but by HPLC analysis no reaction had occurred.

\subsection{Synthesis of $(R)-\mathrm{Cy}_{2} \mathrm{MOP}$}

The ligand of choice for our studies, $(R)-\mathrm{Cy}_{2} \mathrm{MOP}$, is not commercially available. The source of the chirality comes from the starting material, $(R)$-BINOL. The BINOL is methylated as in Scheme 15.
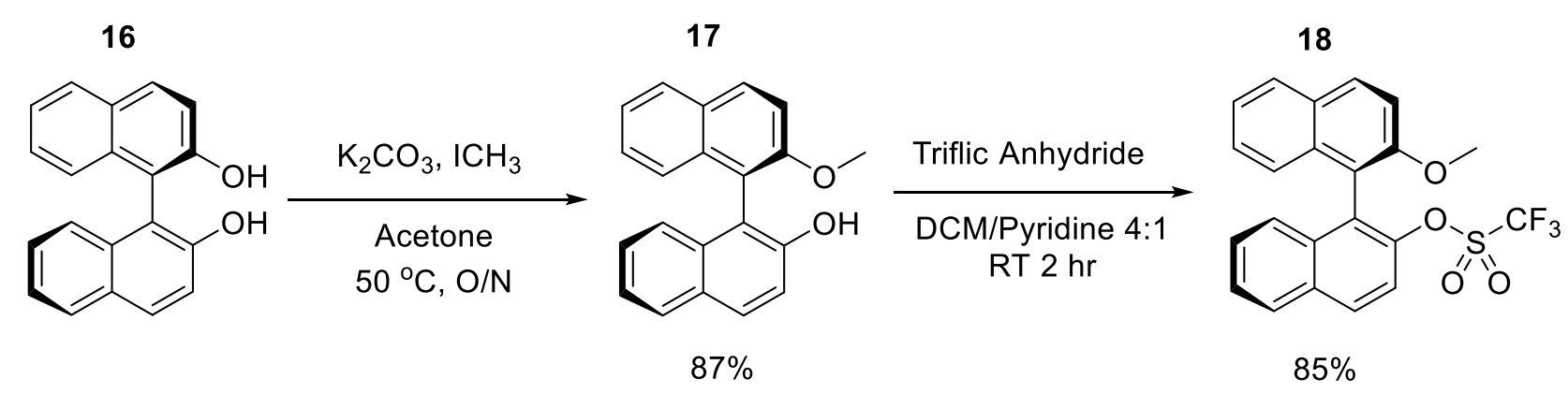

\section{Scheme 15 - Methylation and Triflation of $(R)$-BINOL}

This reaction was a difficult one to make the desired product, as a lot of dimethylated byproduct can be created. The extremely slow addition of the iodomethane with high stirring helped this reaction achieve the good yield observed.

The following reaction to form $\mathbf{1 8}$ also proceeded with good yields. Previous attempts required stirring overnight to achieve good results, but the slow addition of the triflic anhydride and maintaining a concentrated solution allowed this reaction to consume all of the starting 
material in two hours. With a usable amount of $(R)-\mathbf{1 8}$ on hand a large scale reaction was done to prepare the active ligand $(R)-\mathrm{Cy}_{2} \mathrm{MOP}$.

The reaction conditions to make $(R)-\mathrm{Cy}_{2} \mathrm{MOP}$ are similar to that of the BuchwaldHartwig cross-coupling reaction studied in this thesis. The Buchwald-Hartwig reaction involves an aryl-halide and an amine, whereas the reaction to produce $(R)-\mathrm{Cy}_{2} \mathrm{MOP}$ involves the aryltriflate and a phosphine, both reactions use a phosphorus bound palladium catalyst. The reaction is shown in Scheme 16.

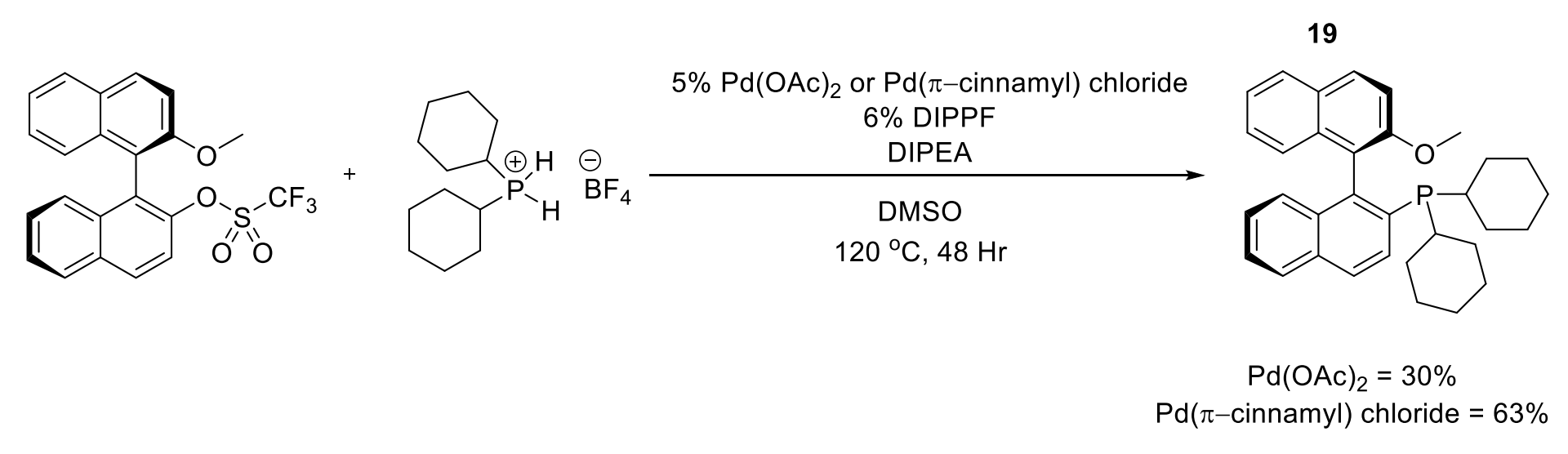

\section{Scheme 16 - Synthesis of $(R)-\mathrm{Cy}_{2} \mathrm{MOP}$ from $(R)$-Me-BINOL-Otf}

The range in yield can be attributed to the switch to the $\operatorname{Pd}(\pi$-cinnamyl) chloride from the palladium acetate. The largest scale this reaction was ran at was $1.16 \mathrm{mmol}$ with a yield of 350 mg $(63 \%)$ there was more than enough to carry out the remainder of the cyclization experiments. The $(R)-\mathrm{Cy}_{2} \mathrm{MOP}$ was compared by HPLC against the racemic $\mathrm{Cy}_{2} \mathrm{MOP}$ that was kindly prepared by Ms. Nande Wright following the same procedure outlined here but starting with racemic BINOL. When the $( \pm)-\mathrm{Cy}_{2} \mathrm{MOP}$ was analyzed by HPLC, there are two peaks observed, at retention times 17.065 and $19.374 \mathrm{~min}$. Allowing the analysis of the enantiopurity of the $(R)$ $\mathrm{Cy}_{2} \mathrm{MOP}$, which only has one peak at 19.186 min, ensuring a $R$ enantiopure conformer. 


\section{Conclusion}

With the use of $(R)$-dicyclohexyl(2'-methoxy-[1,1'-binaphthalen]-2-yl)phosphane, $(R)$ $\mathrm{Cy}_{2} \mathrm{MOP}$ in the Buchwald-Hartwig, excellent enantio- and diastereoselectivity of substituted malonamides can be seen (up to $90 \%$ and $100 \%$, respectively). The selectivity seen is attributed to the effect of the steric bulk on the ligand playing a key role. This system was expanded to the substrate $N 1, N 3$-di([1,1'-biphenyl]-2-yl)-2-(2-bromobenzyl)-2-methylmalonamide but lower selectivity was observed in this case.

To investigate the mechanism further, monoamide malonamide compounds were synthesized. Cyclization of the monoamide compounds would determine if the $(R)-\mathrm{Cy}_{2} \mathrm{MOP}$ ligand or the substrate's chiral center is influencing the stereochemistry of the chiral axis. Once the cyclization reactions were done, there was a lot of loss in enantio- and diastereoselectivies as this could be due to the lack of steric bulk further away from the catalytic site. HPLC analysis of the molecules proved to be difficult, and only ethyl 1-(2-(tert-butyl)phenyl)-3-methyl-2-oxo1,2,3,4-tetrahydroquinoline-3-carboxylate was fully resolved.

Finally, the synthesis of $(R)-\mathrm{Cy}_{2} \mathrm{MOP}$ was done in a three step process, compared to the 8 step process as seen in the literature. Successful characterization and HPLC analysis showed that the chirality of the molecule was retained completely throughout the synthesis.

Future work should isolate the precatalyst systems of the catalyst with these groups of substrates to better understand the interaction occurring. The kinetics reaction of cyclized malonamide compounds needs to be done to fully understand the selectivities that have been seen, or develop models that better reflect the initial findings of Matarazzo. 


\section{Experimental}

Chemicals and solvents were purchased from Sigma-Aldrich. All ${ }^{1} \mathrm{H}$ NMR, ${ }^{13} \mathrm{C}$ NMR, ${ }^{19} \mathrm{~F}$ NMR and ${ }^{31} \mathrm{P}$ NMR spectra were collected on a Bruker $400 \mathrm{MHz}$ NMR. All HPLC chromatograms were recorded on an Agilent 1260 Infinity machine using a photo diode array and a $4.6 \mathrm{~mm} \mathrm{x}$ 250 mm Chiralpak OD-H column.

\subsection{Synthesis Towards Substituted Malonamides}

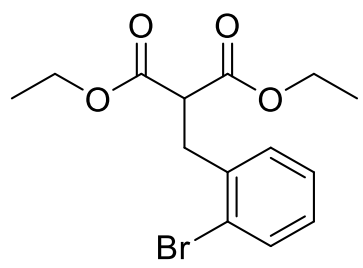

\subsubsection{Diethyl 2-(2-bromobenzyl)malonate (2)}

Sodium hydride $(0.6075 \mathrm{~g}, 15.188 \mathrm{mmol})$ was suspended in dry THF (30 mL, 0.5 M). The reaction was cooled to $0{ }^{\circ} \mathrm{C}$ and diethyl malonate $(2.31 \mathrm{~mL}, 15.188 \mathrm{mmol})$ was added. After 30 minutes of stirring at $0{ }^{\circ} \mathrm{C}$, there was no more elution of $\mathrm{H}_{2}$ gas. 2-Bromobenzyl bromide (4.1757 g, $16.7068 \mathrm{mmol}$ ) was added and the reaction was heated to reflux overnight. The reaction was cooled to room temperature and concentrated under vacuum. The crude mixture was redissolved in EtOAc $(60 \mathrm{~mL})$, and washed with water $(3 \times 30 \mathrm{~mL})$. Once dried over magnesium sulphate and concentrated under vacuum, the crude mixture was purified via flash chromatography eluting with 15\% EtOAc:Hexanes. The reaction yielded a colourless oil in 90\% TLC (20\% EtOAc:Hex $) \mathrm{R}_{\mathrm{f}}=0.23 .{ }^{1} \mathrm{H}$ NMR $\left(\mathrm{CDCl}_{3}, 400 \mathrm{MHz}\right) \delta 7.53-7.51(\mathrm{~m}, 1 \mathrm{H}, \mathrm{Ar}), 7.25-7.18(\mathrm{~m}, 2 \mathrm{H}$, Ar), 7.10-7.06 (m, 1H, Ar), 4.18-4.12 (m, 4H, $\left.\mathrm{CH}_{2} \mathrm{CH}_{3}\right), 3.84$ (t, J=8 Hz, 1H, CHCH 2$) 3.33$ (d,

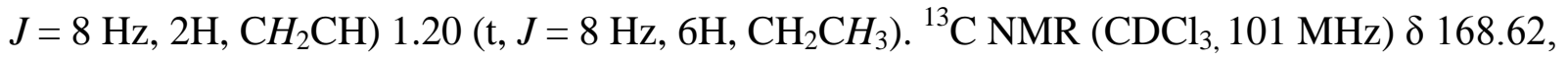
$137.10,132.91,131.44,128.57,127.39,124.55,61.45,51.48,41.63,35.02,14.02,13.97$. 


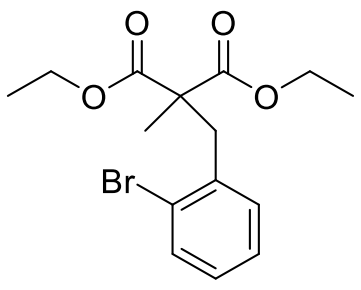

\subsubsection{Diethyl 2-(2-bromobenzyl)-2-methylmalonate (3)}

Sodium hydride $(2.4359 \mathrm{~g}, 60.92 \mathrm{mmol})$ was suspended in dry THF $(120 \mathrm{~mL}, 0.5 \mathrm{M})$. The reaction was cooled to $0{ }^{\circ} \mathrm{C}$ and diethyl 2-(2-bromobenzyl)malonate $(4.0108 \mathrm{~g}, 12.184 \mathrm{mmol})$ was added slowly. After 30 minutes of stirring at $0{ }^{\circ} \mathrm{C}$, there was no more elution of $\mathrm{H}_{2}$ gas. Iodo methane $(3.79 \mathrm{~mL}, 60.92 \mathrm{mmol})$ was added and the mixture was heated to reflux overnight. The reaction was quenched with a drop of ethanol, and concentrated under vacuum. The crude oil was redissolved in EtOAc $(48 \mathrm{~mL})$ and washed with water $(3 \times 24 \mathrm{~mL})$. The crude product was dried over magnesium sulphate and concentrated under vacuum. It was not possible to isolate the crude product from its starting material via flash chromatography or crystallization.

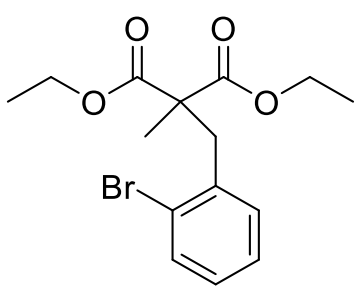

\subsubsection{Diethyl 2-(2-bromobenzyl)-2-methylmalonate (3)}

Sodium hydride (1.2823 g, $32.054 \mathrm{mmol})$ was suspended in dry THF (60 mL, 0.5 M). The reaction was cooled to $0{ }^{\circ} \mathrm{C}$ and diethyl 2-methylmalonate $(4.97 \mathrm{~mL}, 29.14 \mathrm{mmol})$ was added slowly. Once there was no more elution of $\mathrm{H}_{2}$ gas, 2-bromobenzyl bromide was added. The solution was heated to reflux overnight, cooled and concentrated under vacuum. The mixture was diluted in EtOAc $(120 \mathrm{~mL})$, and washed with water $(3 \times 60 \mathrm{~mL})$. Once dried over magnesium sulphate and concentrated under vacuum, the crude product was purified via flash 
chromatography eluting 10\% EtOAc:Hexanes. The reaction gave a colourless oil with a mass of $8.5374 \mathrm{~g}, 89 \%$. TLC (15\% EtOAc:Hexanes ) $\mathrm{R}_{\mathrm{f}}=0.20 .{ }^{1} \mathrm{H}$ NMR (400 MHz, CDCl3) $\delta$ 7.56-7.54 (m, 1H, Ar), $7.24-7.15$ (m, 2H, Ar), $7.12-7.05$ (m, 1H. Ar), $4.32-4.13$ (m, 4H, $\mathrm{CH}_{2} \mathrm{CH}_{3}$ ), $3.53\left(\mathrm{~s}, 2 \mathrm{H}, \mathrm{CH}_{2}\right), 1.40\left(\mathrm{~s}, 3 \mathrm{H}, \mathrm{CH}_{3}\right), 1.27\left(\mathrm{t}, J=7.1 \mathrm{~Hz}, 6 \mathrm{H}, \mathrm{CH}_{2} \mathrm{CH}_{3}\right) .{ }^{13} \mathrm{C} \mathrm{NMR}(101 \mathrm{MHz}$, $\left.\mathrm{CDCl}_{3}\right) \delta 171.83,136.41,133.07,131.37,128.44,127.26,126.26,61.45,55.06,39.34,19.36$, 13.97.

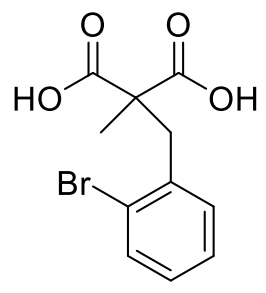

\subsubsection{2-(2-Bromobenzyl)-2-methylmalonic acid (5)}

Diethyl 2-(2-bromobenzyl)-2-methylmalonate $(5.0 \mathrm{~g}, 15.18 \mathrm{mmol})$ was dissolved in a minimum amount of $\mathrm{MeOH}$. While stirring, aqueous 4M sodium hydroxide (15.2 mL, $60.74 \mathrm{mmol})$ was added and the solution was heated to reflux overnight. The reaction was cooled and diluted with water $(15.2 \mathrm{~mL})$. The reaction was extracted with $\mathrm{Et}_{2} \mathrm{O}(3 \times 15 \mathrm{~mL})$, acidified with $6 \mathrm{~N} \mathrm{HCl}$ to $\mathrm{pH}$ 3 over ice and the remaining solution was extracted with EtOAc $(3 \times 15 \mathrm{~mL})$. The organic phase was dried over magnesium sulphate and concentrated under vacuum to yield a white solid (3.7914 g, 91.5\%) $\mathrm{The}^{\mathrm{Et}} \mathrm{O}_{2} \mathrm{O}$ extracts were concentrated under vacuum to afford $0.643 \mathrm{~g}$ of starting material (effectively 100\% based on recovered starting material). TLC (20\%

EtOAc:Hexanes) $\mathrm{R}_{\mathrm{f}}=0.30{ }^{1} \mathrm{H}$ NMR (400 MHz, Acetone) $\delta$ 7.63-7.61 (m, 1H, Ar), 7.40-7.37 (m, $1 \mathrm{H}, \mathrm{Ar}), 7.32-7.28(\mathrm{~m}, 1 \mathrm{H}, \mathrm{Ar}), 7.20-7.16(\mathrm{~m}, 1 \mathrm{H}, \mathrm{Ar}), 3.55\left(\mathrm{~s}, 2 \mathrm{H}, \mathrm{CH}_{2}\right), 1.36\left(\mathrm{~s}, 3 \mathrm{H}, \mathrm{CH}_{3}\right) .{ }^{13} \mathrm{C}$ NMR (101 MHz, Acetone) $\delta 172.36,136.70,132.95,131.43,128.66,127.55,125.90,54.37$, $38.99,18.60$. 


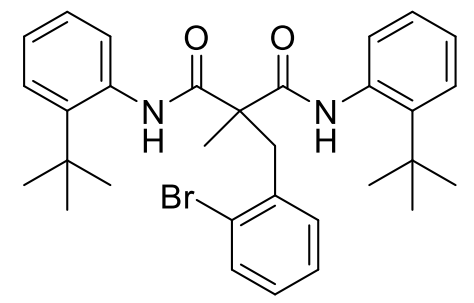

\subsubsection{2-(2-Bromobenzyl)-N1,N3-bis(2-(tert-butyl)phenyl)-2-methylmalonamide (6)}

A round bottom flask was charged with a solution of 2-(2-bromobenzyl)-2-methylmalonic acid $(1.8957 \mathrm{~g}, 6.94 \mathrm{mmol})$ in thionyl chloride $(23 \mathrm{~mL}, 0.3 \mathrm{M})$ and was sealed and heated to $60{ }^{\circ} \mathrm{C}$ for 4 hours. The solution was cooled and concentrated under vacuum. The residual mixture was redisolved in $\mathrm{CHCl}_{3}(23 \mathrm{~mL})$ and concentrated under vacuum a total of three times. The crude mixture was redissolved in DCM $(70 \mathrm{~mL}, 0.1 \mathrm{M})$ and cooled to $0{ }^{\circ} \mathrm{C}$. Once 2-(tert-butyl)aniline $(2.38 \mathrm{~mL}, 15.27 \mathrm{mmol})$ was added slowly over ice, the reaction was stirred at room temperature for an hour. The mixture was then cooled to $0{ }^{\circ} \mathrm{C}$, and triethylamine $(2.13 \mathrm{~mL}, 15.27 \mathrm{mmol})$ was added dropwise and the mixture was heated to reflux overnight. The reaction was cooled to room temperature, washed with $1 \mathrm{M} \mathrm{HCl}(4 \times 70 \mathrm{~mL})$, dried over magnesium sulphate and concentrated under vacuum. The crude mixture was purified via flash chromatography eluting at $20 \%$ EtOAc:Hexanes to yield 1.1213g (30\%) of an off white solid. TLC (EtOAc:Hexanes) $\mathrm{R}_{\mathrm{f}}=0.45$. ${ }^{1} \mathrm{H}$ NMR $\left(400 \mathrm{MHz}, \mathrm{CDCl}_{3}\right) \delta 8.64$ (s, 2H, NH), 7.65 - 7.55 (m, 3H, Ar), 7.48-7.39 (m, 3H, Ar), $7.25-7.14(\mathrm{~m}, 5 \mathrm{H}, \mathrm{Ar}), 7.12-7.08(\mathrm{~m}, 1 \mathrm{H}, \mathrm{Ar}), 3.78\left(\mathrm{~s}, 2 \mathrm{H}, \mathrm{CH}_{2}\right), 1.71\left(\mathrm{~s}, 3 \mathrm{H}, \mathrm{CH}_{3}\right), 1.37(\mathrm{~s}$, $\left.18 \mathrm{H}, \mathrm{C}\left(\mathrm{CH}_{3}\right)_{3}\right) .{ }^{13} \mathrm{C} \mathrm{NMR}\left(101 \mathrm{MHz}, \mathrm{CDCl}_{3}\right) \delta 170.66,142.81,136.22,134.84,133.30,131.54$, $128.77,127.70,127.41,126.73,126.72,126.40,126.10,56.29,42.90,34.56,30.58,18.52,1.02$. 


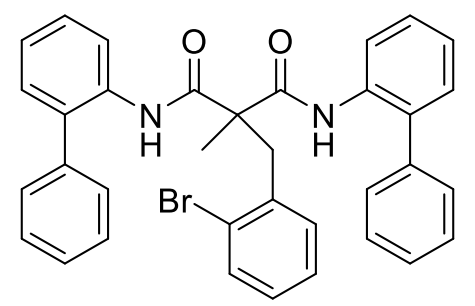

\subsubsection{N1,N3-Di([1,1'-biphenyl]-2-yl)-2-(2-bromobenzyl)-2-methylmalonamide (7)}

A round bottom flask was charged with a solution of 2-(2-bromobenzyl)-2-methylmalonic acid $(1.8957 \mathrm{~g}, 6.94 \mathrm{mmol})$ in thionyl chloride $(23.1 \mathrm{~mL}, 0.3 \mathrm{M})$ and was sealed and heated to $60{ }^{\circ} \mathrm{C}$ for 4 hours. The solution was cooled and concentrated under vacuum. The residual mixture was redisolved in $\mathrm{CHCl}_{3}(23.1 \mathrm{~mL})$ and concentrated under vacuum a total of three times. The crude mixture was redissolved in DCM $(69.4 \mathrm{~mL}, 0.1 \mathrm{M})$ and cooled to $0{ }^{\circ} \mathrm{C}$. Once [1,1'-biphenyl]-2amine $(2.5840 \mathrm{~g}, 15.27 \mathrm{mmol})$ was added slowly over ice, the reaction was stirred at room temperature for an hour. Once cooled to $0{ }^{\circ} \mathrm{C}$, triethylamine $(2.13 \mathrm{~mL}, 15.27 \mathrm{mmol})$ was added dropwise and the mixture was heated to reflux overnight. The reaction was cooled to room temperature, washed with $1 \mathrm{M} \mathrm{HCl}(4 \times 70 \mathrm{~mL})$, dried over magnesium sulphate and concentrated under vacuum. The crude mixture was purified via flash chromatography eluting $20 \%$ EtOAc:Hexanes to yield $2.0188 \mathrm{~g}(49.3 \%)$ of a light yellow compound. TLC (20\% EtOAc:Hexanes) $\mathrm{R}_{\mathrm{f}}=0.33{ }^{1} \mathrm{H}$ NMR $\left(400 \mathrm{MHz}, \mathrm{CDCl}_{3}\right) \delta 8.44(\mathrm{~s}, 2 \mathrm{H}, \mathrm{NH}), 8.13-8.11(\mathrm{~m}, 2 \mathrm{H}$, Ar), $7.58-7.52(\mathrm{~m}, 1 \mathrm{H}, \mathrm{Ar}), 7.43-7.32(\mathrm{~m}, 9 \mathrm{H}, \mathrm{Ar}), 7.25-7.04(\mathrm{~m}, 13 \mathrm{H}, \mathrm{Ar}), 3.37$ (s, 2H, $\left.\mathrm{CH}_{2}\right), 1.06\left(\mathrm{~s}, 3 \mathrm{H}, \mathrm{CH}_{3}\right) .{ }^{13} \mathrm{C}$ NMR $\left(101 \mathrm{MHz}, \mathrm{CDCl}_{3}\right) \delta 169.89,137.69,136.20,134.43,133.31$, $133.12,131.24,130.02,129.25,129.01,128.61,128.26,128.04,127.57,126.18,124.76,121.68$, $56.64,42.59,17.11$. 


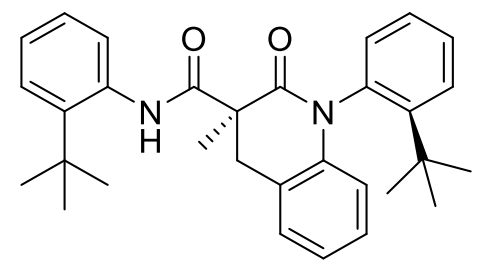

\subsubsection{N,1-Bis(2-(tert-butyl)phenyl)-3-methyl-2-oxo-1,2,3,4-tetrahydroquinoline-3- carboxamide (8)}

A $10 \mathrm{~mL}$ Schlenk flask was charged with 2-(2-bromobenzyl)-N1,N3-bis(2-(tert-butyl)phenyl)-2methylmalonamide (100 mg, $0.182 \mathrm{mmol})$, palladium( $\pi$-cinnamyl) chloride dimer (2.4 mg, $0.00455 \mathrm{mmol})$ and dicyclohexyl(2'-methoxy-[1,1'-binaphthalen]-2-yl)phosphane (8.7 mg, $0.0182 \mathrm{mmol}$ ), with the flask being evacuated and backfilled with $\mathrm{N}_{2}$ in between each addition. Anhydrous toluene $(1.8 \mathrm{~mL}, 0.1 \mathrm{M})$ was added and the solution was evacuated and backfilled with $\mathrm{N}_{2}$ three times. The mixture was heated to $100{ }^{\circ} \mathrm{C}$ for three minutes to dissolve the compounds and cooled to room temperature. $\mathrm{Cs}_{2} \mathrm{CO}_{3}(83.0 \mathrm{mg}, 0.2548 \mathrm{mmol})$ was added under $\mathrm{N}_{2}$ and the solution was heated to $100{ }^{\circ} \mathrm{C}$ for 24 hours. The reaction was cooled, and diluted with EtOAc (5.4 mL). The solution was filtered through celite and concentrated under vacuum. The crude product was purified via flash chromatography, eluting with 5\% EtOAc:Hexanes, to afford $84.3 \mathrm{mg}$ (quantitative) of a white solid. TLC (20\% EtOAc:Hexanes) $\mathrm{R}_{\mathrm{f}}=0.40 .{ }^{1} \mathrm{H}$ NMR (400 $\left.\mathrm{MHz}, \mathrm{CDCl}_{3}\right) \delta 8.41(\mathrm{~s}, 1 \mathrm{H}, \mathrm{NH}), 7.69-7.66(\mathrm{~m}, 1 \mathrm{H}, \mathrm{Ar}), 7.54-7.24(\mathrm{~m}, 7 \mathrm{H}, \mathrm{Ar}), 7.24-6.96$ (m, 6H, Ar), $6.25(\mathrm{~m}, 1 \mathrm{H}, \mathrm{Ar}), 3.82\left(\mathrm{~d}, J=15.6 \mathrm{~Hz}, 1 \mathrm{H}, \mathrm{CH}_{2 \mathrm{a}}\right), 3.13\left(\mathrm{~d}, J=15.6 \mathrm{~Hz}, 1 \mathrm{H}, \mathrm{CH}_{2 \mathrm{~b}}\right)$, $1.82\left(\mathrm{~s}, 3 \mathrm{H}, \mathrm{CH}_{3}\right), 1.40\left(\mathrm{~s}, 9 \mathrm{H}, \mathrm{C}\left(\mathrm{CH}_{3}\right)_{3}\right), 1.29\left(\mathrm{~s}, 9 \mathrm{H}, \mathrm{C}\left(\mathrm{CH}_{3}\right)_{3}\right) .{ }^{13} \mathrm{C} \mathrm{NMR}\left(101 \mathrm{MHz}, \mathrm{CDCl}_{3}\right) \delta$ $173.28,168.29,147.41,142.37,140.69,135.93,135.21,132.22,129.44,129.01,128.71,127.57$, 127.20, 127.07, 126.65, 126.49, 125.91, 123.99, 123.89, 116.63, 50.73, 35.77, 35.23, 34.48, 31.46, 30.57, 24.15. HPLC (Flow rate $=1.0 \mathrm{~mL} / \mathrm{min}, 1 \% \mathrm{IPA}:$ Hexanes $) \mathrm{t}_{\mathrm{R}}$ minor $=5.999 \mathrm{~min}$ 
$($ area $=2030.1)($ single diastereomer $), t_{\mathrm{R}}$ major $=6.413 \mathrm{~min}($ area $=36617.6)($ single

diastereomer $), \mathrm{t}_{\mathrm{R}}$ minor $=6.831 \mathrm{~min}($ area 1998.5) $($ starting material $)$

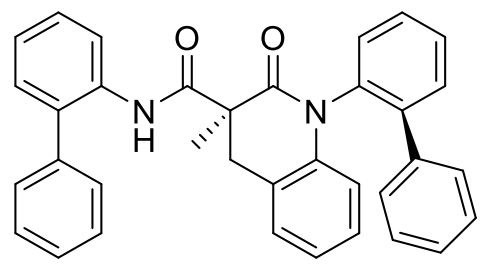

\subsubsection{N,1-Di([1,1'-biphenyl]-2-yl)-3-methyl-2-oxo-1,2,3,4-tetrahydroquinoline-3- carboxamide (9)}

A $10 \mathrm{~mL}$ Schlenk flask was charged with N1,N3-di([1,1'-biphenyl]-2-yl)-2-(2-bromobenzyl)-2methylmalonamide (200 mg, $0.339 \mathrm{mmol}$ ), palladium( $\pi$-cinnamyl) chloride dimer (4.4 mg, $0.0169 \mathrm{mmol}, 5 \%)$ and dicyclohexyl(2'-methoxy-[1,1'-binaphthalen]-2-yl)phosphane (16.2 mg, $0.0339 \mathrm{mmol}, 10 \%$ ), with the flask being evacuated and backfilled with $\mathrm{N}_{2}$ in between each addition. Anhydrous toluene $(3.4 \mathrm{~mL}, 0.1 \mathrm{M})$ was added and the solution was evacuated and backfilled with $\mathrm{N}_{2}$ three times. The mixture was heated to $100{ }^{\circ} \mathrm{C}$ for three minutes to dissolve the compounds and cooled to room temperature. $\mathrm{Cs}_{2} \mathrm{CO}_{3}(154.8 \mathrm{mg}, 0.475 \mathrm{mmol})$ was added under $\mathrm{N}_{2}$ and the solution was heated to $100{ }^{\circ} \mathrm{C}$ for 24 hours. The reaction was cooled, and diluted with EtOAc $(10.2 \mathrm{~mL})$. The solution was filtered through celite and concentrated under vacuum. The crude product was purified via flash chromatography, eluting $10 \%$ EtOAc:Hexanes, to afford a white solid with a mass of $103.44 \mathrm{mg}(60 \%)$, as a mixture of diastereomers. $\mathrm{R}_{\mathrm{f}}=0.25$ (20\% EtOAc:Hexanes) ${ }^{1} \mathrm{H}$ NMR $\left(400 \mathrm{MHz}, \mathrm{CDCl}_{3}\right) \delta 8.83(\mathrm{~s}, 1 \mathrm{H}, \mathrm{NH})$, 8.12-8.10 (m, 1H, Ar), $7.64-6.83(\mathrm{~m}, 24 \mathrm{H}, \mathrm{Ar}), 6.29-6.27(\mathrm{~m}, 1 \mathrm{H}, \mathrm{Ar}), 3.35(\mathrm{~d}, J=15.9 \mathrm{~Hz}$, $\left.1 \mathrm{H}, \mathrm{CH}_{2 \mathrm{a}}\right), 2.66\left(\mathrm{~d}, J=15.9 \mathrm{~Hz}, 1 \mathrm{H}, \mathrm{CH}_{2 \mathrm{~b}}\right), 1.60\left(\mathrm{~s}, 1 \mathrm{H}, \mathrm{CH}_{3}\right), 1.15\left(\mathrm{~s}, 3 \mathrm{H}, \mathrm{CH}_{3}\right) \cdot{ }^{13} \mathrm{C} \mathrm{NMR}(101$ $\left.\mathrm{MHz}, \mathrm{CDCl}_{3}\right) \delta 171.10,169.20,141.41,139.76,138.46,138.19,135.70,134.67,133.88,131.22$, $130.25,129.76,129.22,128.87,128.83,128.79,128.38,128.28,128.12,127.79,127.74,127.42$, 
127.00, 124.71, 123.57, 122.50, 116.48, 49.27, 35.02, 22.74. HPLC (Flow rate $1.0 \mathrm{ml} / \mathrm{min}, 1 \%$ IPA:Hexanes $) t_{\mathrm{R}}$ minor, minor diast. $=10.628 \min ($ area $=2072.2), t_{R}$ major, minor diast. $=$ $11.545 \min (\operatorname{area}=6178.2), \mathrm{t}_{\mathrm{R}}$ major, major diast. $=13.087 \mathrm{~min}(\operatorname{area}=14744.9), \mathrm{t}_{\mathrm{R}}$ minor, major diast. $=15.114 \min ($ area $=6627.4)$.

\subsection{Synthesis Towards Monoamide Compounds}

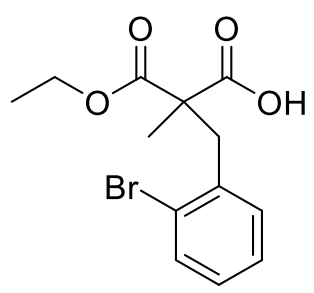

\subsubsection{2-(2-Bromobenzyl)-3-ethoxy-2-methyl-3-oxopropanoic acid (10)}

Diethyl 2-(2-bromobenzyl)-2-methylmalonate (4.0 g, $11.65 \mathrm{mmol})$ was dissolved in EtOH (7.5 $\mathrm{mL}, 1.56 \mathrm{M})$. A separate solution of $\mathrm{NaOH}(0.5594 \mathrm{~g}, 13.986 \mathrm{mmol})$ in EtOH $(8.37 \mathrm{~mL}, 1.67 \mathrm{M})$ was prepared. The reaction mixture was cooled to $0{ }^{\circ} \mathrm{C}$ and the base solution was added slowly over ice. The reaction was heated to reflux for an hour, then concentrated under vacuum. The residual reaction mixture was dissolved in water $(10 \mathrm{~mL})$ and extracted with $\mathrm{Et}_{2} \mathrm{O}(3 \times 5 \mathrm{~mL})$. The aqueous layer was acidified to $\mathrm{pH} 3$ with $1 \mathrm{M} \mathrm{HCl}$. The product was extracted out of the aqueous layer with EtOAc $(3 \times 5 \mathrm{~mL})$. The organic layer was dried over magnesium sulphate and concentrated under vacuum to afford $3.0 \mathrm{~g}(81 \%)$ of a colourless oil. TLC (20\%

EtOAc:Hexanes) $\mathrm{R}_{\mathrm{f}}=0.19{ }^{1} \mathrm{H}$ NMR $\left(400 \mathrm{MHz}, \mathrm{CDCl}_{3}\right) \delta$ 7.57-7.55 (m, 1H, Ar), 7.22-7.21 (m, $2 \mathrm{H}, \mathrm{Ar}), 7.13-7.06(\mathrm{~m}, 1 \mathrm{H}, \mathrm{Ar}), 4.25\left(\mathrm{qd}, J=7.1,1.3 \mathrm{~Hz}, 2 \mathrm{H}, \mathrm{CH}_{2 \mathrm{a} / \mathrm{b}} \mathrm{CH}_{3}\right), 3.54(\mathrm{dd}, J=20,16$ $\left.\mathrm{Hz}, 2 \mathrm{H}, \mathrm{CH}_{2 \mathrm{a} / \mathrm{b}}\right), 1.45\left(\mathrm{~s}, 3 \mathrm{H}, \mathrm{CH}_{3}\right), 1.28\left(\mathrm{t}, J=7.1 \mathrm{~Hz}, 3 \mathrm{H}, \mathrm{CH}_{2} \mathrm{CH}_{3}\right) .{ }^{13} \mathrm{C} \mathrm{NMR}(101 \mathrm{MHz}$, $\left.\mathrm{CDCl}_{3}\right) \delta 177.54,172.10,135.81,133.20,131.31,128.71,127.44,126.23,55.03,52.90,39.54$, 19.41, 13.91 . 


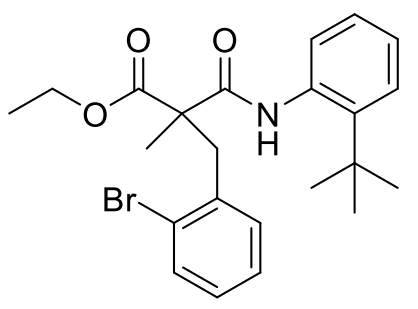

\subsubsection{Ethyl 2-(2-bromobenzyl)-3-((2-(tert-butyl)phenyl)amino)-2-methyl-3- oxopropanoate (11)}

A round bottom flask was charged with a solution of 2-(2-bromobenzyl)-3-ethoxy-2-methyl-3oxopropanoic acid $(3.0 \mathrm{~g}, 9.5 \mathrm{mmol})$ in thionyl chloride $(32.0 \mathrm{~mL}, 0.3 \mathrm{M})$ and was sealed and heated to $60{ }^{\circ} \mathrm{C}$ for 4 hours. The solution was cooled and concentrated under vacuum. The residual mixture was redisolved in $\mathrm{CHCl}_{3}(30.0 \mathrm{~mL})$ and concentrated under vacuum a total of three times. The crude mixture was redissolved in DCM $(95.0 \mathrm{~mL}, 0.1 \mathrm{M})$ and cooled to $0{ }^{\circ} \mathrm{C}$. Once 2-(tert-butyl)aniline $(1.63 \mathrm{~mL}, 10.45 \mathrm{mmol})$ was added slowly over ice, the reaction was stirred at room temperature for an hour. Once cooled to $0{ }^{\circ} \mathrm{C}$, triethylamine $(1.46 \mathrm{~mL}, 10.45$ mmol) was added dropwise and the mixture was heated to reflux overnight. The reaction was cooled to room temperature, washed with $1 \mathrm{M} \mathrm{HCl}(4 \times 50 \mathrm{~mL})$, dried over magnesium sulphate and concentrated under vacuum. The crude mixture was purified via flash chromatography eluting with 20\% EtOAc:Hexanes to yield $2.7322 \mathrm{~g}(65 \%)$ of a light yellow oil. TLC (20\% EtOAc:Hexanes) $\mathrm{R}_{\mathrm{f}}=0.38{ }^{1} \mathrm{H}$ NMR $\left(400 \mathrm{MHz}, \mathrm{CDCl}_{3}\right) \delta 8.85(\mathrm{~s}, 1 \mathrm{H}, \mathrm{NH}), 7.66-7.64(\mathrm{~m}, 1 \mathrm{H}$, Ar), 7.60- $7.55(\mathrm{~m}, 1 \mathrm{H}, \mathrm{Ar}), 7.44-7.41(\mathrm{~m}, 1 \mathrm{H}, \mathrm{Ar}), 7.35-7.32(\mathrm{~m}, 1 \mathrm{H}, \mathrm{Ar}), 7.30-7.15(\mathrm{~m}, 3 \mathrm{H}$, Ar), 7.12-7.07 (m, 1H, Ar), $4.27\left(\mathrm{~m}, 2 \mathrm{H}, \mathrm{CH}_{2} \mathrm{CH}_{3}\right), 3.72\left(\mathrm{~d}, J=14.4 \mathrm{~Hz}, 1 \mathrm{H}, \mathrm{CH}_{2 \mathrm{a}}\right), 3.61(\mathrm{~d}, J$ $\left.=14.4 \mathrm{~Hz}, 1 \mathrm{H}, \mathrm{CH}_{2 \mathrm{~b}}\right), 1.66\left(\mathrm{~s}, 3 \mathrm{H}, \mathrm{CH}_{3}\right), 1.41\left(\mathrm{~s}, 9 \mathrm{H}, \mathrm{C}\left(\mathrm{CH}_{3}\right)_{3}\right), 1.27(\mathrm{t}, J=7.1 \mathrm{~Hz}, 3 \mathrm{H}$, $\left.\mathrm{CH}_{3} \mathrm{CH}_{2}\right) .{ }^{13} \mathrm{C} \mathrm{NMR}\left(101 \mathrm{MHz}, \mathrm{CDCl}_{3}\right) \delta 174.72,169.19,142.70,136.85,135.20,133.16$, $131.00,128.50,127.50,127.48,126.73,126.64,126.14,126.01,62.18,55.36,41.69,34.59$, $30.55,21.50,13.99$. 


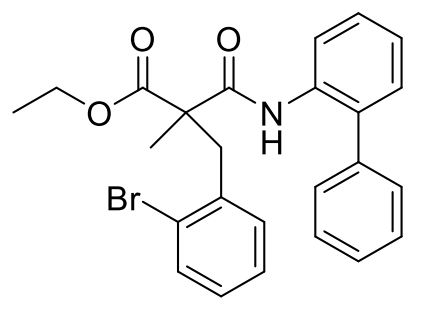

\subsubsection{Ethyl 3-([1,1'-biphenyl]-2-ylamino)-2-(2-bromobenzyl)-2-methyl-3-oxopropanoate} (12)

A round bottom flask was charged with a solution of 2-(2-bromobenzyl)-3-ethoxy-2-methyl-3oxopropanoic acid $(1.5 \mathrm{~g}, 4.75 \mathrm{mmol})$ in thionyl chloride $(15.8 \mathrm{~mL}, 0.3 \mathrm{M})$ and was sealed and heated to $60{ }^{\circ} \mathrm{C}$ for 4 hours. The solution was cooled and concentrated under vacuum. The residual mixture was redisolved in $\mathrm{CHCl}_{3}(15 \mathrm{~mL})$ and concentrated under vacuum a total of three times. The crude mixture was redissolved in DCM $(47.5 \mathrm{~mL}, 0.1 \mathrm{M})$ and cooled to $0{ }^{\circ} \mathrm{C}$. Once [1,1'-biphenyl]-2-amine (0.8842 g, $5.225 \mathrm{mmol})$ was added slowly over ice, the reaction was stirred at room temperature for an hour. Once cooled to $0{ }^{\circ} \mathrm{C}$, triethylamine $(0.7 \mathrm{~mL}, 5.225$ mmol) was added dropwise and the mixture was heated to reflux overnight. The reaction was cooled to room temperature, washed with $1 \mathrm{M} \mathrm{HCl}(4 \times 25 \mathrm{~mL})$, dried over magnesium sulphate and concentrated under vacuum. The crude mixture was purified via flash chromatography eluting with 20\% EtOAc:Hexanes to yield $1.2992 \mathrm{~g}$ (58.8\%) of a light yellow oil. TLC (20\% EtOAc:Hexanes) $\mathrm{R}_{\mathrm{f}}=0.35{ }^{1} \mathrm{H}$ NMR $\left(400 \mathrm{MHz}, \mathrm{CDCl}_{3}\right) \delta 8.37(\mathrm{~s}, 1 \mathrm{H}, \mathrm{NH}), 7.58-7.56(\mathrm{~m}, 1 \mathrm{H}$, Ar), 7.44-7.40 (m, 5H, Ar), 7.29 - 7.26 (m, 3H, Ar), 7.23-7.17 (m, 3H, Ar), 7.13-7.04 (m, 1H, Ar), $4.09\left(\mathrm{q}, J=7.1 \mathrm{~Hz}, 2 \mathrm{H}, \mathrm{CH}_{2} \mathrm{CH}_{3}\right), 3.52\left(\mathrm{~d}, J=3.5 \mathrm{~Hz}, 2 \mathrm{H}, \mathrm{CH}_{2}\right), 1.38\left(\mathrm{~s}, 3 \mathrm{H}, \mathrm{CH}_{3}\right), 1.18$ (t, $\left.J=7.1 \mathrm{~Hz}, 3 \mathrm{H}, \mathrm{CH}_{3} \mathrm{CH}_{2}\right) .{ }^{13} \mathrm{C} \mathrm{NMR}\left(101 \mathrm{MHz}, \mathrm{CDCl}_{3}\right) \delta 173.18,168.78,137.88,136.56$, $134.67,133.06,132.95,131.14,130.04,129.32,129.25,129.02,128.96,128.49,128.41,127.98$, $127.43,126.14,124.57,121.54,61.87,56.00,41.04,19.97,13.90$. 


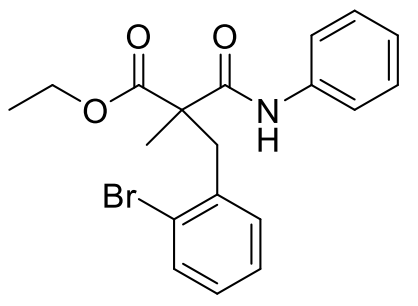

\subsubsection{Ethyl 2-(2-bromobenzyl)-2-methyl-3-oxo-3-(phenylamino)propanoate (13)}

A solution of 2-(2-bromobenzyl)-3-ethoxy-2-methyl-3-oxopropanoic acid (1.5 g, $4.75 \mathrm{mmol})$ in thionyl chloride ( $15.8 \mathrm{~mL}, 0.3 \mathrm{M}$ ) was heated to $60{ }^{\circ} \mathrm{C}$ for 4 hours. The solution was cooled and concentrated under vacuum. The residual mixture was redisolved in $\mathrm{CHCl}_{3}(15 \mathrm{~mL})$ and concentrated under vacuum a total of three times. The crude mixture was redissolved in DCM $(47.5 \mathrm{~mL}, 0.1 \mathrm{M})$ and cooled to $0{ }^{\circ} \mathrm{C}$. Once aniline $(0.477 \mathrm{~mL}, 5.225 \mathrm{mmol})$ was added slowly over ice, the reaction was stirred at room temperature for an hour. Once cooled to $0{ }^{\circ} \mathrm{C}$, triethylamine $(0.7 \mathrm{~mL}, 5.225 \mathrm{mmol})$ was added dropwise and the mixture was heated to $60^{\circ} \mathrm{C}$ overnight. The reaction was cooled to room temperature, washed with $1 \mathrm{M} \mathrm{HCl}(4 \times 25 \mathrm{~mL})$, dried over magnesium sulphate and concentrated under vacuum. The crude mixture was purified via flash chromatography with eluting $20 \%$ EtOAc:Hexanes to yield $1.1567 \mathrm{~g}(62.6 \%)$ of a light yellow oil. TLC (20\% EtOAc:Hexanes) $\mathrm{R}_{\mathrm{f}}=0.28{ }^{1} \mathrm{H}$ NMR $\left(400 \mathrm{MHz}, \mathrm{CDCl}_{3}\right) \delta 9.20(\mathrm{~s}, 1 \mathrm{H}$, NH), 7.60 - 7.46 (m, 3H, Ar), 7.35-7.31 (m, 2H, Ar), 7.20 - 7.01 (m, 4H, Ar), $4.29-4.15$ (m, $\left.2 \mathrm{H}, \mathrm{CH}_{2 \mathrm{a} / \mathrm{b}} \mathrm{CH}_{3}\right), 3.58\left(\mathrm{~d}, J=14.2 \mathrm{~Hz}, 1 \mathrm{H}, \mathrm{CH}_{2 \mathrm{a}}\right), 3.51\left(\mathrm{~d}, J=14.2 \mathrm{~Hz}, 1 \mathrm{H}, \mathrm{CH}_{2 \mathrm{~b}}\right), 1.60(\mathrm{~s}, 3 \mathrm{H}$, $\left.\mathrm{CH}_{3}\right), 1.25\left(\mathrm{t}, J=7.1 \mathrm{~Hz}, 3 \mathrm{H}, \mathrm{CH}_{3} \mathrm{CH}_{2}\right) .{ }^{13} \mathrm{C}$ NMR $\left(101 \mathrm{MHz}, \mathrm{CDCl}_{3}\right) \delta 174.86,168.80,137.71$, $136.41,133.04,130.78,128.97,128.54,127.37,125.83,124.49,120.24,62.20,54.99,42.59$, $21.25,13.89$. 


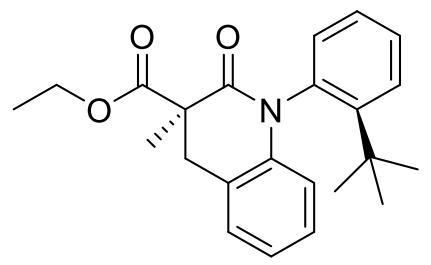

\subsubsection{Ethyl 1-(2-(tert-butyl)phenyl)-3-methyl-2-oxo-1,2,3,4-tetrahydroquinoline-3- carboxylate (14)}

A $10 \mathrm{~mL}$ Schlenk flask was charged with ethyl 2-(2-bromobenzyl)-3-((2-(tertbutyl)phenyl)amino)-2-methyl-3-oxopropanoate ( $200 \mathrm{mg}, 0.448 \mathrm{mmol})$, palladium( $\pi$-cinnamyl) chloride dimer (5.8 mg, $0.0224 \mathrm{mmol}, 5 \%)$ and dicyclohexyl(2'-methoxy-[1,1'-binaphthalen]-2yl)phosphane (21.4 mg, $0.0448 \mathrm{mmol}, 10 \%)$, with the flask being evacuated and backfilled with $\mathrm{N}_{2}$ in between each addition. Anhydrous toluene $(4.5 \mathrm{~mL}, 0.1 \mathrm{M})$ was added to the solution under a stream of $\mathrm{N}_{2}$. The mixture was heated to $100{ }^{\circ} \mathrm{C}$ for three minutes to dissolve the compounds and cooled to room temperature. $\mathrm{Cs}_{2} \mathrm{CO}_{3}(204.4 \mathrm{mg}, 0.627 \mathrm{mmol})$ was added under $\mathrm{N}_{2}$ and the solution was heated to $100{ }^{\circ} \mathrm{C}$ for 24 hours. The reaction was cooled, and diluted with EtOAc $(13.5 \mathrm{~mL})$. The solution was filtered through celite and concentrated under vacuum. The crude product was purified via flash chromatography, eluting at 20\% EtOAc:Hexanes, to afford $160 \mathrm{mg}$ (quant.) of a yellow oil, as a mixture of diastereomers. TLC (20\% EtOAc:Hexanes) $\mathrm{R}_{\mathrm{f}}=$ $0.22{ }^{1} \mathrm{H}$ NMR (400 MHz, CDCl3) $\delta 7.69-7.58$ (m, 2H, Ar), 7.47 - 7.30 (m, 4H, Ar), 7.26 7.12 (m, 3H, Ar), 7.12 - 6.93 (m, 4H, Ar), 6.91-6.89 (m, 1H, Ar), 6.25-6.18 (m, 2H, Ar), 4.39$3.92\left(\mathrm{~m}, 4 \mathrm{H}, \mathrm{CH}_{2} \mathrm{CH}_{3}\right), 3.83\left(\mathrm{~d}, \mathrm{~J}=15.5 \mathrm{~Hz}, 1 \mathrm{H}, \mathrm{CH}_{2}\right.$, minor diastereomer), $3.34(\mathrm{~d}, \mathrm{~J}=15.3 \mathrm{~Hz}$, $1 \mathrm{H}, \mathrm{CH}_{2}$, major diastereomer), $3.09\left(\mathrm{~d}, \mathrm{~J}=15.3 \mathrm{~Hz}, 1 \mathrm{H}, \mathrm{CH}_{2}\right.$, major diastereomer $), 2.85(\mathrm{~d}, \mathrm{~J}=$ 15.6 Hz, $1 \mathrm{H}, \mathrm{CH}_{2}$, minor diastereomer), $1.66\left(\mathrm{~s}, 3 \mathrm{H}, \mathrm{CH}_{3}\right.$, major diastereomer), 1.48 (s, $3 \mathrm{H}, \mathrm{CH}_{3}$, minor diastereomer), $1.28\left(\mathrm{~s}, 9 \mathrm{H}, \mathrm{C}\left(\mathrm{CH}_{3}\right)_{3}\right.$, minor diastereomer), 1.21 (s, $9 \mathrm{H}, \mathrm{C}\left(\mathrm{CH}_{3}\right)_{3}$, major diastereomer), $1.03\left(\mathrm{t}, \mathrm{J}=7.1 \mathrm{~Hz}, 3 \mathrm{H}, \mathrm{CH}_{3} \mathrm{CH}_{2}\right){ }^{13} \mathrm{C} \mathrm{NMR}\left(101 \mathrm{MHz}, \mathrm{CDCl}_{3}\right) \delta 172.29,169.53$, 
$141.22,136.22,131.45,131.20,130.23,130.08,128.86,128.69,128.41,128.26,128.25,127.72$, $127.71,127.69,127.31,127.23,127.06,123.33,122.88,116.44,61.38,50.53,49.91,36.87$, 20.33, 13.92. $\mathrm{HPLC}($ Flow Rate $=1.0 \mathrm{~mL} / \mathrm{min}, 1 \%$ IPA:Hexanes $) \mathrm{t}_{\mathrm{R}}$ minor $=10.364 \mathrm{~min}($ area $=$ $4571.8), \mathrm{t}_{\mathrm{R}}$ major $=11.542 \min (\operatorname{area}=10125.5), \mathrm{t}_{\mathrm{R}} \operatorname{minor}=14.806 \min (\operatorname{area}=8501.1), \mathrm{t}_{\mathrm{R}}$ $\operatorname{minor}=22.130 \min (\operatorname{area}=3771.7)$

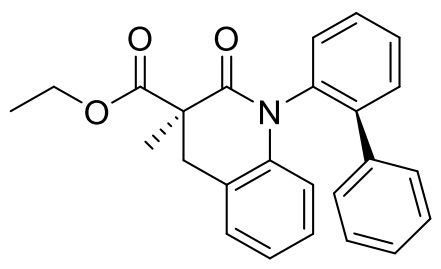

\subsubsection{Ethyl 1-([1,1'-biphenyl]-2-yl)-3-methyl-2-oxo-1,2,3,4-tetrahydroquinoline-3- carboxylate (15)}

A $10 \mathrm{~mL}$ Schlenk flask was charged with ethyl 3-([1,1'-biphenyl]-2-ylamino)-2-(2-

bromobenzyl)-2-methyl-3-oxopropanoate (200 mg, $0.4298 \mathrm{mmol})$, palladium( $\pi$-cinnamyl)

chloride dimer (5.7 mg, $0.02149 \mathrm{mmol}, 5 \%)$ and dicyclohexyl(2'-methoxy-[1,1'-binaphthalen]-

2-yl)phosphane (20.5 mg, $0.04298 \mathrm{mmol}, 10 \%)$, with the flask being evacuated and backfilled with $\mathrm{N}_{2}$ in between each addition. Anhydrous toluene $(4.30 \mathrm{~mL}, 0.1 \mathrm{M})$ was added to the solution under a stream of $\mathrm{N}_{2}$. The mixture was heated to $100{ }^{\circ} \mathrm{C}$ for three minutes to dissolve the compounds and cooled to room temperature. $\mathrm{Cs}_{2} \mathrm{CO}_{3}(196.1 \mathrm{mg}, 0.6017 \mathrm{mmol})$ was added under $\mathrm{N}_{2}$ and the solution was heated to $100{ }^{\circ} \mathrm{C}$ for 24 hours. The reaction was cooled, and diluted with EtOAc $(12.9 \mathrm{~mL})$. The solution was filtered through celite and concentrated under vacuum. The crude product was purified via flash chromatography, eluting with 20\% EtOAc:Hexanes, to afford $76.5 \mathrm{mg}(46 \%)$ of a yellow oil, as a mixture of diastereomers. TLC (20\% EtOAc:Hexanes) 
$\mathrm{R}_{\mathrm{f}}=0.22{ }^{1} \mathrm{H}$ NMR $\left(400 \mathrm{MHz}, \mathrm{CDCl}_{3}\right) \delta 7.59-7.39(\mathrm{~m}, 5 \mathrm{H}, \mathrm{Ar}), 7.27-7.10(\mathrm{~m}, 7 \mathrm{H}, \mathrm{Ar}), 7.00-$ $6.98(\mathrm{~m}, 3 \mathrm{H}, \mathrm{Ar}), 6.91-6.85(\mathrm{~m}, 1 \mathrm{H}, \mathrm{Ar}), 6.32-6.29(\mathrm{~m}, 1 \mathrm{H}, \mathrm{Ar}), 4.31-3.93\left(\mathrm{~m}, 4 \mathrm{H}, \mathrm{CH}_{2} \mathrm{CH}_{3}\right)$, $3.38\left(\mathrm{~d}, J=15.5 \mathrm{~Hz}, 1 \mathrm{H}, \mathrm{CH}_{2}\right.$, minor diastereomer), $3.22\left(\mathrm{~d}, J=15.4 \mathrm{~Hz}, 1 \mathrm{H}, \mathrm{CH}_{2}\right.$, major diastereomer), 2.65 (d, $J=15.5 \mathrm{~Hz}, 1 \mathrm{H}, \mathrm{CH}_{2}$, minor diastereomer), $2.54(\mathrm{~d}, J=15.3 \mathrm{~Hz}, 1 \mathrm{H}$, $\mathrm{CH}_{2}$, major diastereomer), 1.45 (s, $1 \mathrm{H}, \mathrm{CH}_{3}$, minor diastereomer), 1.41 (s, $3 \mathrm{H}, \mathrm{CH}_{3}$, major diastereomer), 1.24 (t, $J=7.1 \mathrm{~Hz}, 1 \mathrm{H}, \mathrm{CH}_{3} \mathrm{CH}_{2}$, minor diastereomer), 1.07 (t, $J=7.1 \mathrm{~Hz}, 3 \mathrm{H}$, $\mathrm{CH}_{3} \mathrm{CH}_{2}$, major diastereomer). ${ }^{13} \mathrm{C}$ NMR $\left(101 \mathrm{MHz}, \mathrm{CDCl}_{3}\right) \delta 172.29,141.22,136.22,131.20$, $130.08,128.86,128.69,128.41,128.26,128.25,127.81,127.72,127.69,127.31,127.23,123.33$, $122.88,116.44,61.38,49.91,36.87,20.33,13.92$.

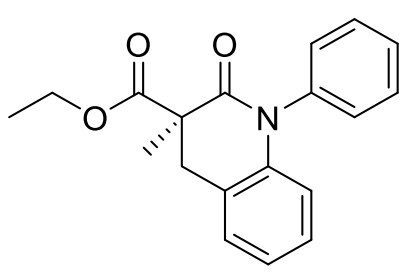

\subsubsection{Ethyl 3-methyl-2-oxo-1-phenyl-1,2,3,4-tetrahydroquinoline-3-carboxylate (16)}

A $10 \mathrm{~mL}$ Schlenk flask was charged with Ethyl 2-(2-bromobenzyl)-2-methyl-3-oxo-3(phenylamino)propanoate (200 mg, $0.5125 \mathrm{mmol})$, palladium( $\pi$-cinnamyl) chloride dimer (6.6 $\mathrm{mg}, 0.0256 \mathrm{mmol}, 5 \%)$ and dicyclohexyl(2'-methoxy-[1,1'-binaphthalen]-2-yl)phosphane (24.5 $\mathrm{mg}, 0.05125 \mathrm{mmol}, 10 \%$ ), with the flask being evacuated and backfilled with $\mathrm{N}_{2}$ in between each addition. Anhydrous toluene $(5.1 \mathrm{~mL}, 0.1 \mathrm{M})$ was added to the solution under a stream of $\mathrm{N}_{2}$. The mixture was heated to $100{ }^{\circ} \mathrm{C}$ for three minutes to dissolve the compounds and cooled to room temperature. $\mathrm{Cs}_{2} \mathrm{CO}_{3}(233.7 \mathrm{mg}, 0.7175 \mathrm{mmol})$ was added under $\mathrm{N}_{2}$ and the solution was heated to $100{ }^{\circ} \mathrm{C}$ for 24 hours. The reaction was cooled, and diluted with EtOAc $(15.4 \mathrm{~mL})$. The 
solution was filtered through celite and concentrated under vacuum. The crude product was purified via flash chromatography, eluting with 20\% EtOAc:Hexanes, to afford $141.6 \mathrm{mg}$ (89.2\%) of a yellow oil. TLC (20\% EtOAc:Hexanes) $\mathrm{R}_{\mathrm{f}}=0.18 .{ }^{1} \mathrm{H}$ NMR $\left(400 \mathrm{MHz}, \mathrm{CDCl}_{3}\right) \delta$ 7.53-7.51 (m, 2H, Ar), 7.46-7.42 (m, 1H, Ar), 7.29-7.21 (m, 2H, Ar), 7.22-7.21 (m, 1H, Ar), 7.08-7.04 (m, 1H, Ar), 6.99-6.98 (m, 1H, Ar), 6.36-6.33 (m, 1H, Ar), 4.15 (dq, $J=10.8,7.1 \mathrm{~Hz}$ $\left.1 \mathrm{H}, \mathrm{CH}_{2} \mathrm{CH}_{3}\right), 4.06\left(\mathrm{dq}, J=10.8,7.1 \mathrm{~Hz}, 1 \mathrm{H}, \mathrm{CH}_{2} \mathrm{CH}_{3}\right), 3.46\left(\mathrm{~d}, J=15.5 \mathrm{~Hz}, 1 \mathrm{H}, \mathrm{CH}_{2 \mathrm{a}}\right), 3.10(\mathrm{~d}$, $\left.J=15.5 \mathrm{~Hz}, 1 \mathrm{H}, \mathrm{CH}_{2 \mathrm{~b}}\right), 1.63\left(\mathrm{~s}, 3 \mathrm{H}, \mathrm{CH}_{3}\right), 1.10\left(\mathrm{t}, J=7.1 \mathrm{~Hz}, 3 \mathrm{H}, \mathrm{CH}_{3} \mathrm{CH}_{2}\right) \cdot{ }^{13} \mathrm{C} \mathrm{NMR}(101$ $\left.\mathrm{MHz}, \mathrm{CDCl}_{3}\right) \delta 172.29,169.70,141.15,138.69,129.82,128.79,128.17,128.10,127.50,123.54$, $123.10,116.67,61.50,49.96,37.20,20.52,13.95$.

\subsection{Synthesis Towards $\mathrm{Cy}_{2} \mathrm{MOP}$}

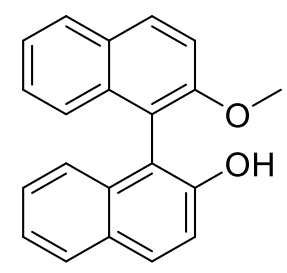

\subsection{1 $(R)-2$ '-Methoxy-[1,1'-binaphthalen]-2-ol (17)}

A solition of $\mathrm{K}_{2} \mathrm{CO}_{3}(3.459 \mathrm{~g}, 25.025 \mathrm{mmol})$ in acetone $(182 \mathrm{~mL})$ was stirred for 30 minutes at room temperature. $(R)-(+)-1,1^{\prime}-\mathrm{Bi}(2-n a p h t h o l)(6.514 \mathrm{~g}, 22.75 \mathrm{mmol})$ was added and the solution was cooled to $0{ }^{\circ} \mathrm{C}$. Iodomethane $(1.407 \mathrm{~mL}, 22.75 \mathrm{mmol})$ was added extremely slowly over ice. The solution was heated to $50{ }^{\circ} \mathrm{C}$ overnight. The reaction was cooled and filtered through celite with the celite being washed with $\mathrm{Et}_{2} \mathrm{O}$. The crude mixture was concentrated under vaccum and purified via flash chromatography eluting in neat DCM to afford the target compound in $5.944 \mathrm{~g}$ (87\%) yield. The product is a light yellow solid. TLC (neat DCM) $\mathrm{R}_{\mathrm{f}}=0.42{ }^{1} \mathrm{H}$ NMR (400 MHz, $\left.\mathrm{CDCl}_{3}\right) \delta 8.13-7.03(\mathrm{~m}, 12 \mathrm{H}, \mathrm{Ar}), 4.98(\mathrm{~s}, 1 \mathrm{H}, \mathrm{OH}), 3.83\left(\mathrm{~s}, 3 \mathrm{H}, \mathrm{CH}_{3}\right) .{ }^{13} \mathrm{C} \mathrm{NMR}(101 \mathrm{MHz}$, 
$\left.\mathrm{CDCl}_{3}\right) \delta 156.02,151.26,134.07,133.80,131.07,129.81,129.46,129.17,128.17,128.15$, 127.35, 126.42, 124.94, 124.84, 124.20, 123.25, 117.50, 115.40, 115.04, 113.86, 56.70.

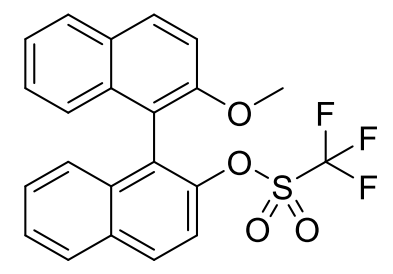

\subsection{2 (R)-2'-Methoxy-[1,1'-binaphthalen]-2-yl trifluoromethanesulfonate (18)}

(R)-2'-Methoxy-[1,1'-binaphthalen]-2-ol (3.0 g, $9.9916 \mathrm{mmol})$ was dissolved in DCM (30 mL). Pyridine $(2.40 \mathrm{~mL}, 4.16 \mathrm{M})$ was added and the mixture was cooled to $0{ }^{\circ} \mathrm{C}$. Triflic anhydride (5.55 mL, $32.97 \mathrm{mmol})$ was added dropwise over 10 minutes. An extra portion of DCM (70 mL) was needed to maintain stirring since a precipitate was forming. The reaction was stirred for 30 minutes at $0{ }^{\circ} \mathrm{C}$. The organic phase was washed with $1 \mathrm{M} \mathrm{HCl}(50 \mathrm{~mL})$, saturated $\mathrm{NaHCO}_{3}(50$ $\mathrm{mL})$ and brine $(50 \mathrm{~mL})$, in sequential order. The crude mixture was concentrated under vacuum and purified via flash chromatography, eluting with 50\% DCM:Hexanes to afford the white solid product (3.6959 g, 85.5\%). TLC (50\% DCM:Hexanes) $\mathrm{R}_{\mathrm{f}}=0.36{ }^{1} \mathrm{H} \mathrm{NMR}\left(400 \mathrm{MHz}, \mathrm{CDCl}_{3}\right) \delta$ $8.16-6.98(\mathrm{~m}, 12 \mathrm{H}, \mathrm{Ar}), 3.87\left(\mathrm{~s}, 3 \mathrm{H}, \mathrm{CH}_{3}\right) .{ }^{13} \mathrm{C} \mathrm{NMR}\left(101 \mathrm{MHz}, \mathrm{CDCl}_{3}\right) \delta$ 155.23, 145.69, 133.70, 133.61, 132.61, 131.11, 130.25, 128.88, 128.28, 128.15, 127.42, 127.33, 126.96, 126.91, $126.87,124.84,123.73,119.90,119.57,116.72,115.17,112.97,56.20 .{ }^{19} \mathrm{~F}$ NMR $(376 \mathrm{MHz}$, $\left.\mathrm{CDCl}_{3}\right) \delta-74.89$.

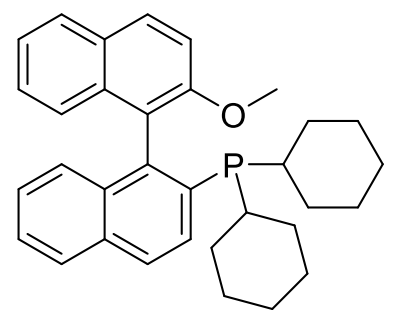




\subsection{3 (R)-Dicyclohexyl(2'-methoxy-[1,1'-binaphthalen]-2-yl)phosphane (19)}

A Schlenk flask was charged with $(R)-2$ '-methoxy-[1,1'-binaphthalen]-2-yl

trifluoromethanesulfonate $(500 \mathrm{mg}, 1.156 \mathrm{mmol})$, dicyclohexylphosphonium tetrafluoroborate (363.8 mg, $1.2716 \mathrm{mmol}$ ), palladium( $\pi$-cinnamyl) chloride dimer (15 mg, $0.0289 \mathrm{mmol}, 5 \%$, and 1,1'-bis(di-i-propylphosphino)ferrocene $(29.0 \mathrm{mg}, 0.06936 \mathrm{mmol}, 6 \%)$. The flask was evacuated and backfilled with $\mathrm{N}_{2}$ three times. Under a stream of $\mathrm{N}_{2}, \mathrm{DMSO}(6.60 \mathrm{~mL}, 0.1735 \mathrm{M})$ and diisopropyl ethyl amine $(2.00 \mathrm{~mL}, 191.7 \mathrm{mmol})$ were added. The reaction was heated to 120 ${ }^{\circ} \mathrm{C}$ for 48 hours. The reaction was cooled and diluted with EtOAc $(132 \mathrm{~mL})$. The organic phase was washed with water $(5 \times 66 \mathrm{~mL})$. The organic phase was dried over magnesium sulphate and concentrated under vacuum. The crude product was purified via flash chromatography eluting with 10\% EtOAc:Hexanes, to afford a white solid (346.6 mg, 62.5\%). TLC (20\%

EtOAc:Hexanes) $\mathrm{R}_{\mathrm{f}}=0.55{ }^{1} \mathrm{H}$ NMR $\left(400 \mathrm{MHz}, \mathrm{CDCl}_{3}\right) \delta 8.05-6.83(\mathrm{~m}, 12 \mathrm{H}, \mathrm{Ar}), 3.75(\mathrm{~s}, 3 \mathrm{H}$, $\left.\mathrm{CH}_{3}\right), 1.90-0.70\left(\mathrm{~m}, 20 \mathrm{H}, \mathrm{CH}_{2}\right) .{ }^{13} \mathrm{C} \mathrm{NMR}\left(101 \mathrm{MHz}, \mathrm{CDCl}_{3}\right) \delta 154.40,143.59,143.27$, 135.06, 134.30, 133.57, 133.36, 133.29, 129.62, 129.19, 128.55, 127.89, 127.83, 126.99, 126.73, $126.27,126.19,125.99,125.81,123.20,122.51,112.30,55.53,35.47,35.32,34.57,34.43,30.70$, 30.61, 30.45, 30.03, 29.92, 27.65, 27.40, 27.32, 27.20, 26.59, 26.41. ${ }^{31} \mathrm{P}$ NMR (162 MHz, $\left.\mathrm{CDCl}_{3}\right) \delta$-8.82. HPLC (Flow Rate $=0.5 \mathrm{~mL} / \mathrm{min}, 0.1 \%$ IPA:Hexanes) $\mathrm{t}_{\mathrm{R}}$ major $=19.217 \mathrm{~min}$ $($ area $=6083.8)$ 


\section{Appendix}

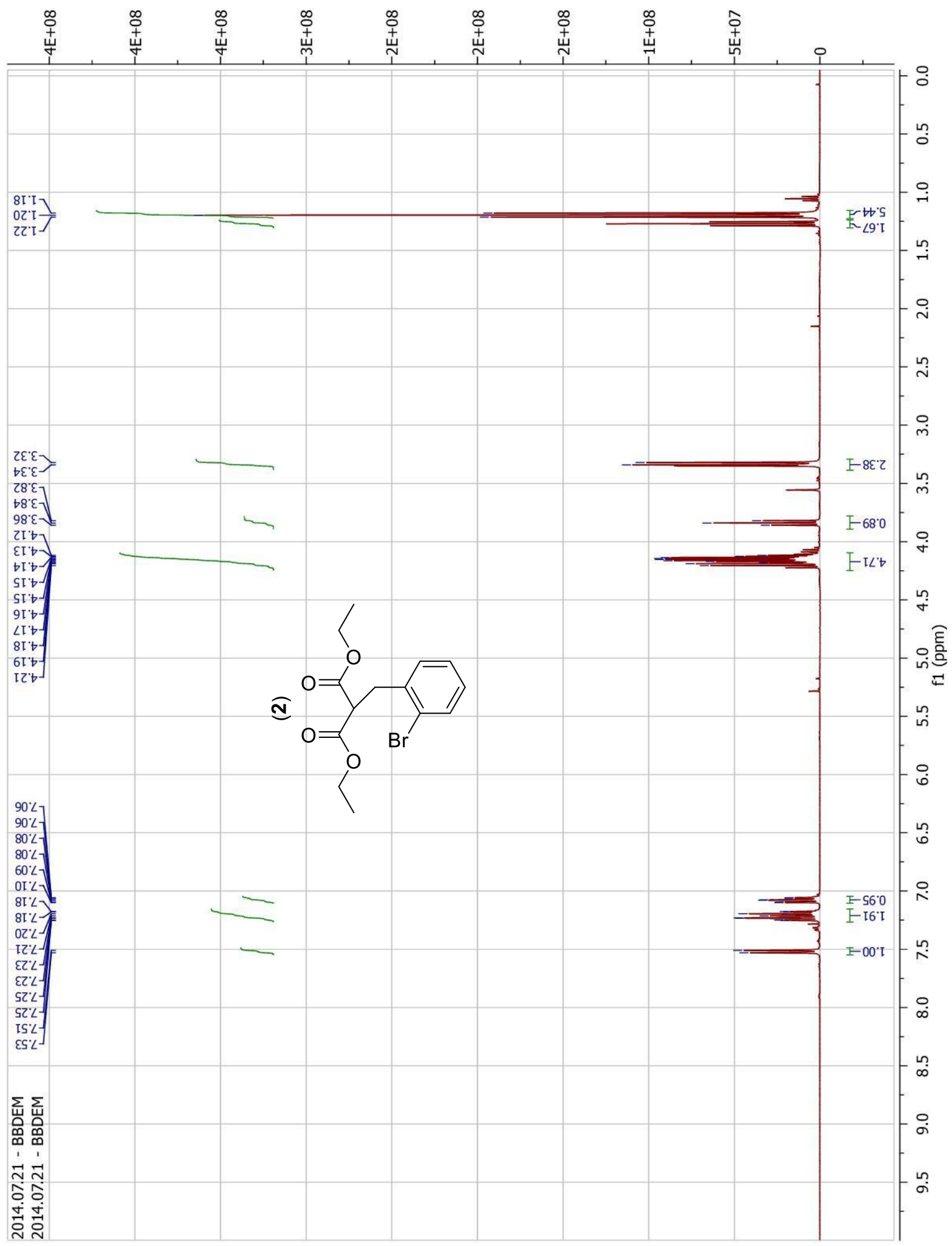



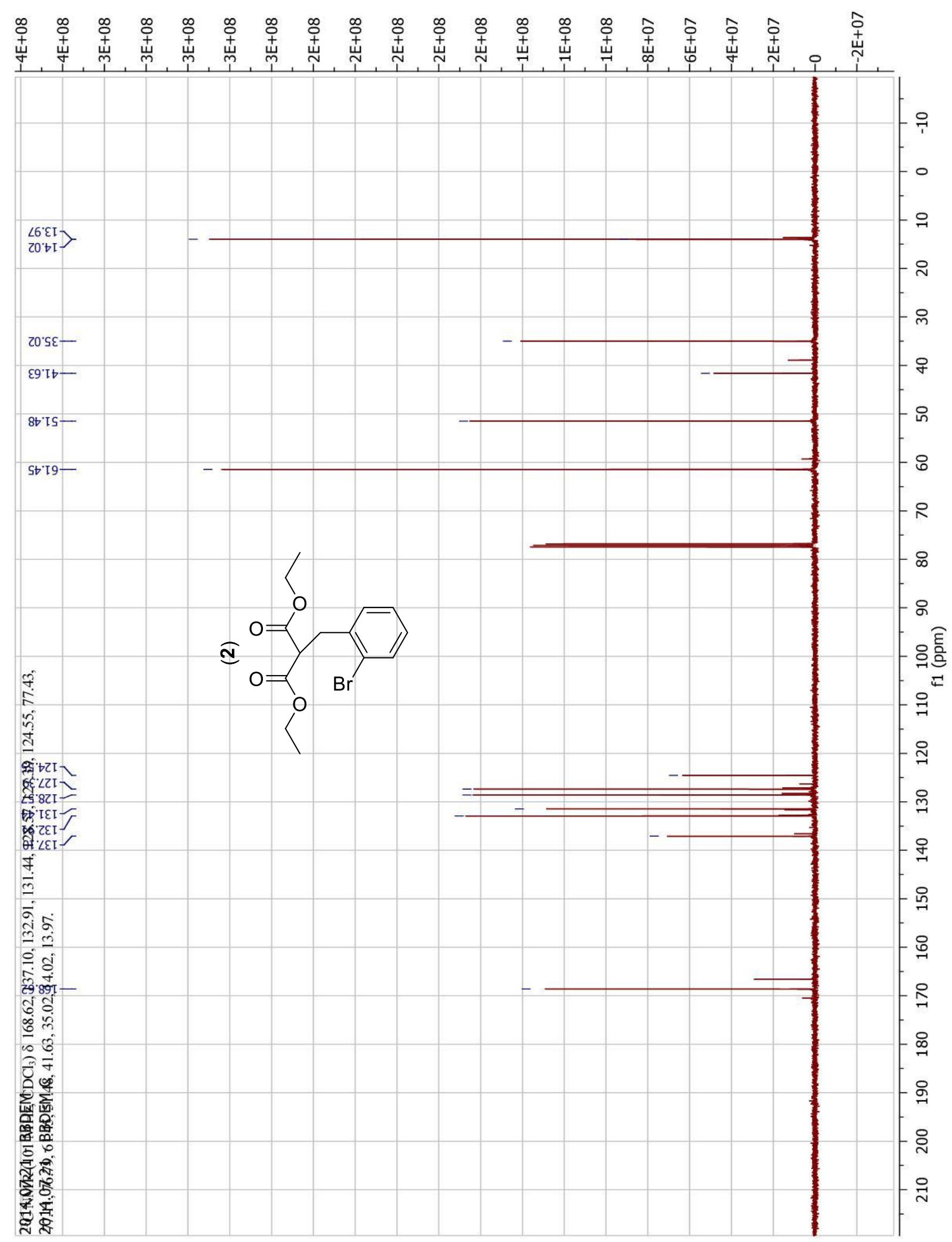


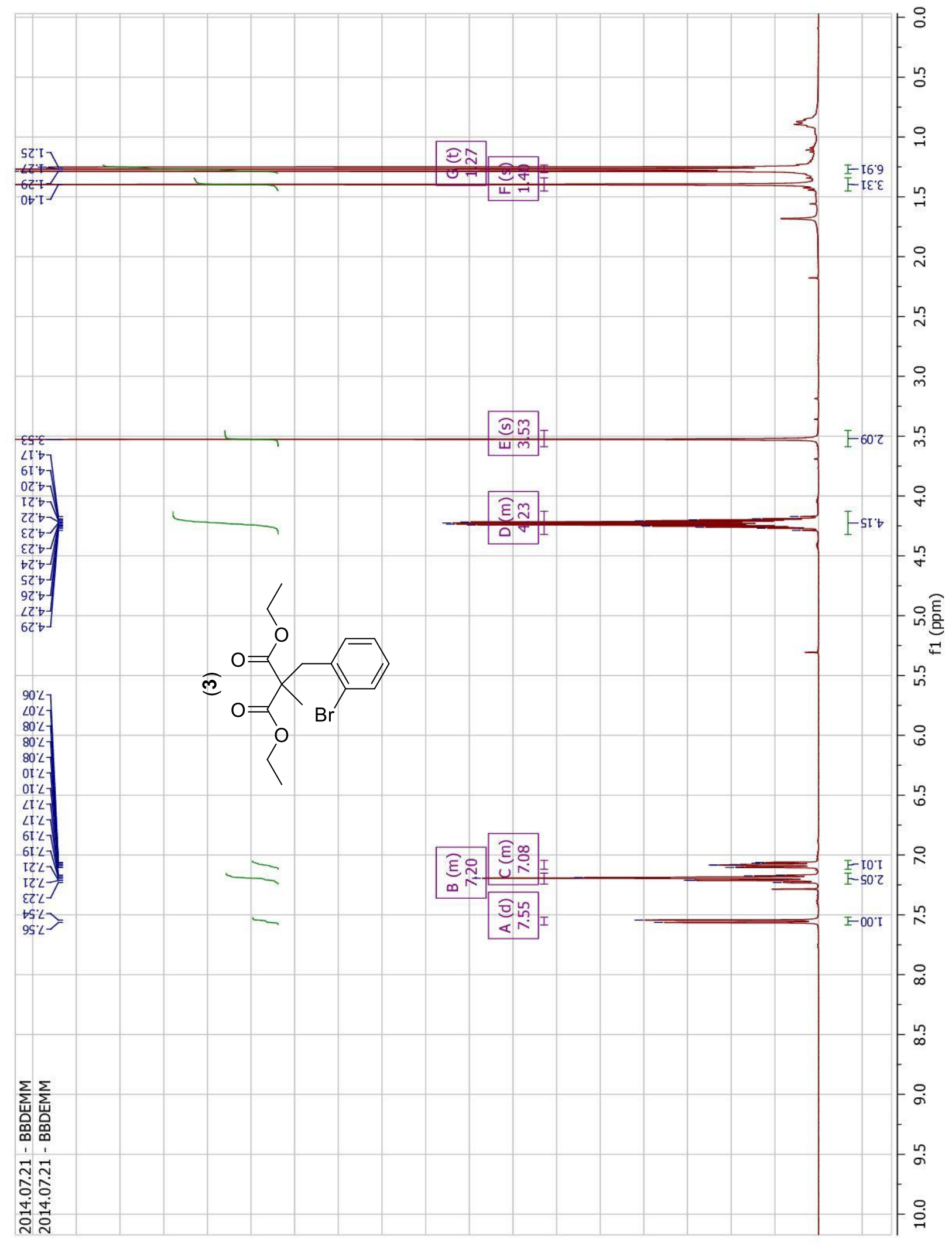




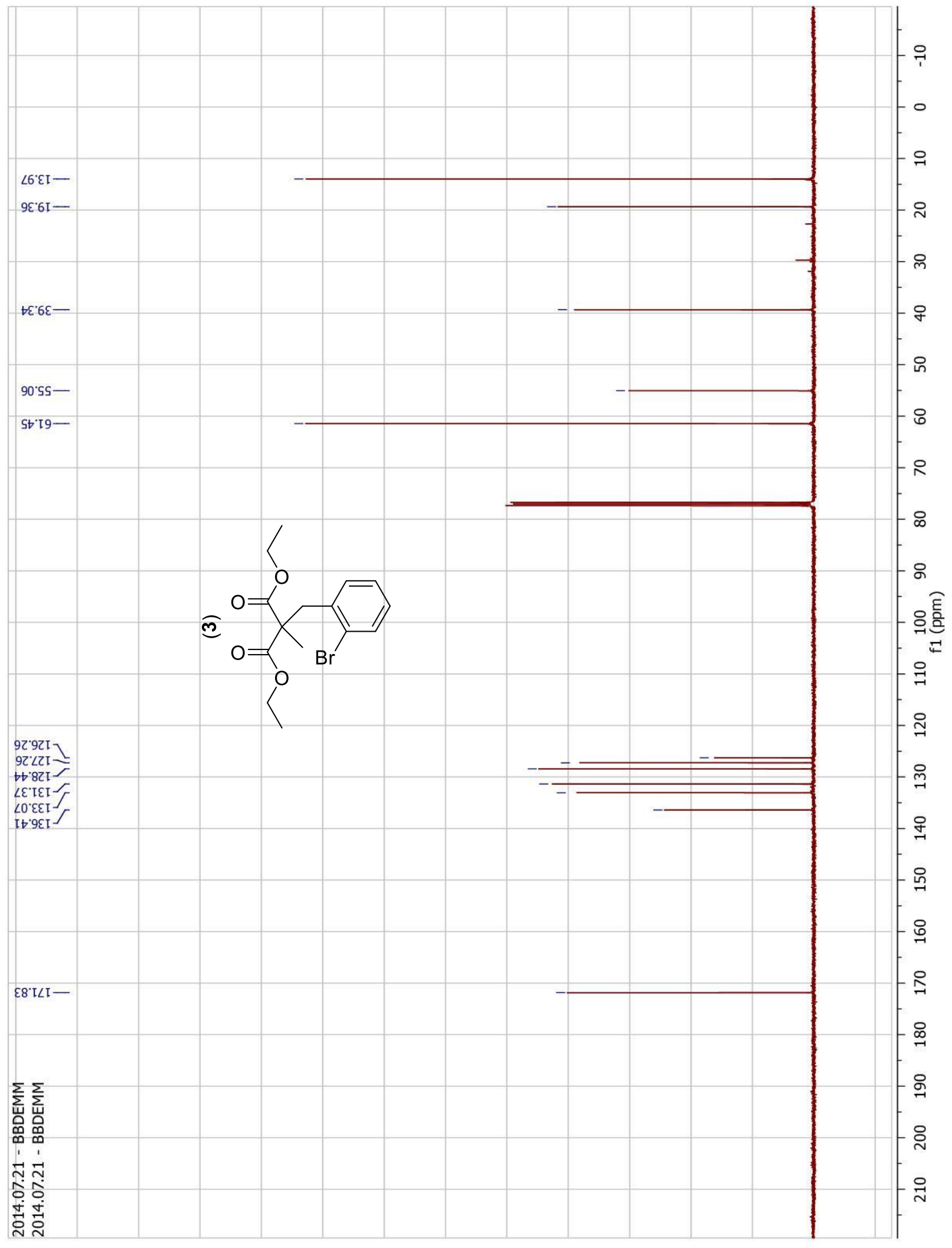




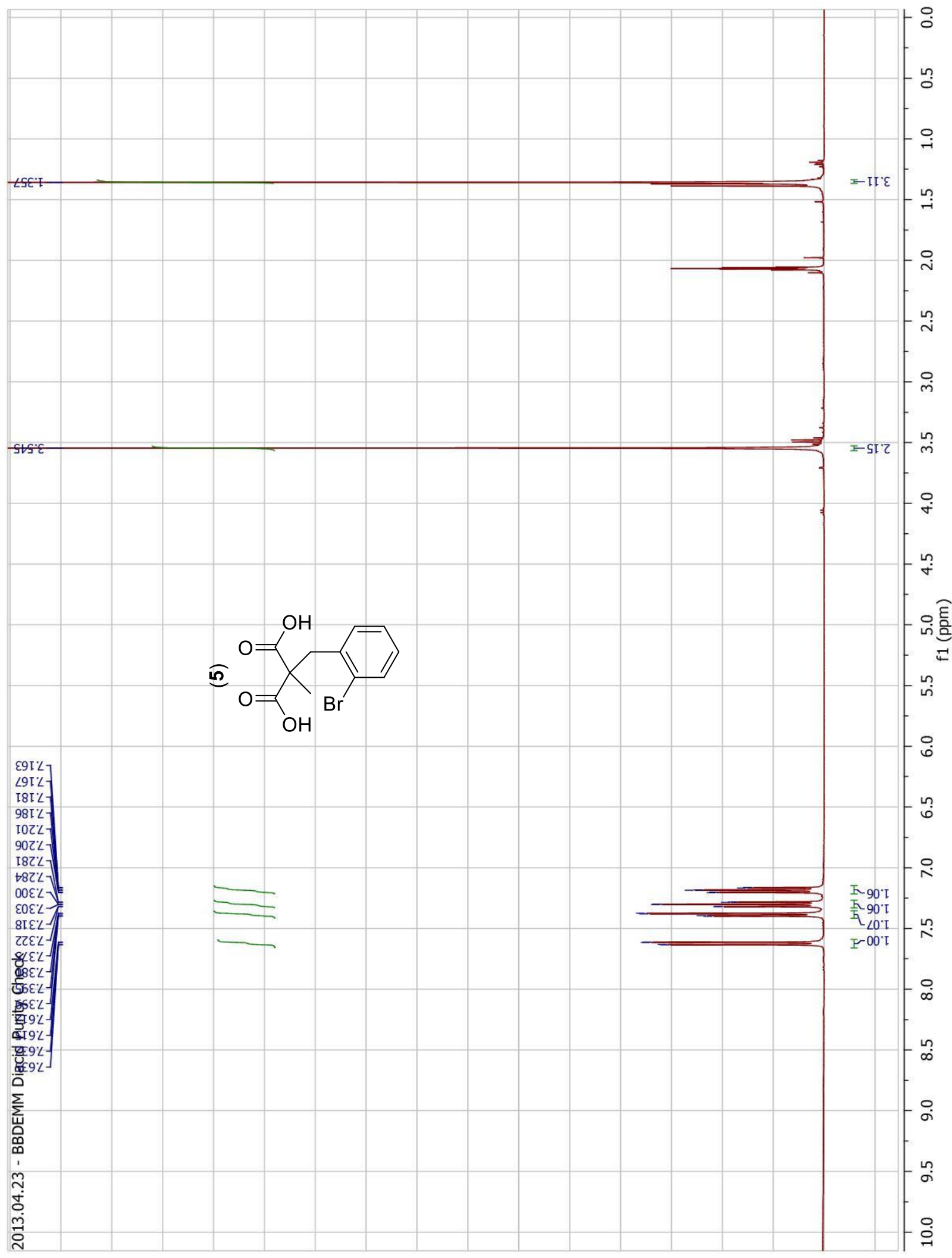




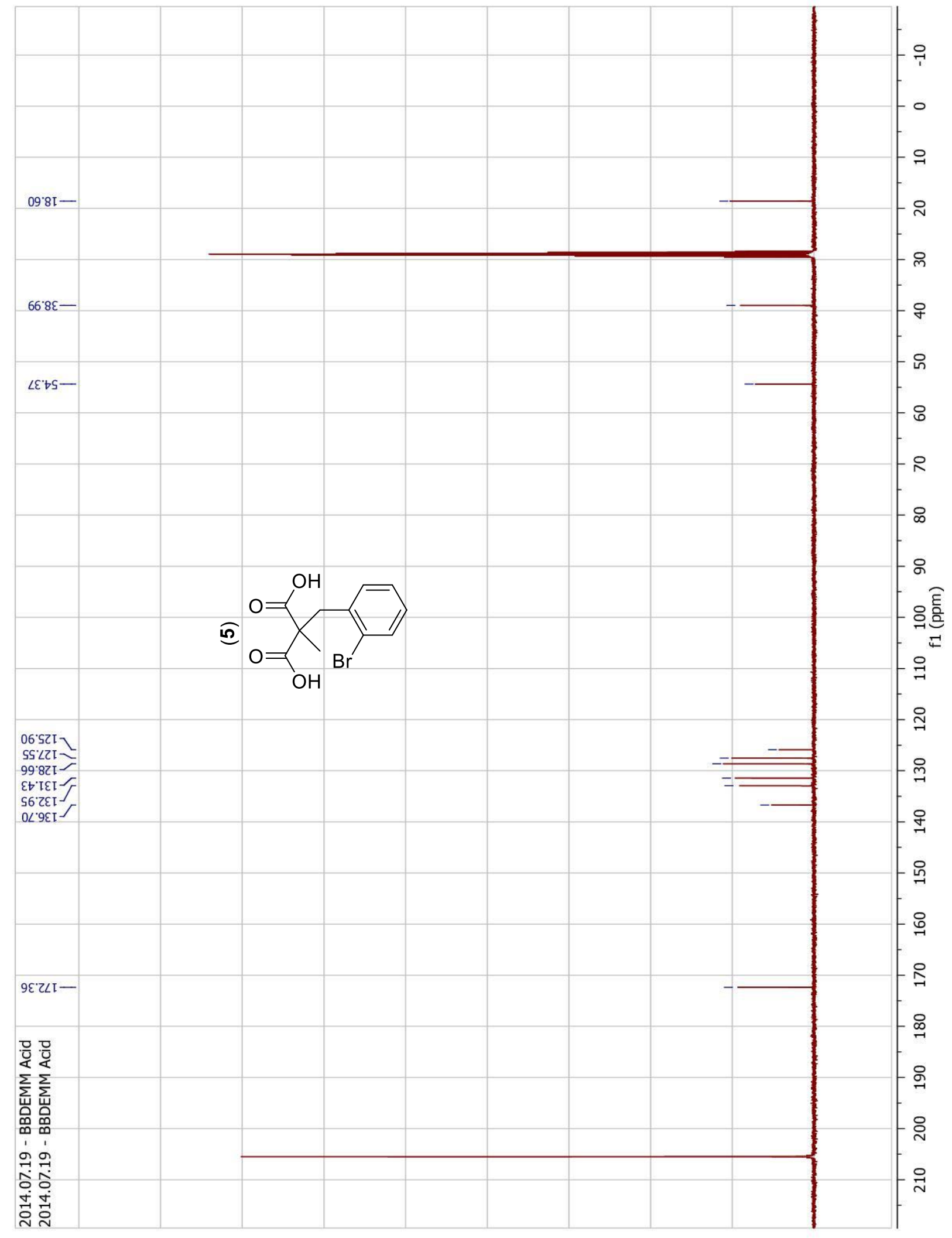




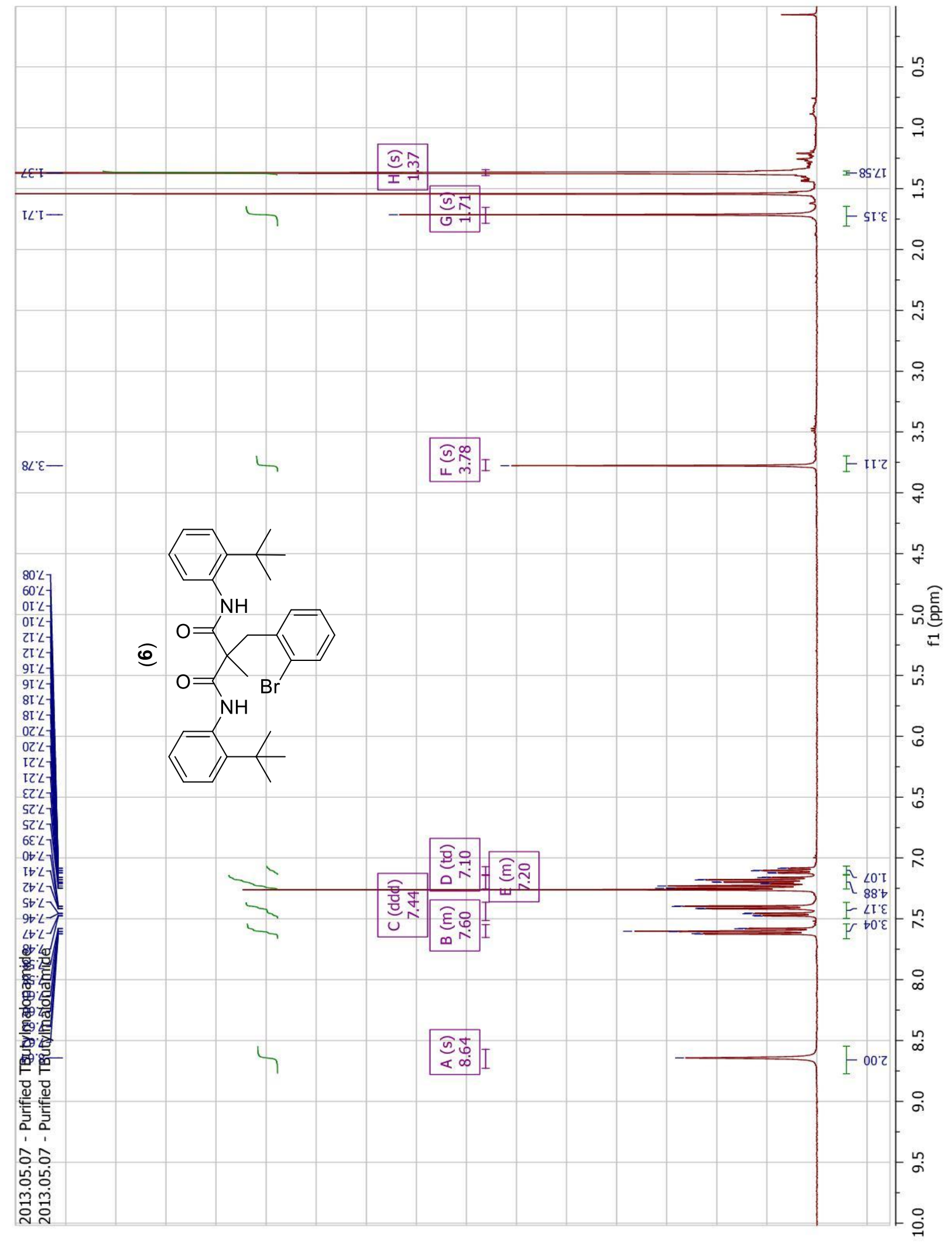




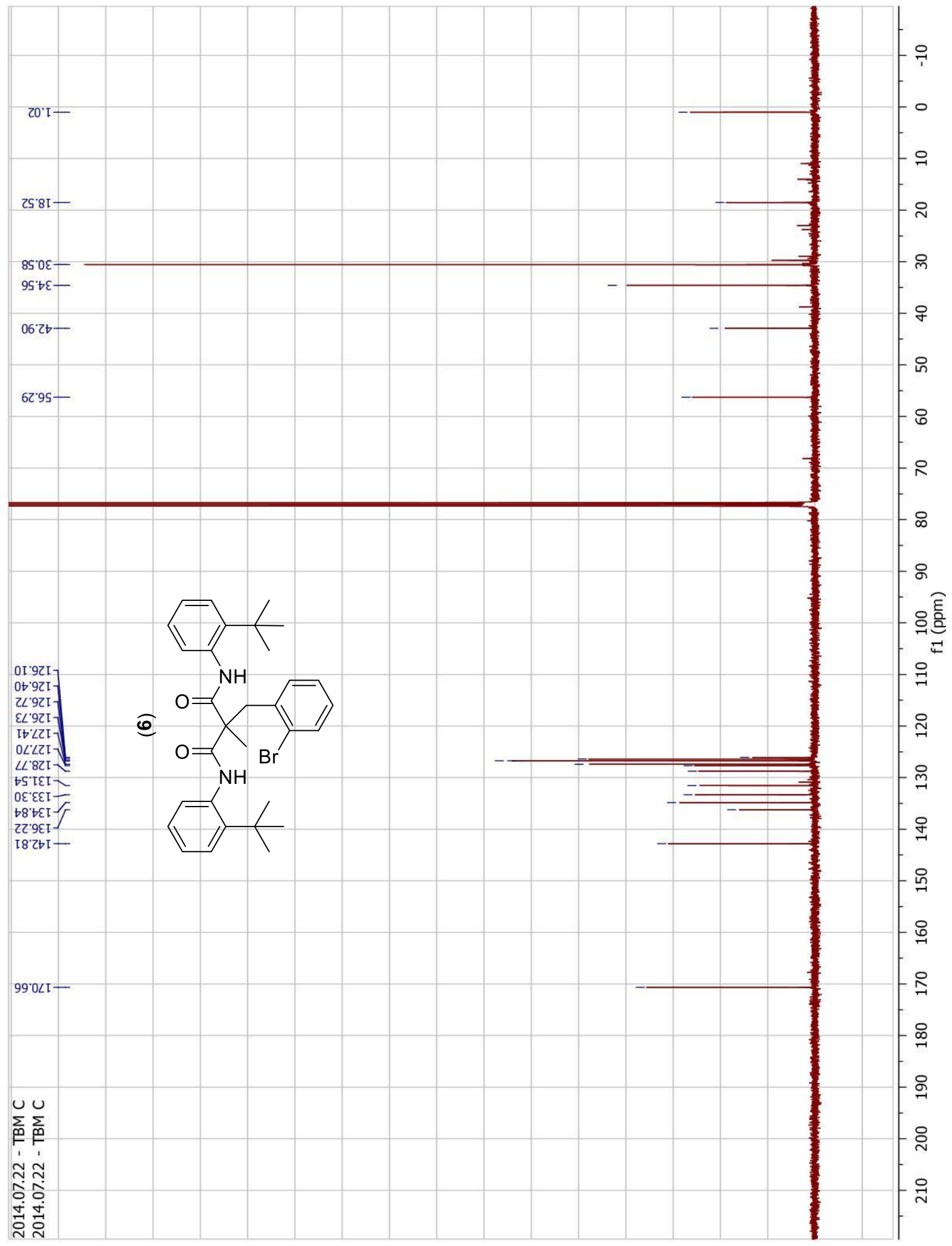




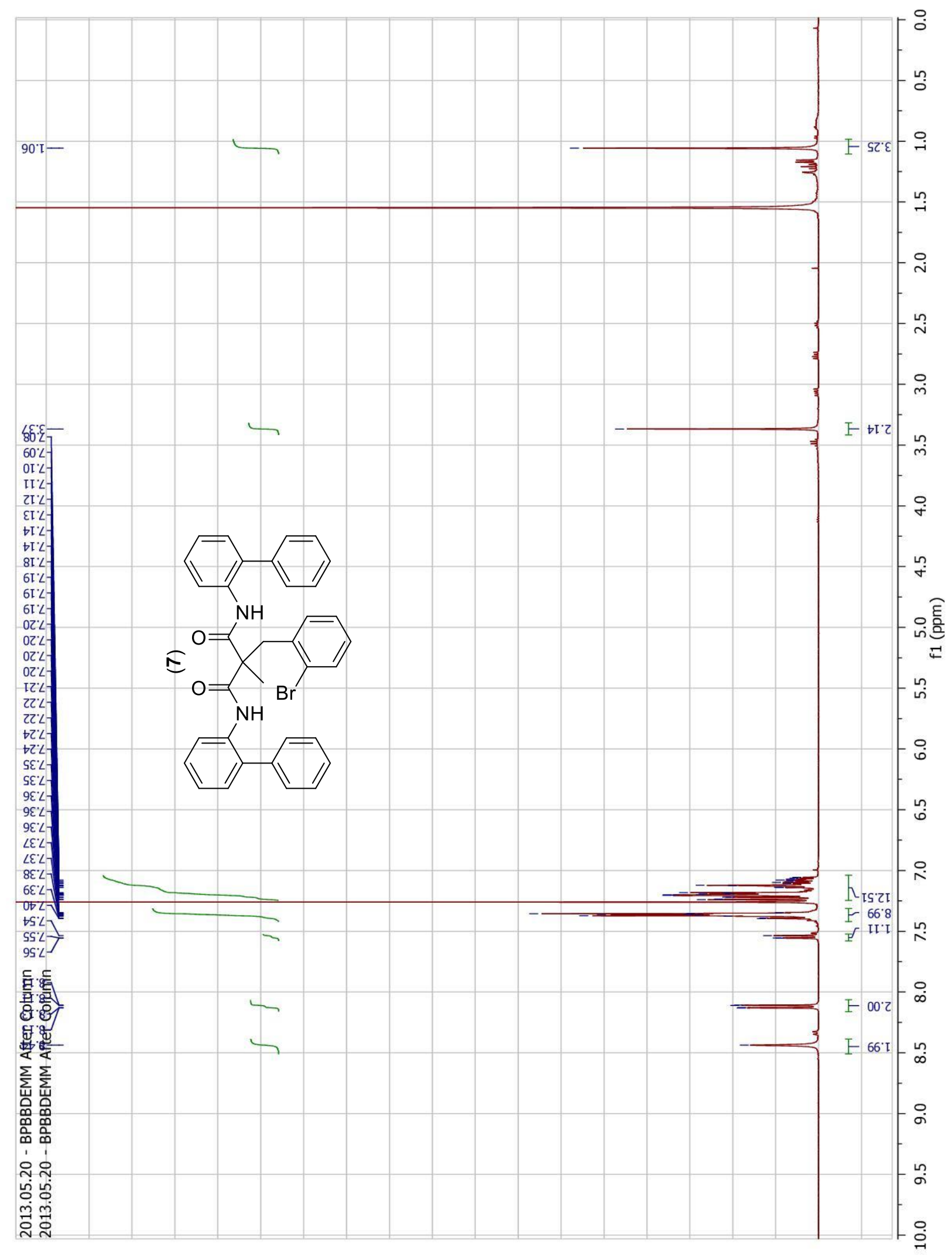




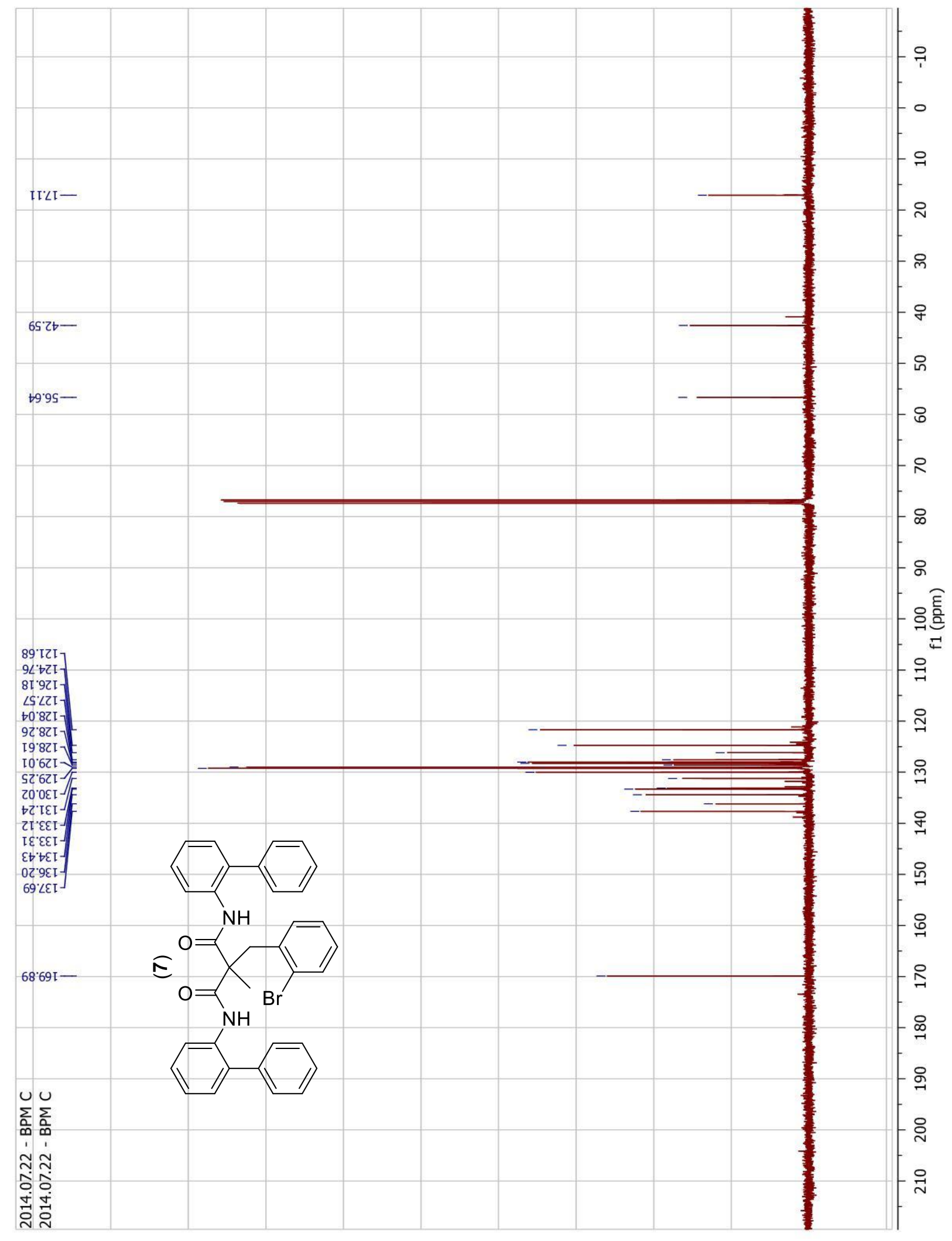




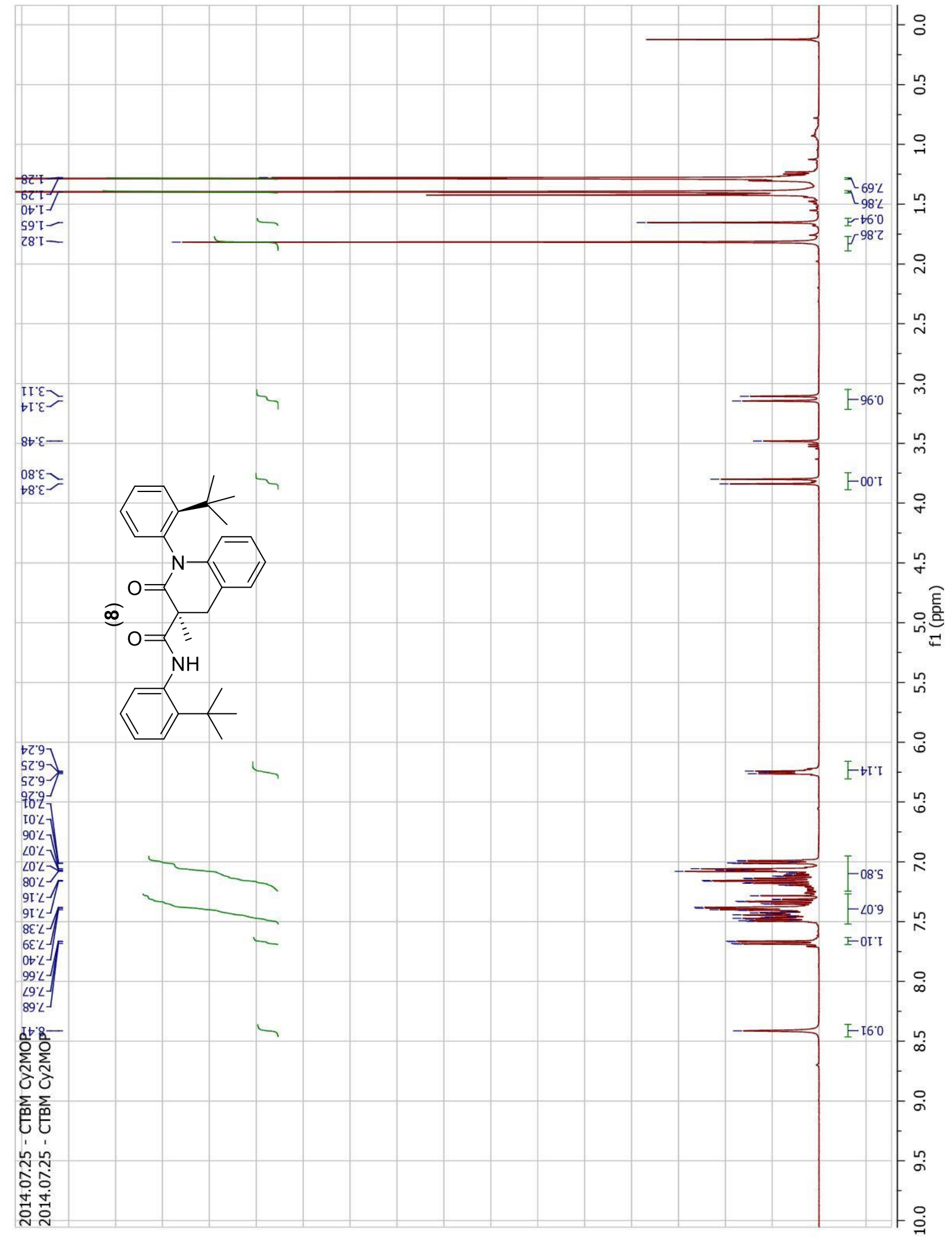




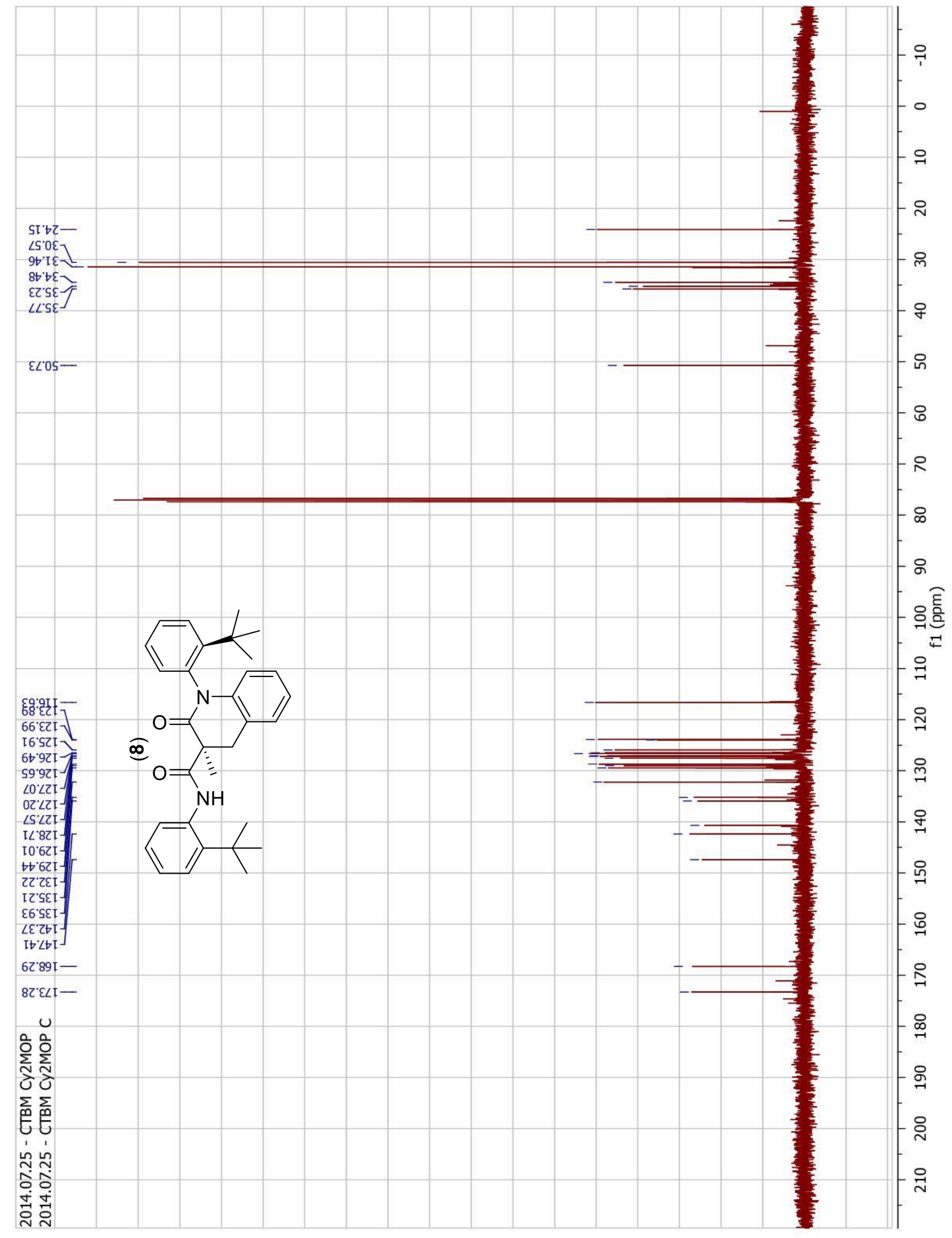




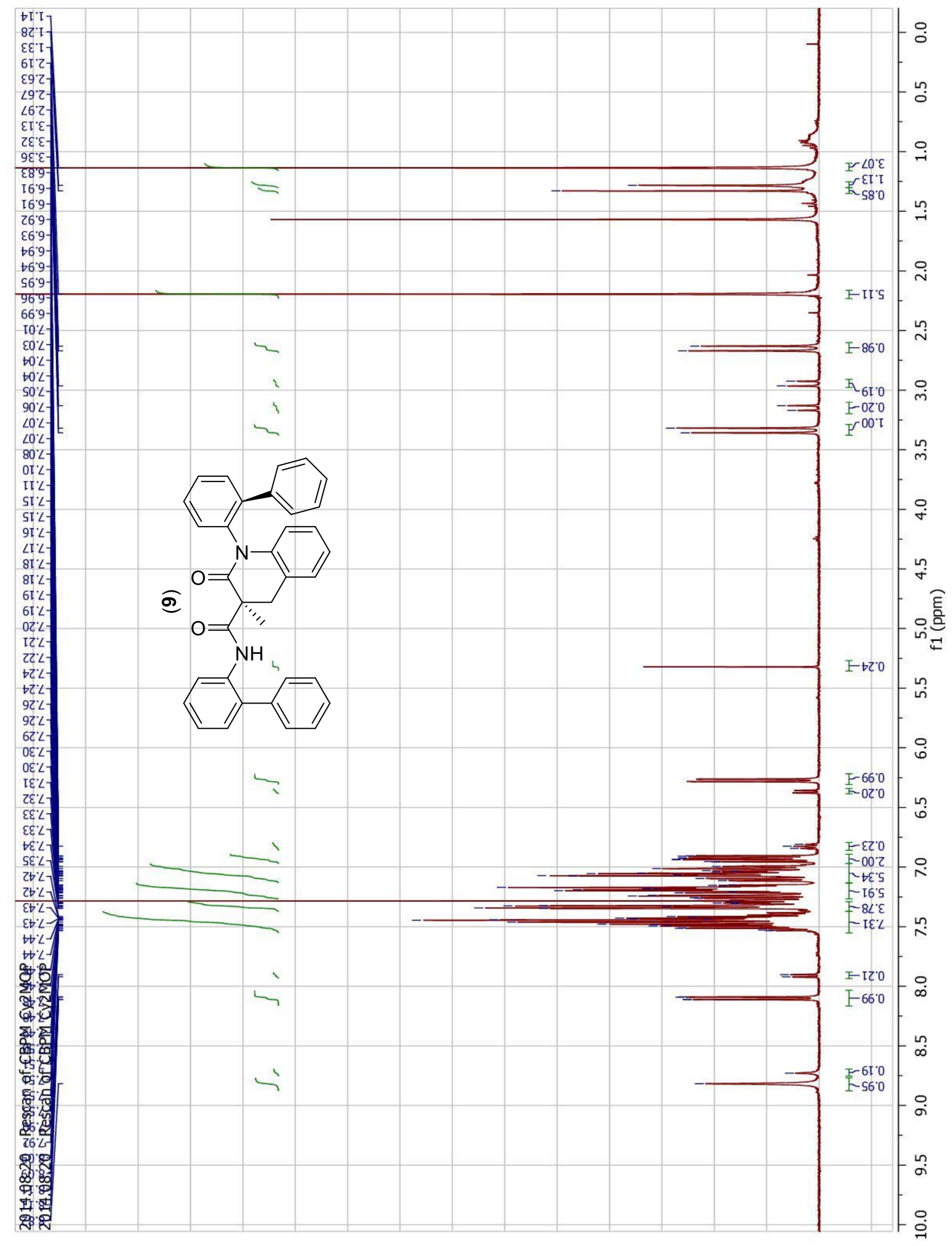




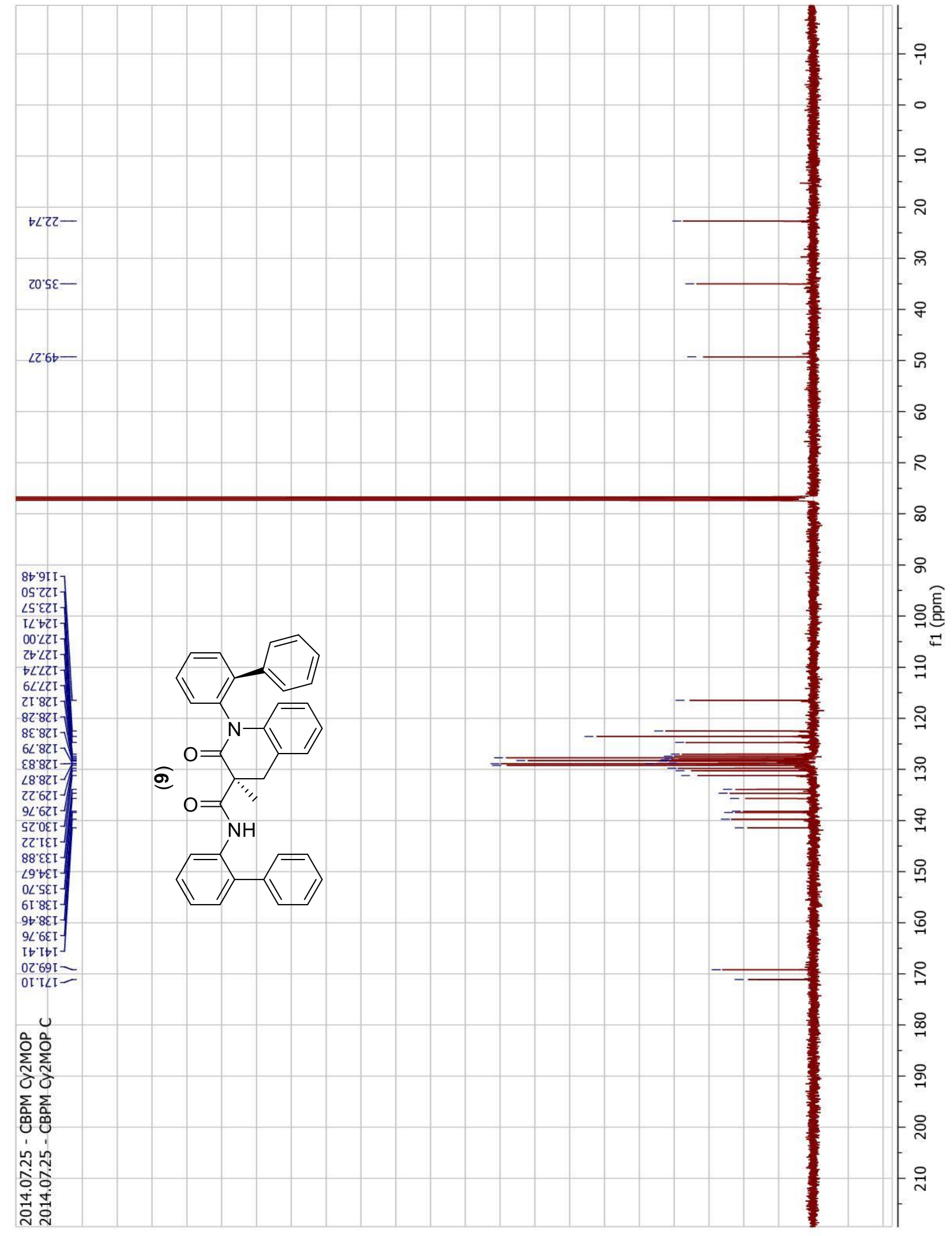




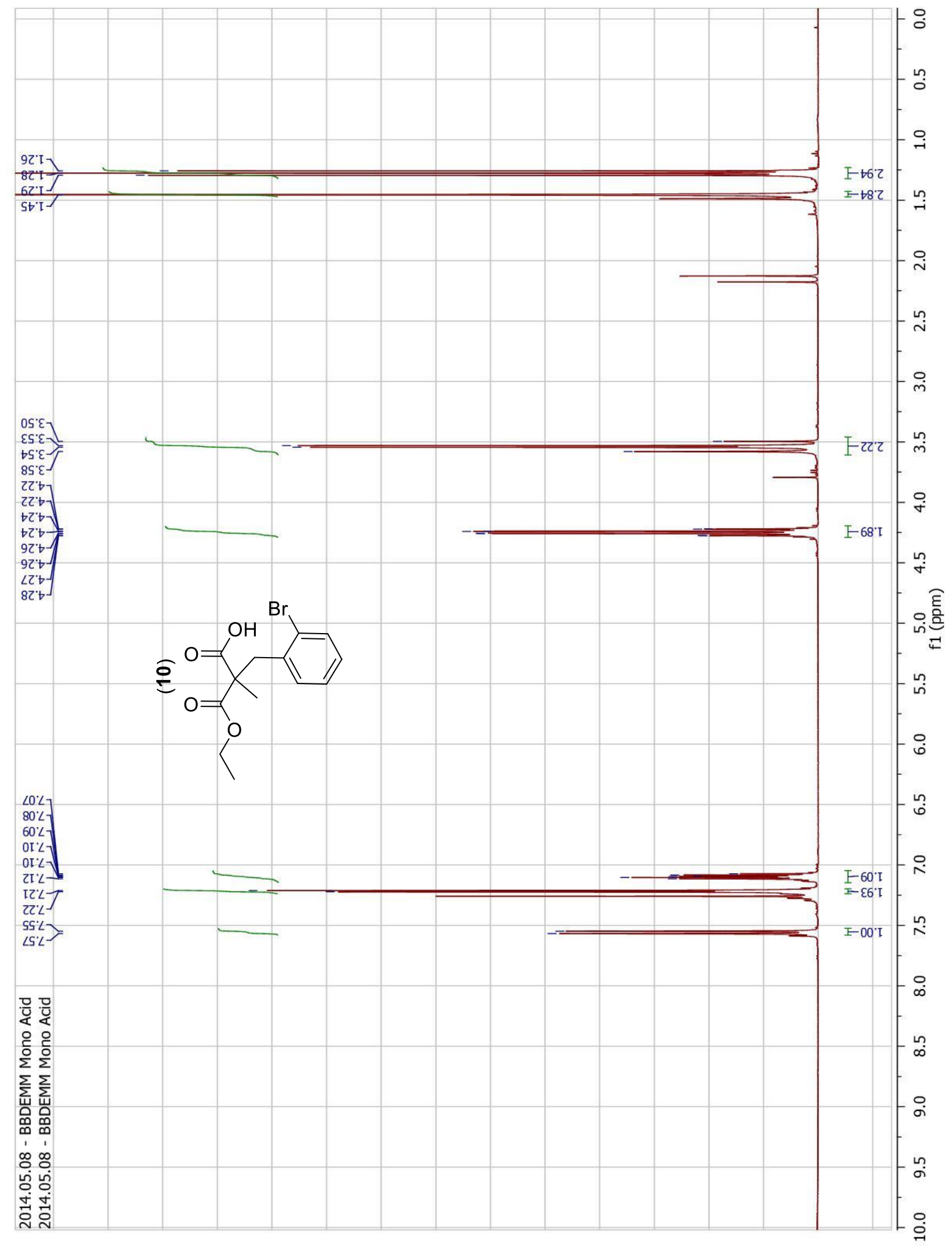




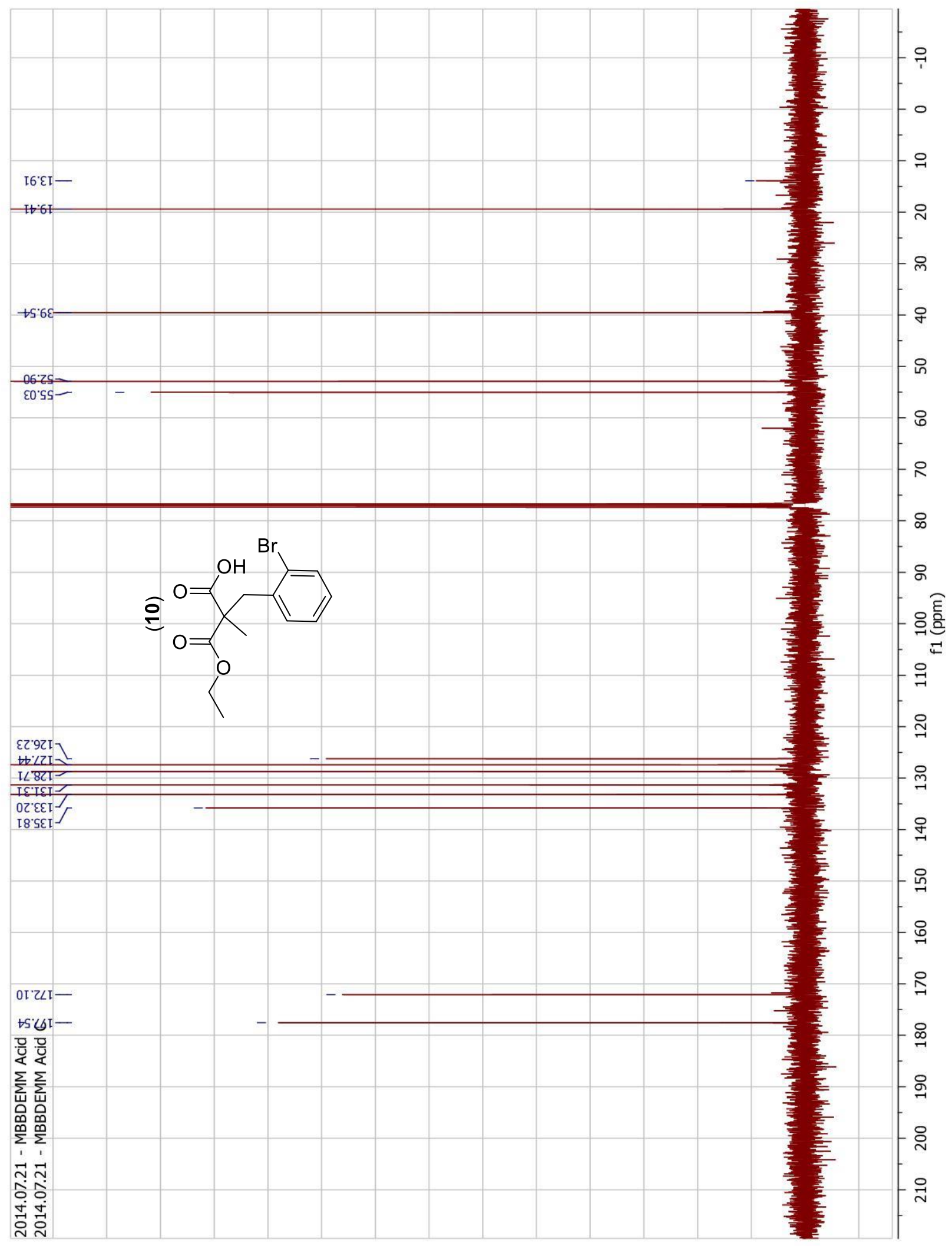

83 


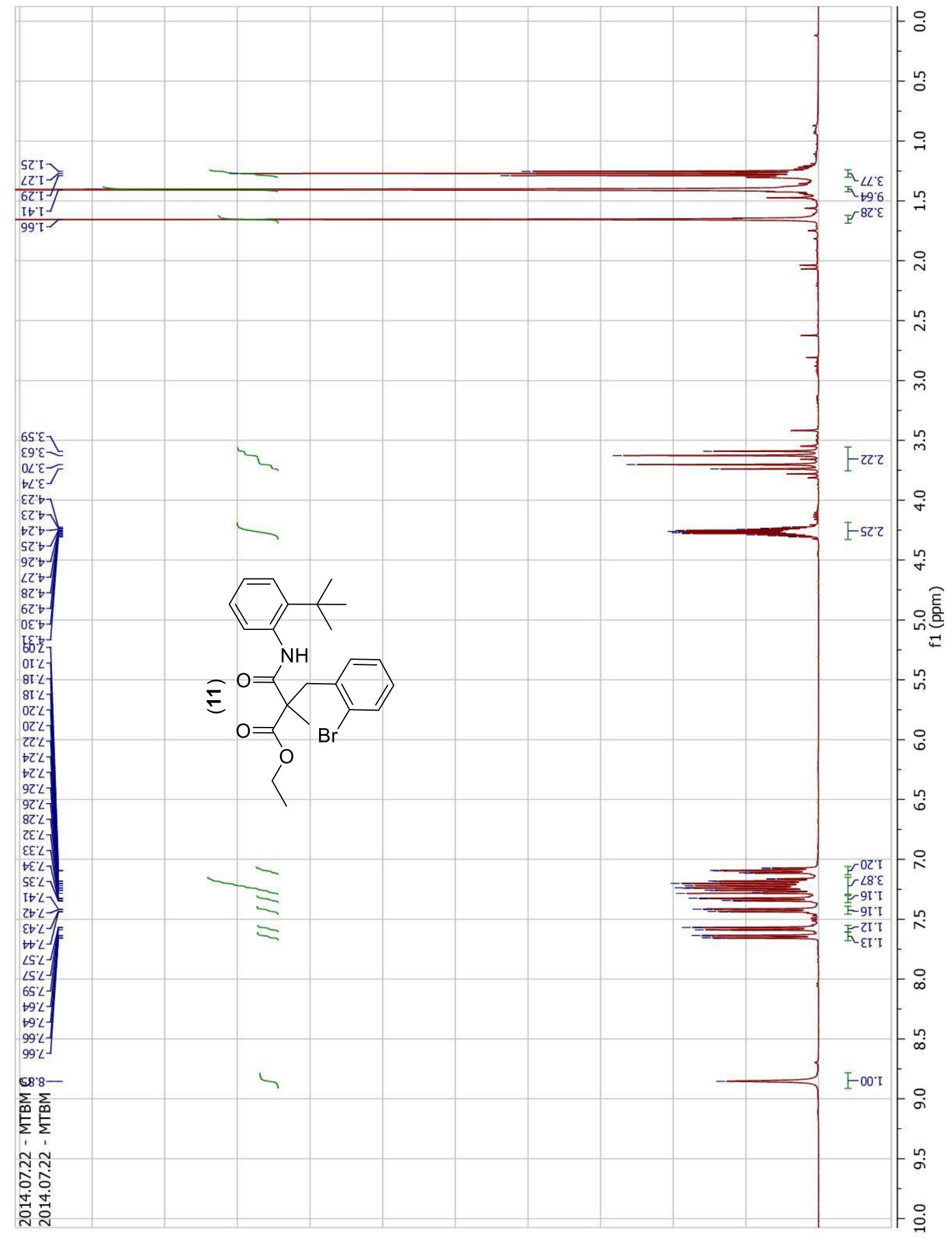




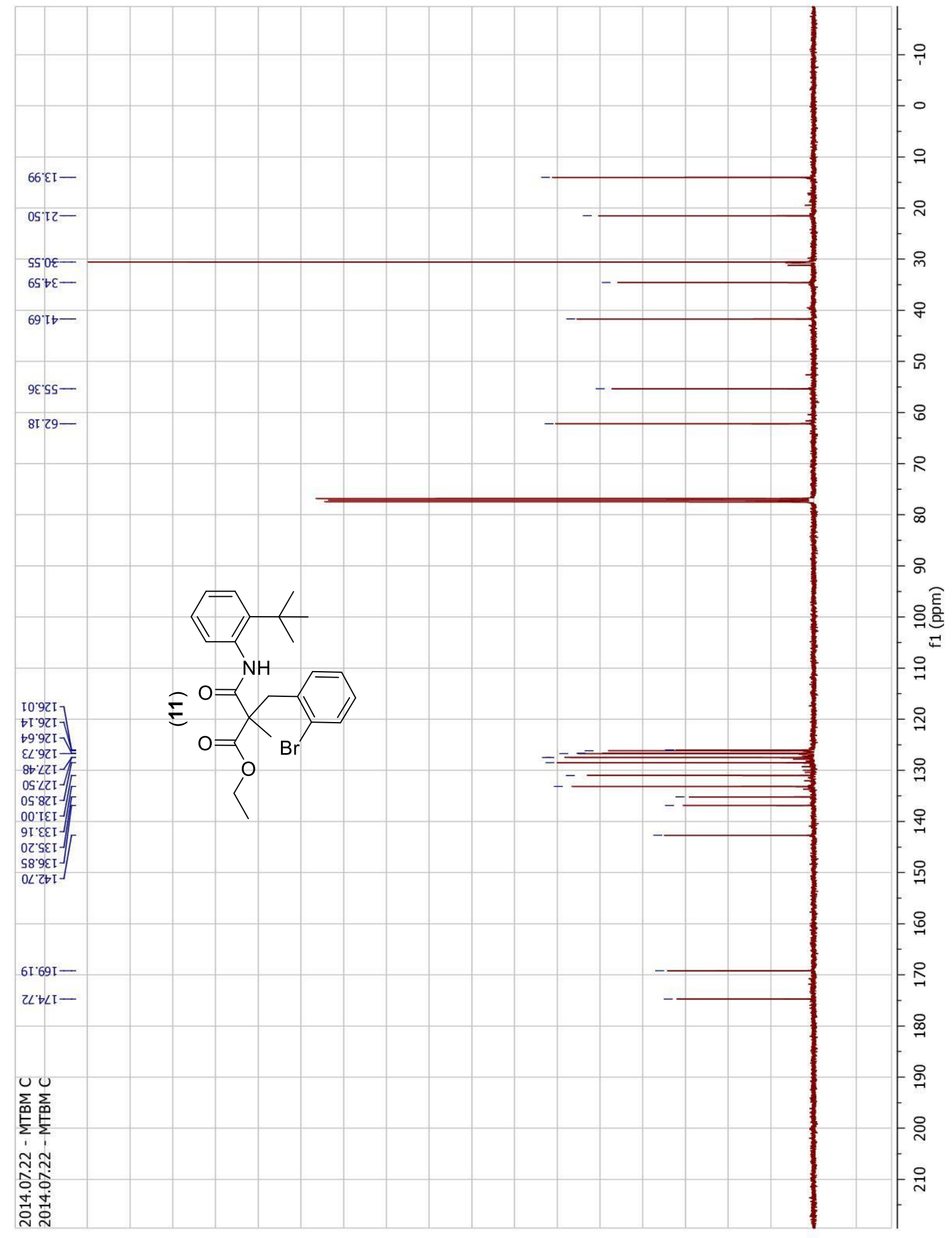




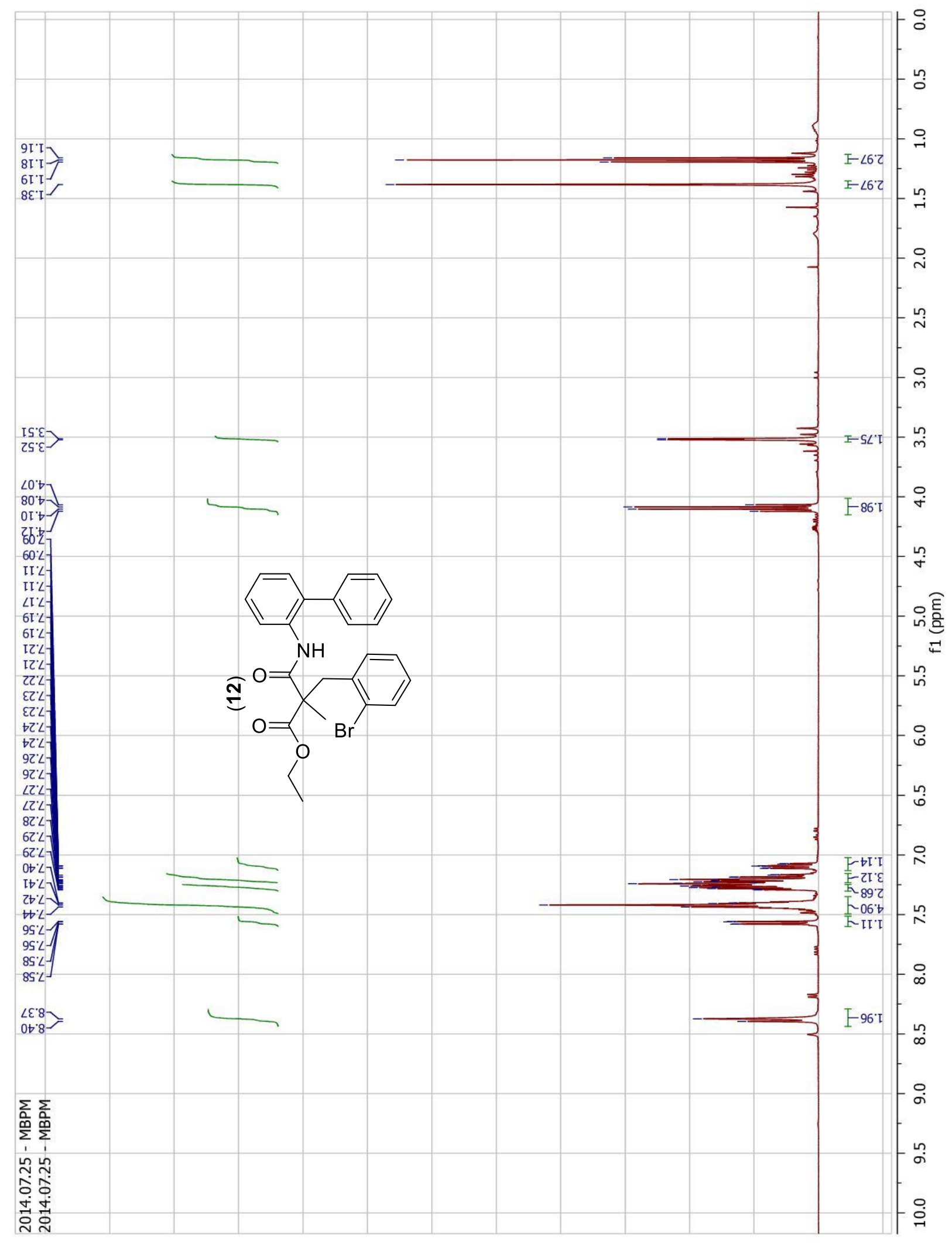




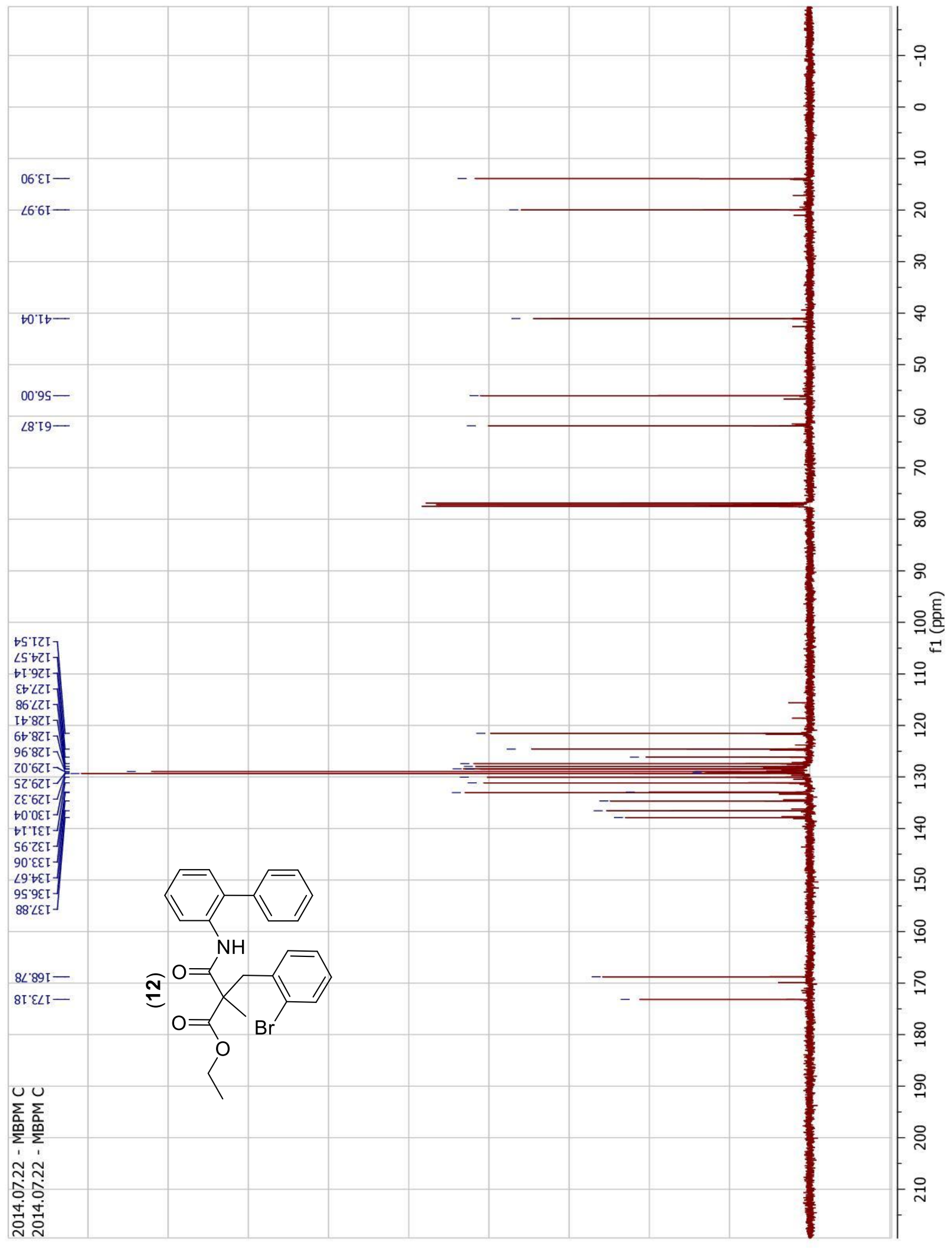




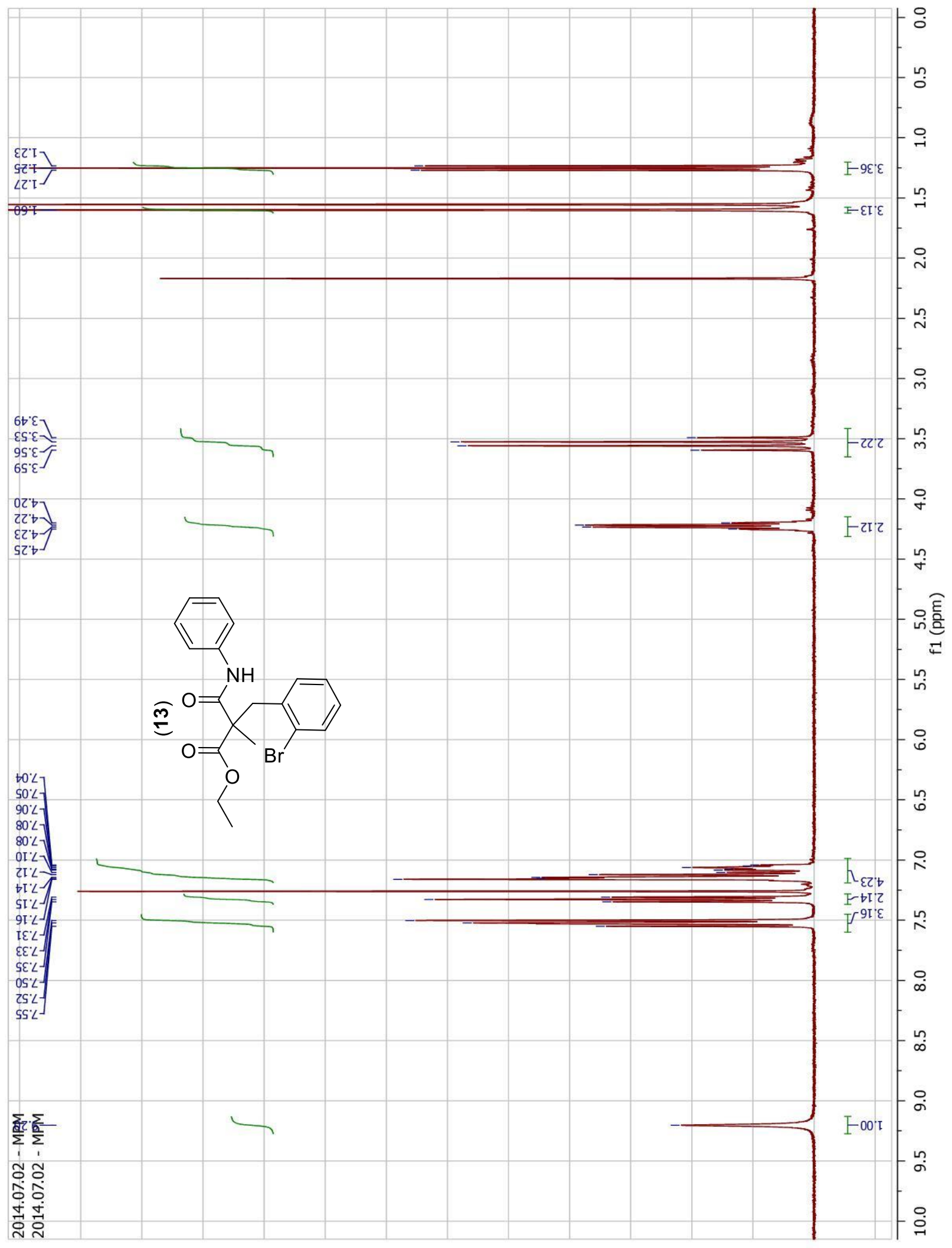




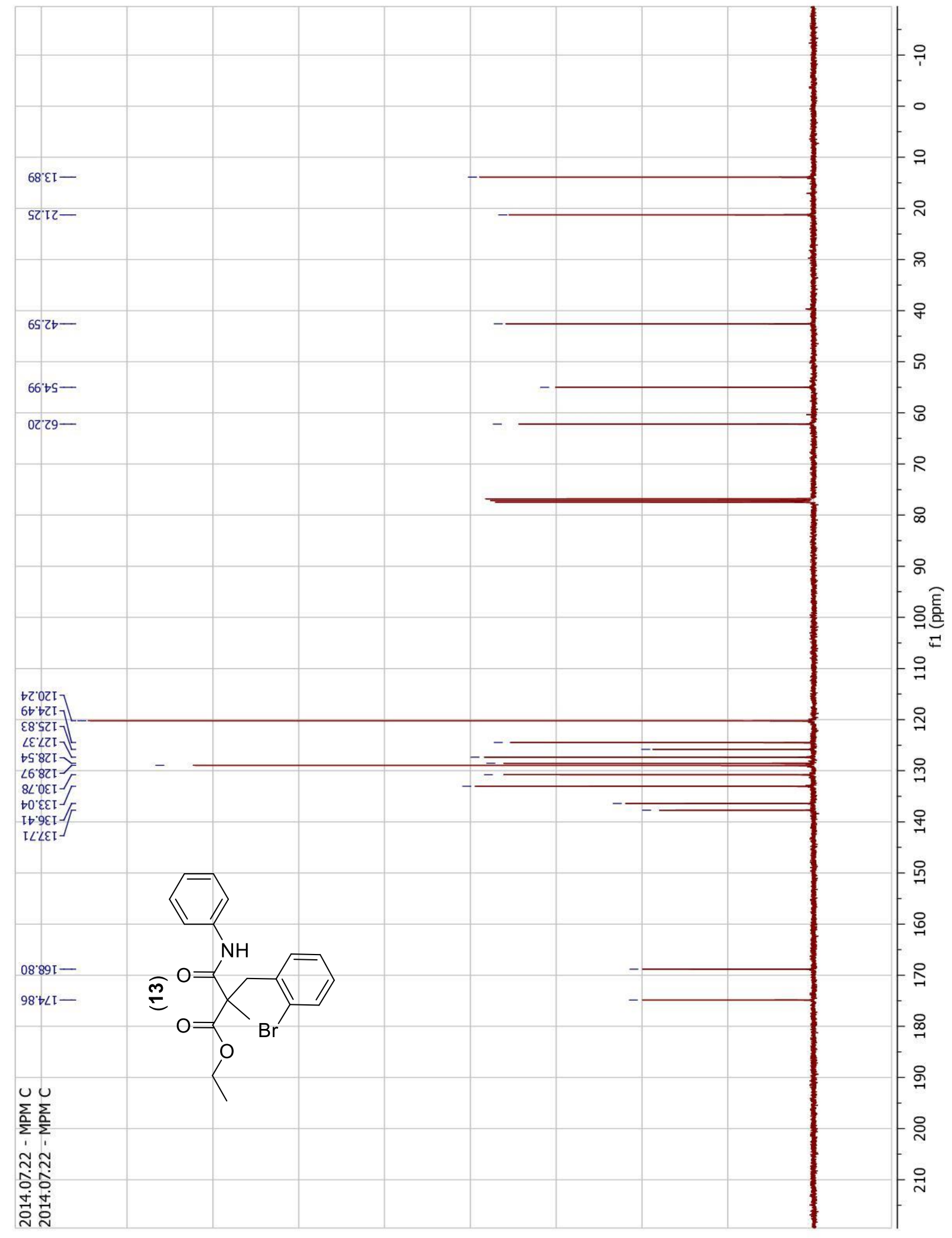




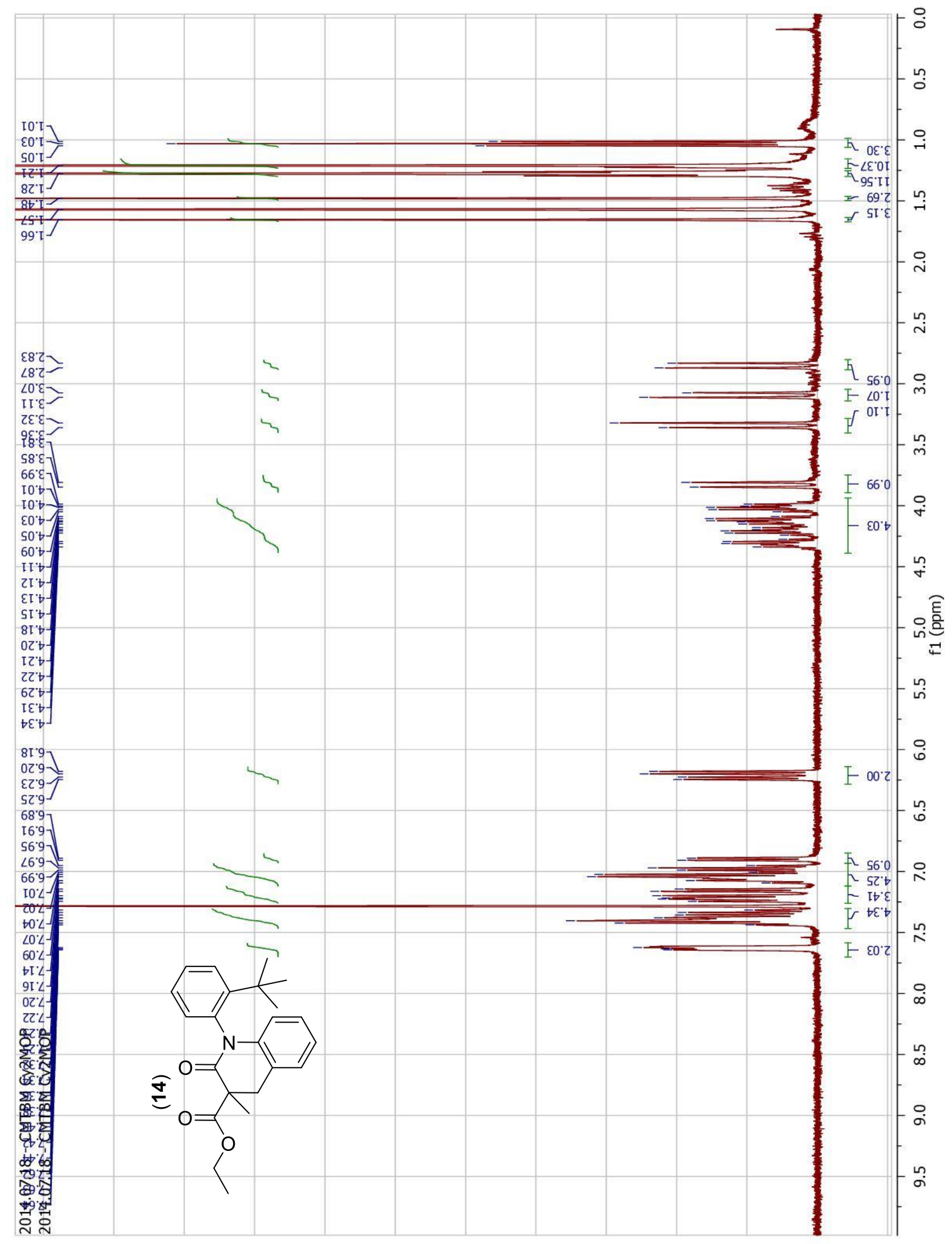




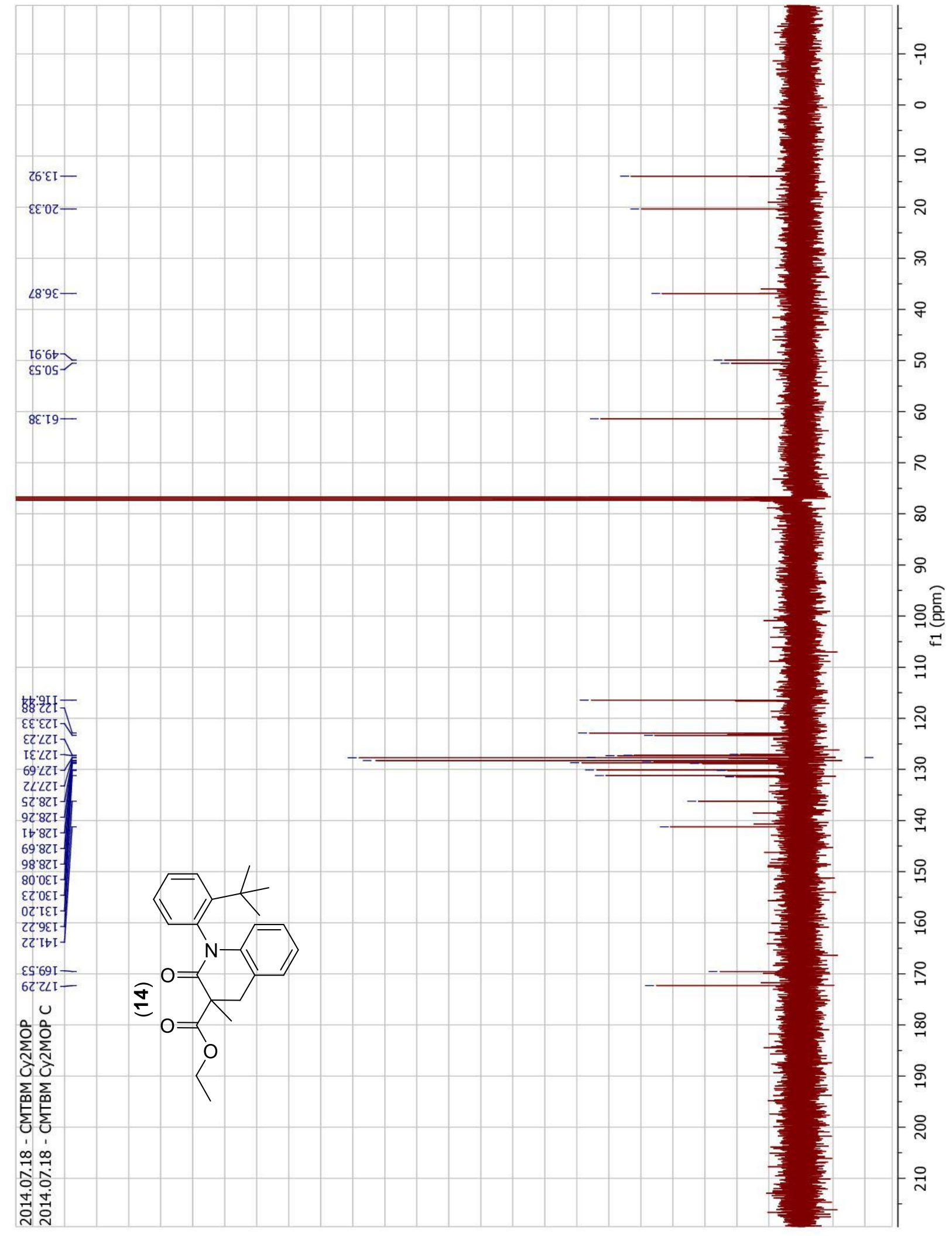




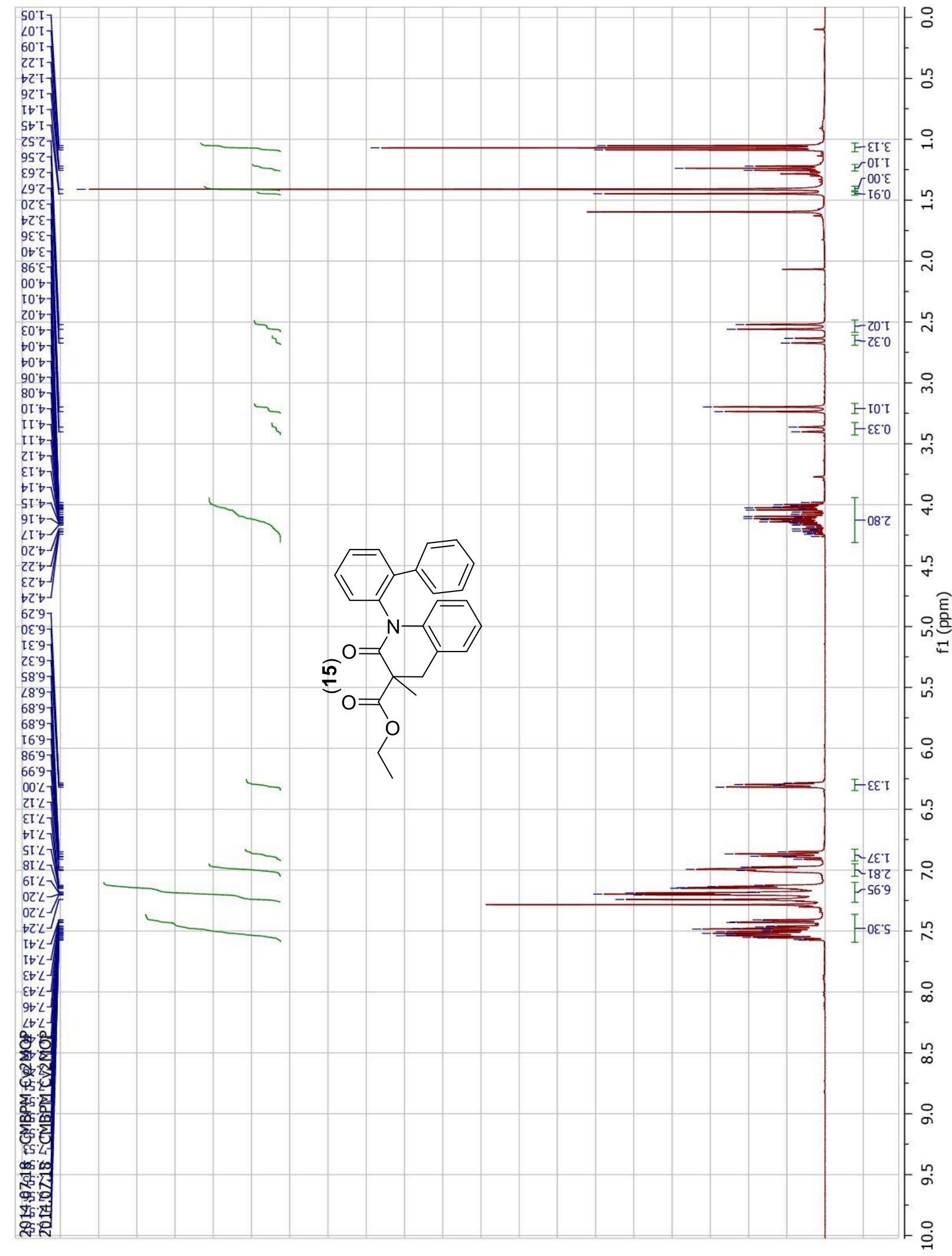




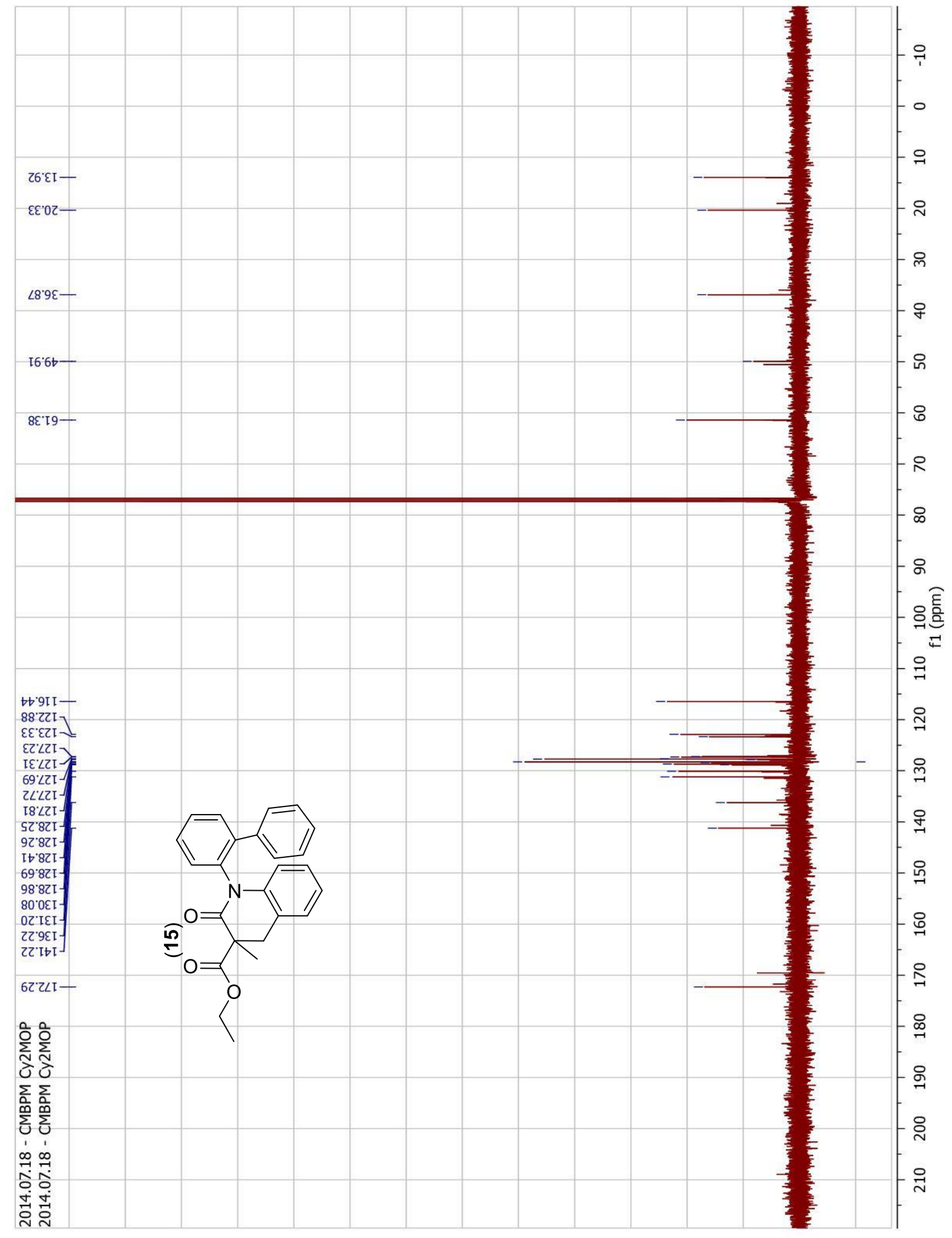




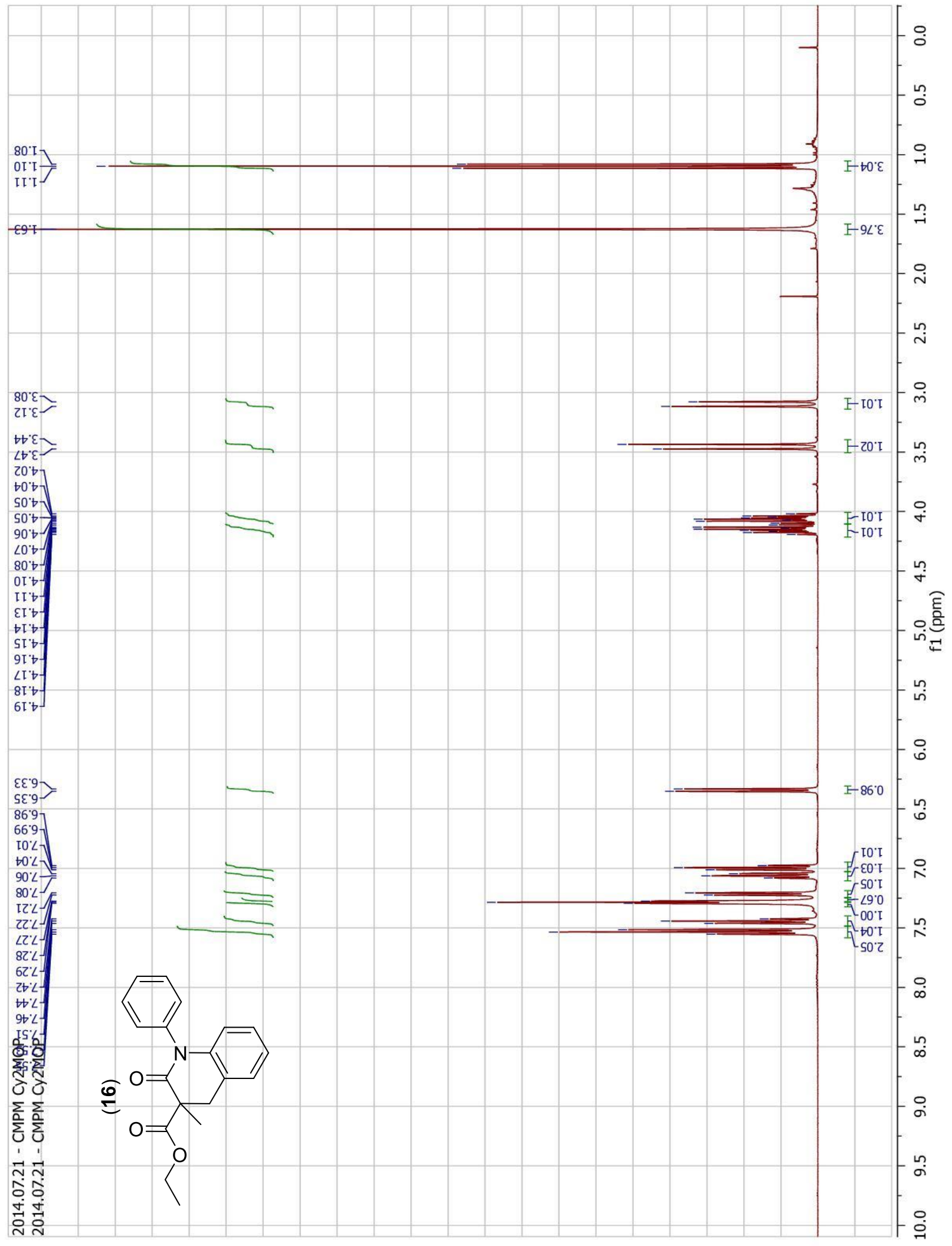




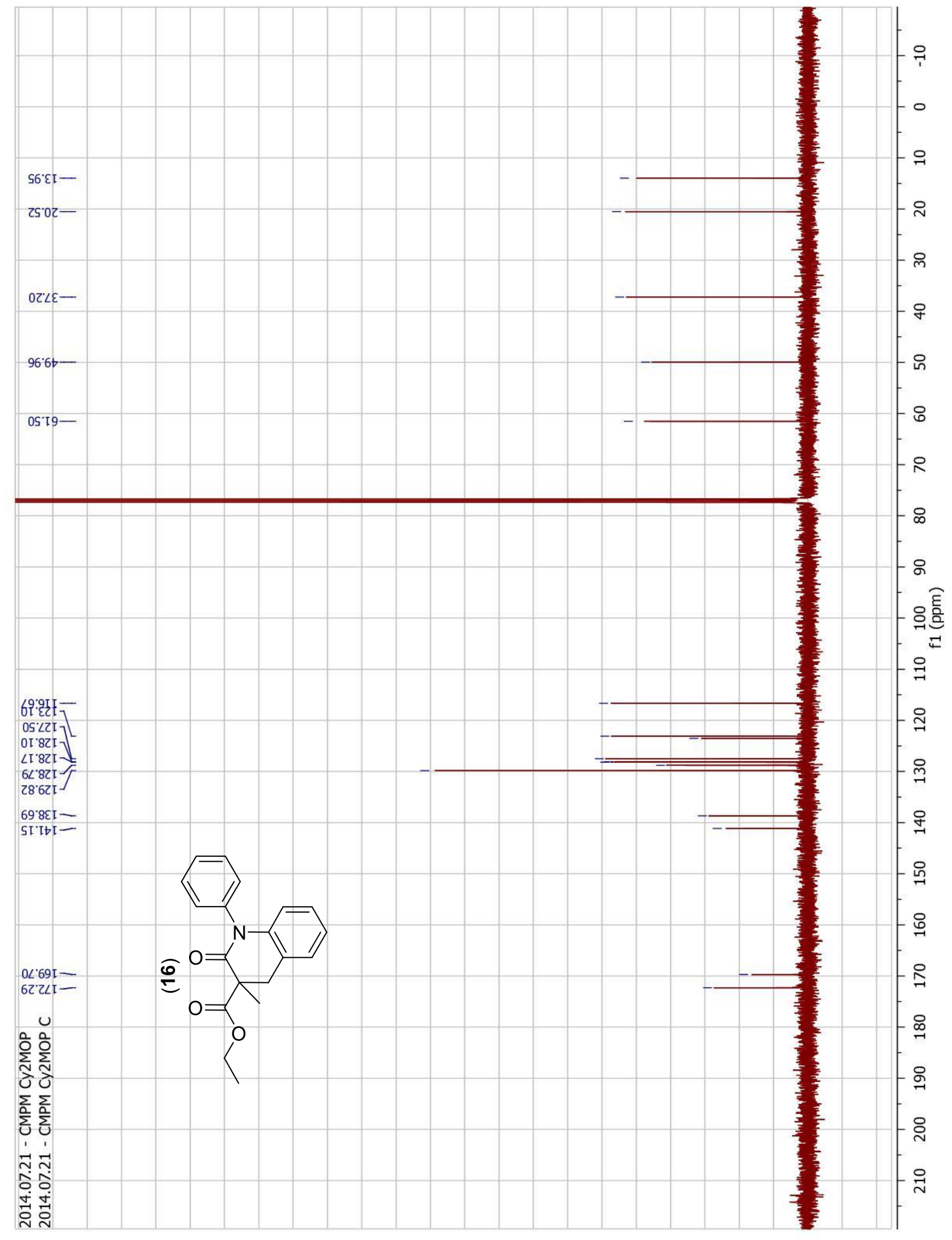




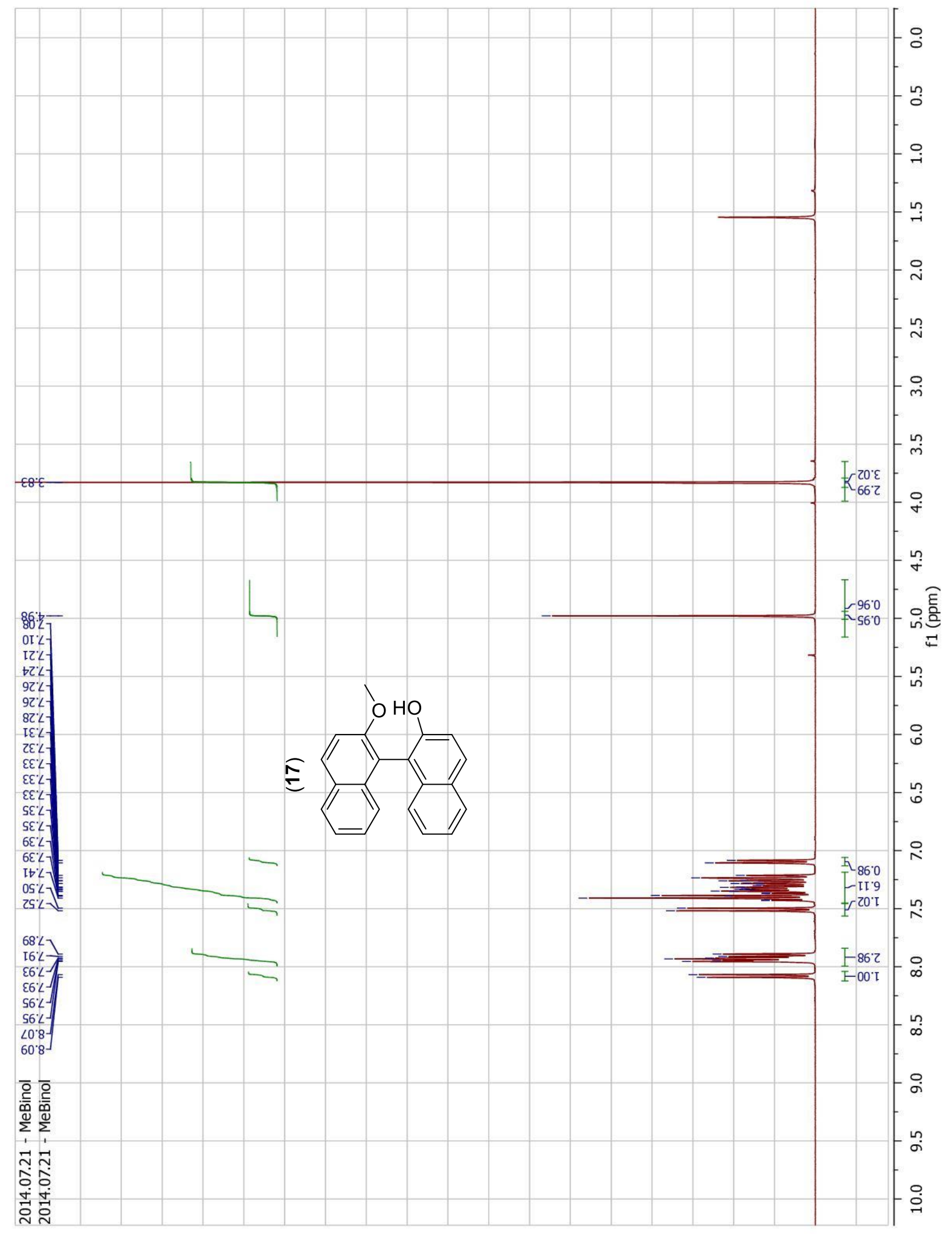




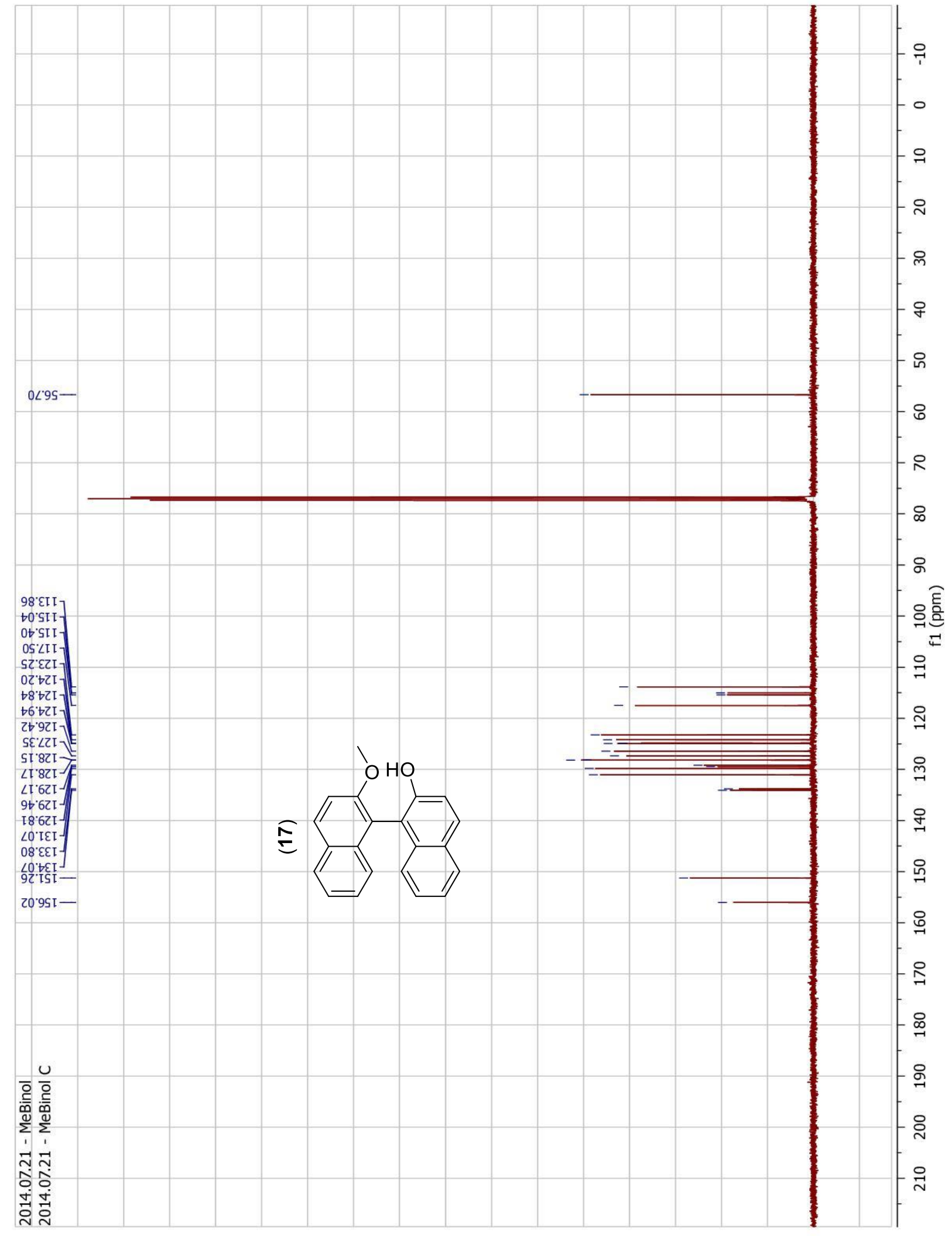




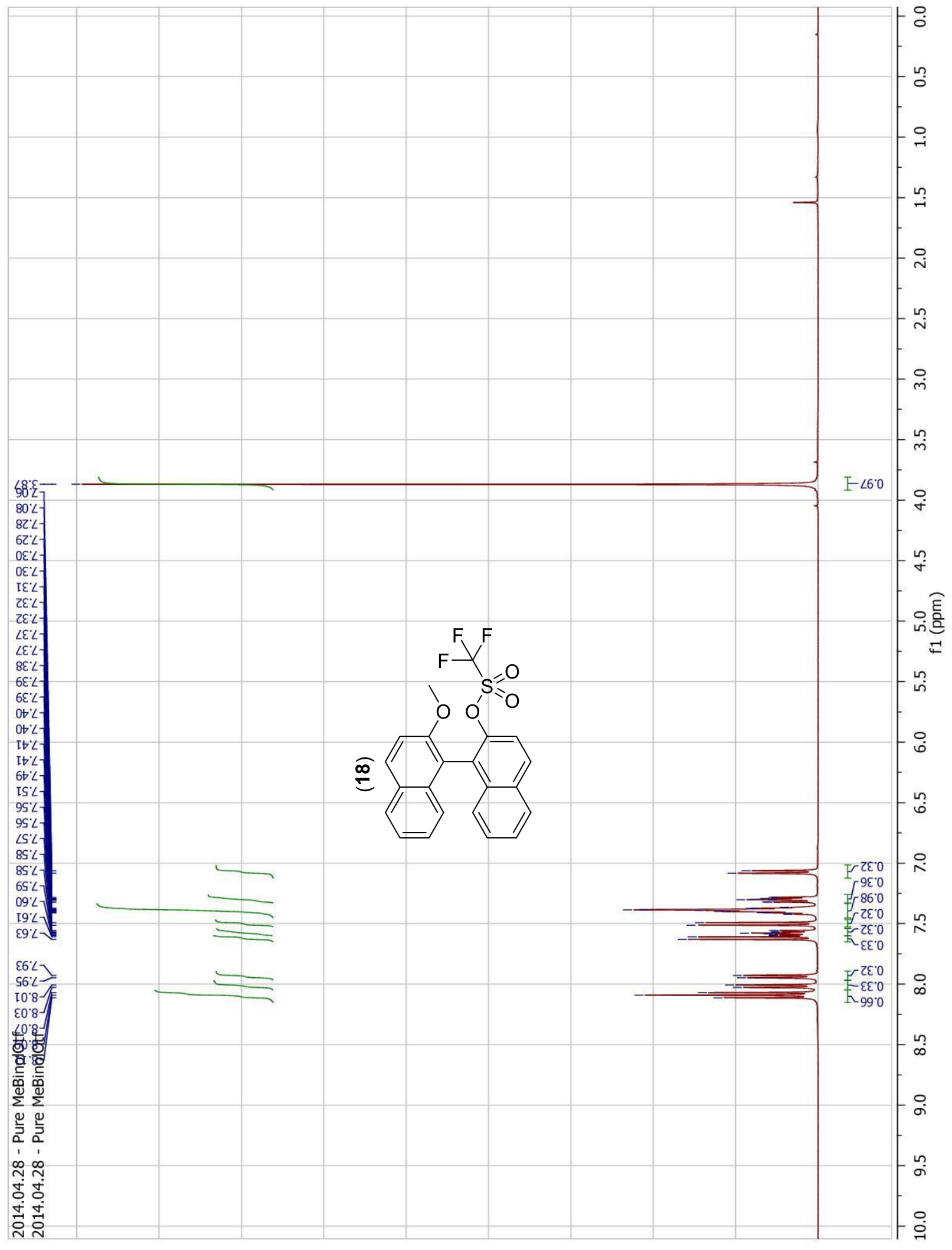




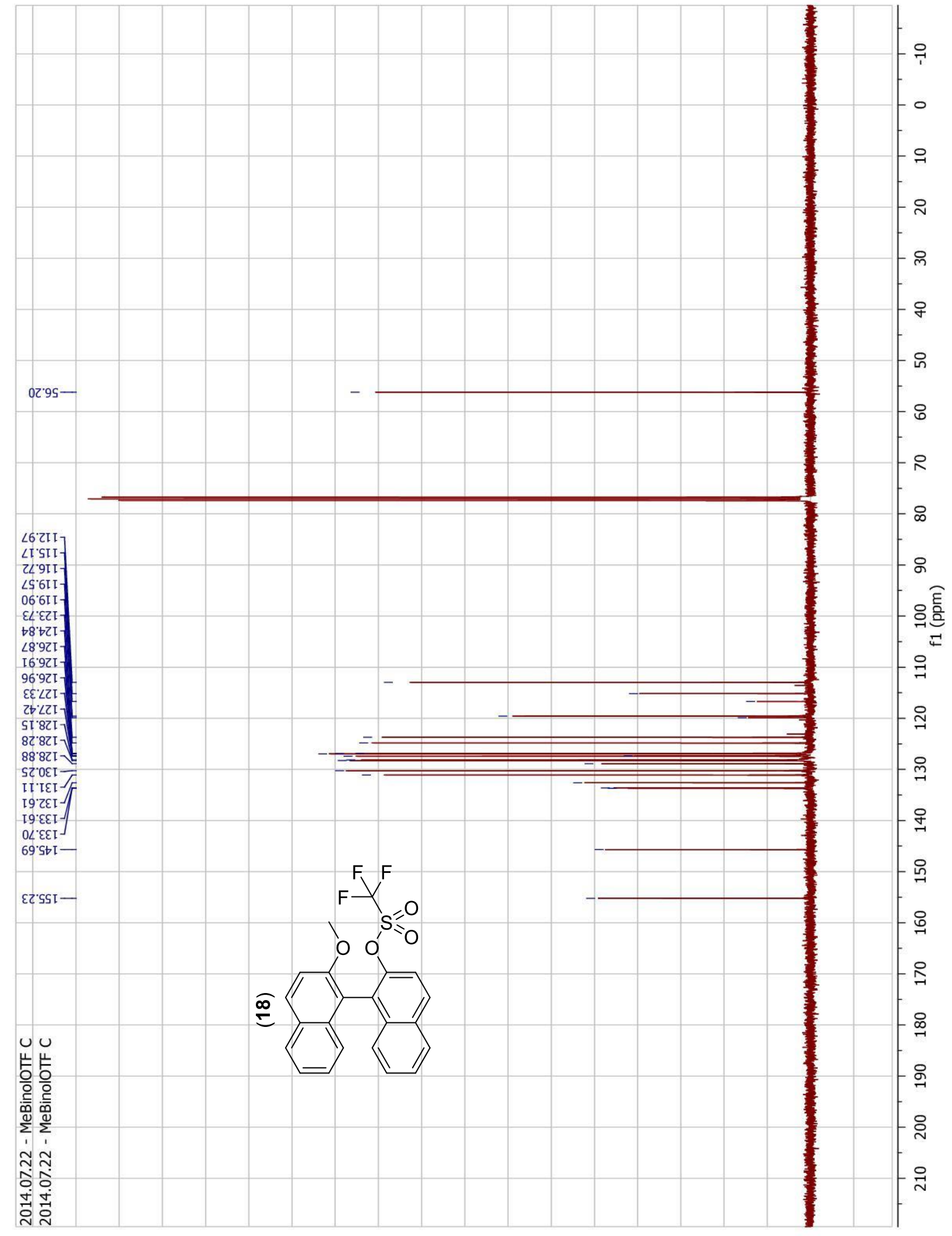




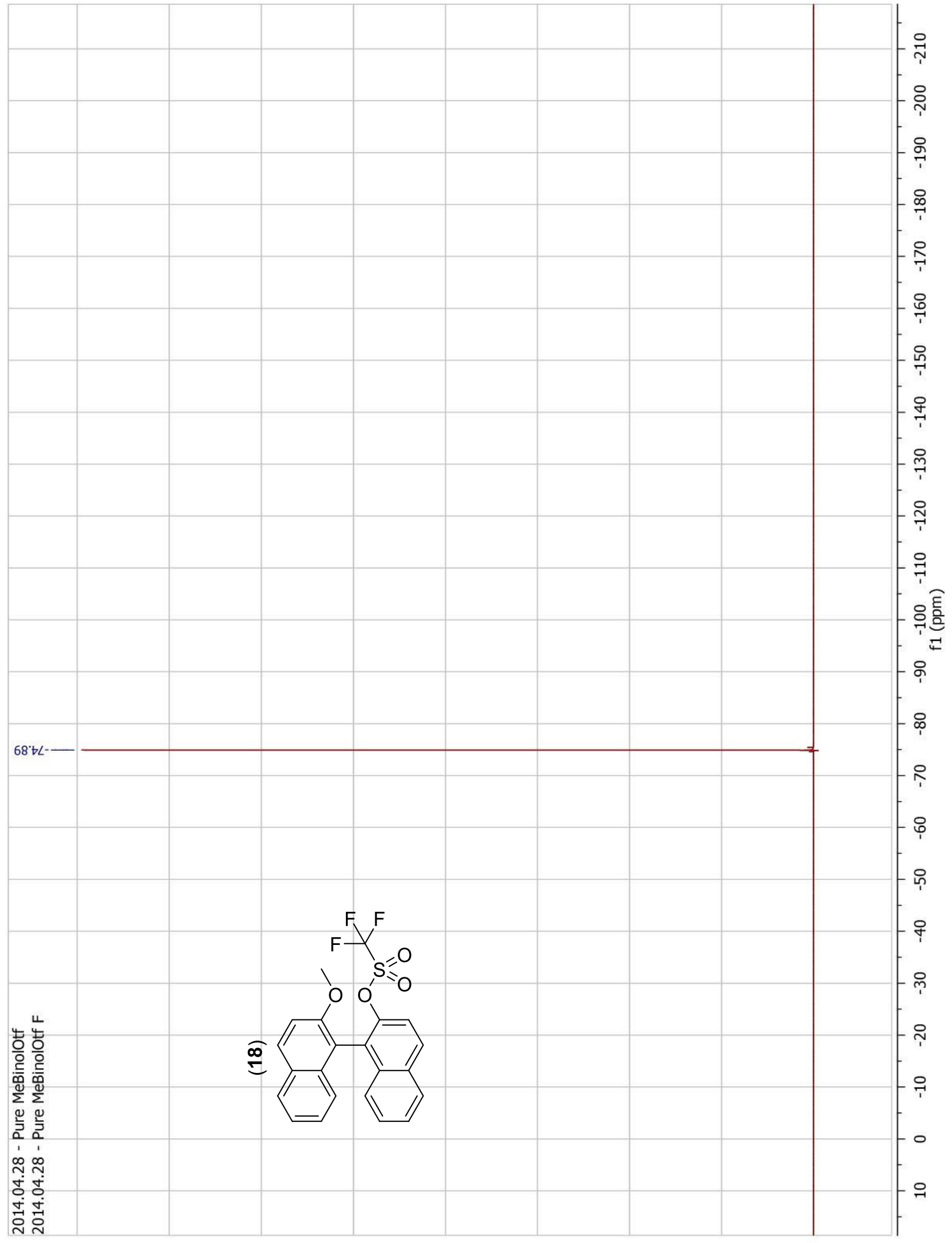




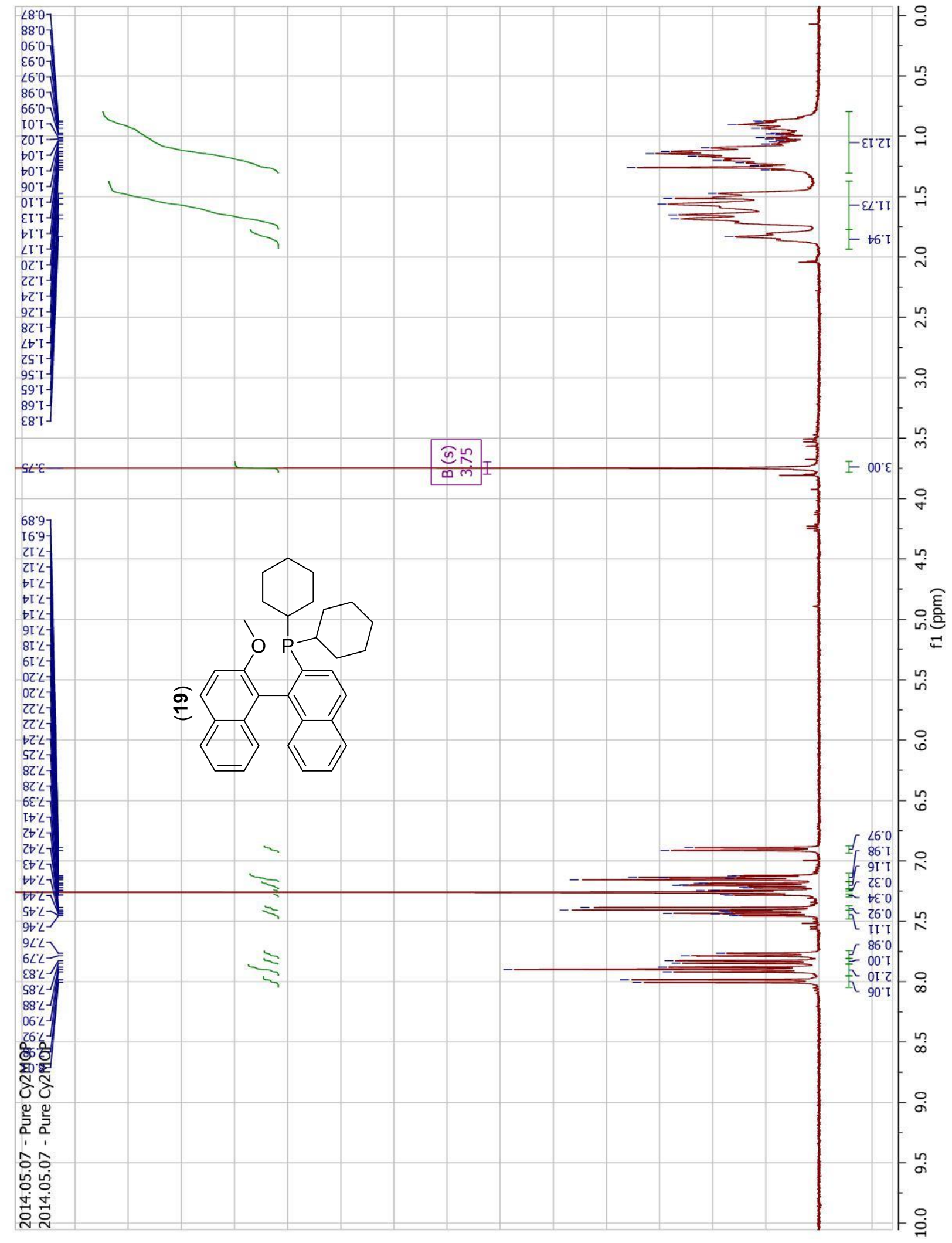




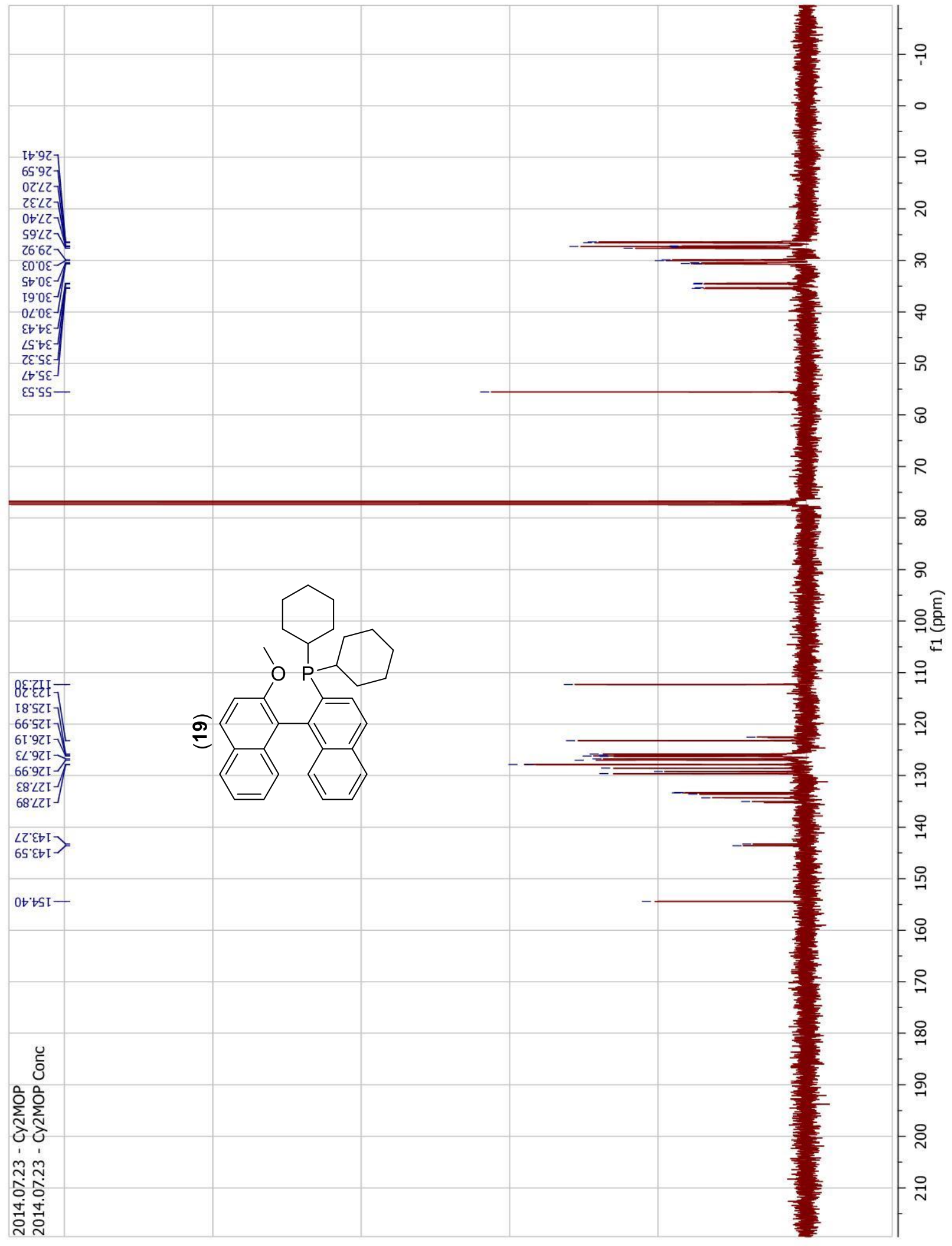




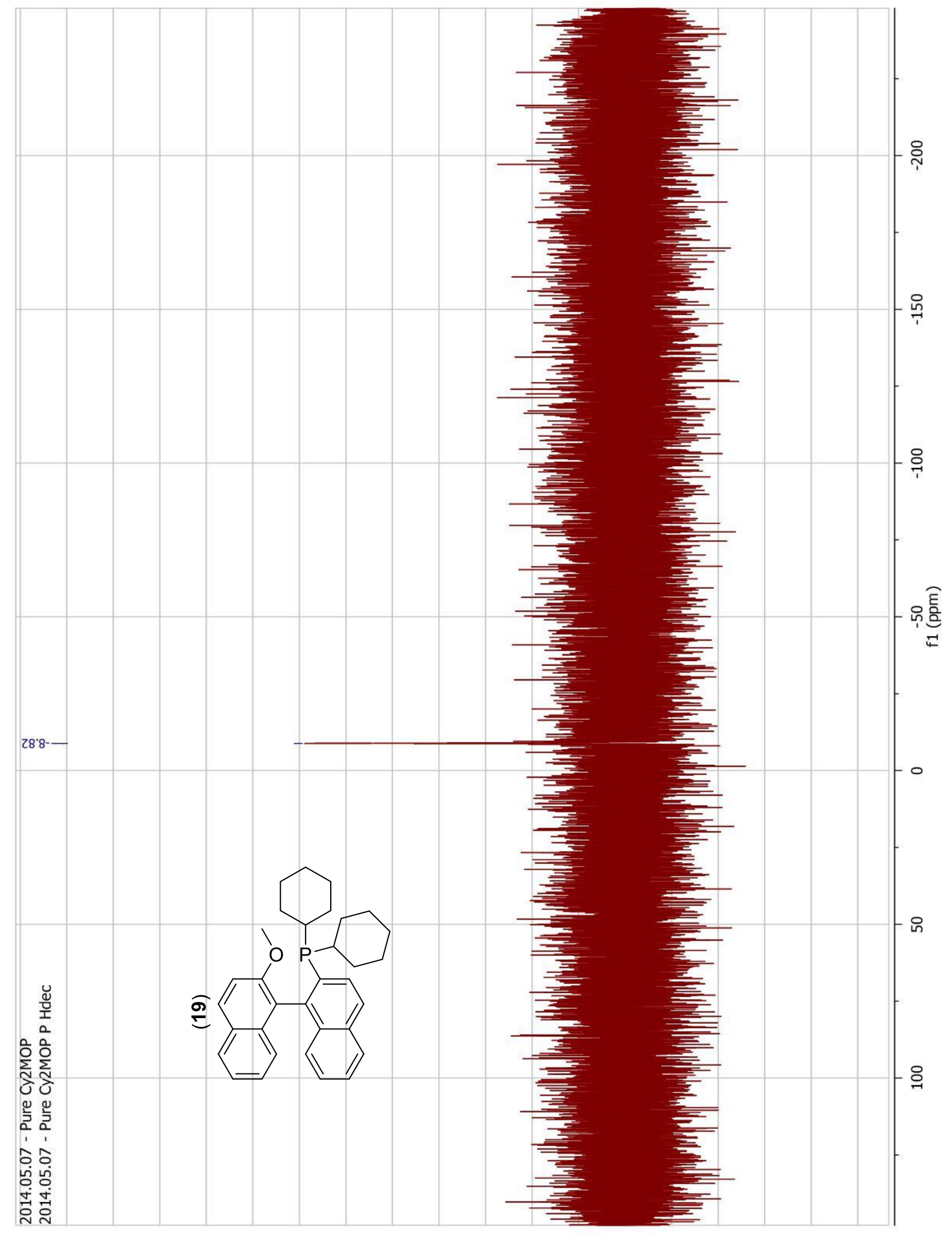


Print of window 38 : Current Chromatogram(s)

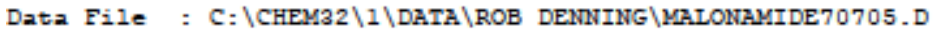

Sample Name : CTBM SPHOS

$==$

Acq. Operator: SYsTEM

Acq. Instrument : Instrument 1

Injection Date : 7/3/2014 1:29:25 PM

Seq. Line : 3

Location : Vial 15

$\operatorname{Inj}: 1$

Acq- Method : C: $\backslash$ CHEM32\} \backslash 1 \backslash \text { METHODS } \backslash \text { RDMTBM.M }

Last changed : 7/3/2014 12:46:13 PM by SYSTEM

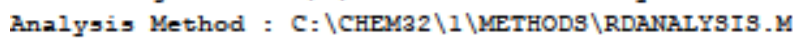

Last changed : 8/21/2014 10:20:31 AM by SYSTEM

Additional Info : Peak(s) manually integrated

Current Chromatogram(s)

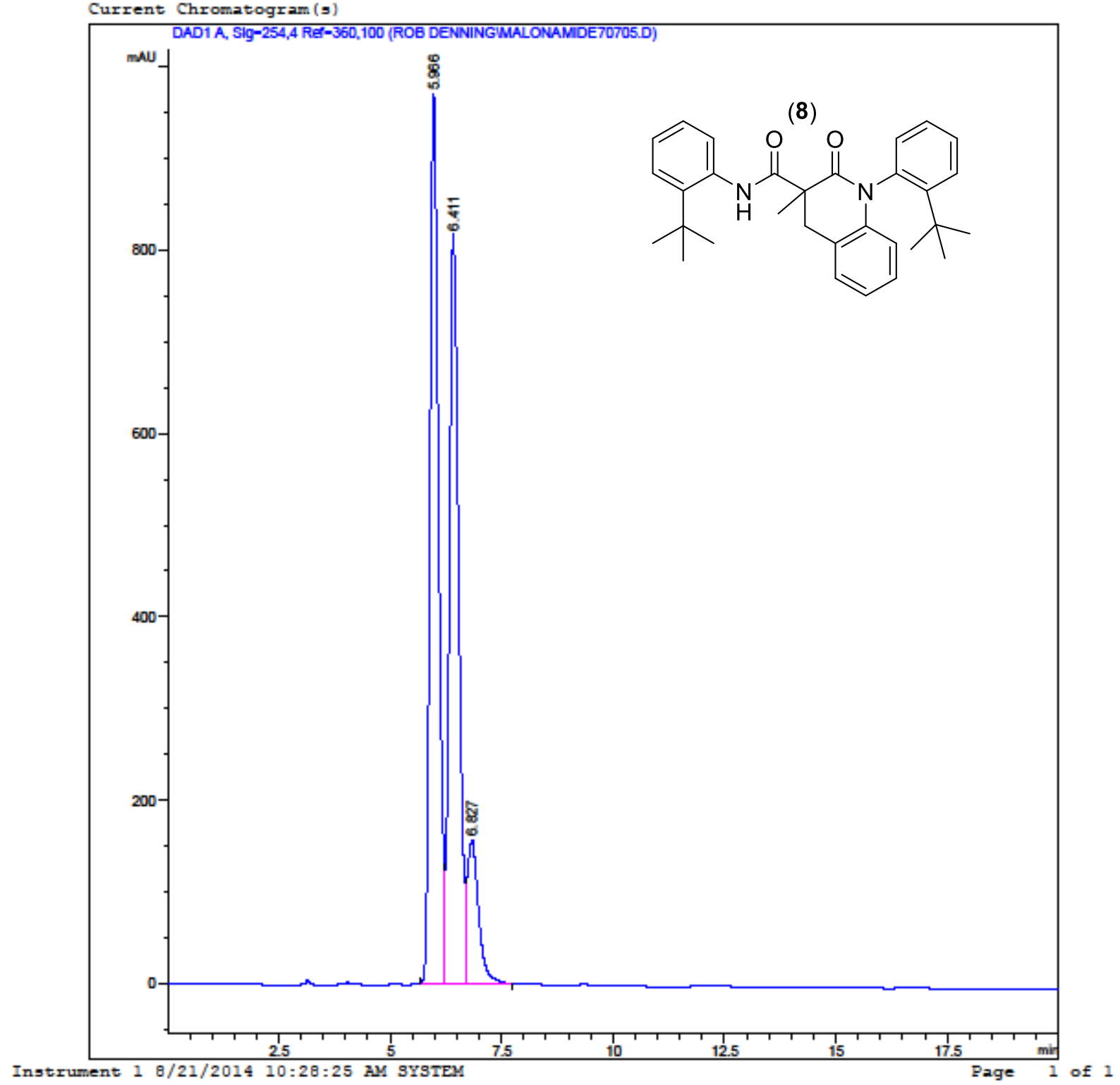




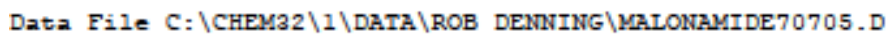

Sample Name: CTBM SPHOS

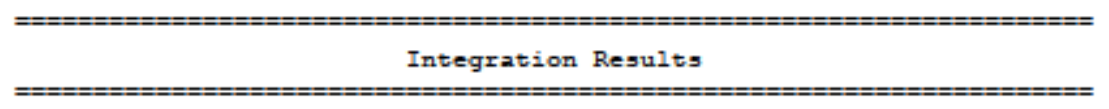

Signal 1: DAD1 A, Sig=254,4 Ref=360,100

\begin{tabular}{|c|c|c|c|c|c|c|c|}
\hline $\begin{array}{c}\text { Peak } \\
\ddagger\end{array}$ & $\begin{array}{l}\text { Time } \\
\text { [min] }\end{array}$ & Type & $\begin{array}{r}\text { Area } \\
\text { [mad*s] }\end{array}$ & $\begin{array}{l}\text { Height } \\
\text { [maU] }\end{array}$ & $\begin{array}{l}\text { Width } \\
\text { [min] }\end{array}$ & $\begin{array}{l}\text { Start } \\
\text { [min] }\end{array}$ & $\begin{array}{l}\text { End } \\
\text { [min] }\end{array}$ \\
\hline$\cdots$ & ----- & $1-3$ & - & $--1--1$ & ---- & ----- & ---- \\
\hline 1 & 5.966 & BV & $1.30622 \mathrm{e} 4$ & 969.74005 & 0.2091 & 5.673 & 6.220 \\
\hline 2 & 6.411 & vV & $1.19770 e^{4}$ & 816.89691 & 0.2251 & 6.220 & 6.693 \\
\hline 3 & 6.827 & VB & 2768.18359 & 157.07123 & 0.2596 & 6.693 & 7.711 \\
\hline
\end{tabular}


Print of window 38 : Current Chromatogram(s)

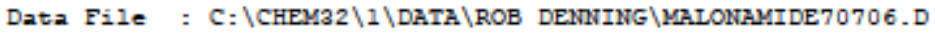

Sample Name : CTBM CY2

\section{(1)}

Acq. Operator : sYsTEM

Acq. Instrument : Instrument 1

Injection Date : 7/3/2014 1:50:28 PM

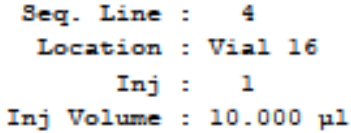

Acq- Method : C: $\backslash$ CHEM $2 \backslash 1 \backslash$ METHODS $\backslash$ RDMTBM.M

Last changed : 7/3/2014 12:46:13 PM bY SYSTEM

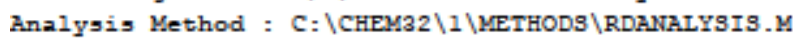

Last changed : 8/21/2014 10:20:31 AM by SYSTEM

Additional Info : Peak(s) manually integrated

Current Chromatogram(s)

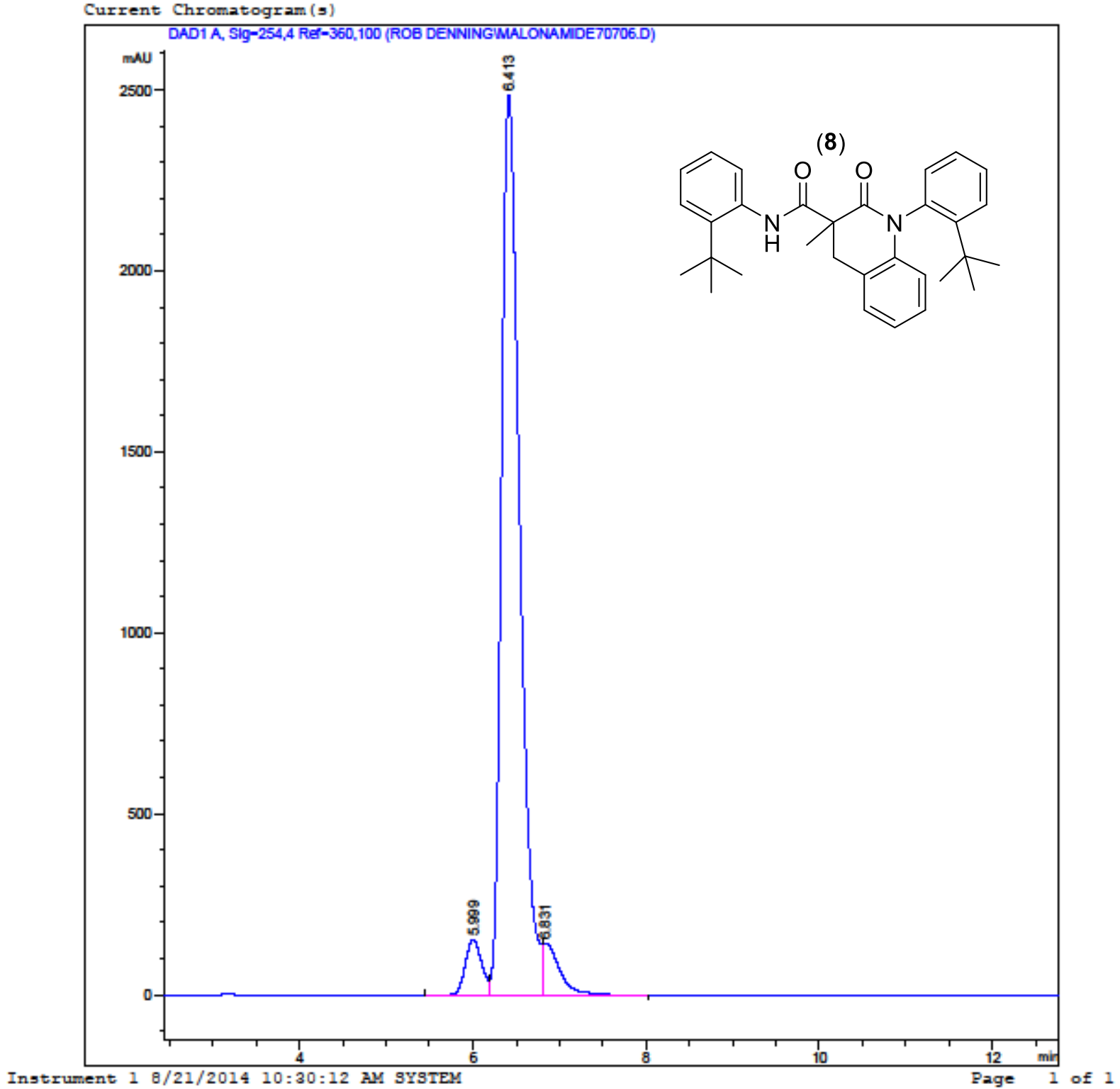




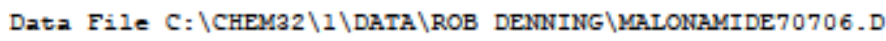

Sample Name: CTBM CY2

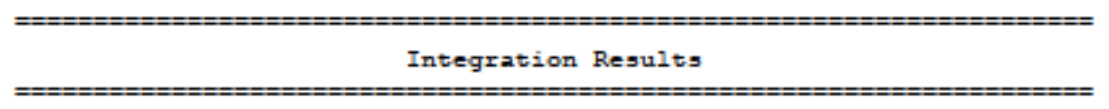

Signal 1: DAD1 A, Sig=254, 4 Ref $=360,100$

\begin{tabular}{|c|c|c|c|c|c|c|c|}
\hline $\begin{array}{c}\text { Peak } \\
\ddagger\end{array}$ & $\begin{array}{l}\text { Time } \\
\text { [min] }\end{array}$ & Type & $\begin{array}{r}\text { Area } \\
{[\mathrm{mAN} s]}\end{array}$ & $\begin{array}{l}\text { Height } \\
\text { [mad] }\end{array}$ & $\begin{array}{l}\text { Width } \\
\text { [min] }\end{array}$ & $\begin{array}{l}\text { Start } \\
\text { [min] }\end{array}$ & $\begin{array}{l}\text { End } \\
\text { [min] }\end{array}$ \\
\hline-1 & ---- & & $---1--1--1$ & - & ----- & 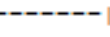 & ------1 \\
\hline 1 & 5.999 & BV & 2030.17273 & 152.66888 & 0.2071 & 5.437 & 6.185 \\
\hline 2 & 6.413 & vV & $3.66176 \mathrm{e} 4$ & 2486.60107 & 0.2258 & 6.185 & 6.800 \\
\hline 3 & 6.831 & VB & 1998.51538 & 142.45128 & 0.2097 & 6.800 & 8.023 \\
\hline
\end{tabular}


Print of all graphic windows

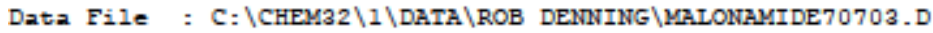

Sample Name : CBPM SPHOS

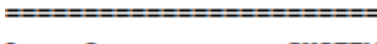

Acq- Operator : SYSTEM

Acq. Instrument : Instrument 1

Injection Date : 7/3/2014 12:47:21 PM

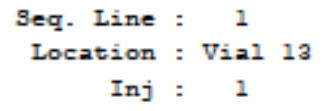

Acq- Method : C: $\backslash$ CHEM32\} \backslash 1 \backslash \text { METHODS } \backslash \text { RDMTBM.M }

Last changed : 7/3/2014 12:46:13 PM by SYSTEM

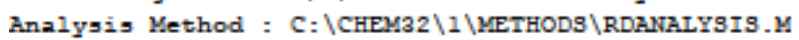

Last changed : 8/21/2014 10:20:31 AM by SYSTEM

Additional Info : Peak(s) manually integrated

Current Chromatogram(s)

(9)

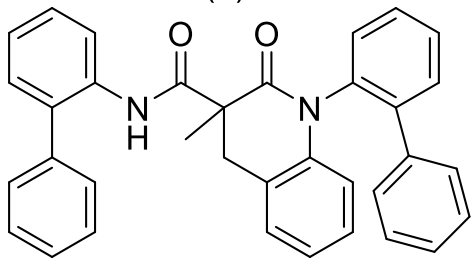

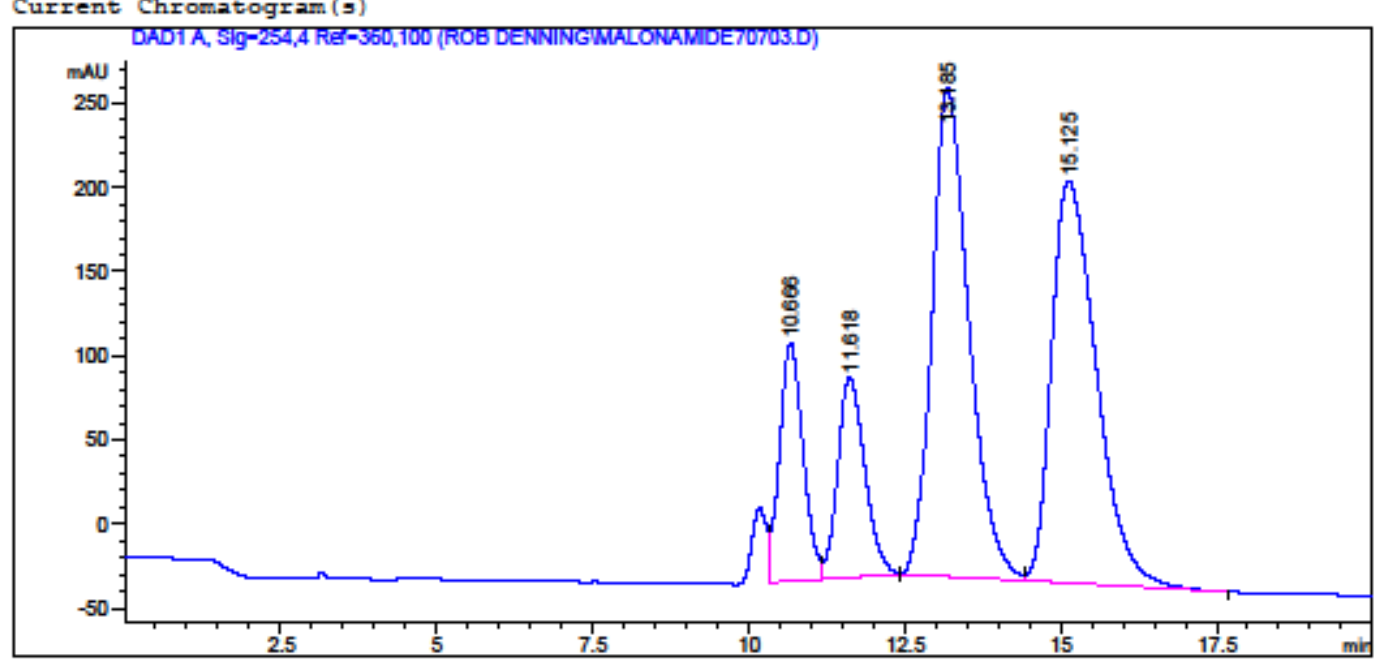




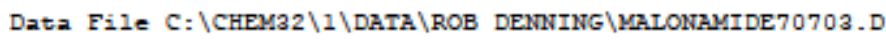

Sample Name: CBPM SPHOS

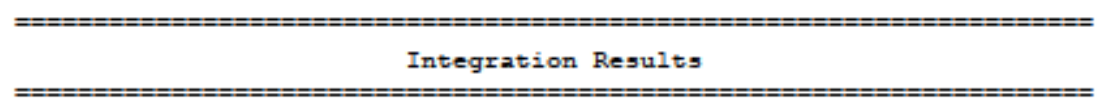

Signal 1: DAD1 A, Sig=254, 4 Ref $=360,100$

\begin{tabular}{|c|c|c|c|c|c|c|c|}
\hline $\begin{array}{c}\text { Peak } \\
\ddagger\end{array}$ & $\begin{array}{l}\text { Time } \\
\text { [min] }\end{array}$ & Type & $\begin{array}{r}\text { Area } \\
{\left[m U^{*} s\right]}\end{array}$ & $\begin{array}{l}\text { Height } \\
\text { [mad] }\end{array}$ & $\begin{array}{l}\text { Width } \\
\text { [min] }\end{array}$ & $\begin{array}{l}\text { Start } \\
\text { [min] }\end{array}$ & $\begin{array}{l}\text { End } \\
\text { [min] }\end{array}$ \\
\hline-1 & ------ & & - & - n-n. & 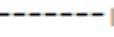 & $--\infty$ & $-\cdots$ \\
\hline 1 & 10.666 & vV & 3693.66138 & 141.52080 & 0.4005 & 10.331 & 11.179 \\
\hline 2 & 11.618 & VB & 3582.96191 & 118.78698 & 0.4659 & 11.179 & 12.420 \\
\hline 3 & 13.185 & BV & $1.19085 \mathrm{e} 4$ & 290.71176 & 0.6179 & 12.420 & 14.405 \\
\hline 4 & 15.125 & VBA & $1.19644 e^{4}$ & 239.17972 & 0.7856 & 14.405 & 17.676 \\
\hline
\end{tabular}


Print of window 38 : Current Chromatogram(s)

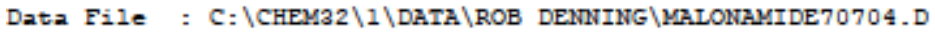

Sample Name: CBPM CY2

\section{(1)}

Acq. Operator : sYsTEM

Acq. Instrument : Instrument 1

Injection Date : 7/3/2014 1:08:23 PM

Seq. Line : 2

Location : Vial 14

$\operatorname{Inj}: 1$

Inj Volume : $10.000 \mathrm{\mu l}$

Acq- Method : C: $\backslash$ CHEM32\} \backslash 1 \backslash \text { METHODS } \backslash \text { RDMTBM.M }

Last changed : 7/3/2014 12:46:13 PM by SYSTEM

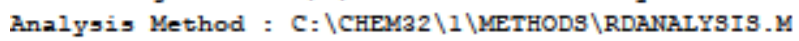

Last changed : 8/21/2014 10:20:31 AM by SYSTEM

Additional Info : Peak(s) manually integrated

Current Chromatogram (s)

(9)

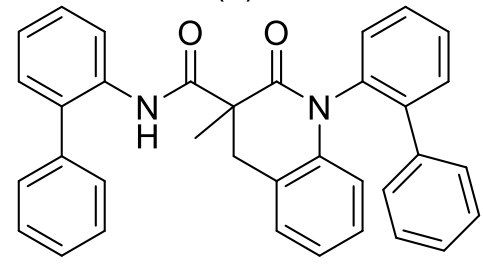

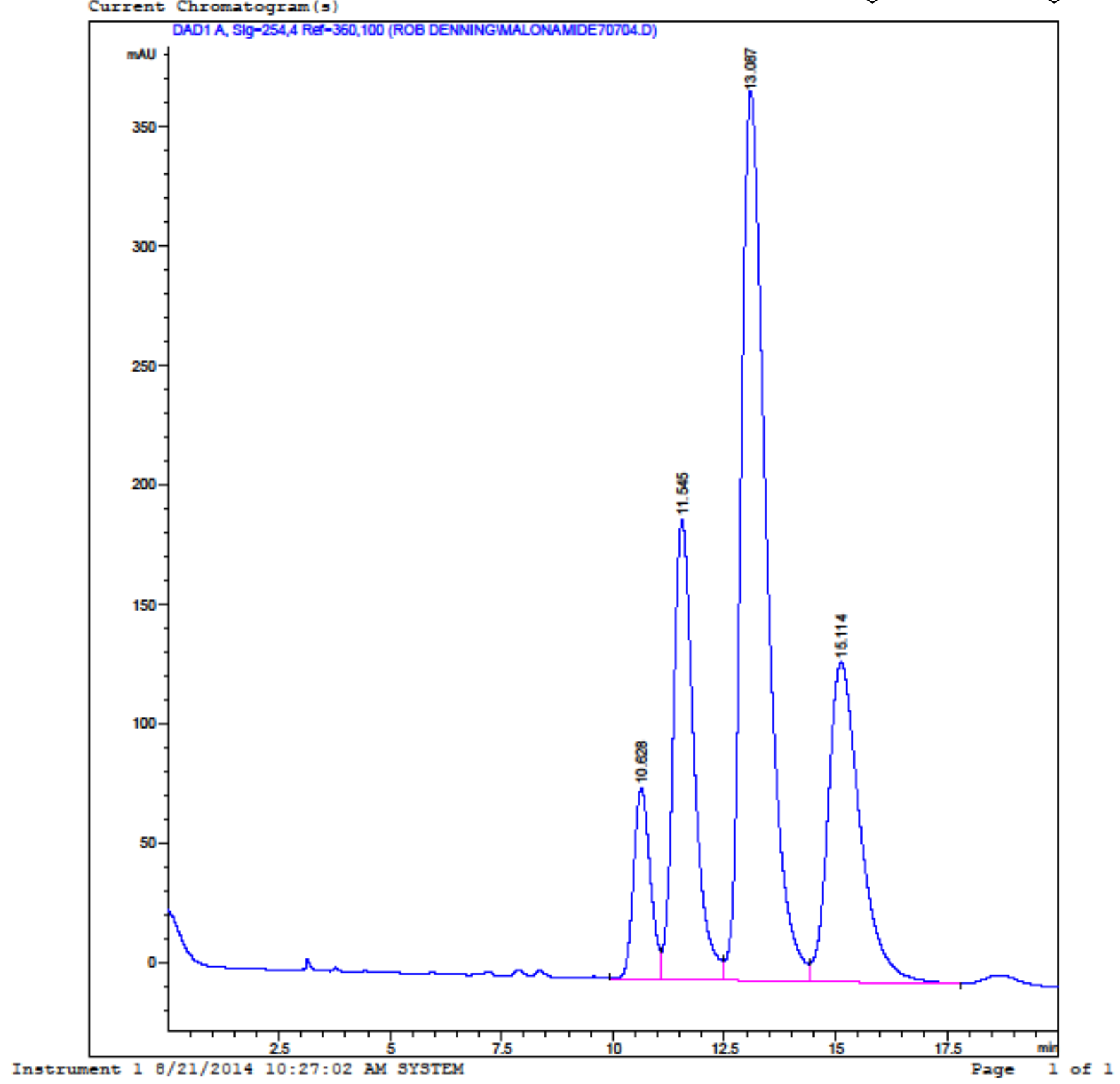


Data File C: \CHEM32\1\DATA \ROB DENIING \MaLONaMIDE70704.D

Sample Name: CBPM CY2

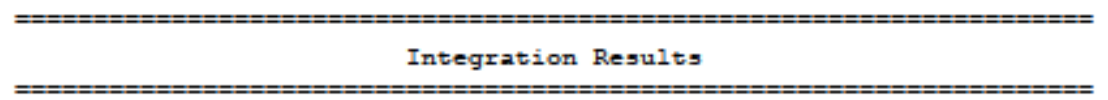

Signal 1: DAD1 A, Sig=254, 4 Ref $=360,100$

\begin{tabular}{|c|c|c|c|c|c|c|c|}
\hline $\begin{array}{c}\text { Peak } \\
\ddagger\end{array}$ & $\begin{array}{l}\text { Time } \\
\text { [min] }\end{array}$ & Type & $\begin{array}{r}\text { Area } \\
\text { [mad*s] }\end{array}$ & $\begin{array}{l}\text { Height } \\
\text { [mad] }\end{array}$ & $\begin{array}{l}\text { Width } \\
\text { [min] }\end{array}$ & $\begin{array}{l}\text { Start } \\
\text { [min] }\end{array}$ & $\begin{array}{l}\text { End } \\
\text { [min] }\end{array}$ \\
\hline- & & & $-\cdots-1$ & 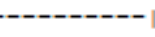 & 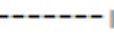 & 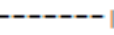 & $-\cdots$ \\
\hline 1 & 10.628 & BV & 2072.21118 & 80.13913 & 0.3997 & 9.935 & 11.076 \\
\hline 2 & 11.545 & vV & 6178.20801 & 192.70490 & 0.4860 & 11.076 & 12.472 \\
\hline 3 & 13.087 & vV & $1.47449 e 4$ & 372.27863 & 0.6001 & 12.472 & 14.399 \\
\hline 4 & 15.114 & VB & 6627.40869 & 133.83157 & 0.7477 & 14.399 & 17.808 \\
\hline
\end{tabular}


Print of window 38 : Current Chromatogram(s)

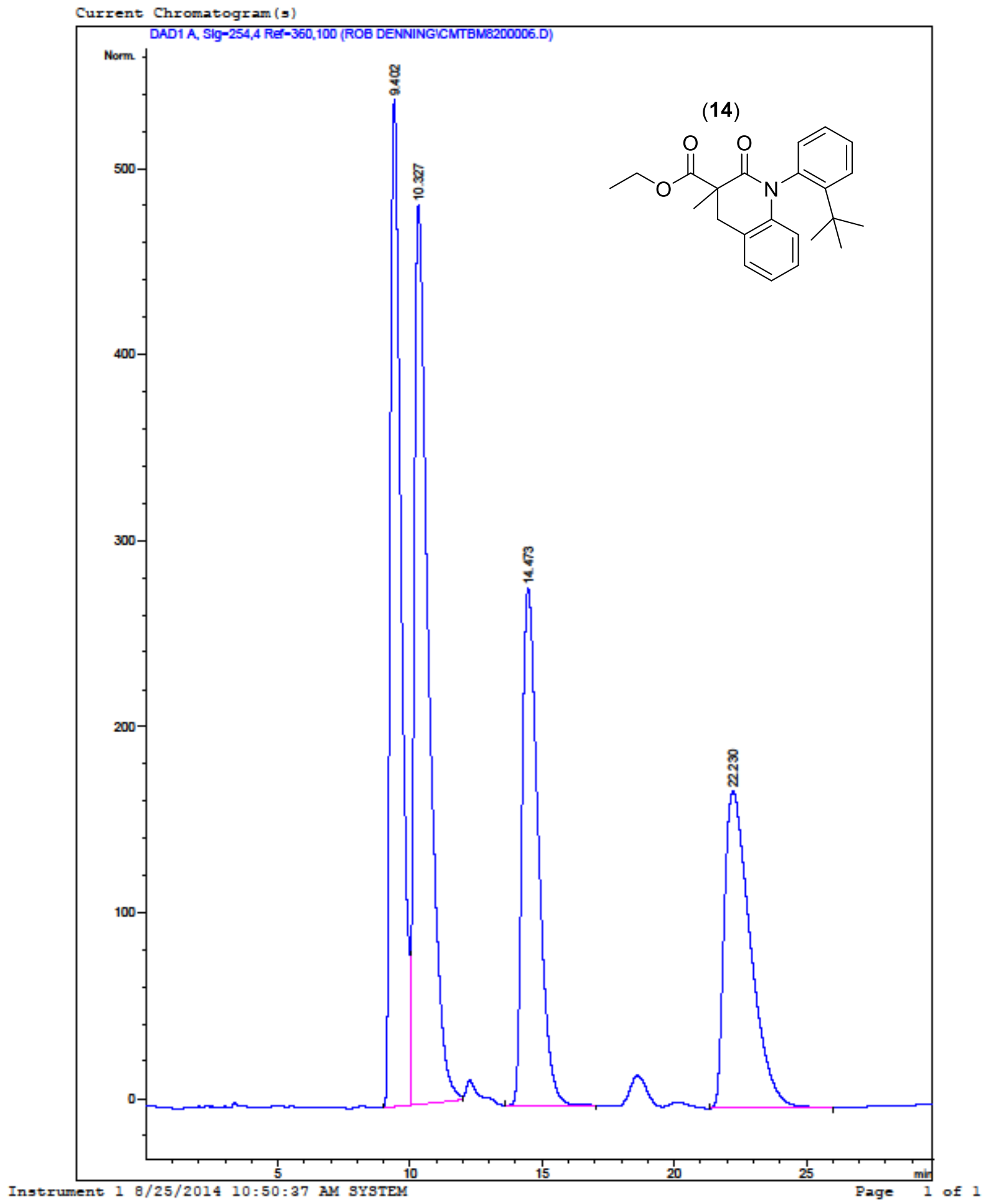


Print of window 38 : Current Chromatogram (s)

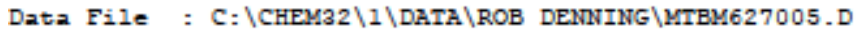

Sample Name : CMTBM

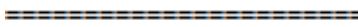

Acq. Operator : sYsTEM

Acq. Instrument : Instrument 1

Injection Date : 6/27/2014 1:13:57 PM

Seq. Line : 2

Location : Vial 2

$\operatorname{Inj}: 1$

Acq- Method : C: $\backslash$ CHEM32\} \backslash 1 \backslash \text { METHODS } \backslash \text { RDMTBM.M }

Last changed : 6/27/2014 12:42:01 PM by SYSTEM

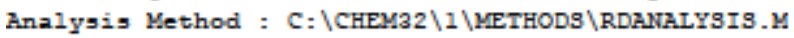

Last changed : 8/21/2014 10:39:03 AM by SYSTEM

(modified after loading)

Current Chromatogram(s)

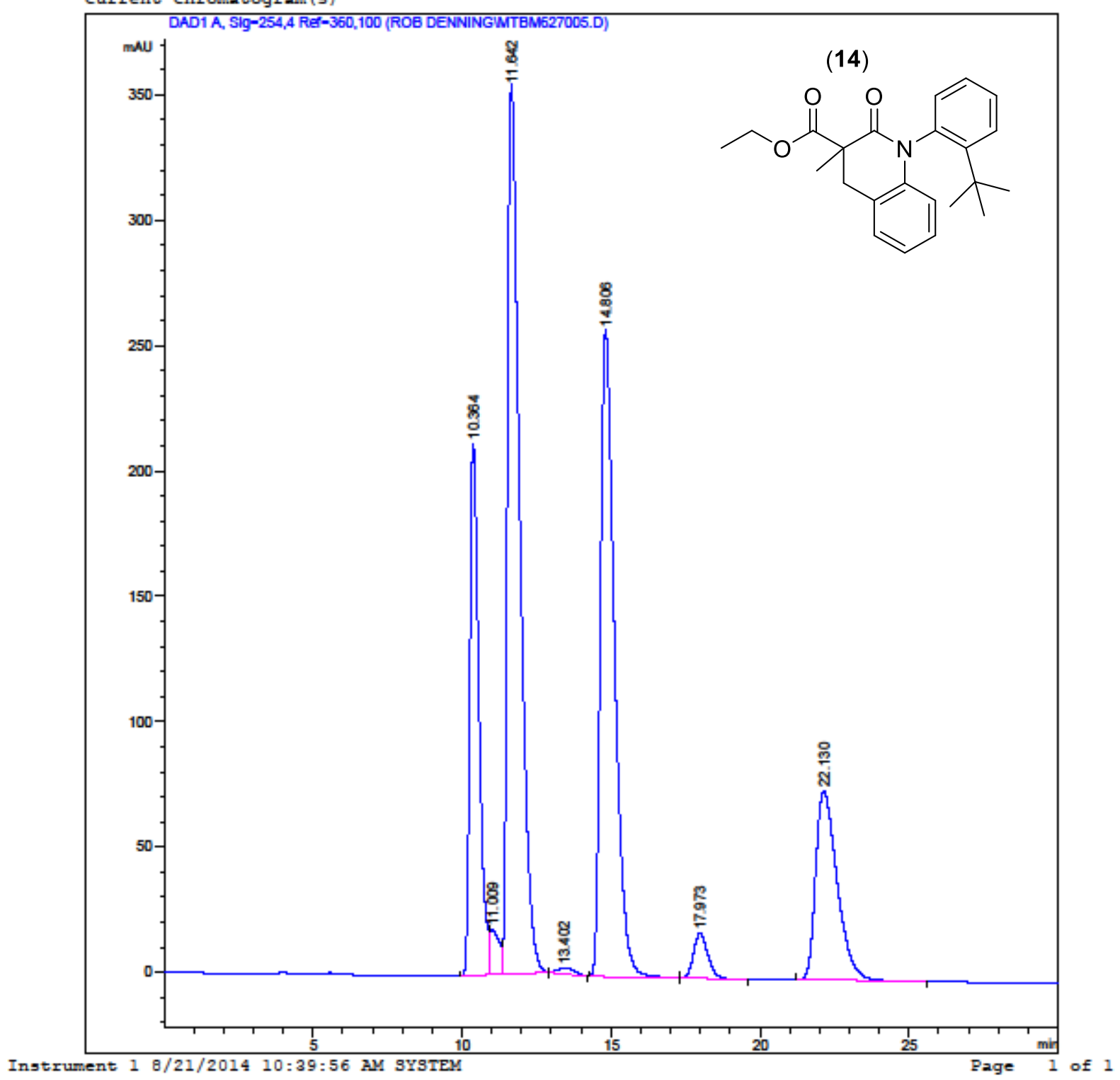




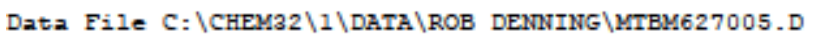

Sample Name: CMTBM

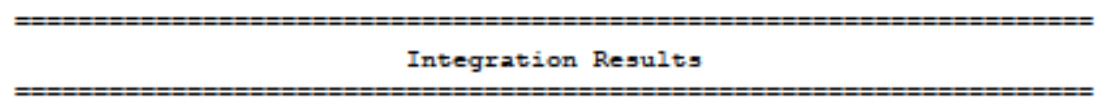

Signal 1: DAD1 A, Sig=254, 4 Ref $=360,100$

\begin{tabular}{|c|c|c|c|c|c|c|c|}
\hline $\begin{array}{c}\text { Peak } \\
\ddagger\end{array}$ & $\begin{array}{l}\text { Time } \\
\text { [min] }\end{array}$ & Type & $\begin{array}{r}\text { Area } \\
{\left[m \mathrm{~m}^{*} \mathrm{~s}\right]}\end{array}$ & $\begin{array}{l}\text { Height } \\
\text { [mad] }\end{array}$ & $\begin{array}{l}\text { Width } \\
\text { [min] }\end{array}$ & $\begin{array}{l}\text { Start } \\
\text { [min] }\end{array}$ & $\begin{array}{l}\text { End } \\
\text { [min] }\end{array}$ \\
\hline & & & & & & & $-1-1$ \\
\hline 1 & 10.364 & BV & 4571.75439 & 212.26962 & 0.3293 & 9.955 & 10.919 \\
\hline 2 & 11.009 & vV & 381.17456 & 18.00923 & 0.2929 & 10.919 & 11.330 \\
\hline 3 & 11.642 & VB & $1.01255 \mathrm{e} 4$ & 354.96542 & 0.4328 & 11.330 & 12.906 \\
\hline 4 & 13.402 & $\mathrm{BB}$ & 99.05111 & 2.28091 & 0.7146 & 12.909 & 14.209 \\
\hline 5 & 14.806 & $\mathrm{BB}$ & 8501.06445 & 258.04272 & 0.5024 & 14.235 & 17.269 \\
\hline 6 & 17.973 & $\mathrm{BB}$ & 591.14038 & 17.90004 & 0.5113 & 17.295 & 19.569 \\
\hline 7 & 22.130 & BBA & 3771.65088 & 75.69991 & 0.7633 & 21.215 & 25.582 \\
\hline
\end{tabular}


Print of window 38 : Current Chromatogram(s)

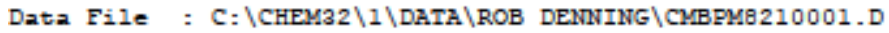

Sample Name: CMBPM SPHOS

$==$

Acq. Operator : SYsTEM

Acq. Instrument : Instrument 1

Injection Date : 8/21/2014 12:57:00 PM

Seq. Line : 1

Location : Vial 6

$\operatorname{Inj}: 1$

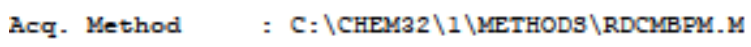

Last changed : 8/21/2014 12:55:54 PM by SYSTEM

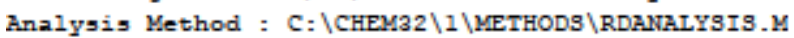

Last changed : 8/21/2014 2:45:54 PM by SYSTEM

(modified after loading)

Current Chromatogram (s)

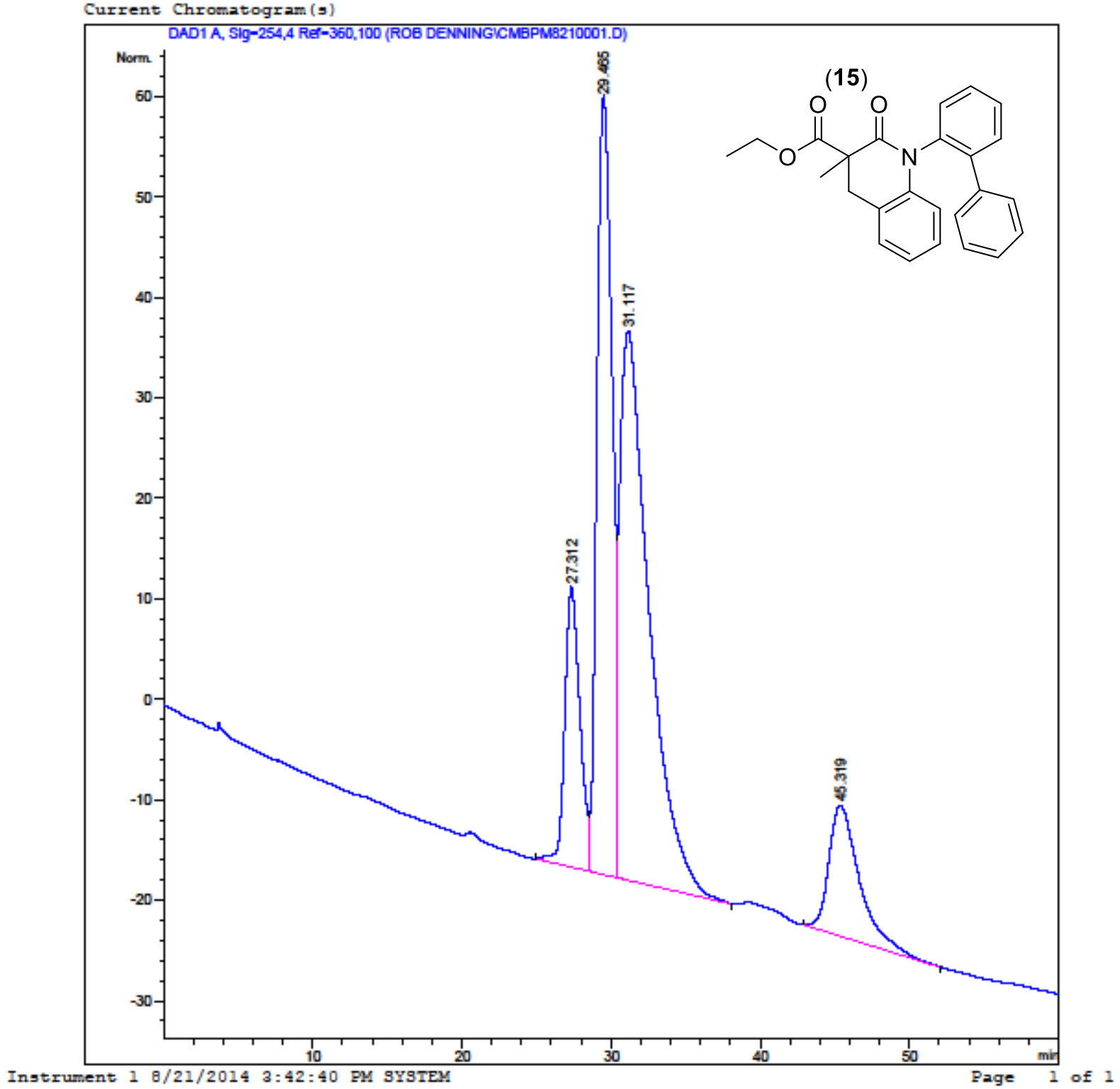




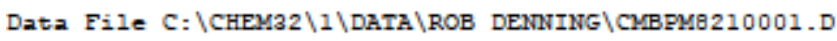

Sample Name: CMBPM SPHOS

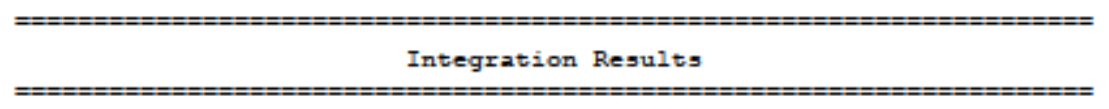

Signal 1: DAD1 H, Sig $=250,4$ Ref $=360,100$

\begin{tabular}{|c|c|c|c|c|c|c|c|}
\hline $\begin{array}{c}\text { Peak } \\
\ddagger\end{array}$ & $\begin{array}{l}\text { Time } \\
\text { [min] }\end{array}$ & Type & $\begin{array}{r}\text { Area } \\
{\left[m U^{*} s\right]}\end{array}$ & $\begin{array}{l}\text { Height } \\
\text { [mad] }\end{array}$ & $\begin{array}{l}\text { Width } \\
\text { [min] }\end{array}$ & $\begin{array}{l}\text { Start } \\
\text { [min] }\end{array}$ & $\begin{array}{l}\text { End } \\
\text { [min] }\end{array}$ \\
\hline-1 & ----- & 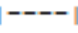 & - & $-\infty-\infty$ & 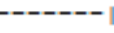 & --- & 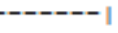 \\
\hline 1 & 27.311 & BV & 2166.86206 & 30.71970 & 1.0669 & 24.855 & 28.493 \\
\hline 2 & 29.466 & vV & 5966.80225 & 84.18759 & 1.1229 & 28.493 & 30.386 \\
\hline 3 & 31.116 & VB & 8140.27637 & 59.35410 & 1.9241 & 30.386 & 38.089 \\
\hline 4 & 45.319 & BBA & 2021.15308 & 14.24312 & 2.0015 & 42.915 & 51.915 \\
\hline
\end{tabular}


Print of window 38 : Current Chromatogram(s)

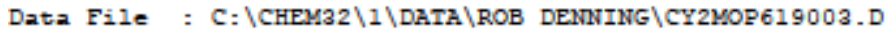

Sample Name: RacCy2MOP

$=$

Acq. Operator: SYsTEM

Acq. Instrument : Instrument 1

Injection Date : 6/19/2014 2:47:05 PM

Seq. Line : 1

Location : Vial 1

$\operatorname{Inj}: 1$

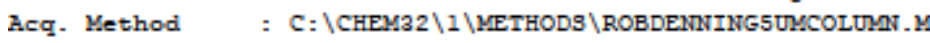

Last changed. $\quad 6 / 19 / 20142: 46: 15$ PM by SYSTEM

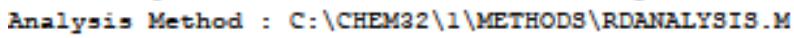

Last changed : 8/21/2014 10:32:26 AM by SYSTEM

(modified after loading)

Additional Info : Peak(s) manually integrated

Inj Volume : $4.000 \mu 1$

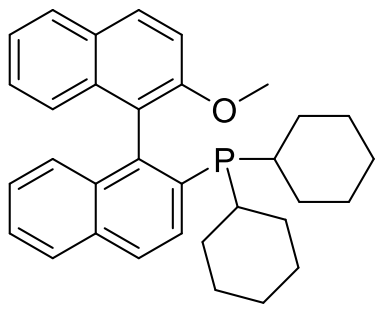

Current Chromatogram (s)

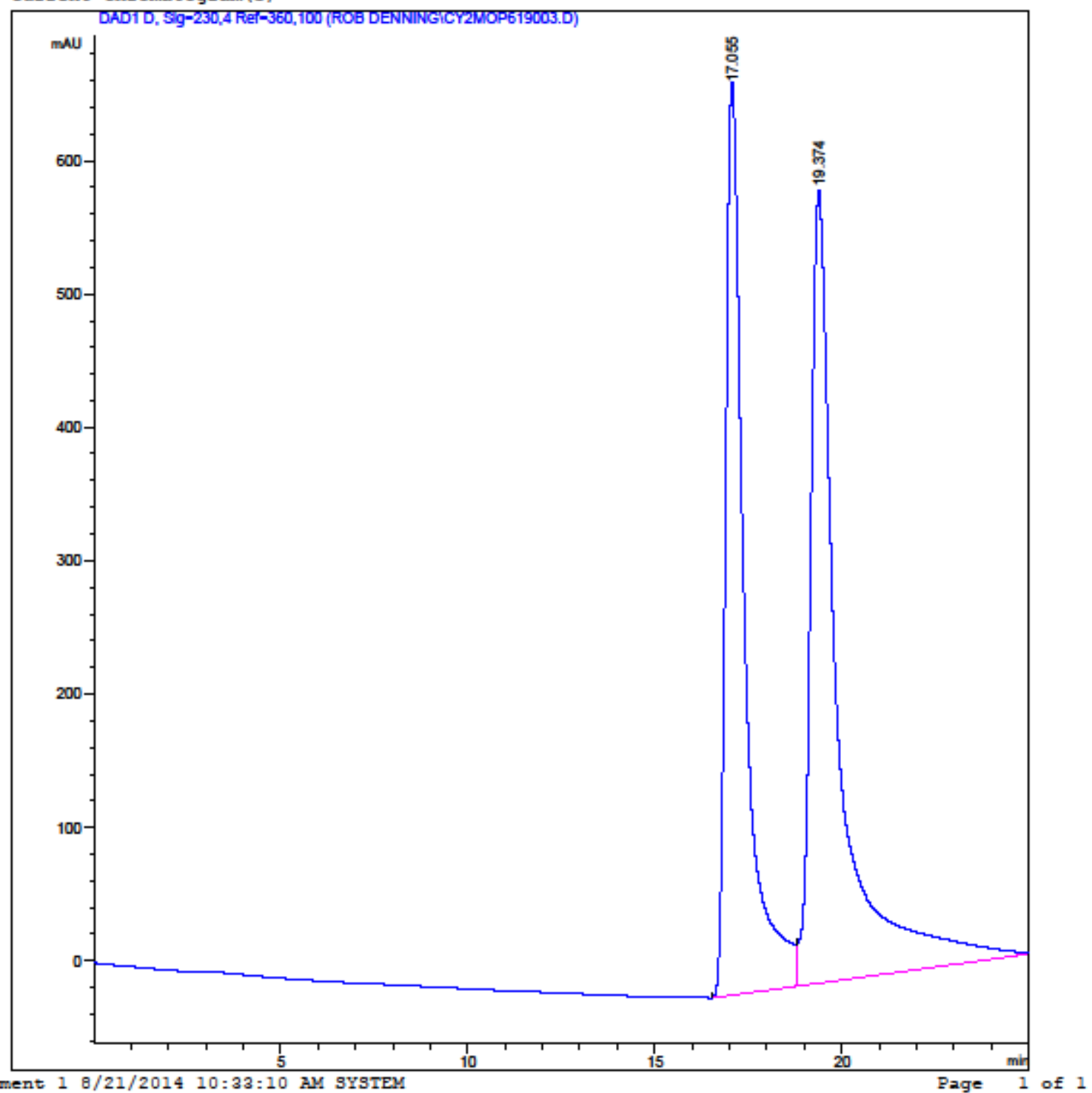




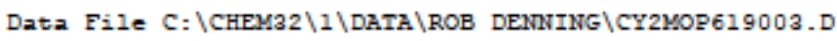

Sample Name: RacCy2MOP

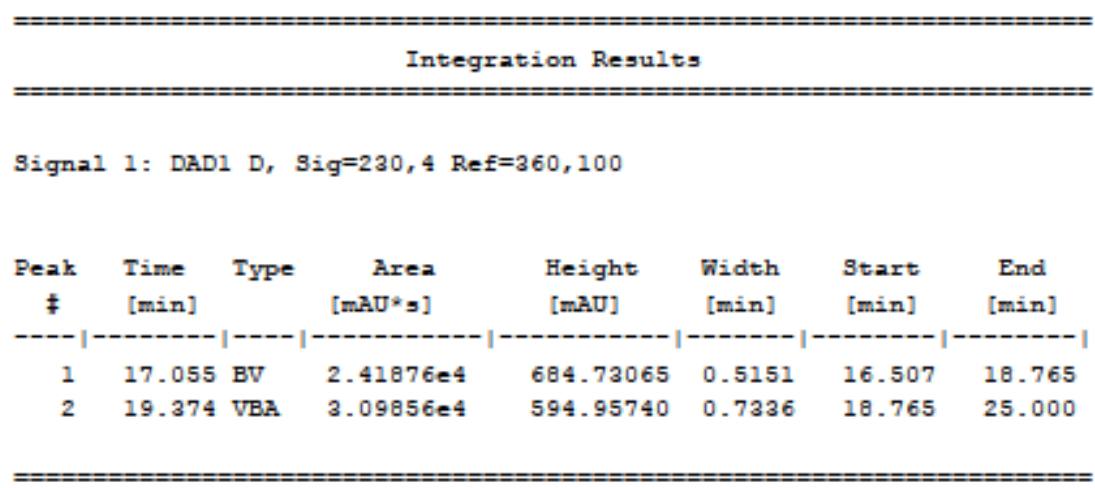


Print of window 38 : Current Chromatogram(s)

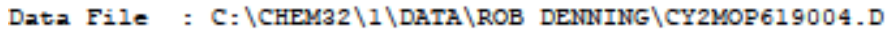

Sample Name : Cy2MOP

\section{(1)}

Acq- Operator : sYsTEM

Acq. Instrument : Instrument 1

Injection Date : 6/19/2014 3:12:56 PM

Seq. Line : 2

Location : Vial 2

$\operatorname{Inj}: 1$

Inj Volume : $4.000 \mathrm{pl}$

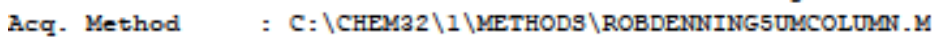

Last changed. $\quad 6 / 19 / 20142: 46: 15$ PM bY SYSTEM

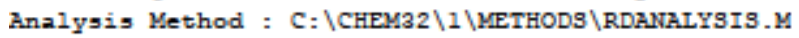

Last changed : 8/21/2014 10:32:26 AM by SYSTEM

(modified after loading)

Additional Info : Peak(s) manually integrated

(19)

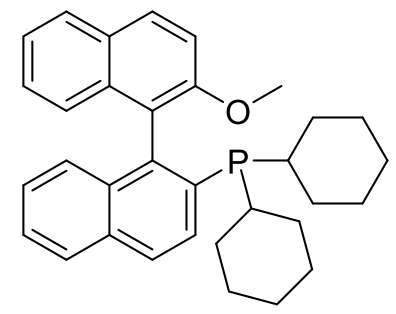

Current Chromatogram (s)

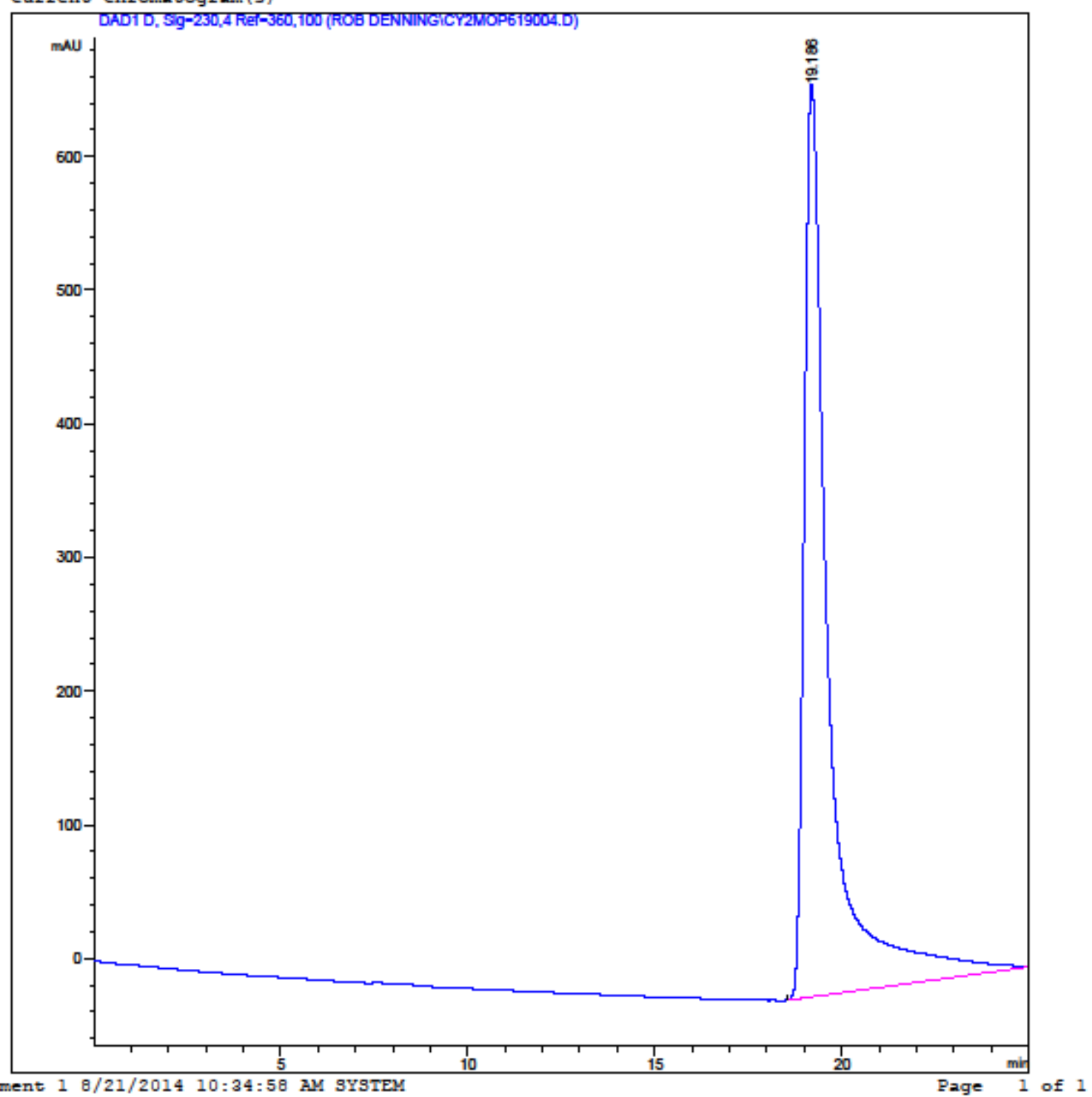




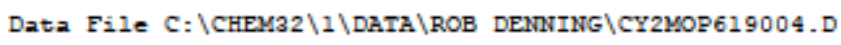

Sample Name: Cy2MOP

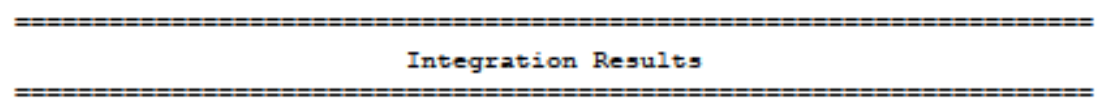

Signal 1: DAD1 D, Sig $=230,4$ Ref $=360,100$

\begin{tabular}{|c|c|c|c|c|c|c|c|}
\hline $\begin{array}{c}\text { Peak } \\
\ddagger\end{array}$ & $\begin{array}{l}\text { Time } \\
\text { [min] }\end{array}$ & Type & $\begin{array}{r}\text { Area } \\
\text { [mad*s] }\end{array}$ & $\begin{array}{l}\text { Height } \\
\text { [mad] }\end{array}$ & $\begin{array}{l}\text { Width } \\
\text { [min] }\end{array}$ & $\begin{array}{l}\text { Start } \\
\text { [min] }\end{array}$ & $\begin{array}{l}\text { End } \\
\text { [min] }\end{array}$ \\
\hline . & & & & & & & 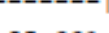 \\
\hline 1 & 19.186 & BBA & $3.18221 e^{4}$ & 682.95551 & 0.6676 & 18.538 & 25.001 \\
\hline
\end{tabular}




\section{Bibliography}

1. Hornback, J. M. Organic Chemistry 2nd Ed. (2006).

2. Moss, G. P. Basic Terminology of Stereochemistry (IUPAC Recommendations 1996). Pure Appl. Chem. 68, 2193-2222 (1996).

3. Holder, J. C. et al. Mechanism and enantioselectivity in palladium-catalyzed conjugate addition of arylboronic acids to $\beta$-substituted cyclic enones: insights from computation and experiment. J. Am. Chem. Soc. 135, 14996-5007 (2013).

4. Buchwald, S. L. Palladium-Catalyzed Aromatic Aminations with in Situ Generated Aminos tannanes. J. Am. Chem. Soc. 7901-7902 (1994).

5. Paul, F., Patt, J. \& Hartwig, J. F. Palladium-Catalyzed Formation of Carbon-Nitrogen Bonds. Reaction Intermediates and Catalyst Improvements in the Hetero Cross-Coupling of Aryl Halides and Tin Amides. J. Am. Chem. Soc. 116, 5969-5970 (1994).

6. Louie, J. \& Hartwig, J. F. Palladium Catalyzed Synthesis of Arylamines from Aryl Halides. Mechanistic Studies Lead to Coupling in the Absence of Tin Reagents. Tetrahedron Lett. 36, 3609-3612 (1995).

7. Muzart, J. On the behavior of amines in the presence of Pd0 and PdII species. J. Mol. Catal. A Chem. 308, 15-24 (2009).

8. Amatore, C., Carre, E. \& Jutand, A. Rates and Mechanism of the Formation of Zerovalent Palladium Complexes from Mixtures of $\mathrm{Pd}(\mathrm{OAc}) 2$ and Tertiary Phosphines and Their Reactivity in Oxidative Additions. Organometallics 14, 1818-1826 (1995).

9. Wagaw, S., Rennels, R. A. \& Buchwald, S. L. Palladium-Catalyzed Coupling of Optically Active Amines with Aryl Bromides. J. Am. Chem. Soc. 119, 8451-8458 (1997).

10. Sirvent, J. A., Foubelo, F. \& Yus, M. Stereoselective synthesis of indoline, tetrahydroquinoline, and tetrahydrobenzazepine derivatives from o-bromophenyl N-tertbutylsulfinyl aldimines. J. Org. Chem. 79, 1356-67 (2014).

11. Uzarewicz-Baig, M., Koppenwallner, M., Tabassum, S. \& Wilhelm, R. Highly regioselective synthesis of chiral diamines via a Buchwald-Hartwig amination from camphoric acid and their application in the Henry reaction. Appl. Organomet. Chem. n/an/a (2014). doi:10.1002/aoc.3162

12. Bogányi, B. \& Kámán, J. A concise synthesis of indoloquinoline skeletons applying two consecutive Pd-catalyzed reactions. Tetrahedron 69, 9512-9519 (2013). 
13. Porosa, L. \& Viirre, R. D. Desymmetrization of malonamides via an enantioselective intramolecular Buchwald-Hartwig reaction. Tetrahedron Lett. 50, 4170-4173 (2009).

14. Takenaka, K., Itoh, N. \& Sasai, H. Enantioselective Synthesis of C 2 -Symmetric Spirobilactams via Pd-Catalyzed Intramolecular Double N -Arylation. Org. Lett. 11, 1483-1486 (2009).

15. Kitagawa, O., Takahashi, M., Yoshikawa, M. \& Taguchi, T. Efficient synthesis of optically active atropisomeric anilides through catalytic asymmetric $\mathrm{N}$-arylation reaction. J. Am. Chem. Soc. 127, 3676-7 (2005).

16. Sci, C., Surry, D. S. \& Buchwald, S. L. Dialkylbiaryl phosphines in Pd-catalyzed amination : a user's guide. Chem. Sci. 2, 27-50 (2011).

17. Uozumi, Yasuhiro; Suzuki, Nobuhiro; Ogiwara, Aya; Hayashi, T. Preparation of optically active binaphthylmonophosphines (MOP's) containing various functional groups.

Tetrahedron 50, 4293-302 (1994).

18. Hamada, T., Chieffi, A., Ahman, J. \& Buchwald, S. L. An improved catalyst for the asymmetric arylation of ketone enolates. J. Am. Chem. Soc. 124, 1261-8 (2002).

19. Hayashi, T., Naito, M., Matsumoto, Y.\& Uozumi, Y. Catalytic Asymmetric Reduction of Allylic Esters with Formic Acid Catalyzed by Palladium-MOP Complexes. J. Am. Chem. Soc. 116, 775-776 (1994).

20. Gladiali, S. et al. Asymmetric allylic alkylation catalyzed by $\mathrm{Pd}(\mathrm{II})$-complexes with (S)BINPO, a hemilabile axially chiral P,O-heterodonor inducer. Tetrahedron: Asymmetry 15, 1477-1485 (2004).

21. Xie, X., Zhang, T. Y. \& Zhang, Z. Synthesis of Bulky and Electron-Rich MOP-type Ligands and Their Applications in Palladium-Catalyzed C - N Bond Formation. J. Org. Chem. 71, 6522-6529 (2006).

22. Matarazzo, A. \& Viirre, R. D. Recent Advances Towards the Development of Enantioand Diastereoselective Palladium Catalyzed Nitrogen Arylation Reactions. 199 (2011). 